\title{
Initial Demonstration of the NRC's Capability to Conduct a Performance Assessment for a High-Level Waste Repository
}

Manuscript Completed: March 1992

Date Published: May 1992

R. Codell, N. Eisenberg, D. Fehringer, W. Ford,

T. Margulies*, T. McCartin*, J. Park, J. Randall*

Office of Nuclear Material Safety and Safeguards

Office of Nuclear Regulatory Research

U.S. Nuclear Regulatory Commission

Washington, DC 20555

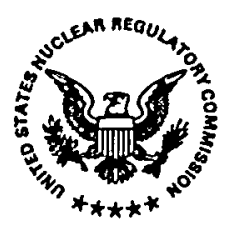

*Office of Nuclear Regulatory Research 


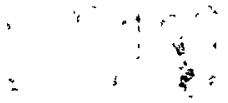

$$
\begin{aligned}
& 5
\end{aligned}
$$




\section{DISCLAIMER}

This report was prepared as an account of work sponsored by an agency of the United States Government. Neither the United States Government nor any agency thereof, nor any of their employees, make any warranty, express or implied, or assumes any legal liability or responsibility for the accuracy, completeness, or usefulness of any information, apparatus, product, or process disclosed, or represents that its use would not infringe privately owned rights. Reference herein to any specific commercial product, process, or service by trade name, trademark, manufacturer, or otherwise does not necessarily constitute or imply its endorsement, recommendation, or favoring by the United States Government or any agency thereof. The views and opinions of authors expressed herein do not necessarily state or reflect those of the United States Government or any agency thereof. 


\section{DISCLAIMER}

Portions of this document may be illegible in electronic image products. Images are produced from the best available original document. 


\begin{abstract}
In order to better review licensing submittals for a HighLevel Waste Repository, the U.S. Nuclear Regulatory Commission staff has expanded and improved its capability to conduct performance assessments. This report documents an initial demonstration of this capability. The demonstration made use of the limited data from Yucca Mountain, Nevada to investigate a small set of scenario classes. Models of release and transport of radionuclides

from a repository via the groundwater and direct release pathways provided preliminary estimates of releases to the accessible environment for a 10,000 year simulation time. Latin hypercube sampling of input parameters was used to express results as distributions and to investigate model sensitivities. This methodology demonstration should not be interpreted as an estimate of performance of the proposed repository at Yucca Mountain, Nevada.
\end{abstract}




\section{CONTENTS}

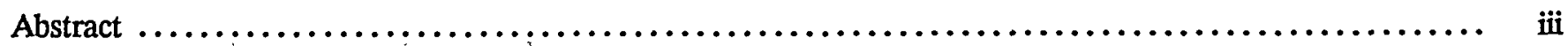

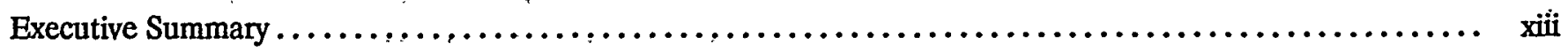

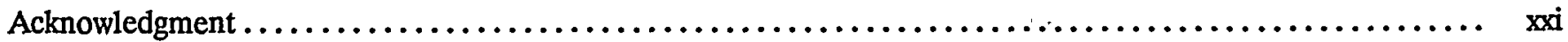

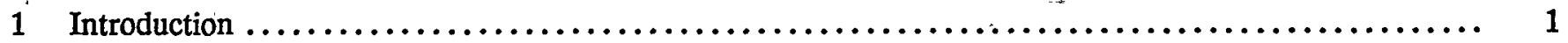

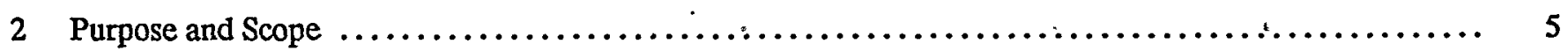

3 Organization and Staffing $\ldots \ldots \ldots \ldots \ldots \ldots \ldots \ldots \ldots \ldots \ldots \ldots \ldots \ldots \ldots \ldots \ldots \ldots \ldots \ldots \ldots \ldots \ldots \ldots, 9$

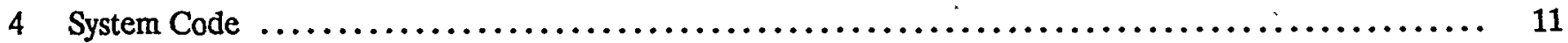

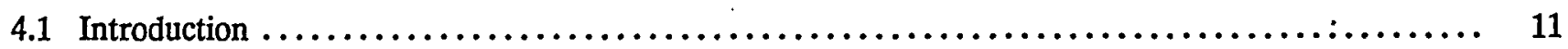

4.2 Requirements for the Development of the System Code $\ldots \ldots \ldots \ldots \ldots \ldots \ldots \ldots \ldots \ldots \ldots \ldots \ldots$

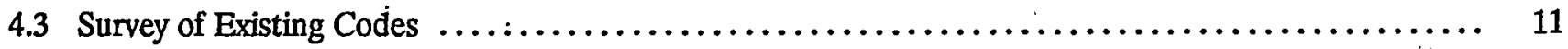

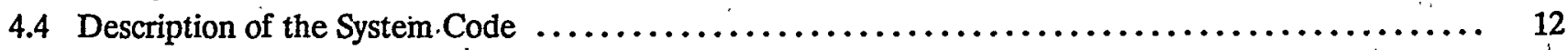

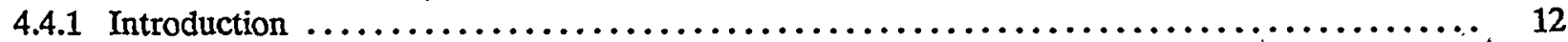

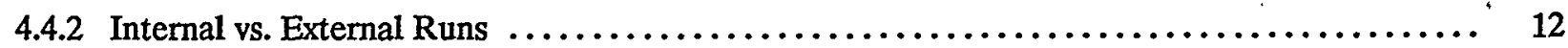

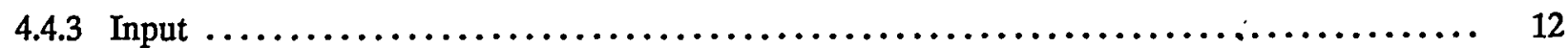

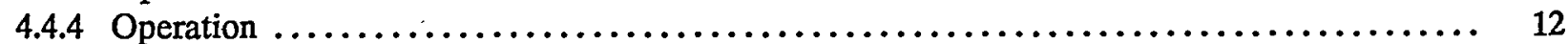

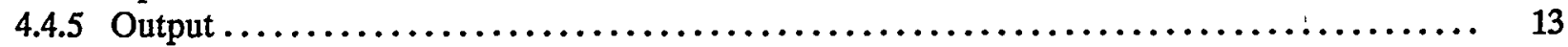

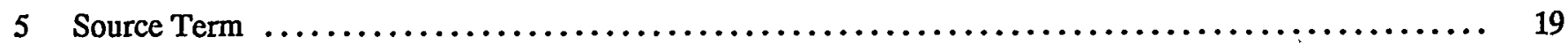

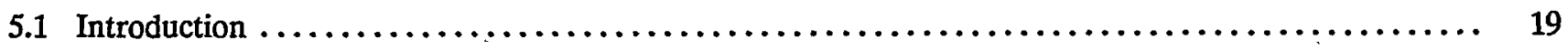

5.2 Review of Important Issues for Selecting Source Term Models $\ldots \ldots \ldots \ldots \ldots \ldots \ldots \ldots \ldots \ldots \ldots \ldots$

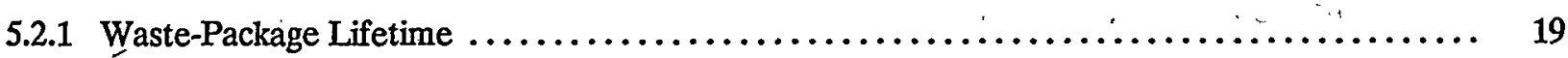

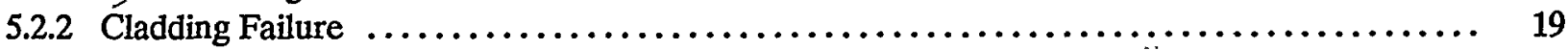

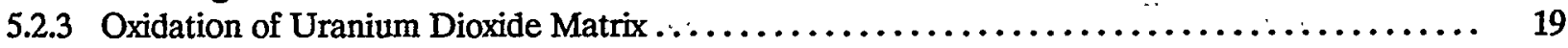

5.2.4 Release of Dissolved Radionuclides from the Fuel $\ldots \ldots \ldots \ldots \ldots \ldots \ldots \ldots \ldots \ldots \ldots \ldots \ldots$

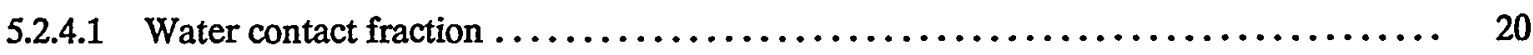

5.2 .5 Release of Gaseous Radionuclides $\ldots \ldots \ldots \ldots \ldots \ldots \ldots \ldots \ldots \ldots \ldots \ldots \ldots \ldots \ldots \ldots$

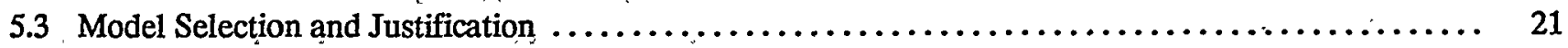

5.3.1 Model for Dissolved Radionuclides $\ldots \ldots \ldots \ldots \ldots \ldots \ldots \ldots \ldots \ldots \ldots \ldots \ldots \ldots \ldots \ldots \ldots, 21$

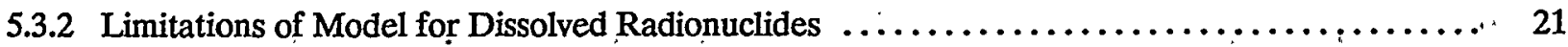

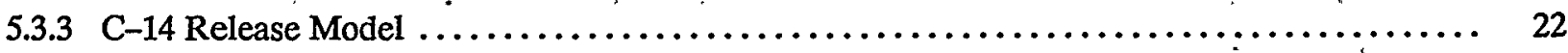

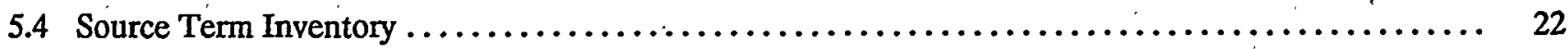

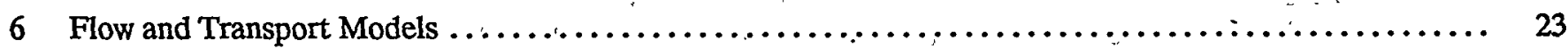

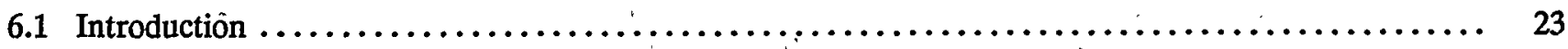

6.2 Definition of Issues for Selecting Performance-Assessment Transport Models $\ldots \ldots \ldots \ldots \ldots \ldots \ldots 23$

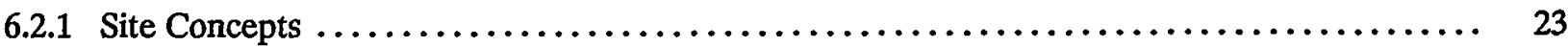

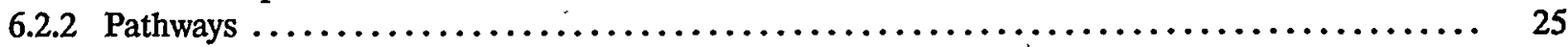

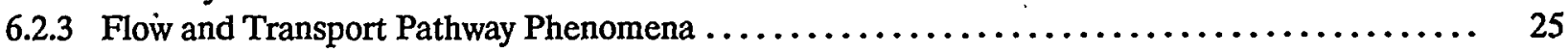




\section{CONTENTS (continued)}

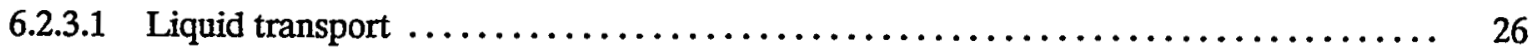

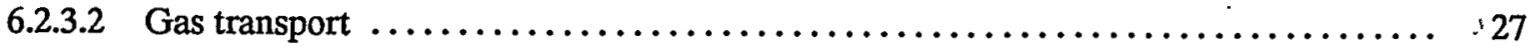

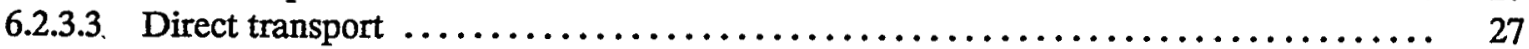

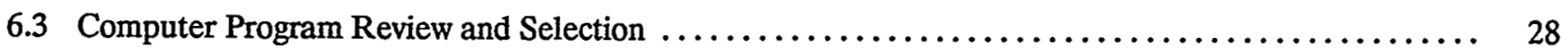

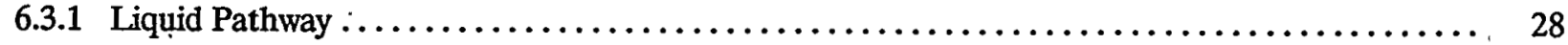

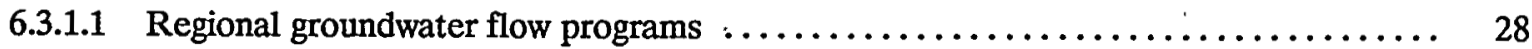

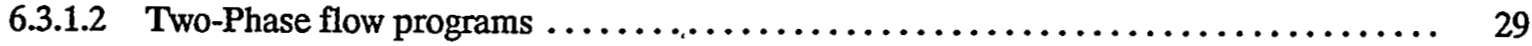

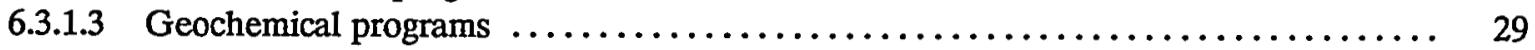

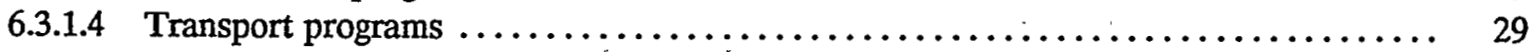

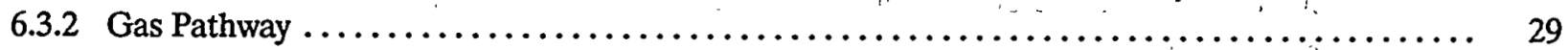

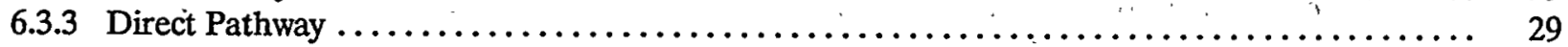

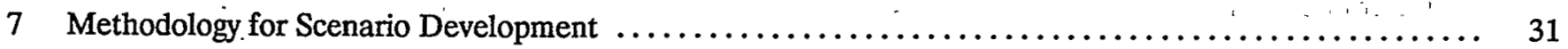

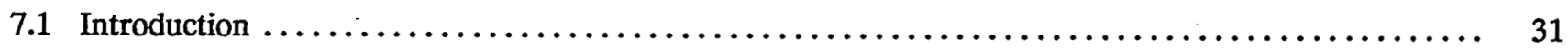

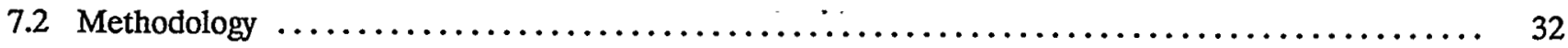

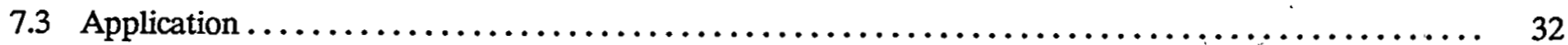

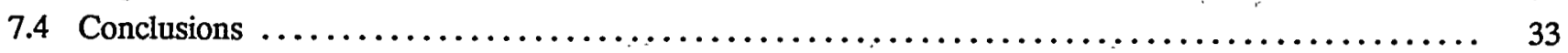

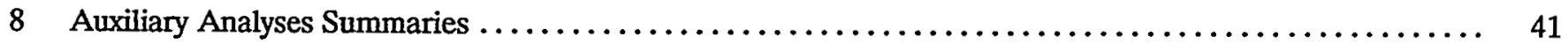

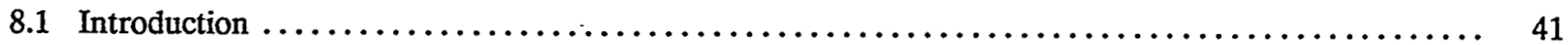

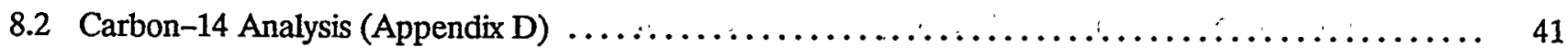

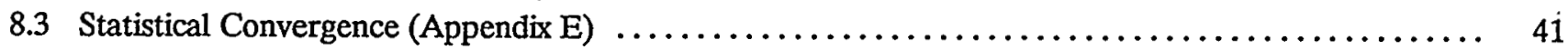

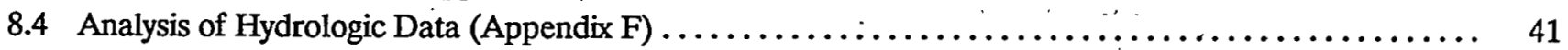

8.5 Two-Dimensional Flow Simulation (Appendix G) $\ldots \ldots \ldots \ldots \ldots \ldots \ldots \ldots \ldots \ldots \ldots \ldots \ldots \ldots \ldots$

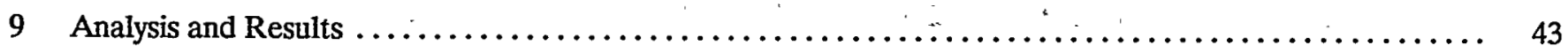

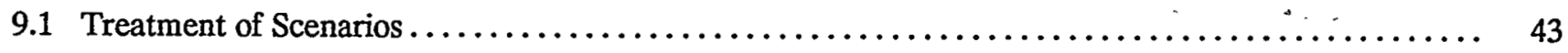

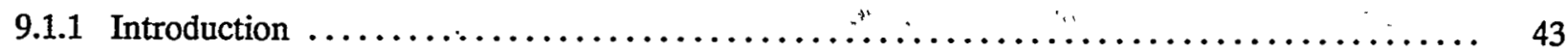

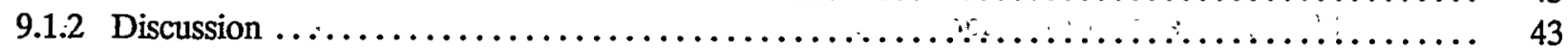

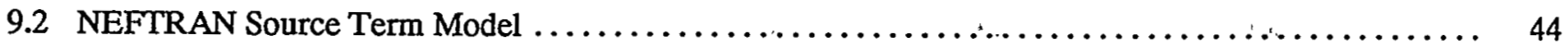

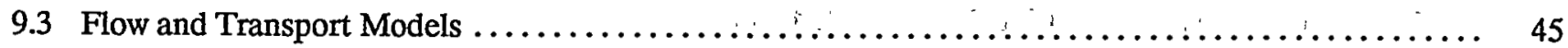

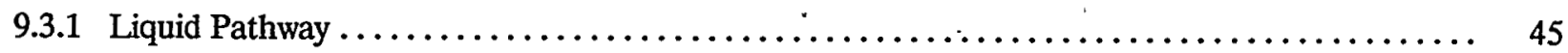

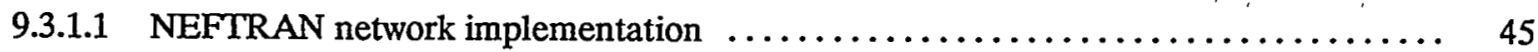

9.3.1.2 Implementation of matrix and fracture flow.in NEFTRAN $\ldots \ldots \ldots \ldots \ldots \ldots \ldots \ldots, 45$

9.3.1.3 Implementation of transport phenomena within NEFTRAN $\ldots \ldots \ldots \ldots \ldots \ldots \ldots .50$

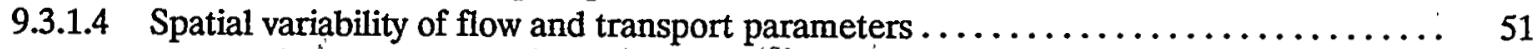

9.3.1.5 Effective values of flow and transport coéfficients ...................... 52

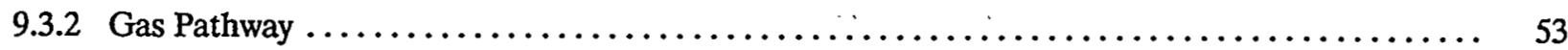

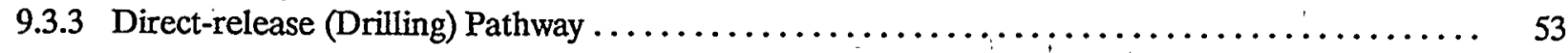




\section{CONTENTS (continued)}

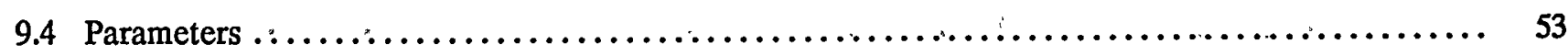

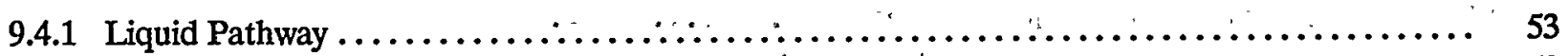

9.4.2 Sampling Parameters for NEFTRAN Aralysis $\ldots \ldots \ldots \ldots \ldots \ldots \ldots \ldots \ldots \ldots \ldots \ldots \ldots \ldots \ldots$

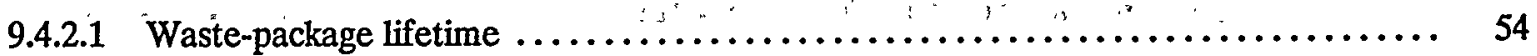

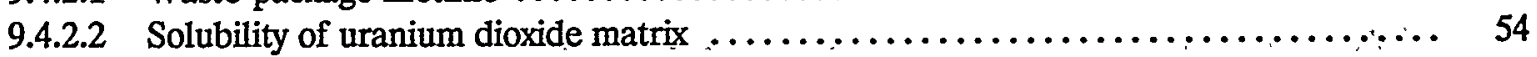

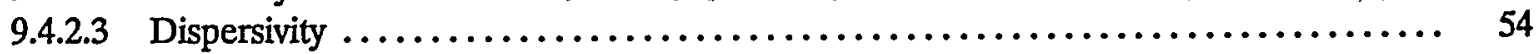

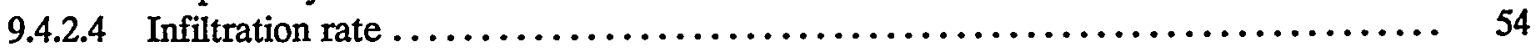

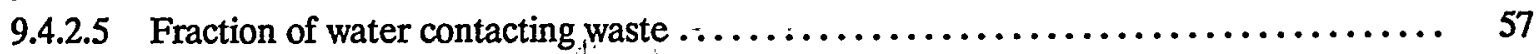

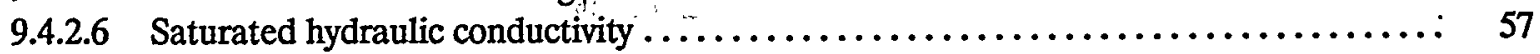

9.4.2.7 Spatial correlation of saturated hydraulic conductivity $\ldots \ldots \ldots \ldots \ldots \ldots \ldots \ldots \ldots$

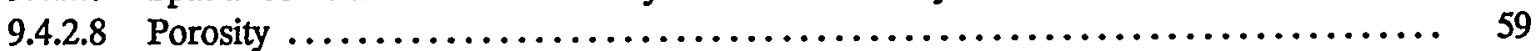

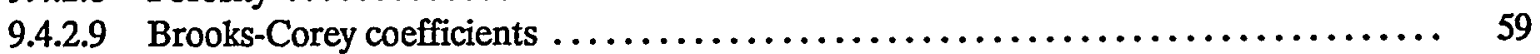

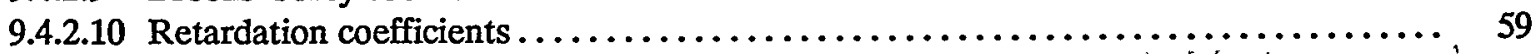

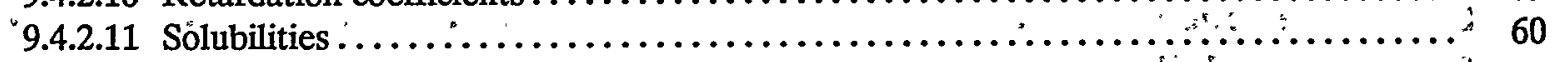

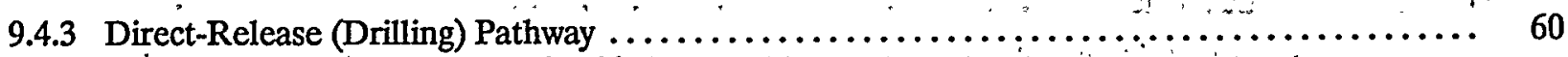

9.5 Sensitivities and Uncertainties for Liquid-Pathway Analysis $\ldots \ldots \ldots \ldots \ldots \ldots \ldots \ldots \ldots \ldots \ldots \ldots \ldots, 60$

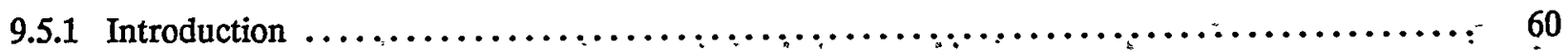

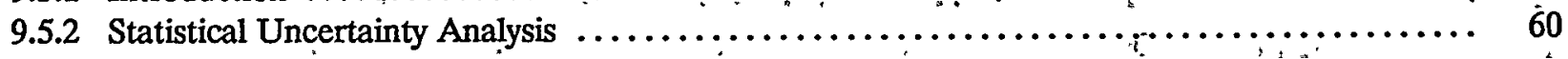

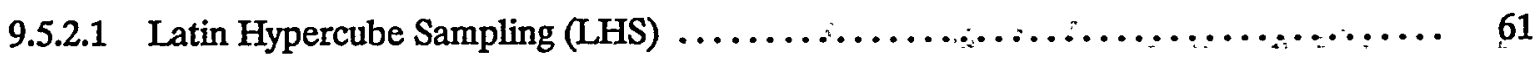

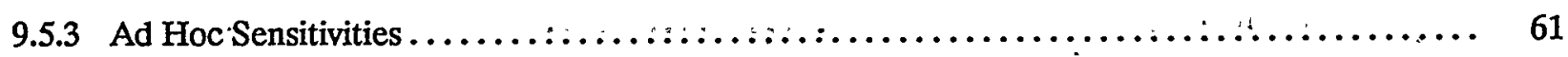

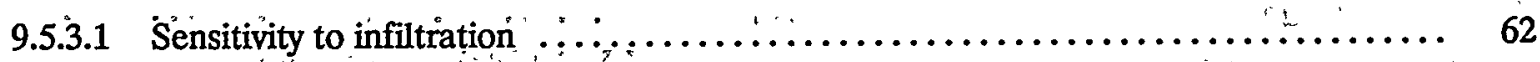

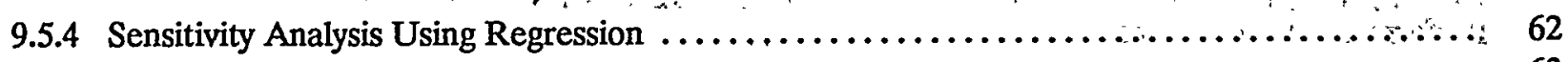

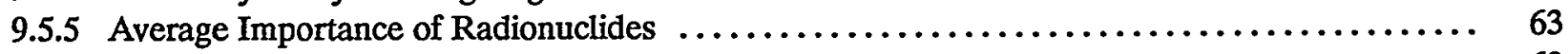

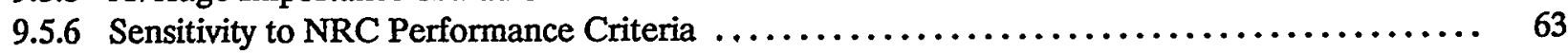

9.5.6.1 Effects of NRC performance criteria on CCDFs $\ldots \ldots \ldots \ldots \ldots \ldots \ldots \ldots \ldots \ldots$

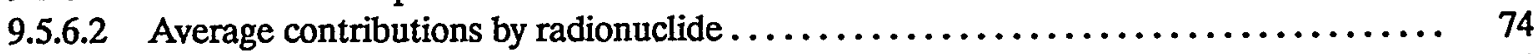

9.5.6.3 - Ad Hoc Sensitivities to NRC Criteria $\ldots \ldots \ldots \ldots \ldots \ldots \ldots \ldots \ldots \ldots \ldots \ldots \ldots \ldots \ldots \ldots \ldots$

9.6 Total System Results $\ldots \ldots \ldots \ldots \ldots \ldots \ldots, \ldots \ldots \ldots, \ldots \ldots \ldots \ldots \ldots \ldots \ldots \ldots \ldots \ldots, \ldots \ldots \ldots \ldots \ldots, 75$

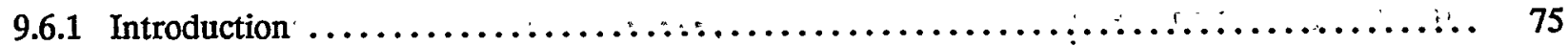

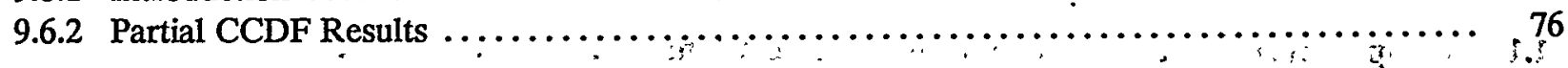

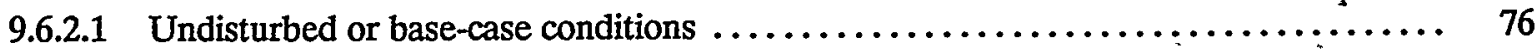

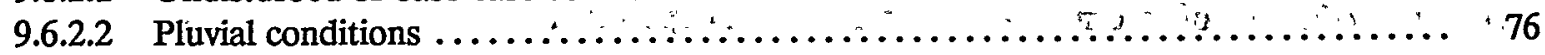

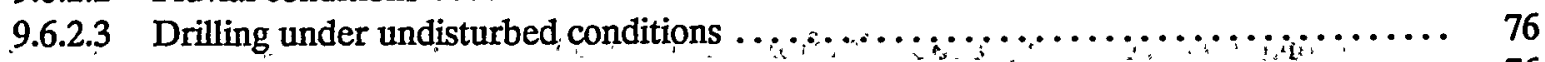

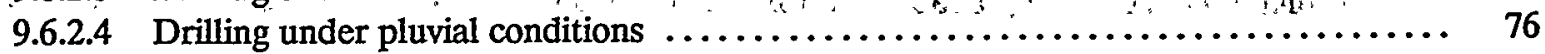

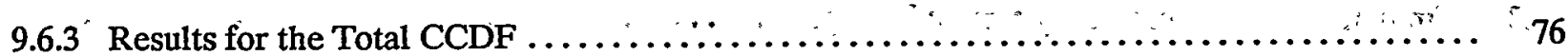




\section{CONTENTS (continued)}

Page

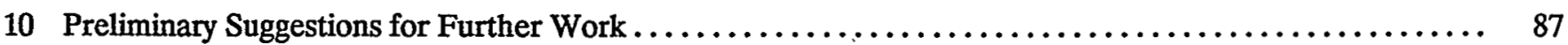

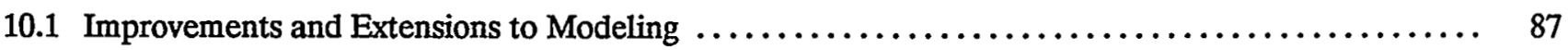

10.2 Improvements and Extensions to Auxiliary Analyses $\ldots \ldots \ldots \ldots \ldots \ldots \ldots \ldots \ldots \ldots \ldots \ldots \ldots . . \ldots$

10.3 Recommendations for Additional Scientific Input .......................... 91

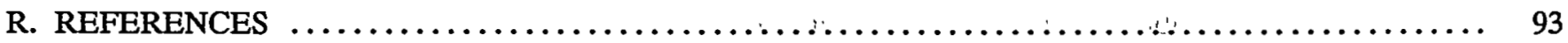

\section{APPENDICES}

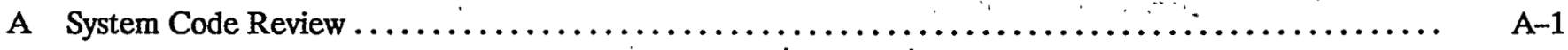

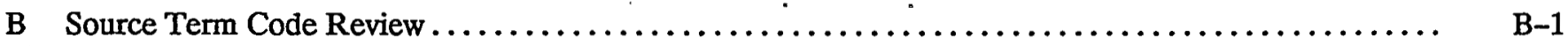

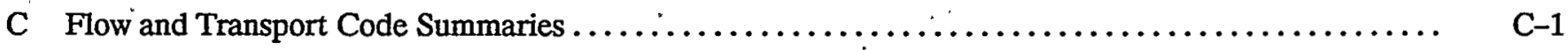

D Gaseous Releases of Carbon-14 ............................................. D

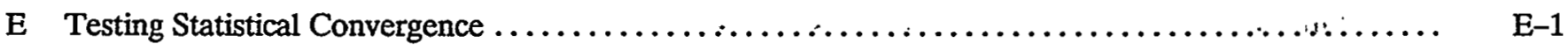

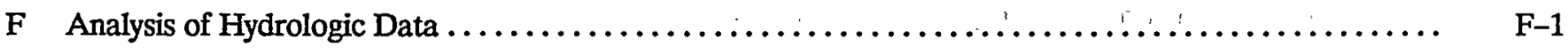

G Two-Dimensional Cross Sectional Flow Model $\ldots \ldots \ldots \ldots \ldots \ldots \ldots \ldots \ldots \ldots \ldots \ldots \ldots \ldots \ldots \ldots \ldots$. G-1

H Analysis for Drilling Scenario $\ldots \ldots \ldots \ldots \ldots \ldots \ldots \ldots, \ldots \ldots \ldots \ldots \ldots \ldots, \ldots \ldots \ldots \ldots \ldots \ldots, \mathrm{H}-1$

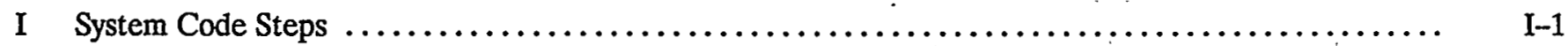

$\mathrm{J}$ Documentation of Files and Programs on INEL CRAY XMPi24 for Repository Performance Calculations

\section{FIGURES}

ES.1 Components of a total system performance assessment $\ldots \ldots \ldots \ldots \ldots \ldots \ldots \ldots \ldots \ldots \ldots \ldots \ldots$ xviii

ES.2 Composite CCDF curve for the scenario classes considered in Phase 1 of the

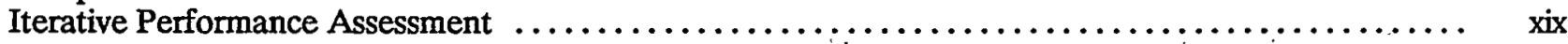

1.1 Components of a total system performance assessment $\ldots \ldots \ldots \ldots \ldots \ldots \ldots \ldots \ldots \ldots \ldots \ldots \ldots \ldots$

4.1 Flow diagram of external and internal modes of operation. $\ldots \ldots \ldots \ldots \ldots \ldots \ldots \ldots \ldots \ldots \ldots \ldots$

4.2 Determination of scenario probabilities from the probabilities of fundamental events $\ldots \ldots \ldots \ldots \ldots$

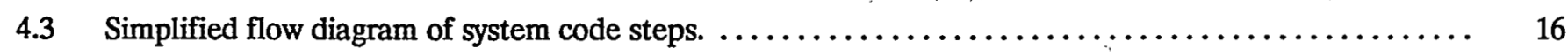

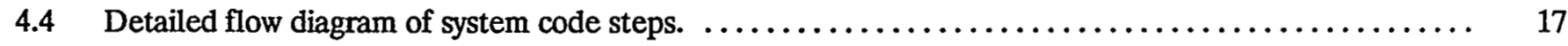

4.5 System code data array for normalized radionuclide releases. $\ldots \ldots \ldots \ldots \ldots \ldots \ldots \ldots \ldots \ldots \ldots . \ldots$ 


\section{FIGGURES (continued)}

Page

9.1 Conceptualization of a hydrogeologic cross-section through the unsaturated zone at Yúcca

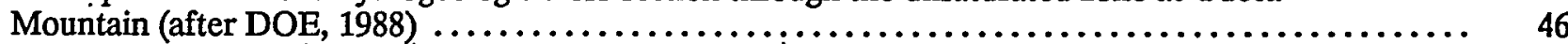

9.2 " Hydrostratigraphic units used to simulate the variation in depths and units existing below the

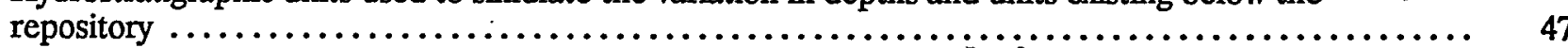

9.3 Geologic map of Yucca Mountain showing repository drift perimeter (after DOE, 1988) .......... 48

9.4 Representation of the allocation of repository area and radionuclide inventory of the four

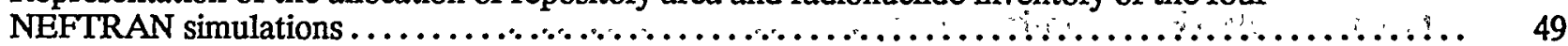

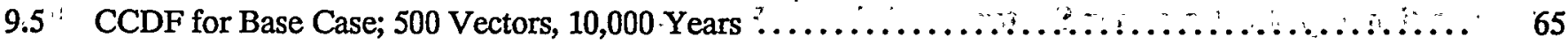

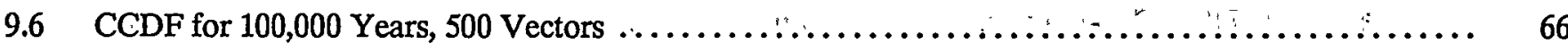

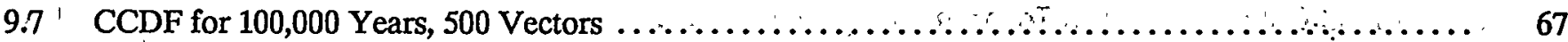

9.8 CCDF for 100,000 Years, 500 Vectors. Compare Column $D$ to all $: \ldots \ldots \ldots \ldots \ldots \ldots \ldots \ldots \ldots$

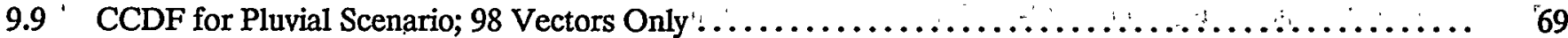

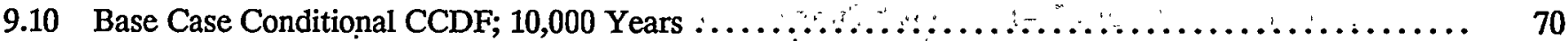

9.11 Base Case Liquid Pathway Scenario; 10,000 Years Effects of Groundwater Travel Time on

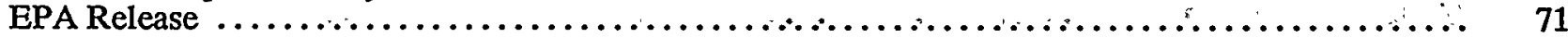

9.12 Base Case Liquid Pathway Scenario; 10,000 Years Effects of Release Rate from Engineered Barrier :. 72

9.13 Base Case Liquid Pathway Scenario; 10,000 Years Effects of Engineered Barrier Lifetime’ . . . ....... . . 73

9.14 Determination of scenario probabilities from the probabilities of fundamental events $\ldots . . \ldots \ldots \ldots . . .78$

9.15. Graphical representation of hypothetical CCDF with the EPA containment requirements

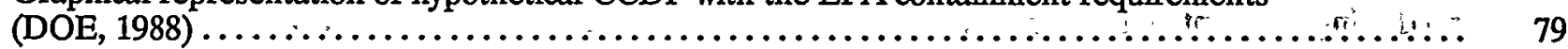

9.16 Plot of an empirical CCDF against the EPA containment requirements (DOE, 1988) . ........... 79

9.17 Partial CCDF for Undisturbed Conditions $\ldots \ldots \ldots \ldots \ldots \ldots \ldots \ldots \ldots \ldots \ldots \ldots \ldots \ldots \ldots \ldots \ldots$

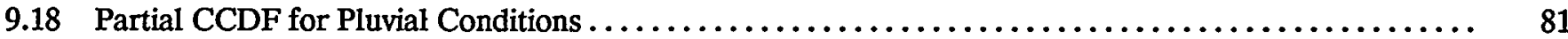

9.19 Partial CCDF for Drilling Under Undisturbed Conditions $\ldots \ldots \ldots \ldots \ldots \ldots \ldots \ldots \ldots \ldots \ldots \ldots \ldots . . . \ldots 2$

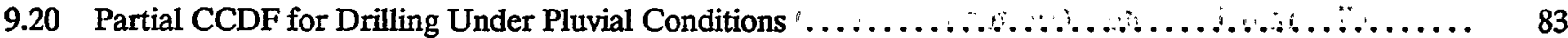

9.21 Composite CCDF Curve for the Scenario Classes Considered in Phase 1 of the Iterative Performance Assessment ..................................................... 84

9.22 Total CCDF for Phase 1 of the Iterative Performance Assessment $\ldots \ldots \ldots \ldots \ldots \ldots \ldots \ldots \ldots \ldots \ldots . .85$

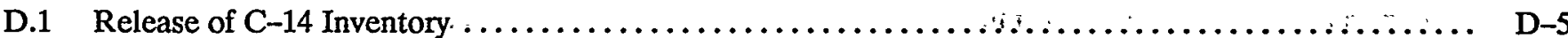




\section{FIGURES (continued)}

D.2 Gas convection velocities along the repository center line at 100 years after waste emplacement $\ldots \ldots$ D-7

D.3 Carbon-14 travel time from the repository to the surface for ambient conditions, 2,000, 10,000, and 50,000 years (modified from Ampter, et al., 1988) $\ldots \ldots \ldots \ldots \ldots \ldots \ldots \ldots \ldots \ldots \ldots \ldots \ldots \ldots \ldots \ldots$

E.1 Statistical Convergence; 100 vs. 500 Vectors, 10,000 Years, Base Case $\ldots \ldots \ldots \ldots \ldots \ldots \ldots \ldots$ E-2

F.1 Histogram of Topopah Springs Porosity Values $\ldots \ldots \ldots \ldots \ldots \ldots \ldots \ldots \ldots \ldots \ldots \ldots \ldots \ldots \ldots \ldots \ldots \ldots \ldots \ldots$

F.2 Histogram of Calico Hills Porosity Values $\ldots \ldots \ldots \ldots \ldots \ldots \ldots \ldots \ldots \ldots \ldots \ldots \ldots \ldots \ldots \ldots$

F.3 Location map of holes used in Scatter and Variogram Plots $\ldots \ldots \ldots \ldots \ldots \ldots \ldots \ldots \ldots \ldots \ldots$

F.4 Scatter Plot, Hole USW GU-3, Topopah Springs Unit $\ldots \ldots \ldots \ldots \ldots \ldots \ldots \ldots \ldots \ldots \ldots \ldots \ldots \ldots \ldots \ldots \ldots \ldots$

F.5 Scatter Plot, Hole USW GU-4, Topopah Springs Unit $\ldots \ldots \ldots \ldots \ldots \ldots \ldots \ldots \ldots \ldots \ldots \ldots \ldots \ldots \ldots \ldots \ldots \ldots \ldots \ldots$

F.6 Scatter Plot, Hole UE25a-1, Topopah Springs Unit $\ldots \ldots \ldots \ldots \ldots \ldots \ldots \ldots \ldots \ldots \ldots \ldots \ldots \ldots$

F.7 Porosity Variogram, Hole USW G-4, Topopah Springs Unit $\ldots \ldots \ldots \ldots \ldots \ldots \ldots \ldots \ldots \ldots \ldots \ldots \ldots \ldots$

F.8 Porosity Variogram, Hole UE25a-1, Topopah Springs Unit $\ldots \ldots \ldots \ldots \ldots \ldots \ldots \ldots \ldots \ldots \ldots$

G.1 Hydrogeologic units and boundary conditions used in the cross setional simulation using the VAM2D computer program $\ldots \ldots \ldots \ldots \ldots \ldots \ldots \ldots \ldots \ldots \ldots \ldots \ldots \ldots \ldots$, G-2

H.1a Intercept geometry for vertical emplacement $\ldots \ldots \ldots \ldots \ldots \ldots \ldots \ldots \ldots \ldots \ldots \ldots \ldots \ldots \ldots, \quad H-3$

H.1b Intercept geometry for horizontal emplacement $\ldots \ldots \ldots \ldots \ldots \ldots \ldots \ldots \ldots \ldots \ldots \ldots \ldots \ldots \ldots \ldots \ldots$

H.2 Geometry for volume excavated by a borehole through a horizontally emplaced waste canister ...... H-5

H.3 Conceptual view of drilling through waste canister and contaminated rock below the repository and drilling into contaminated rock

H.4 Depiction of quantity of waste in packages and host rock from the time of waste emplacement until the end of leaching (all waste leached from waste package) . .

\section{TABLES}

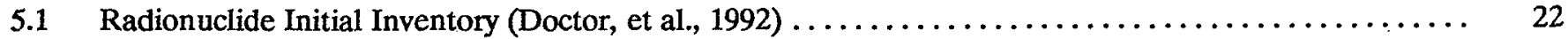

6.1 Identification of Liquid Pathway Processes and Estimated Effect on Calculating Cumulative Release

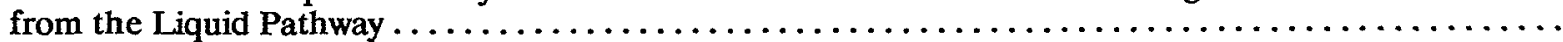

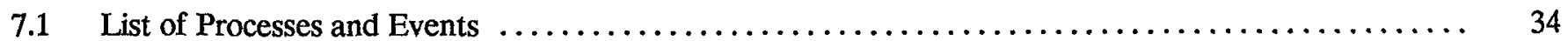

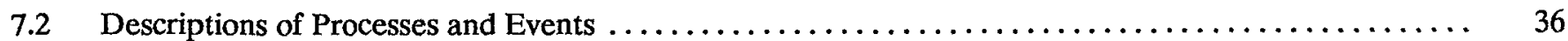




\section{TABLES (continued)}

Page

9.1 Columns Representing the Yucca Mountain Repository $\ldots \ldots \ldots \ldots \ldots \ldots \ldots \ldots \ldots \ldots \ldots \ldots$

9.2 Examples of Known and Suspected Correlations $\ldots \ldots \ldots \ldots \ldots \ldots \ldots \ldots \ldots \ldots \ldots \ldots \ldots \ldots$

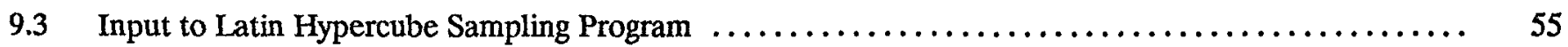

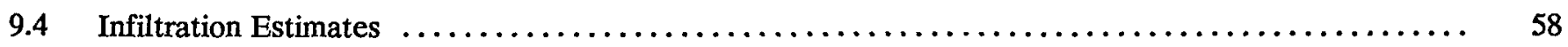

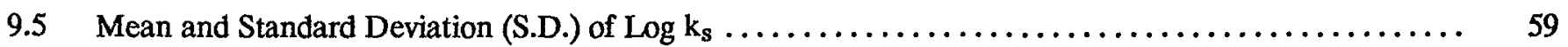

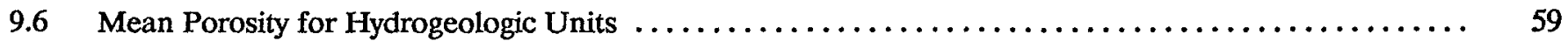

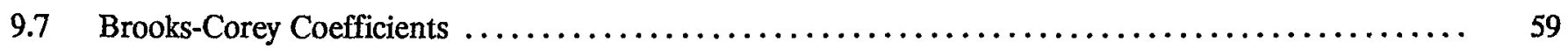

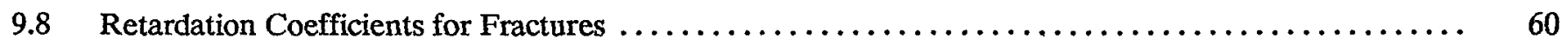

9.9 Steps to Perform Uncertainty and Sensitivity Analysis $\ldots \ldots \ldots \ldots \ldots \ldots \ldots \ldots \ldots \ldots \ldots \ldots \ldots \ldots \ldots \ldots \ldots$

9.10 Regression of Liquid Pathway Cumulative Releases (Raw data correlations) $\ldots \ldots \ldots \ldots \ldots \ldots \ldots .63$

9.11 Average Importance of Radionuclides to EPA Release Limits $\ldots \ldots \ldots \ldots \ldots \ldots \ldots \ldots \ldots \ldots \ldots$

9.12 Fractional Contribution by Radionuclide to EPA Release Ratio for Unrestricted Vectors and

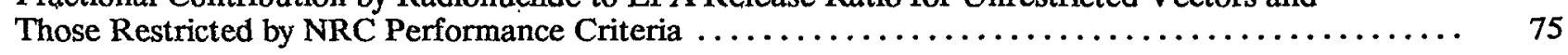

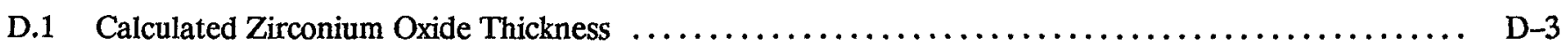

D.2 Release.Fraction as Function of Release Time $\ldots \ldots \ldots \ldots \ldots \ldots \ldots \ldots \ldots \ldots \ldots \ldots \ldots \ldots \ldots \ldots \ldots \ldots$

G.1 Hydraulic Properties Used in the Two-Dimensional Simulation of a Layered Tuff Site

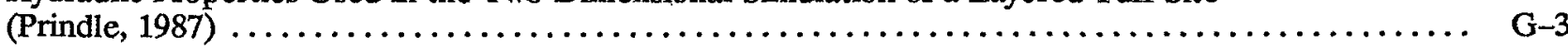

G.2 Ratio of Horizontal to Vertical Flow at the Interfaces Between Different Hydrologic Units over Differing Infiltration Rates. 
$+$ 


\section{EXECUTIVE SUMMARY}

\section{ES.1 INTRODUCTION}

The objective of this effort was to expand and improve the U.S, Nuclear Regulatory Commission (NRC) staff capability to conduct performance assessments independently. By, expanding and developing the NRC staff capability to conduct such analyses, NRC would be better able to conduct an independent technical review of the U.S. Department of Energy, (DOE) licensing, submittals for a high-level waste (HLW) repository.

These activities were divided initially into Phase 1 and Phase 2 activities. Additional phases may follow as part of a program of iterative performance assessment at the NRC. The NRC staff conducted Phase 1 activities primarily in CY 1989 with minimal participation from NRC contractors. The Phase 2 activities were to involve NRC contractors actively and to provide for the transfer of technology. Phase 2 activities are scheduled to start in CY 1990, to allow Sandia National Laboratories to complete development and transfer of computer codes and the Center for Nuclear Waste Regulatory Analyses (CNWRA) to be in a position to assist in the acquisition of the codes.

The results presented here have had limited peer review, have numerous simplifying assumptions, consider only a limited number of scenarios, and are based on limited data; thus, the numerical results should not be taken as representative of the performance of the proposed repository at Yucca Mountain, Nevada. The analysis is also replete with uncertainties regarding conceptual models, data, physicochemical models, and models and data for predicting scenarios. In the conduct of this-limited study, the authors did not encounter any problems indicating that the U.S. Environmental Protection Agency (EPA) standard could not be implemented. However, due to the incomplete scenario analysis in this demonstration, not all aspects of the standard were tested (e.g., the difficulties in estimating scenario probabilities). Therefore, taking these tentative results of a preliminary analysis out of context, or separating these tentative results from these caveats, may lead to the inappropriate interpretation and use of the results.

This report is intended to demonstrate the capability to conduct a performance assessment. The report is not intended to provide guidance on performance assessment methods or on the conduct of NRC staff reviews of performance assessments. Furthermore, it should not be considered as NRC staff guidance on the interpretation and implementation of NRC rules and regulations.

\section{ES.2 PURPOSE}

Given this background, the primary focus of the Phase 1 activities was to demonstrate the staff capability to conduct a total system-performance assessment in an independent fashion. By demonstrating such an independent capability, the NRC staff has provided evidence of a degree of readiness for the forthcoming review of licensing material to be provided by the DOE. In addition, by exercising this capability for independent review, the NRC staff has accomplished several-secondary objectives, including:

1. Performing an evaluation of the adequacy of existing analytical tools, both methodologies and computational methods;

2. Obtaining valuable insights into the need for further development of methodologies and computational tools;

3. Obtaining valuable insights into the data needed, from the DOE Site Characterization Program, to conduct performance assessments, including the priority of these data needs. (Because of the uncertainties in the analysis, these insights are limited, especially for this Phase 1 effort.)

\section{ES.3 SCOPE}

The performance assessment is considered to be comprised of two parts:

1. quantitative estimation of total system performance through the use of predictive models, and

2. documentation and detailed auxiliary analyses, where appropriate, to support the assumptions, data, and modeling approaches used to obtain quantitative estimates of performance.

Both aspects of performance assessment were addressed in the Phase 1 effort.

The focus of this Phase 1 demonstration was the EPA containment standard that requires the total system performance measure for an HLW repository to be expressed by a complementary cumulative distribution function (CCDF) of radionuclide releases to the accessible environment, weighted by a factor approximately proportional to radiotoxicity, integrated over an appropriate period of time $(10,000$ years is the current regulatory requirement). This performance measure was estimated by following the steps outlined in the information flow diagram (Figure ES.1). For the Phase 1 effort, these steps 
were all executed, but some (steps 2 and 3 ) were only executed to a limited degree. These steps are described briefly below:

1. System Description - In this step, the various important components of the waste-disposal system-the waste form, the engineered barrier (the canister, the repository, backfill, if any), and the site-are described in terms useful to modeling radionuclide migration to the environment. This step usually requires the synthesis of information from many different disciplines in the natural sciences and engineering.

2. Scenario Analysis-Scenarios representing alternàtive futures for the system and possible future.states of the environment are screened and chosen. Probabilities are estimated for the scenarios chosen. This step usually requires the synthesis of information from many different disciplines in the natural sciences and engineering.

3. Consequence Analysis-The consequence in terms of cumulative release of radionuclides to the accessible environment over a specified time period (usually 10,000 or more years) is calculated for each scenario and usually numerous realizations of possible parameter values.

4. Performance Measure Calculation (CCDF)-The consequences for each scenario, in terms of normalized cumulative releases of radionuclides to the environment over a specified period of time, are calculated and the results are displayed in a curve of consequences versus the probability that such consequences will be exceeded. Compliance with the performance criteria is determined by comparing the $\mathrm{CCDF}$ to a compliance curve, which the CCDF must not exceed.

5. Sensitivity and Uncertainty. Analysis-Sensitivity analysis investigates the change in performance measures caused by incremental changes in the values of input parameters and data. Uncertainty analysis attempts to quantify the uricertainty in performance estimates in terms of the major sources of uncertainty, including uncertainty in input parameters, uncertainty in modeling (both the conceptual model of the geometry and characterization of the system and the process model of what physicochemical processes occur and how they are manifested), and uncertainty about future states of nature. Modeling uncertainty was not quantified in Phase 1.

6. Documentation-The most effective documentation 'must make clear the assumptions used in the analy- sis, their bases, and the implications of their uses explicit.

Two types of uncertainty are usually treated explicitly in the generation of the CCDF: (1) uncertainty due to future states of nature and (2) uncertainty in the values of parameters determining system performance. Modeling uncertainty, including conceptual model uncertainty, is usually not treated explicitly in the generation of the CCDF. The CCDF is a curve of the likelihood that the consequence is more than a certain magnitude. For the repository system, considerable uncertainty exists concerning the values of parameters used to "estimate the consequences of the repository. This uncertainty is displayed on the CCDF, by combining the probability of a given scenario. with the probability of a given set of input parameters for that scenario.

Because of the complexity of the calculation of the CCDF, the staff deemed it appropriate, but not absolutely necessary, that the generation ${ }_{i}$ of the CCDF be performed by a computer code.

As explained previously, only a rudimentary performance assessment was intended for the Phase 1 effort, because of limited data, resources, and time, and because aid from NRC contractors, which could contribute to the Phase 1 goals, was not currently available. Because of the constraints on this activity, the scope of the effort was limited. Some of these limitations were:

- Only a preliminary analysis was intended in Phase 1.

- Use of currently available modeling tools was to be maximized; additional computer code development was to be minimized.

- The analysts were to take advantage of the limited data available for the Yucca Mountain Site.

- The scopes of the analyses were constrained by the time and resources made available to do it; the effort was scaled down from the original plan for this work.

- As many components of the methodology as possible were to be executed, given the limited time and resources available; this required reducing the depth to which certain aspects were demonstrated.

- For the Phase 1 effort, the EPA containment standard was to be the major focus; other regulatory standards were considered only incidentally.

-.. Phase 1 was executed by NRC staff only; other than existing reports, papers, and computer software packages already delivered, no contractor help was available for Phase 1, except infrequent and short personal communication.

- CNWRA involvement in Phase 1 was primarily as an observer, but was expected to become more active as 
the CNWRA performance-assessment capability expands.

\section{ES.4 ACCOMPLISHMENTS}

The NRC staff demonstrated its capability to conduct independently performance assessments for an $\mathrm{HLW}$ repository. Figure ES.2 shows how a CCDF for the total system can be constructed from curves for separate scenario classes. (The caveats stated on the next page indicate why this CCDF is not considered to be representative of total system performance of a proposed Yucca Mountain repository.) In doing such assessments, the staff gained insight into the capabilities and limitations of the currently available performance-assessment methodology. In achieving this primary objective, the NRC staff also achieved the following major accomplishments during Phase 1:

1. Modeled a potential liquid pathway of the undisturbed scenario class for the Yucca Mountain repository using:

a. the NEFTRAN computer code, to simulate transport in the unsaturated zone,

b. four vertical transport legs under the repository to account for spatial variability,

c, a modified treatment of waste form dissolution, and

d." a nonmechanistic model of waste package failure.

This liquid pathway modeling was extended to treat pluvial conditions.

2. Developed and used a total system code, to represent total system performance, as a CCDF, for a limited set of scenario classes, using preliminary data and numerous assumptions.

3. Developed a model and the corresponding computer code to treat human intrusion by drilling.

4. Performed a preliminary statistical analysis of results (sensitivity and uncertainty) using several techniques including Latin Hypercube Sampling (LHS) and regression analysis methods.

5. Executed several auxiliary analyses, which looked at:

a. the potential for non-vertical flow,

b. 'the sampling requirements for CCDF generation, c. the consequences of $\mathrm{C}-14$ gaseous releases, and

d. the statistical analysis of available hydrologic data for input to flow and transport models

\section{ES.5 TENTATIVE RESULTS}

In considering these tentative results, some important caveats should be recognized. Taking these tentative re- : sults of a preliminary analysis out of context, or separating these tentative results from these caveats, may lead to the inappropriate interpretation and use of the results.

1. The results presented here have had limited peer review, have numerous simplifying assumptions, and are based on limited data; therefore, the numerical results should not be taken as representative of the performance of a repository at Yucca ${ }_{5}$ Mountain, Nevada.

2. The analysis was replete with uncertainties regarding:

- conceptual models,

- data,

- physicochemical models, and

- models and data for predicting scenarios.

3. Only a limited set of scenario classes was incorporated in the modeling, so the total CCDF presented in this report cannot truly represent total system performance.

4. The modeling of waste-package failure was nonmiechanistic and rudimentary; therefore, this aspect of repository performance is probably not adequately represented.

5. The liquid flow and transport models used attempted to simulate key aspects of the performance of a repository at Yucca Mountain, but did so indirectly through modifications of transport analysis for saturated rock. A more direct representation of flow and transport in partially saturated, fractured rock is needed to ensure more confidence in the results:

Given the caveats just stated, the reader is reminded that the following tentative conclusions should be used only with these substantial limitations kept in mind. Based on a preliminary analysis, the staff has reached some tentative conclusions:

1. The fact that the Yucca Mountain repository, like others, is designed so that the waste is emplaced over a substantial area, appears to be an important aspect determining performance, and should be included in models of performance; important aspects appear to be areal variability of: 
- waste package failure,

- depth of rock to water table, and

- potential of rock units to sustain fracture flow.

2. The gaseous release of carbon-14 could be an important factor in repository performance, but more analyses and data are needéd to determine how important.

3. Two-dimensional modeling of the HYDROCOIN Yucca Mountain description resulted in significant lateral movement of water for unsaturated groundwater-infiltration rates 'greatèr than $0.2 \mathrm{~mm} / \mathrm{yr}$.' Nonvertical flow could be an important factor in repository performance, which warrants additional analysis and data.

4. For scenario classes allowing releases along the liquid pathway, the most significant contributors to the consequences represented by the CCDF were isotopes of plutonium. As plutonium behavior is poorly. understood, large uncertainties exist regarding:

- colloids,

- retrograde solubility, and

- sensitivity of chemistry to oxidation state.

5. For releases along the liquid pathway, the important input parameters appear, to be: _ is

- infiltration flux,

- fraction of infiltrating groundwater contacting the waste,

- uranium matrix solubility; and

- saturated hydraulic conductivity for the Calico Hills Vitric unit.

6. Consequence codes used in this study may not be sufficiently efficient to allo'w analyzing numerous scenarios, each with many iniput parametter vectors, so that total system performance is adequately characterized.

\section{ES.6 PRELIMINARY SUGGESTIONS FOR FURTHER WORK}

Based on this preliminary analysis and the limitations noted, the authors have some preliminary suggestions about the directions for further technical work to take. These do not represent an official NRC position, but are the views of the individual staff members who wrote this report. Several of these suggestions relate to aspects of the methodology that are missing or need improvement or that have not yet been incorporated into the NRC performance-assessment capability.t Other suggestions relate to the general lack of data for Yucca Mountain. Some of this suggested work is clearly the responsibility of
DOE; other items could be performed by NRC, DOE, or a third party. These suggestions are based on the work described in this report; they have not been correlated with other NRC staff views or with the DOE site characterization program. Therefore, these suggestions are not intended to and should not be taken as indications of deficiencies in the DOE Site "Characterization Plan. These recommendations for technical improvements include the following:

ES.6.1 Recommended Improvements to Modeling of Performance

\section{General}

1. Add the capability for modeling additional scenario classes.

2. Test the system code, using the consequence codes as subroutines, instead of generating data sets external to the system code.

3. Acquire, test, and evaluate codes developed by Sandia National Laboratories (SNL) for a repository in the unsaturated zone.

4. Explore, with the CNWRA, the adaptation of the FPPA (Fast Probabilistic Performance Assessment) methodology to generate the total system CCDF.

5. Evaluate additional codes, which could not be acquired and evaluated during this short-time effort, to determine whether existing codes can meet the NRC modeling needs, or whether additional code developiment is needed.

\section{Flow and Transport}

1. Refine groundwater modeling (e.g., by. considering higher dimensions).

2. Incorporate a model of gas-pathway transport in the

$\therefore$ calculation of the CCDF.

3. Include flow and transport through the saturated zone.,$\cdots$

4. Directly model transport through a partially saturated, fractured rock, instead of the indirect, approximate representation used in Phase 1.

5. Explicitly model fracture/matrix coupling.

\section{Source Term}

1. Attempt to develop or use a previously developed mechanistic model of waste-package failure.

2. Develop a mechanistic model of contact between groundwater and the waste. 
3. Treat the repository as a source of radionuclides distributed in time and space, instead of as a point source.

ES.6.2 Recommended Improvements to and Extensions of Auxiliary Analyses

1. Perform detailed geochemical analyses to investigate:

- the use of $\mathrm{k}_{\mathrm{d}}$ 's (distribution coefficients),

- the effects of spatially varying saturation on radionuclide migration,

- the waste form, groundwater, tuff interactions,

- the waste package degradation,

- the oxidation of the spent fuel matrix, and

- the geochemical behavior of plutonium.

2. Evaluate heat effects at early time periods; estimate the thermal, hydrologic, and geochemical environment of the repository at early times.

3. Evaluate importance of thermally and barometrically driven air flow on repository performance at Yucca Mountain.

4. Perform detailed hydrologic analysis for Yucca Mountain, to provide better data to the transport analysis and to examine, in more detail, various alternative hypotheses regarding hydrology at Yucca Mountain.

\section{ES.6.3 Recommendations for Additional Scientific Input}

(Some of these items could be performed by either DOE or NRC, whereas others are clearly the responsibility of DOE)

1. Develop and demonstrate a mathematically rigorous, scientifically robust, method for scenario analysis.

2. Obtain geoscience data for modeling volcanism.

3. Obtain geoscience and hydrologic data for modeling faulting, uplift, and subsidence at Yucca Mountain.

4. Obtain laboratory chemical analysis to determine the partitioning of radionuclides in various compartments of the spent-fuel waste form.

5. Obtain field and laboratory data on phenomena important to the near-field behavior of the repository, especially the effects of heat.

6. Obtain more data on plutonium geochemistry.

7. Obtain a better understanding of waste-package corrosion in the unsaturated zone.

8. Obtain field and laboratory data and perform analyses to investigate the issue of non-vertical flow at Yucca Mountain.

9. Obtain field data on the transport of gaseous radionuclides (C-14) at Yucca Mountain. 


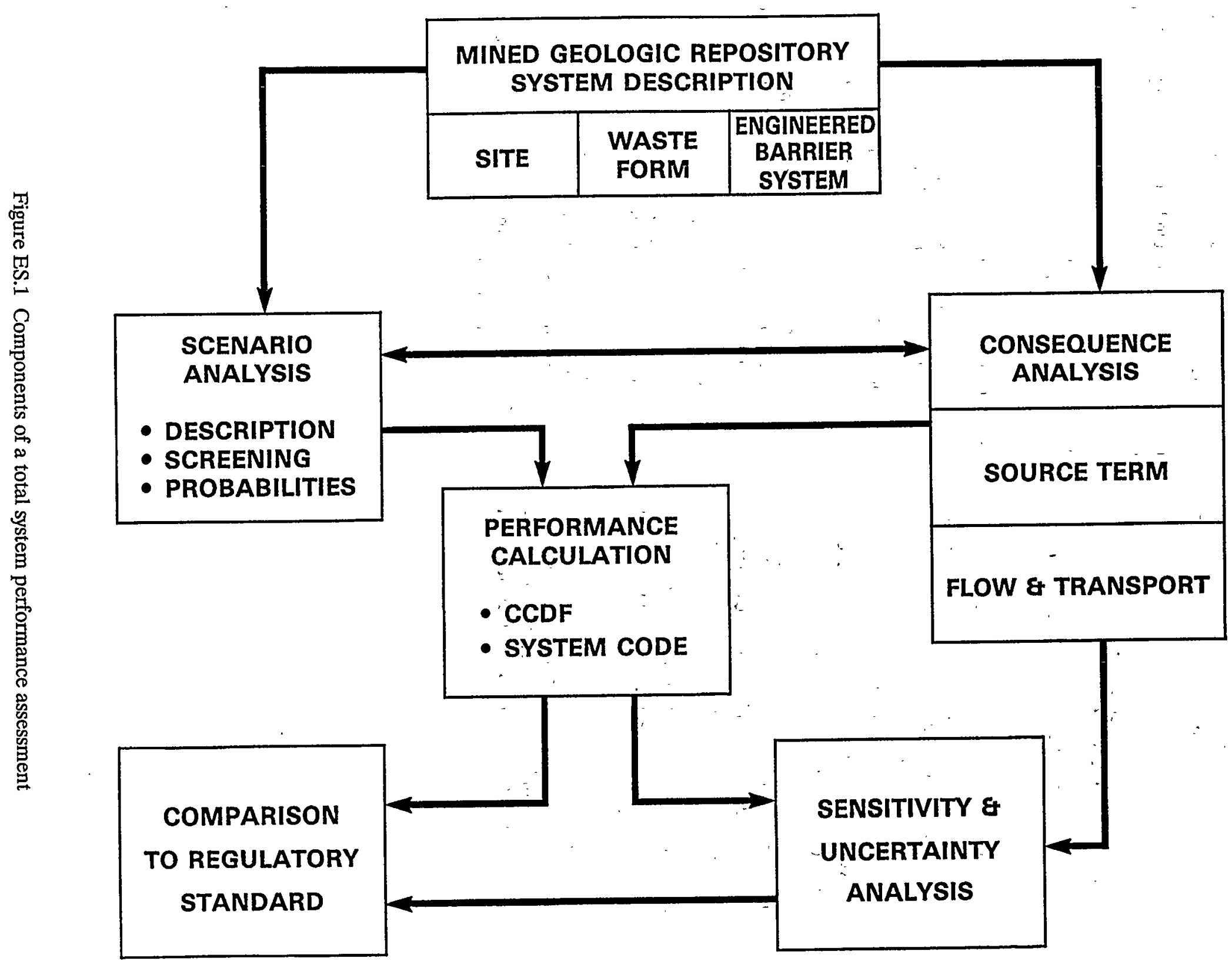




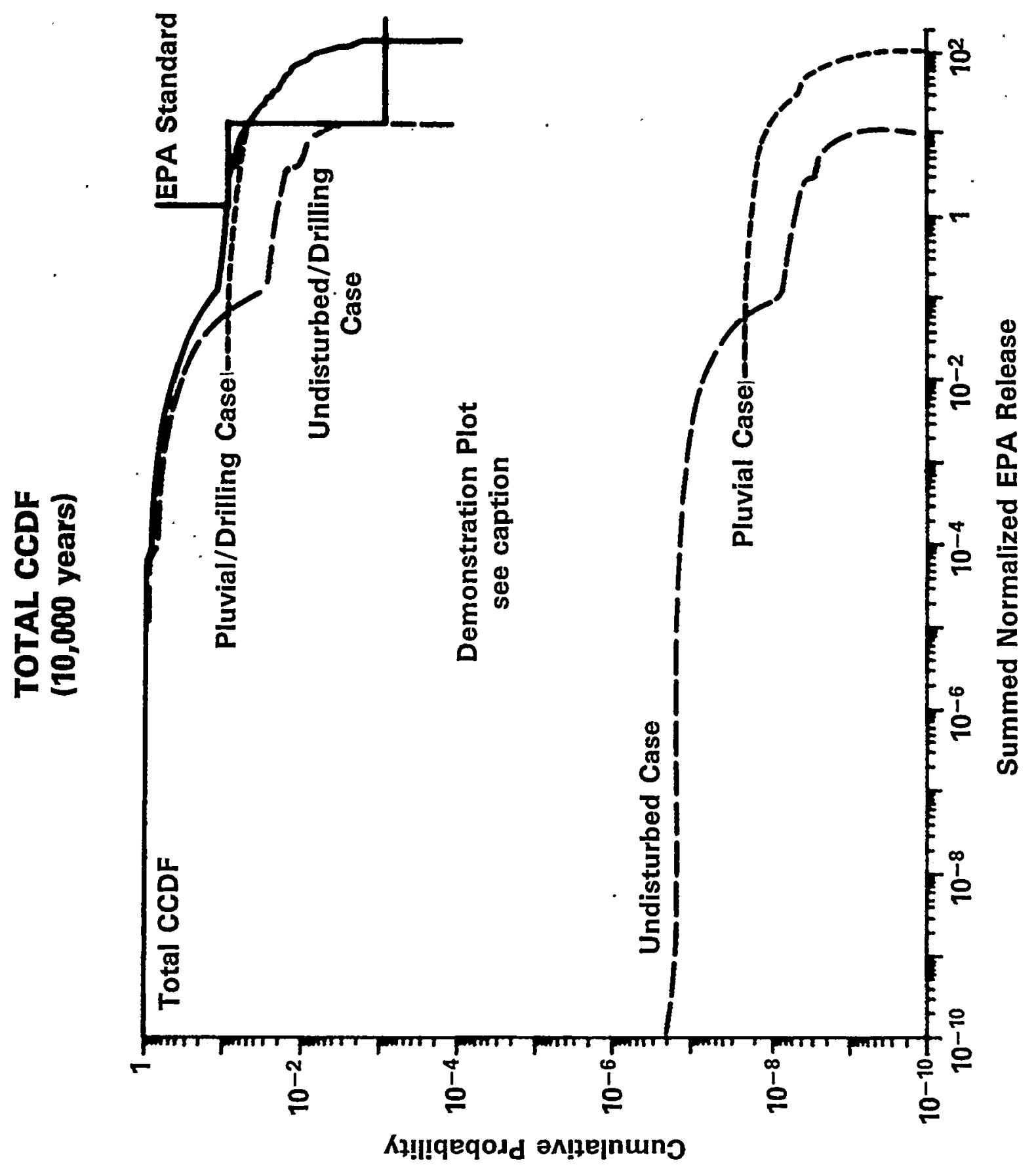

Figure ES.2 Composite CCDF curve for the scenario classes considered in Phase 1 of the Iterative Performance Assessment. Results based on 598 vectors, yielding 1196 values, 1094 after duplication. This graph presents results from an initial demonstration of staff capability to conduct a performance assessment. The graph, like the demonstration, is limited by the use of many simplifying assumptions and sparse data. 
Executive Summary 


\section{ACKNOWLEDGMENT}

The work described in this report was a team effort that included input from the authors as well as from additional staff members. The authors would like to express their collective appreciation to those NRC staff who contributed to this report:
J. Bradbury, NMSS
T. Mo, NMSS
J. Trapp, NMSS
K. Chang, NMSS
C. Peterson, NMSS
T. Margulies, RES
N. Coleman, NMSS
J. Pohle, NMSS 


$$
\begin{aligned}
& 1+\ldots,+\infty \\
& 1 \times+,+\infty
\end{aligned}
$$

$12,{ }^{\prime \prime 2}$

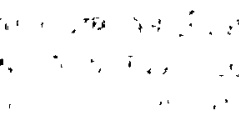

\section{INTRODUCTION

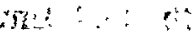

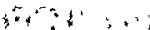
stration, of the U.S Nuclear. Regulatory Commission (NRC) capability to execute a performance assessment of a high-level nuclear waste (HLW) repository.

This demonstration was performed as the initial step in a sequence of planned iterative performance assessments to be undertaken by the NRC staff and NRC contractors. Performance assessment of an HLW repository, like other systematic safety-assessment methodologies, benefits substantially by being conducted in an iterative manner, primarily because the lessons learned regarding modeling improvements, data needs, and methodology can be addressed in subsequent iterations. This activity was undertaken to maintain and to enhance the independent NRC staff capability to evaluate performance assessments submitted as part of a license application. This capability consists of at least two aspects: (1) the capability to provide an independent check on key aspects of the licensee's assessment and (2) the capability to probe the licensee's assessment for potential weaknesses, based on a familiarity with the methods, data, and assumptions used in the assessment.

In addition, these iterative performance assessments are expected to provide insights helpful in developing regulatory products, including: (1) technical positions, rulemakings, and other regulatory guidance; (2) evaluations of site characterization activities; and (3) evaluations of the NRC research program.

Currently, two phases, of potentially several iterations, are planned for these iterative performance assessment activities. Phase 1, a demonstration, was intended to: (1) result in a framework for performance-assessment modeling; (2) with the limited resources allocated to perform this activity, provide a rudimentary demonstration of a performance-assessment modeling capability; and (3) be accomplished with a minimum of technical input and interaction with NRC contractors, except for work and products already documented and delivered to NRC. Phase 2, is intended to: (1) be accomplished in FY 90 and beyond; (2) incorporate significant products to be delivered by NRC contractors, most notably the Tuff Performance Assessment Methodology currently under development by Sandia National Laboratories (SNL); and (3) provide a more complete, accurate, sophisticated, and realistic performance--assessment modeling capability. Additional phases (iterations) may be added as this work proceeds.

An interdisciplinary, integrated approach was envisioned when the initial plans for this activity were developed in late 1988 to early 1989 . Although a portion of the work was continued by some staff for a time, sustained effort by staff on this Phase 1 demonstration did not resume until August/September 1989. At that time, the effort was restructured: The major features of this restructuring included:

- Concluding the Phase 1 work in 3 months, i.e., no later than November 30, 1989.

- Attempting to execute as many steps as possible in the performance-assessment methodology, while at the same time tailoring the activities to fit into the time and resources allowed.

- Establishing a smaller core group of participants to be responsible for the work. The involvement of other staff and continual peer review, as originally envisioned in late 1988, would be deferred until after November 30, 1989, to expedite the effort.

- Dividing the work into five parts:

1. Scenario Analysis

2. Flow and Transport

3. Source Term

4. System Code

5. Auxiliary Analyses

Working groups, or teams, were set up to conduct the Phase 1 analyses for the first four of these topical areas. These teams roughly correspond to the methodological steps of performance assessment shown in Figure 1.1. The auxiliary analyses were conducted by individual staff members.

This report is largely structured along the same lines used to organize the work. Sections ES through 3 provide introductory material. These sections are:

ES - Executive Summary

1.0 - Introduction

2.0 - Purpose and Scope

3.0 - Organization and Staffing

Sections 4 through 8 of this report describe the work performed by the various teams:

4.0 - System Code

5.0 - Source Term

6.0 - Flow and Transport Models

7.0 - Methodology for Scenario Development

8.0 - Auxiliary Analysis Summaries 
Because Phase 1 was a demonstration of capability, these sections may be taken as a status report on progress made to date. They should in no way be taken as the description of a definitive approach to these components of performance assessment.

Section 9, "Analysis and Results," presents the limited results of this Phase' 1 demonstration. Section 10, "Preliminary Suggestions for Further Work," presents some preliminary thoughts on the direction for Phase 2 efforts. Because of the limited nature of the analysis, no conclusions or recommendations about the proposed repository at Yucca Mountain are given or intended to be given. The authors did not encounter any problems indicating that the U.S. Environmental Protection Agency (EPA) standard (40 CFR Part 191) could not be implemented. However, due to the incomplete scenario analysis in this demonstration, not all aspects of the standard were tested (e.g., the difficulties in estimating scenario probabilities).

Finally, Appendices A through J provide more detailed material on the auxiliary analyses and other aspects of the Phase 1 work. "

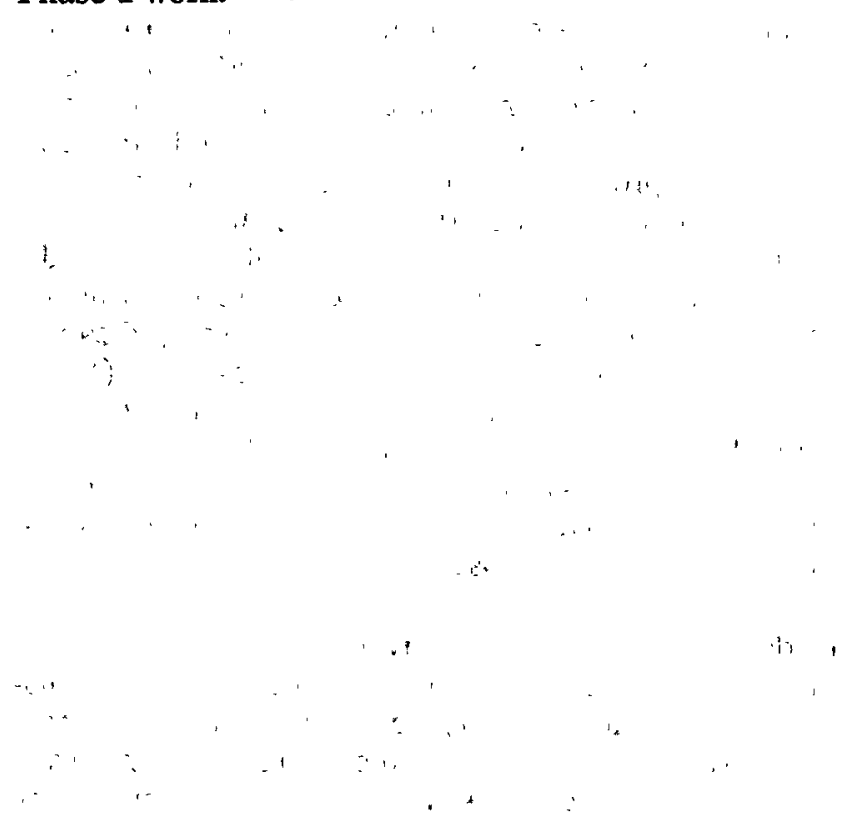




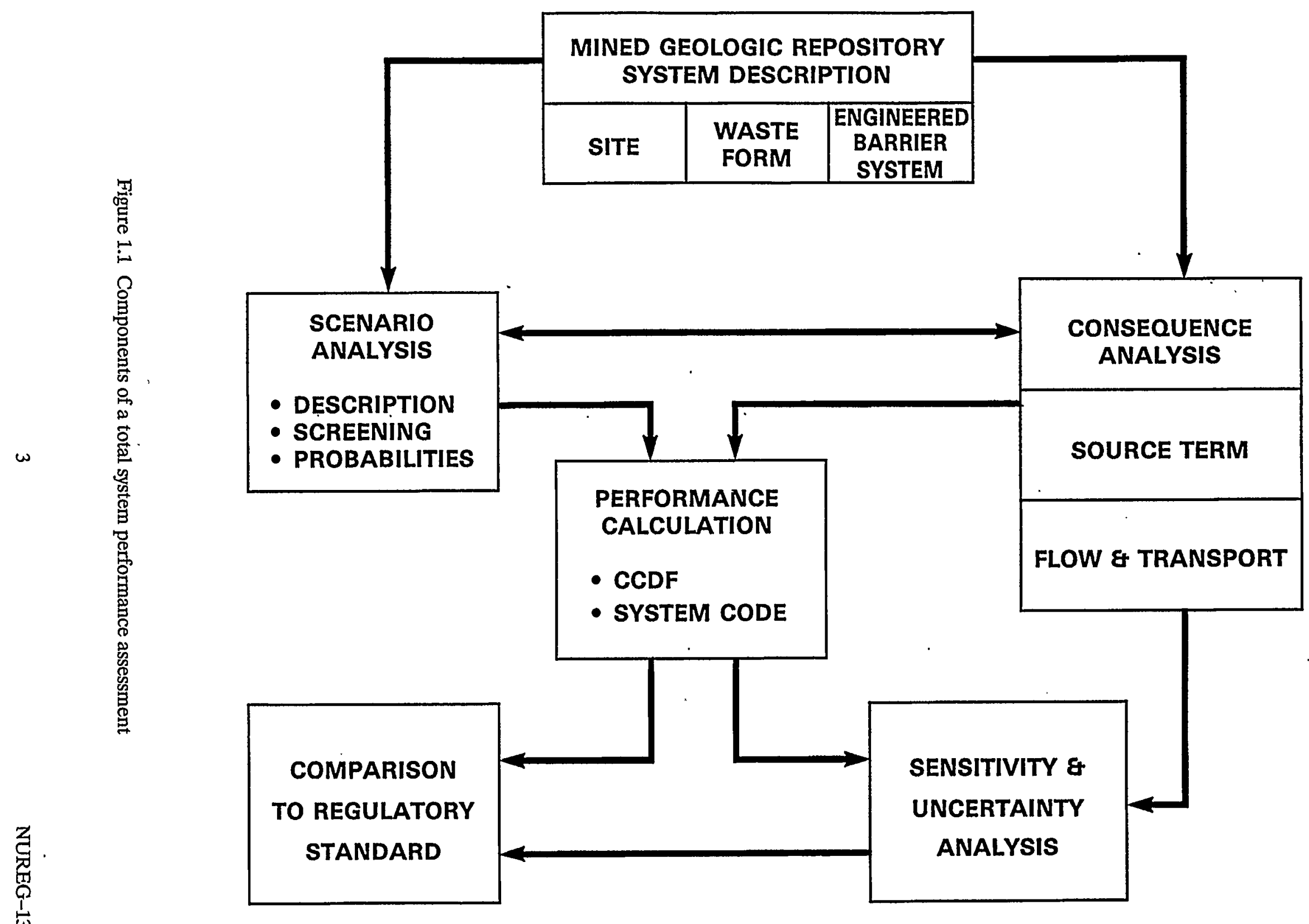




\section{PURPOSE AND SCOPE}

The primary purpose of Phase 1 of the iterative performance asses'sment activity was to demonstrate the capability of the NRC staff to conduct, independently, 'a performance assessment of a proposed HLW repository. An independent assessment capability is considered to be an important aspect of the licensing review to be conducted by the NRC staff. To achieve these goals, a limited, preliminary total system performance assessment was conducted.

The performance assessment was considered to be comprised of two parts:

(1) the quantitative estimation of total system performance through the use of predictive models, and ${ }_{t \rightarrow}$.

(2) documentation, including detailed auxiliary analyses, where appropriate, to support the assumptions, data, and modeling approaches used to obtain quantitative estimates of performance.

Both of these aspects were addressed in the Phase 1 effort.

In accomplishing the primary goal of Phase 1, some worthwhile secondary goals were achieved:

- The existing analytical tools to conduct a performance assessment (both methodologies and computer codes) were evaluated.

- Insight was obtained into the needs for the development or improvement of methodologies.

- Insight into the needs for site characterization was obtained.

The total system performance measure for an HLW repository can be expressed by a complementary cumulative distribution function (CCDF) of radionuclide releases to the accessible environment, weighted by a factor approximately proportional to radiotoxicity, and integrated over an appropriate period of time $(10,000$ years is the current regulatory requirement). This performance measure is mandated by the EPA standard (40 CFR Part 191) for the containment of waste by an HLW repository. This performance measure is incorporated into NRC's regulation? 10 CFR Part 60, along with additional performance measures relating to: (1) waste-package lifetime, (2) fractional release of radionuclides from the engineered barrier system (EBS), and (3) groundwater travel time. The representation of repository performance by a CCDF of weighted cumulative releases incorporates: (1) consideration of the various components impeding the movement of radionuclides to the accessible environment; and
(2) consideration of a range of conditions and events that could affect future performance.

The CCDF was estimated by following the steps outlined below, which are shown in Figure 1.1. For the Phase 1 effort; all these steps were performed, but some (for example, Steps 2 and 3 ) were executed only to a limited degree, and only portions of others (for example, Step 5) were done.

1. System Description-The repository is broken into its component parts for the purposes of modeling. These components include the waste, the mined repository, and the portion of the geosphere surrounding the repository through which the radionuclides, in time, migrate. The system description must include information to support development of models describing repository performance and to determine parameters upon which the models depend.

2. Scenario Analysis-Șcenariòs representing alternative futures for the system and possible future states of the environment are screened and chosen. Probiabilities are estimated for the chosen scenarios.

3. Consequence Analysis-Models are developed to describe the performance of the repository. The coinsequence, in terms of cumulative release of radionuclides to the accessible environment over a specified time period (usually 10,000 or more years), is calculated for each scenario and usually for nu-1 merous realizations of possible parameter values. In addition to being incorporated by way of cumulative releases into the CCDF (Step 4), certain types of consequences might also be considered separately, for comparisons to standards for maximum doses to individuals and for maximum concentration in groundwater. (These were beyond the scope of Phase 1.) For purposes of dividing up the work, the consequence analysis was conducted by the Source Term and the Flow and Transport Teams. . yi ..

4. 'Performance Measure Calculation (CCDF)-The'consequences for each scenario, in terms of normalized cumulative releases of radionuclides to the environment over a specified period of time, are calculated, and the results are displayed in a curye of consequences versus the probability that such consequences might be exceeded. Compliance with the performance criteria is determined by comparing the curve to a compliance curve that provides limits that the calculated curve must not exceed.

5. Sensitivity and Uncertainty 'Analysis-Sensitivity' analysis investigates the change in performance 
measures caused by incremental changes in the values of input parameters and data. Uncertainty analysis attempts to quantify the uncertainty in performance estimates in terms of the major sources of uncertainty, including uncertainty in input parameters, in modeling (both the conceptual model of the geometry and characterization of the system and the process model of what physicochemical processes occur and how they are manifested), and in future states of nature. Uncertainty in modeling, including conceptual model uncertainty, was not quantified in Phase 1.

6. Documentation-Documentation must make clear the assumptions used in the analysis, their bases, and the implications of their uses.

Two types of uncertainty are usually treated explicitly in the generation of the CCDF: (1) uncertainty due to future states of nature, and (2) uncertainty in the values of paramèters determining system performance. In a safety analysis for a more conventional type of system, the response of the system to any single future state of nature to be considered would be a single-valued estimate of system performance (in the parlance of the repository system, a single value of consequence). System performance would then be described by the plot of consequences versus the likelihood of the future state of nature (scenario) producing that consequence; such a curve would be the distribution function. The integral of such a curve over probability would yield a cumulative distribution function; i.e., the likelihood that the consequence would be of a certain magnitude or less. The CCDF would be the curve of the likelihood that the consequence would be more than a certain magnitude.

For the repository system, considerable uncertainty exists concerning the values of parameters used to estimate the consequences of the repository. Traditionally, the uncertainty from this source is also displayed on the CCDF by: (1) describing some or all of the parameters used to estimate consequences as distributions of values rather than point estimates; (2) choosing a value of each parameter required to describe system performance from these distributions representative of some portion of the various distributions; (3) estimating performance based on a given realization of parametric values; (4) noting the conditional parametric probability, i.e., the joint probability density for the given realization or region of parameter space (for uncorrelated parameters, this would be the product of the individual parameter probabilities); and (5) calculating the $\mathrm{CCDF}$, using the parametric probability multiplied by the probability of the scenario. This process is complicated further when consideration of different scenarios makes it necessary to yary: (1) the consequence models for different scenarios, and/or (2) the distributions of parameters (either the range of parame- ters, the magnitude of the parameters, or the shape of the distribution), depending on the scenarios.

Because of the complexity involved in the CCDF calculation, it was decided that the generation of this curve would be performed using a computer code. At a minimum, such a code would be needed to: (1) sequence through all the scenarios to be considered; (2) choose the consequence models and parametric distributions corresponding to the scenario being analyzed; (3) sample the parameter space appropriate to the given scenario; (4) estimate consequences based on the models and parameter values for the scenario; and (5) combine the parametric and scenario probabilities and the calculated consequences to generate the CCDF.

Although the primary focus of the Phase 1 demonstration was the EPA containment 'standard and the associated performance measure (cumulative releases to the accessible environment), some calculations of performance measures related to the NRC subsystem requirements, such as groundwater travel time, fractional release rate, and waste package lifetime were performed. These calculations were performed to demonstrate the capabilities of the performance-assessment methodology and the ability of the staff to exercise the methodology. These calculations are intended as examples and should not be considered to be methods for calculating quantities in a regulatory context that the NRC staff considers acceptable.

As explained in Section 1, only a rudimentary performance assessment was interided for this Phase 1 demonstration, because of limited resources and time, and because input from NRC contractors that could contribute to the accomplishment of the goals was not available..Because of these constraints, the scope of the effort was limited. Some of these limitations on the Phase 1 effort were:

- Only a preliminary analysis would be performed.

- The effort would be scaled down from the original January 1989 plan for this work.

'I:.'

- Onily currently available modeling tools would be used; computer code development would be minimized.

- The analysts would take advantage of the limited data available for the Yucca Mountain site.

- As many components of the methodology as possible would be executed, given the limited time and resources available; this would require reducing the depth to which certain aspects were demonstrated.

- The EPA containment standard would be the only performance standard considered. The EPA standards for individual protection and groundwater protection would be investigated at some later time, 
as would the subsystem requirements of $10 \mathrm{CFR}$ 60.113 .

- The demonstration would be executed by NRC staff, only. The Center for Nuclear Waste Regulatory Analyses' (CNWRA) involvement would be primarily as an observer.

- Other than existing reports, papers, and computer software packages already delivered, the only con- tractor contribution would be via personal communication.

To perform this preliminary performance assessment and demonstrate the staff capability to conduct such work, the following types of activities were performed: (1)computations and support, including: data input, model setup, code development and testing, code execution, and output analysis; (2) auxiliary analyses, including: evaluation of assumptions and preprocessing raw data; and (3) documentation. 
-

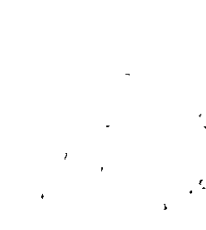

$+$

it

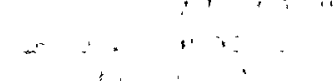

.

1,1

, 


\section{ORGANIZATION AND STAFFING}

NRC staff members from both the Offices of Nuclear Materials Safety and Safeguards. (NMSS) and Nuclear Regulatory Research (RES) worked on Phase 1. To coordinate the efforts of the two offices, the organizers of Phase 1 designated an administrative project manager from NMSS and two office technical coordinators, one from NMSS and one from RES. The technical staff involved in Phase 1 came from both offices. The assignment of technical staff to technical efforts in Phase 1 was done without regard to office affiliation.

The project manager and technical coordinators facilitated communications among the various technical participants and managers. The technical coordinators also proposed plans for technical activities, schedules, and staffing for Phase 1, for approval by NMSS and RES management. 



\section{SYSTEM CODE}

\subsection{Introduction}

In the Phase 1 demonstration, a system code was developed to process information needed to generate a CCDF representative of the performance of an HLW repository. To obtain the CCDF, this code treated sequentially a set of scenarios that -represented possible future states of nature. Consequence modules associated with the available release pathways calculated the cumulative radionuclide release, over the 10,000-year simulation time, for each of four scenarios analyzed in Phase 1 . These consequence modules were products of work performed under the Source Term and the Flow and Transport Tasks, that are documented in Sections 5, 6, and 9 of this report. Each scenario yielded numerous cumulative release values, resulting from the multiple parametric input vectors used in a realization. Probabilities assigned to each consequence within each scenario were then combined with the likelihoods of the scenarios themselves, to form the CCDF.

In accomplishing these tasks, the system code handled two types of uncertainty inherent in a CCDF. First, it treated the uncertainty in the future states of nature by looking at sets of scenarios that attempted to describe those future states. Secondly, the code handled the uncertainty related to the variability in model parameters by using multiple sets of parametric input vectors when executing the pathway consequence modules.

\subsection{Requirements for the Development of the System Code}

The development of the system code is a continuing process, consistent with the ongoing iterative performance-assessment activity. Throughout its development, this code should meet certain minimum requirements:

1. The computational modules for calculating consequences, comprised of one or more computer codes for the source term and the flow and transport calculations, produce output in terms of cumulative radionuclide release to the accessible environment. The system code must be capable of receiving these data.

2. The system code must be able to treat two of the types of uncertainty incorporated in a CCDF characterizing repository performance: (1) the uncertainty in future states of nature, and (2) the uncertainty in model parameters used to estimate cumulative reIeases.
3. To treat uncertainty in future states of nature properly, the system code must be able to treat different scenarios (or more properly scenario classes) that attempt to describe those future states and obtain the corresponding data on cumulative releases of radionuclides.

4. To treat properly the uncertainty related to the variability in parameters used in the consequence models, the system code must be able to collect and process cumulative release data generated from multiple sets of parametric input vectors.

5. Because many scenarios are expected to allow radionuclide releases by more than one pathway (e.g., in groundwater, by gas, and/or by direct release), the system code must be able to obtain cumulative releases corresponding to the specified pathways.'

6. The system code should have built-in protection to ensure the consistency of the assumptions used within a single simulation. For example, the per formance time period $(10,000$ years for the current EPA standard) should be the same for all scenarios, and pathways in any given representation of the repository to which the system code is applied.

7. The system code should be able to present results in both tabular and graphical formats.

\subsection{Survey of Existing Codes}

The staff evaluated several computer codes to determine their suitability (as a whole or in part) for use as a system program in this effort. Although all the surveyed codes were not "system codes" per se, each was reviewed in terms of how well it fit the requirements expressed in Section 4.2. Appendix A provides a detailed discussion and description of the codes evaluated.

Based on the results of the review; the staff decided to develop its own system code rather than to adopt an existing one. There were several reasons for this choice. First, adapting an existing program to meet the staff's needs and to be compatible with the NRC computing environment would likely be as time-consuming as development of a new code. Secondly, an NRC-written code could be more closely tailored to the specific requirements and needs of the project than one developed outside NRC. Finally, the more promising system codes for potential use in this work would not be available to the staff within the timeframe set. 


\subsection{Description of the System Code}

\subsubsection{Introduction}

This section presents a brief description of the system code developed by the staff for this demonstration. The maniner of code execution (i.e., internal vs. external), the input data requirements, the type of output available, and a brief outline of the system program are presented.

\subsubsection{Internal vs. External Runs}

The system code can be executed in either the "internal" or the "external" mode (Figure 4.1). This distinction refers to the time at which the output files from the consequence modules are generated. In the internal mode, consequence modules are run and cumulative radionuclide releases calculated as the system code is executed. This requires that the modules be integrated closely with the code. For external runs, however, the modules are separate from the system code, and as a result, the cumulative releases can be generated and placed in files at any time before iteration of the system code. Internal executions would appear to make sensitivity analyses easier, because simulation parameters are global. Thus, changes to the input files for subsequent runs need be made only once. This decreases the opportunity for error, while offeringincreased convenience and quality assurance to the analyst: Simulations in the external mode offer the opportunity to repeat earlier runs as long as the output files from the consequence modules are uniquely identifiable. In addition, external runs would appear to be more economical in terms of both computer time and money, since they do not require the execution of either the Latin Hypercube Sampling (LHS) routine or the consequence modules.

In Phase 1, although both modes of operation were allowed, the system code was demonstrated only in the external mode.

\subsubsection{Input}

The Phase 1 system code required input data in the following five areas: (1) general run information, (2) scenario-specific information, (3) probabilities of those scenarios occurring, (4) EPA release limits for the initial radionuclide inventory; and (5) cumulative radionuclide releases due to the effects of the scenarios.

The analyst created a file consisting of both the general run data and the scenario-specific information. This file supplied the execution mode, the simulation time period, and the amount of output desired, as well as the scenarios (total number, names, release pathways) to consider.
A scenario's probability is estimated by combining the probabilities of the processes and events making up the scenario. For this demonstration, the staff modeled four scenario classes based on two fundamental events: a pluvial period (or not) and drilling at the site (or not). Figure 4.2 shows the probabilities assigned to the events and the scenarios. The probability of occurrence of drilling was assumed to be independent of the probability of the occurrence of pluvial conditions.

The EPA release limits were taken from 40 CFR Part 191, Appendix A, Table 1. Given in curies released per 1,000 Metric Tons of Heavy Metal (MTHM), these limits were converted in the system code to release limits for the initial inventory of 70,000 MTHM assumed for this demonstration. EPA ratios were calculated, using these limits, for each released radionuclide.

The cumulative releases of radionuclides were calculated by the consequence modules; which modeled the repository release via the available pathways assigned to each scenario:

\subsubsection{Operation}

To obtain a CCDF estimating repository performance, the system code treated a set of scenarios describing possible future states of nature, and accessed the estimated cumulative releases corresponding to each scenario. The code next combined this data from the scenarios into the $\mathrm{CCDF}$, and printed the CCDF as a graph and/or table. This section, along with Figures 4.3 and 4.4 , provides a more detailed explanation of how the system codeaccomplished these tasks.

The effects of each scenario were assessed in the following manner. First, had the system code been set to run in the internal mode, conséquence modules for the potential release pathways specified for a scenario would have been executed. Next, the cumulative releases calculated by the modules, either internally or externally; using LHS-generated input vectors, were read into the program and stored in temporary arrays. Then, each radionucliderelease pair was compared to its EPA release limit, and a corresponding normalized.EPA ratio was calculated by the following formula:

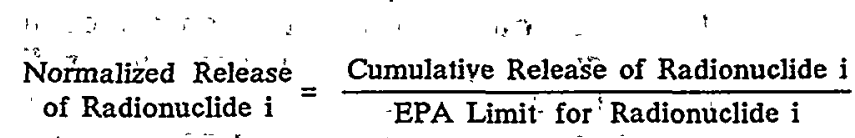

These normalized releases were then placed into a fourdimensional array arranged by scenario, radionuclide, vector, and release pathway (Figure 4.5). Once the effects of all scenarios had been modeled, this array was used as a data base over which different summation routines took place. These routines created a second array of summed normalized EPA releases, ordered by scenario and vector, 
by adding up normalized releases for all radionuclides over all release pathways.

Then, for each scenario, probabilities.were calculated for the consequences associated with a particular input vector. These likelihoods were based on the assumption that every vector within the scenario was equally probable. For example, given this assumption, the likelihood of occurrence of a single vector within a scenario containing 500 vectors is equal to $1 / 500$ or .002 . Following the assignment of probabilities, the consequences within each scenario class were sorted, duplicates eliminated, and the likelihoods adjusted accordingly.

The array for each scenario then contained unique, ordered consequences with associated likelihoods of occurrence. Then, in order to obtain a representative cumulative distribution function, scenario probabilities were factored in by multiplying the probability of each consequence by the likelihood of its scenario.

Finally, the results from all scenarios considered were combined, the summed normalized releases with their probabilities ordered and sorted, and a running sum of the probabilities created. This outcome was graphed as a CCDF on a $\log -\log$ plot of summed normalized EPA release against cumulative probability.

\subsubsection{Output}

Results generated by the system code were written to two output files. In addition to the data needed to graph the total CCDF, these files contained normalized releases broken down by scenario, vector, release pathway, and radionuclide, or various combinations of these categories.

A commercially available software graphics package was used to plot the CCDF. 


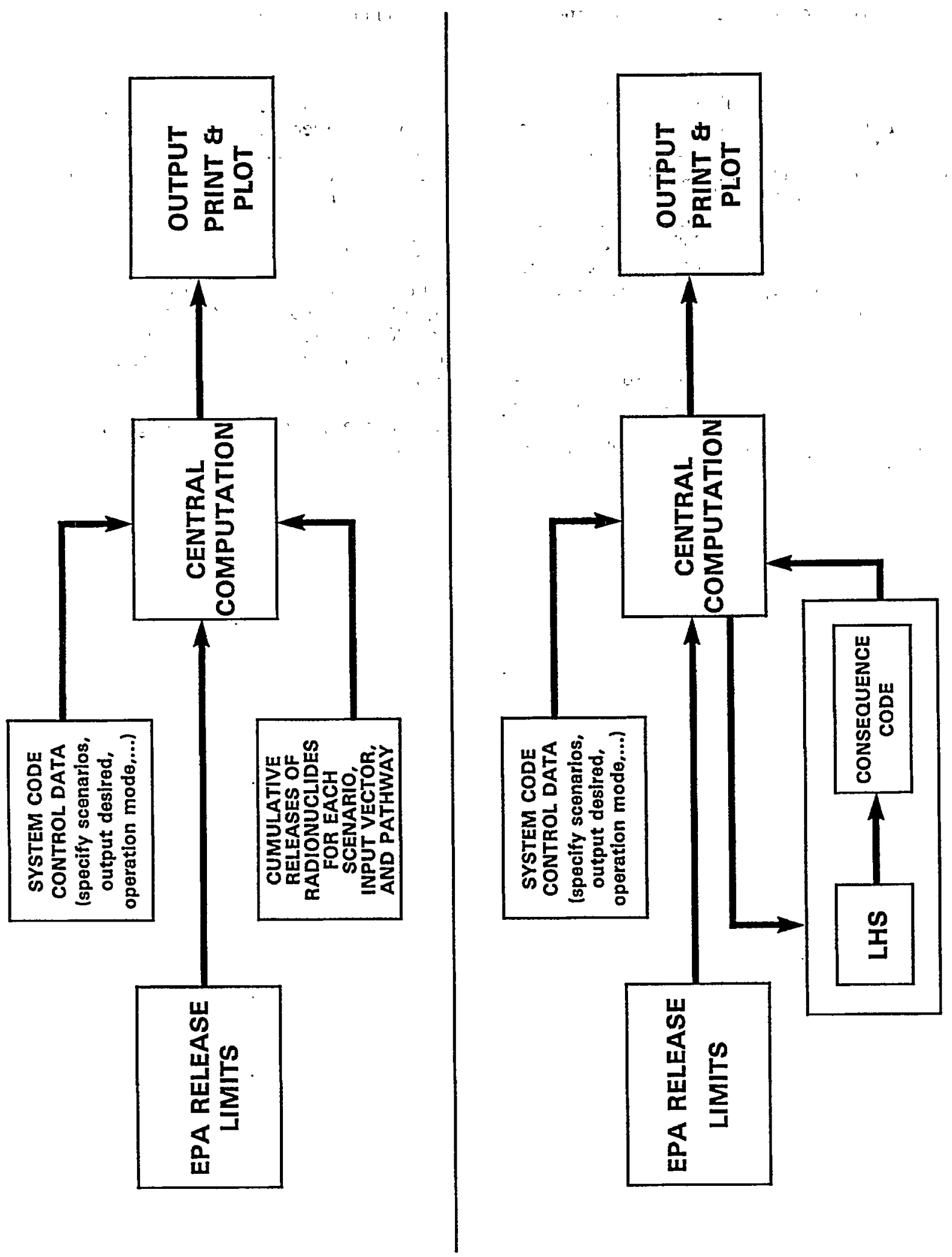

Figure 4.1 Flow diagram of external and internal modes of operation. 


\section{DETERMINATION OF SCENARIO PROBABILITIES FROM THE PROBABILITIES OF FUNDAMENTAL EVENTS}

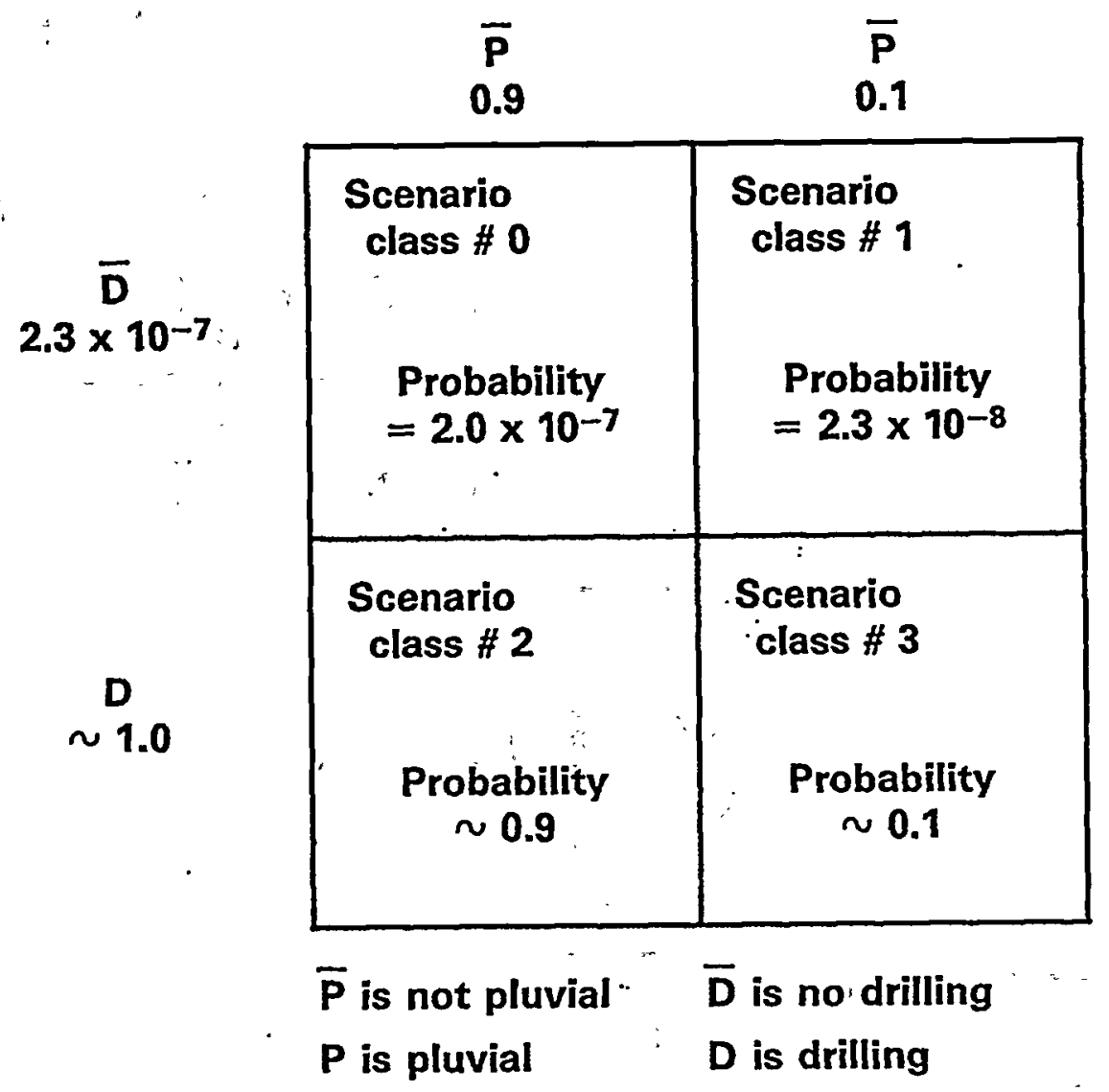

Scenario class \# 0 is no drilling, not pluvial Scenario class \# 1 is no drilling, with pluvial Scenario class \# 2 is drilling, not pluvial Scenario class \# 3 is drilling and pluvial

Note: Probability combinations assume that fundamental events have independent probabilities of occurrence; this is not a general restriction.

Figure 4.2 Determination of scenario probabilities from the probabilities of fundamental events. This figure presents results from an initial demonstration of staff capability to conduct a performance assessment. The figure, like the demonstration, is limited by the use of many simplifying assumptions and sparse data. 
Cumulative Release

for each:

- Scenario

SIMPLIFIED FLOW

- Nuclide

DIAGRAM OF

- Vector

Form EPA

Ratio, R,

for each:

- Vector

- Scenario

\section{SYSTEM CODE}

Form (R,

Probability)

pairs for all

Scenarios

combined 


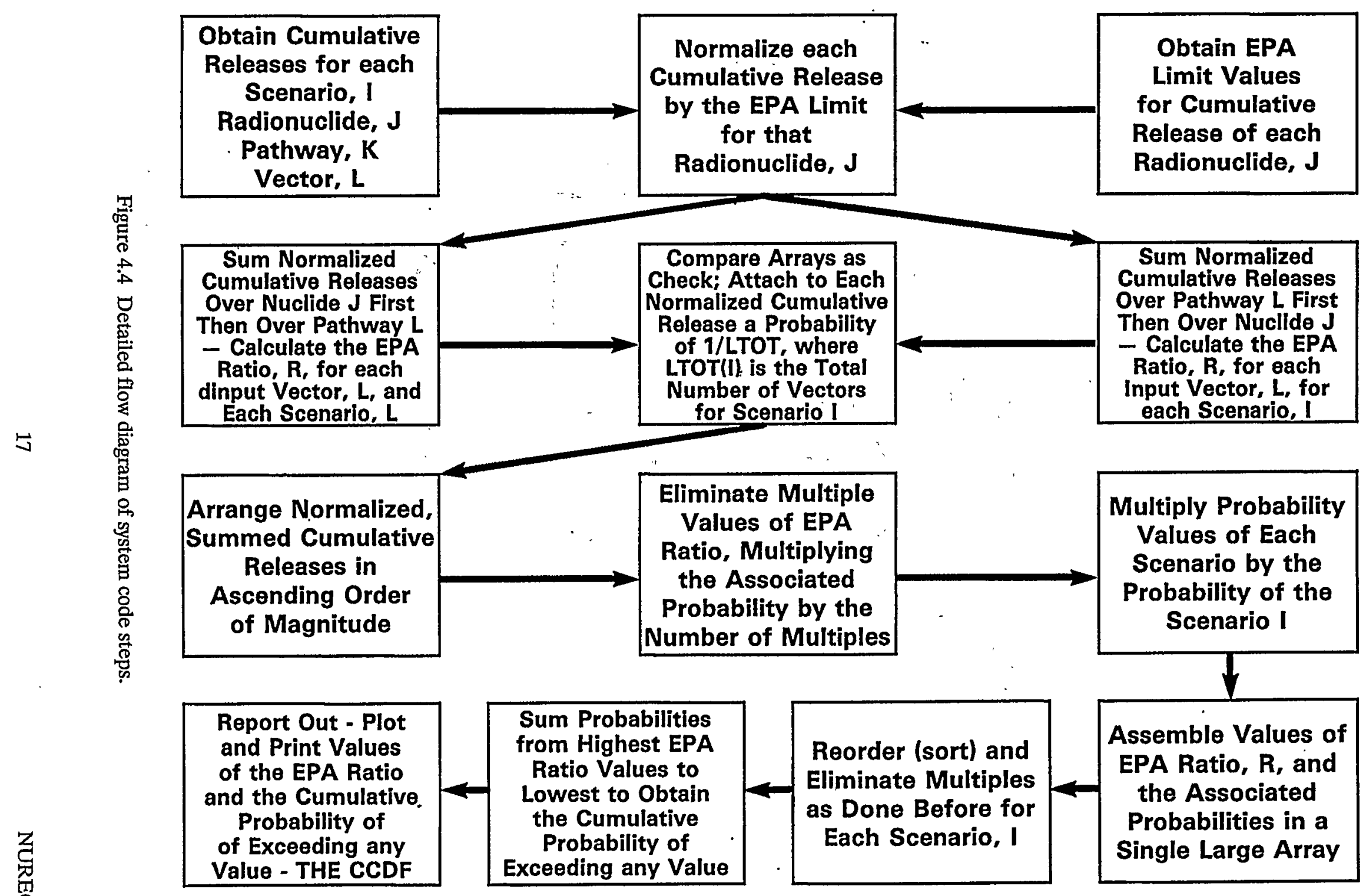


DATA ARRAY FOR SYSTEM CODE INPUT

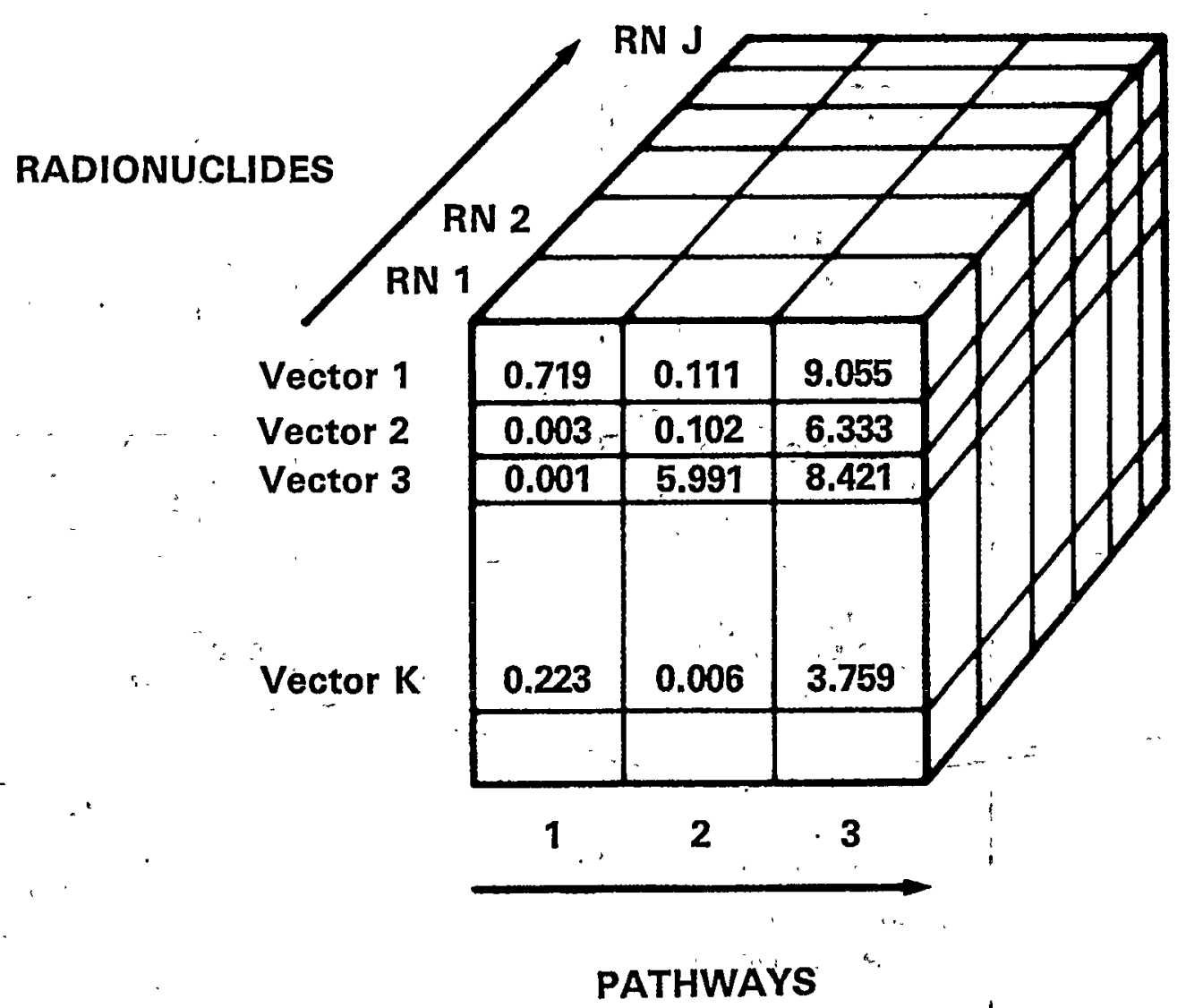

Array for

Scenario \# 0 


\section{SOURCE TERM}

\subsection{Introduction}

The demonstration of the performance-assessment methodology depended in part on developing oradopting a source term model that could consider the rate of release of the radionuclides from the engineered barrier system. The staff reviewed several assessments of the Yucca Mountain site performed for the U.S. Department of Energy (DOE) by national laboratories. Other source term models not developed for the Yucca Mountain case were reyiewed also. Appendix B provides a synopsis of these reviews. None of the models were completely satisfactory, because important data on actual spent fuel inder the expected repository conditions was not yet available.

The staff's model drew on features found in these assessments. In many cases, it was necessary to make simplifying assumptions. These assumptions were believed to lean on the side of conservatism.

\subsection{Review of Important Issues for Selecting Source Term Models}

The radioactive waste, consisting mainly of spent lightwater reactor fuel, will be stored in metal canisters. A typical canister, according to current DOE plans, is about 4.8 meters long, 0.66 meters in diameter and has a wall thickness of $1 \mathrm{~cm}$ (Site Characterization PIan (SCP), Section 7.3.1.3) (DOE, 1988). Small amounts of nuclear wastes in other forms, such as vitrified defense wastes, may also be stored in the repository, but the demonsträtion focused only on the spent fuel wastes. The source term model must account for the processes in the near field that determine the rate at which radionuclides are released, including corrosion and physical destruction of the waste package, oxidation of the cladding and the spent fuel, gaseous releases, contact between liquid water and the fuel, and transport of the released radionuclides beyond the confines of the engineered barrier.

\subsubsection{Waste-Package Lifetime}

The canisters will be sealed and most probably filled with an inert gas. They must first be breached before there can be any release of radionuclides. Several measures will be used to reduce the likelihood of canister breaching: (1) the canisters will be made of corrosion-resistant material; (2) there will be an air gap between the canister and the host rock to prevent any direct contact with pore water; and (3) the decay heat may create a dry zone for several hundreds of years after emplacement, further isolating the canisters from contact with liquid water.
Irrespective of these measures, canisters may still fail. Some of the mechanisms that might lead to failure are:

- Mechanical damage by excavation failure, earthquakes, magmatic intrusions or human intrusions

- Corrosion by hot steam or water dripping through fractures

- Corrosion by direct contact of canister with rock; e.g., loss of air gap because of spallation of rock or infilling by water-borne sediment

- Corrosion by immersion because of rise in regional water table or perched water table

$\because$ Heat pipe effect

\subsubsection{Cladding Failure}

Most of the spent fuel will be protected by thin cladding, usually zirconium alloy, but in some cases stainless steel. In'a small fraction of the cases, the cladding will be flawed by pinhole leaks or damaged (Van Konynenberg, et al., 1987). The cladding is an additional layer of corrosion resistance for the fuel, protecting the fuel from oxidation or water contact for a time. Since it is very thin (typically $0.6 \mathrm{~mm}$ ) relative to the canister thickness, cladding has usually been ignored in performance-assessment studies.

Aside from the potential corrosion protection offered by the cladding, the cladding itself is likely to contain $\mathrm{C}-14$, produced by activation of impurities in the zirconium metal or picked up from the circulating water in the reactor. Cladding corrosion thus might prove to be a source for the release of $\mathrm{C}-14$ from the waste.'Releases of gaseous C-14 are discussed in Appendix D.

\subsubsection{Oxidation of Uranium Dioxide Matrix}

Uranium dioxide is unstable in an oxidizing environment (Grambow, 1989). Because the repository will be located in unsaturated rock, there will be oxygen available to oxidize the uranium dioxide after failure of the waste package and cladding. Before failure, the canisters will most likely be filled with an inert gas to prevent oxidation, although it is possible to have oxidation directly from water that might be contained in the fuel rods, particularly those fuel rods that have already failed. The rate of oxidation depends, among other things, on temperature, so the time that the waste package fails might be important. Oxidation of the uranium dioxide is potentially important to the performance model, because uranium in higher valence states is much more soluble than in low valence states. If the fuel is immersed in water, the rate of oxidation may be the limiting rate for congruent dissolution of the fuel matrix (Doctor, et àl., 1992). In addition, oxidation of the fuel under dry or moist steam 
conditions can cause an increase in its volume and porosity, with the consequence that the ease at which the gaseous radionuclides such as $\mathbf{C}-14$ could be released might increase.

\subsubsection{Release of Dissolved Radionuclides from the Fuel}

Initially, the canisters and the spent fuel are. likely to produce sufficient heat to dry out their surroundings or create a dry steam environment. Eventually however, liquid water might come into contact with the-spent fuel, allowing it to dissolve and release its inventory. of radionuclides to the environment. Most of the inventory of radionuclides wiil be entrapped by the uranium dioxide matrix of the fuel, and will be released slowly as the matrix disintegrates. Some of the radionuclides released from the matrix might precipitate immediately because of their low solubility, thereby limiting their release (Ogard, et al., 1983), or may form colloids (Thompson, 1989). Some of the more-volatile radionuclides such as $\mathrm{C}-14$, cesium, and iodine tend to migrate from the matrix and collect at intergranular boundaries and in the gap between the fuel and the cladding, particularly while still in the reactor. These volatile radionuclides will be released more quickly than those released by congruent dissolution.

\subsubsection{Water contact fraction}

DOE plans to emplace the canisters in the host rock in a manner that it considers can reduce the likelihood of water coming into contact with the waste (SCP, Section 8.3.5.9) (DOE, 1988). A proposed emplacement plan would have the canisters stored vertically with an air gap between the canister and the rock walls. Furthermore, DOE considers that the heat generated by the waste may create a significant zone of dry rock around the canisters, isolating them until such time that the water can infiltrate the rock again. Water might still come into contact with the canisters by several mechanisms:

- Circulating water generated by the decay heat

- Infiltrating water flowing through fractures and dripping onto the canisters

- Loss of the air gap caused by failure of the emplacement holes through'. mechanical and thermal stresses, or mineral and sediment infilling

There are other possible sources of water available to the fuel, other than vertically infiltrating precipitation, but these were not included explicitly in the Phase 1 calculations. Two potentially important sources are: (1) lateral inflows from areas of perched water and (2) liquid water circulation caused by heat-driven evaporation and condensation. Lateral infiltration might divert infiltrating groundwater, causing some of the waste packages to come into contact with liquid water, but at the same time, directing water away from other waste packages.

The significance of the issue of thermally-driven water circulation is difficult to determine at this time. If all heat generated by the nuclear waste.went into evaporation of water; the flux would far exceed the likely infiltration rate. It may be the case that these phenomena are shortlived and unimportant during the period of canister integrity, when most of the water driven off would be diverted from the canisters rather than returning. Of course, the relationships between heat production, eváporation, and circulation are far from simple, and must be approached with sophisticated modeling tools. Models such as TOUGH (Preuss, 1987) would be required to carry these arguments further. They were beyond the scope of the Phase 1 study, but should be planned for subsequent studies.

The water contact fraction was characterized by a ratio relating the amount of water infiltrating the site to that coming into contact with the waste canisters. Simple calculations were performed to estimate the fraction of the waste canisters exposed to purely vertical infiltration by taking the ratio of the cross-sectional area of the canisters to the total area of land surface projected by the repository. This ratio was calculated to be approximately 0.0011 . This simple figure does not capture the true nature of water contact, because, in its uninterrupted state, infiltrating water is likely to flow around the canisters because of the matrix suction of the unsaturated rock. The analysis in DOE's environmental assessment of Yucca Mountain (DOE, 1986) assumed a contact fraction of 0.025 , but no basis was specified for this choice. Other analyses have specified that all water infiltrating the site contacts the waste (Doctor, et al., 1992). DOE design goals specify that for the first 300 years following closure, 95 percent of the canisters should be essentially dry, and the remaining 5 percent have contact with less than 5 liters of water per year. From 300 to 1000 years after closure, up to 10 percent of the canisters can have 5 liters per year contact (SCP, Section 8:3.5.9) (DOE, 1988). Section 8.3.5.10 of the SCP allows contact of less than 20 liters of water per year per canister for up to 10 percent of the canisters, however. This figure was estimated as 80 times the expected maximum flux for canisters emplaced vertically.

\subsubsection{Release of Gaseous Radionuclides}

There are several 'gaseous radionuclides in spent fuel, although many of these are short-lived and of no longterm concern. The most significant radionuclides are carbon-14 and possibly iodine-129 (only at elevated temperatures). $\mathrm{C}-14$ would be released from the cladding, the cladding-fuel gap, and the matrix. The gaseous releases would be partitioned between the groundwater and air, depending on environmental factors such as saturation, temperature; and concentration of bicarbonate ions. 
None of the models reviewed in Appendix B handles the releases of $\mathrm{C}-14$ in a very sophisticated way. The models either treat the $\mathrm{C}-14$ as a component of the fuel released to the groundwater by congruent dissolution of the fuel matrix, or all is released instantaneously upon failure of the waste canister.

The release of $\mathrm{C}-14$ from the repository is of interest to disposal in unsaturated rock because there is at least the possibility of a fast pathway to the accessible environment through fractures, excavations, and tunnels. Two models of transport of C-14 in the geosphere of Yucca Mountain indicate that the time for $C-14$ released at the repository level to reach the atmosphere would be on the order of hundreds to a few thousand years, too short a time to depend on decay to diminish the importance of $\mathrm{C}-14$ cumulative releases to the accessible environment (Knapp, 1987; Amter, et al., 1988). An assumption of instantaneous release from a failed canister may too pessimistic. On the other hand, the assumption that all C-14 is contained in the matrix and released only as the matrix dissolves may be too optimistic, because a substantial fraction of the C-14 may be contained in places other than the matrix, e.g., the cladding. Laboratory data on the location of various radionuclides in spent fuel under different conditions will reduce this modeling uncertainty.

\subsection{Model Selection and Justification}

\subsubsection{Model for Dissolved Radionuclides}

The source term model provides calculations of radionuclide releases to the flow and transport calculations. For this study, the source term model incorporated in the Network Flow and Transport (NEFTRAN) computer code (Longsine, et al., 1987) was adopted. Radionuclide releases would occur only after failure of the waste package, characterized as a single failure time $t_{f}$ (it was recognized that waste-canister failure would probably be distributed in time and space, but the NEFTRAN model was incapable of dealing explicitly with the source term in this manner).

Upon failure of the engineered barrier at time $t_{f}$, radionuclide release would be governed by either the leaching rate determined by the rate of dissolution of the waste form, or limited by the solubility of the individual radionuclides, $S_{i}$. For the former, the rate of release would be:

$$
\mathrm{R}_{\mathrm{i}}(\mathrm{t})=\lambda_{\mathrm{L}} \mathrm{M}_{\mathrm{i}}(\mathrm{t}),
$$

where $\mathrm{M}_{\mathrm{i}}=$ the inventory at time $t$ of the radionuclide in the waste.
The leach rate $\lambda_{\mathrm{L}}$ was determined by the combination of the infiltration rate $(I)$, the fraction of water contacting the waste (f), the surface area of the repository (A), the solubility of the waste form $\left(\mathrm{S}_{\mathrm{u}}\right)$, and the initial inventory of the waste form $\left(\mathrm{M}_{\mathrm{O}}\right)$ :

$$
\lambda_{\mathrm{L}}=\mathrm{I} \times \mathrm{f} \times \mathrm{A} \times \mathrm{S}_{\mathrm{u}} / \mathrm{M}_{\mathrm{O}}
$$

If the solubility limit would be exceeded by the release calculated by Equation 5.1, i.e., if $R_{i}(t)>S_{i} I A$ f, then the release rate was cut off at the solubility limit:

$$
R_{i}(t)=S_{i} \text { IAf. }
$$

where $S_{i}=$ the solubility of radionuclide $i$.

The release rate $R_{i}(t)$ became a flux boundary condition to the transport equation.

\subsubsection{Limitations of Model for Dissolved Radionuclides}

The most significant limitations of the dissolved radionuclide source term model are believed to be:

- The model ignores the diffusion-limited case, where there might be the buildup of a boundary layer limiting the release of solubility-limited radionuclides (this mechanism would apply only if there were a

. continuous liquid water path between the fuel and the rock).

- For larger infiltration rates, the model cannot represent phenomena that would tend to limit the rate of release, such as the forward rate of reaction for oxidation of the spent fuel, and the possibility that oxidants might not be available in unlimited quantities because they would be consumed within the canisters.

- The model assumes intimate contact between the groundwater and the waste, ignoring features such as the air gap, designed to prevent such contact. It in effect assumes there is no protection for the fuel from the water, even though the fuel has multiple layers of protection, including the air gap, waste package, and cladding.

- The model incorporates a single time to failure, even though it is more likely that waste packages would fail in a distributed manner in time and space.

- Releases from the matrix of low-solubility radi-

- onuclides might result in colloid formation rather than precipitation.

- The model does not take into account radionuclides that might not fit neatly into the three compartments (unleached, undissolved, and dissolved), such as those collecting in the grain boundaries and in the cladding gap. 
- The model ignores the potentially significant amount of liquid water circulation through evaporation and condensation of groundwater that might be caused by the repository heat, i.e., a "heat-pipe."

The use of this model was based on expediency, because the fundamental framework was already in place in the NEFTRAN code and required a minimum of reprogramming to adjust the coefficients to represent the Yucca Mountain case. Adjustment of the coefficients of the model allowed a wide latitude of potential source term conditions to characterize either congruent dissolution of the uranium matrix or solubility-limited releases.

\subsubsection{C-14 Release Model}

Very little is known about the long-term release of gaseous radionuclides from spent fuel under conditions anticipated at Yucca Mountain. The only data on releases from spent fuel indicate a rapid, small release of $\mathrm{C}-14$ upon failure of the fuel rod, and very slow release thereafter (Van Konynenberg, et al., 1984). Because of the speculative nature of the $\mathrm{C}-14$ release model, gaseous release pathways were not included into the overall systems analysis, but were treated separately as an auxiliary analysis (see Appendix D).

\subsection{Source Term Inventory}

The inventory of radionuclides assumed for the source term in the Phase 1 study was typical of previous analyses of the performance of repository at Yucca Mountain and is given in Table 5.1 (Doctor, et al., 1992). The list was restricted to 29 isotopes, chosen from a more extensive list of fission and activation products found in spent fuel, on the basis of half lives, potential inventories and radiotoxicity (in terms of their EPA cumulative release limits):

Table 5.1 Radionuclide Initial Inventory (Doctor, et al., 1992)

\begin{tabular}{lll}
\hline Radionuclide & Half-life, yrs & Inventory, Ci \\
\hline Curium-246 & $5.50 \mathrm{E} 03$ & $2.45 \mathrm{E} 03$ \\
Curium-245 & $9.30 \mathrm{E} 03$ & $1.26 \mathrm{E} 04$ \\
Americium-243 & $7.95 \mathrm{E} 03$ & $9.80 \mathrm{E} 05$ \\
Americium-241 & $4.58 \mathrm{E} 02$ & $1.12 \mathrm{E} 08$ \\
Plutonium-242 & $3.79 \mathrm{E} 05$ & $1.12 \mathrm{E} 05$ \\
Plutonium-241 & $1.32 \mathrm{E} 01$ & $4.83 \mathrm{E} 09$ \\
Plutonium-240 & $6.58 \mathrm{E} 03$ & $3.15 \mathrm{E} 07$ \\
Plutonium-239 & $2.44 \mathrm{E} 04$ & $2.03 \mathrm{E} 07$ \\
Plutonium-238 & $8.60 \mathrm{E} 01$ & $1.40 \mathrm{E} 08$ \\
Neptunium-237 & $2.14 \mathrm{E} 06$ & $2.17 \mathrm{E} 04$ \\
Uranium-238 & $4.51 \mathrm{E} 09$ & $2.24 \mathrm{E} 04$ \\
Uranium-236 & $2.39 \mathrm{E} 07$ & $1.54 \mathrm{E} 04$ \\
Uranium-235 & $7.10 \mathrm{E} 08$ & $1.12 \mathrm{E} 03$ \\
Uranium-234 & $2.47 \mathrm{E} 05$ & $5.18 \mathrm{E} 03$ \\
Uranium-233 & $1.62 \mathrm{E} 05$ & $2.66 \mathrm{E} 00$ \\
Thorium-229 & $7.34 \mathrm{E} 03$ & $1.96 \mathrm{E}-03$ \\
Thorium-230 & $8.00 \mathrm{E} 04$ & $2.87 \mathrm{E}-01$ \\
Radium-226 & $1.60 \mathrm{E} 03$ & $5.18 \mathrm{E}-04$ \\
Lead-210 & $2.23 \mathrm{E} 01$ & $4.90 \mathrm{E}-05$ \\
Cesium-137 & $3.00 \mathrm{E} 01$ & $5.25 \mathrm{E} 09$ \\
Cesium-135 & $3.00 \mathrm{E} 06$ & $1.89 \mathrm{E} 04$ \\
Iodine-129 & $1.59 \mathrm{E} 07$ & $2.31 \mathrm{E} 03$ \\
Tin-126 & $1.00 \mathrm{E} 05$ & $3.36 \mathrm{E} 04$ \\
Technetium-99 & $2.15 \mathrm{E} 05$ & $9.10 \mathrm{E} 05$ \\
Zirconium-93 & $9.50 \mathrm{E} 05$ & $1.19 \mathrm{E} 05$ \\
Strontium-90 & $2.90 \mathrm{E} 01$ & $3.64 \mathrm{E} 09$ \\
Nickel-59 & $8.00 \mathrm{E} 04$ & $2.10 \mathrm{E} 03$ \\
Carbon-14 & $5.73 \mathrm{E} 03$ & $9.80 \mathrm{E} 04$ \\
\hline
\end{tabular}




\section{FLOW AND TRANSPORT MODELS}

\subsection{Introduction}

The quantification of the consequences of HLW disposal is anticipated to require the analysis of groundwater flow and transport of radionuclides in liquid, gas, and direct release pathways. These ănalyses typically will be based on site conceptual models that are then implemented in computer programs for calculational use in a performance assessment. For this study, a review of information on unsaturated fractured tuff and transport-pathway phenomena, and flow and transport computer programs was conducted to select computer programs to provide calculational tools with which to demonstrate the performance-assessment capability. The purpose of this section is to describe the information that was collected and used to select the programs for quantifying consequences.

It should be pointed out that the definition of the site conceptual model(s) will typically be based on detailed laboratory and field investigations for the site under consideration. This site conceptual model(s) will undoubtedly be the most important factor in selecting a computer program for site analyses. However, a well-characterized HLW site does not currently exist. As described above, the model selection, for this study, was based on a review of published information. The authors do not consider the review comprehensive and do not intend the model selection to represent an endorsement of any particular conceptual model(s) for the Yucca Mountain site or a recommended approach to modeling flow and transport in unsaturated fractured tuff.

\subsection{Definition of Issues for Selecting Performance-Assessment Transport Models}

The definition of the technical issues for defining and selecting flow and transport models was based on the characteristics of an unsaturated fractured tuff medium and the pathways anticipated to be analyzed. This information was obtained from published reports concerning performance assessment in geologic media and groundwater flow and transport in the geosphere, with an emphasis on unsaturated fractured media.

\subsubsection{Site Concepts}

The Yucca Mountain site is located on and immediately adjacent to the southwestern portion of the Nevada Test Site. Yucca Mountain is a prominent group of northtrending, fault-block ridges. The terrain at the site is largely controlled by high-angle normal faults and eastward-tilted volcanic rocks. Slopes are locally steep $(15$ to 30 degrees) on the west-facing side of Yucca Mountain and along some of the valleys that cut into the more gently sloping ( 5 to 10 degrees) east side of the mountain.

For this study, the hydrostratigraphic units of interest at Yucca Mountain were comprised primarily of ash-flow and ash-fall tuffs that originated from eruptions during the development of calderas. The amount of welding, fracturing, unit thickness, and chemical alteration varies greatly from one layer to the next. The major hydrostratigraphic units beneath Yucca Mountain, starting at the surface and moving downward are: alluvium, Tiva Canyon welded unit, Paintbrush nonwelded unit, Topopah Springs welded unit, Calico Hills (vitric and zeolitic) nonwelded unit, Crater Flat welded and nonwelded unit (Prow Pass member and Bullfrog member) (see Figure 6.1).

Three broad categories that describe these tuffs are: densely welded tuffs, nonwelded vitric tuffs, and nonwelded zeolitized tuffs. The densely welded tuffs are highly fractured. These tuffs have a very low saturated matrix conductivity (less than $1 \mathrm{~mm} /$ year) and a saturated conductivity for the fractures that is probably several orders of magnitude or more higher than the matrix value. The nonwelded vitric tuffs have fewer fractures and a higher matrix saturated conductivity $(100-10,000 \mathrm{~mm} /$ year). The fractures for this unit would have a relatively low saturated conductivity. The nonwelded zeolitized tuffs have few fractures and low matrix-saturated conductivity (less than $1 \mathrm{~mm} / \mathrm{year}$ ) and low fracture saturated conductivity. The contacts between these units generally tend to occur over short distances and involve large differences in hydrologic properties (Prindle, 1987).

Based on current information on hydrogeologic units and theories of flow at Yucca Mountain, DOE (from page 3-195 of the Yucca Mountain SCP) described the conceptualization of flow from the Topopah Springs (TSw) unit to the water table as follows (DOE, 1988):

1. "Flow in the TSw unit is expected to be essentially vertical and under steady-state conditions to occur as flow within the matrix for fluxes less than some critical value of flux related to the saturated matrix hydraulic conductivity, and predominantly as fracture flow at fluxes higher than the critical value.

2. Lateral flow may be induced in the TSw unit at its contact with the underlying Calico Hills nonwelded unit $(\mathrm{CHn})$. The circumstances under which this may occur depend on the magnitude of the flux in the TSw unit and whether this unit is underlain by the low-conductivity zeolitic facies (CHnz) or the 
6. Flow and Transport Models

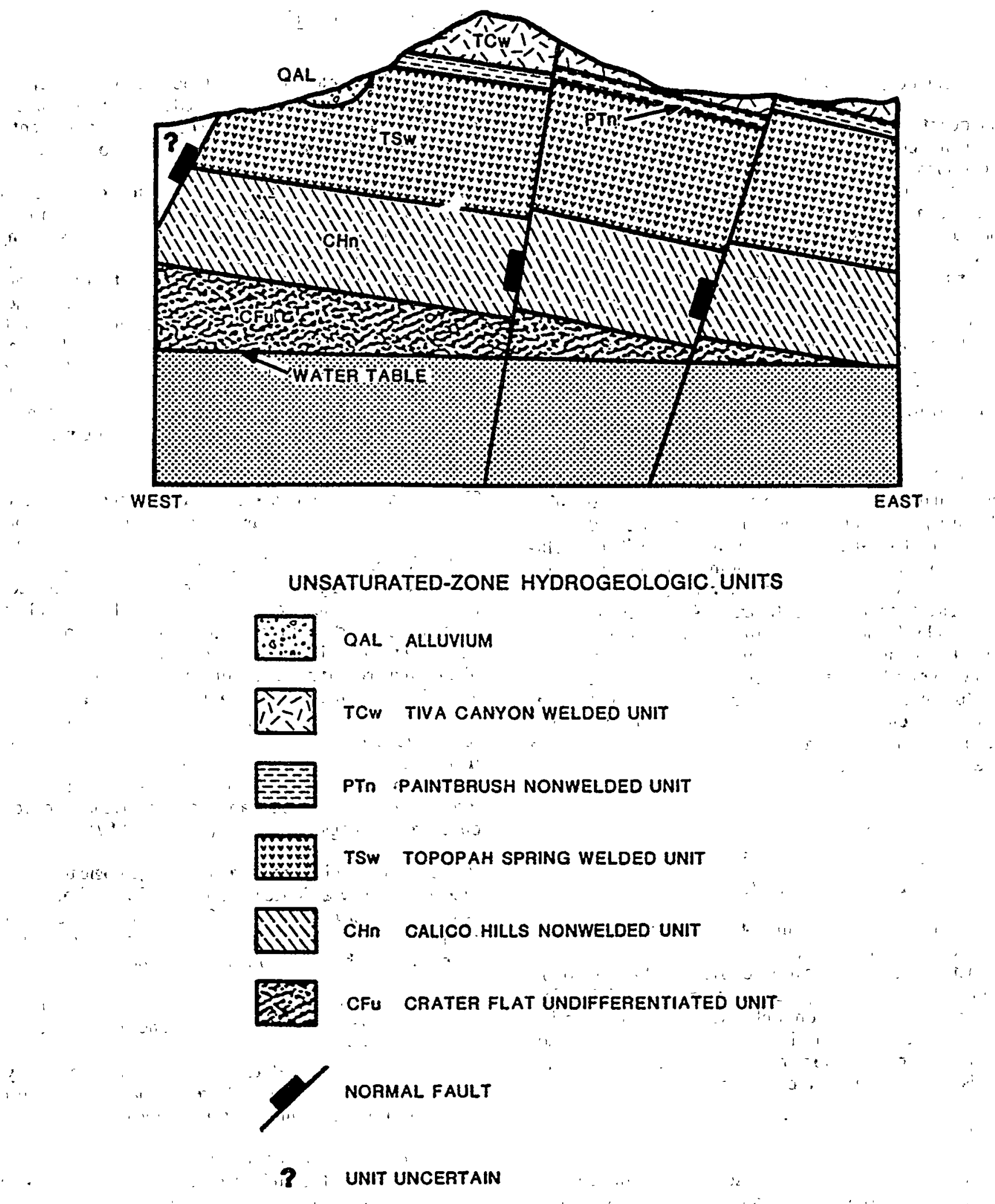

Figure 6.1. Conceptualization of a hydrogeologic cross-section through the unsaturated zone at Yucca Mountain (after DOE, 1988) 
relatively higher-conductivity vitric facies (CHnv) of the CHn unit. At low fluxes within the TSw unit, lateral flow may be produced by capillary-barrier effects within the matrix of the TSw unit where it overlies the $\mathrm{CHnv}$ unit. At high fluxes, efficient fracture flow in the TSw unit may produce lateral flow as well as vertical flow where the low conductivity $\mathrm{CHn}$ unit underlies the TSw unit.

3. Flow in both the CHnvi and $\mathrm{CHnz}$ units is predominantly vertical through the matrix (although a lateral component may occur parallel to the bedding within the vitric CHnv unit) and continues directly to the water table wherever the latter transects the $\mathrm{CHn}$ unit. Where the CHn unit lies above the water table, flow is presumed to proceed vertically downward to the water table through the Crater Flat undifferentiated unit (CFu):

4. The nearly vertically oriented fault zones and their associated fracturing may be highly effective pathways for vertical moisture flow, especially in the competent TCw and TSw units. But faults may impede lateral flow and may thus produce perchedwater bodies where the faults transect zones or horizons of significant lateral flow."

Additionally, very little data are available on estimated infiltration rates and deep percolation rates past the repository. Estimates of deep percolation rates past the repository horizon are described on page 3-205 of the SCP (DOE, 1988) as:

"." "Wilson (1985) reviewed available site and regional hydrogeologic data in order to set conservative upper limits on the present, net vertically downward moisture flux "below the repository horizon at Yucca Mountain and on the present rate of net recharge to the saturated zone in the vicinity of Yucca Mountain: Wilson (1985) concludes (1) that the liquidwater percolation flux, directed vertically downward in the matrix of the TSw unit below the repository horizon, probably is less than 0.2 $\mathrm{mm} / \mathrm{yr}$ and (2) that the area averaged rate of net recharge to the saturated zone in the vicinity of Yucca Mountain probably is less than 0.5 . $\mathrm{mm} / \mathrm{yr}$. Although Wilson (1985) considered a number of processes, such as upward watervapor flow in the fractures of the TSw unit at the repository horizon, these upper bounds on percolation and recharge fluxes must be regarded as preliminary estimates that have asyet-unknown limits of uncertainty."

It was considered that the definition of a conceptual model for flow and transport in unsaturated fractured tuff depended on fracture-matrix interactions and the rate of infiltration. The current review indicated that the effects of fractures on groundwater flow and of flow diversion at layer boundaries will need to be assessed and their sensi-, tivity to infiltration rates determined. However, for the present study, it was assumed that groundwater-flow would be one-dimensional and in the vertical direction.

The role of fractures and flow diversion at unit boundaries could have significant affects on flux rates through a repository. Although flow diversion was the subject of a limited auxiliary analysis (see Appendix G), future analyses will need to consider fracture-matrix interactions and further consider flow diversion where fractures can affect the flow.

\subsubsection{Pathways}

The assessment of a repository in the unsaturated zone could involve the following three pathways: (1) liquid; (2) gas, and (3) direct. The most obvious release path for radionuclides away from the repository is the liquid pathway. For the present study, it was assumed that radionuclides would be transported vertically in the unsaturated zone toward the water table, and releases were calculated at the water table.

The gas pathway is a potential concern for a repository located in the unsaturated zone because of the presence of carbon-14. It is present in the emplaced waste in quan-, tities at least one order of magnitude greater than the release limit specified in Appendix A of the EPA standard. It can exist as one of several gasses $\left(\mathrm{CO}_{2}\right.$, methane, acetylene), and could therefore move relatively rapidly compared to its half-life ( 5720 years) through the unsatu-. rated fractured rock and along pathways such as access tunnels and excavations. In addition, unlike most of the other radionuclides in the waste, transport in the geosphere is not likely to depend strongly on the influx of water to the repository, and can proceed under totally dry conditions. (However, release from the waste may de-' pend on the water influx.)

Finally a release pathway could occur as a result of a "direct" release. The "direct" release pathway encompasses a couple of possible scenario types such as a release due to drilling into the repository and a release due to a disruptive event like a magmatic eruption. The consideration of the consequences due to volcanic activity was too involved to be included in the current study; therefore, the direct release pathway considered only releases due to drilling. Releases resulting from volcanism will need to be addressed in future work.

\subsubsection{Flow and Transport Pathway . Phenomena}

Performance assessment of potential releases of radioactivity from nuclear waste requires an understanding of a 
number of complicated transport phenomena for the pathways under consideration. The transport pathways to be analyzed are the liquid pathway, the gas pathway (primarily involving the transport of carbon-14), and a direct release pathway (due to a drilling scenario). This section describes, in a preliminary way, some phenomena associated with the transport of radionuclides in groundwater and the phenomena considered in this study.

\subsubsection{Liquid transport}

A common starting point in the development of a transport model is a qualitative statement of the conservation of mass in the liquid phase for an elemental volume (Freeze, 1979):

$\begin{array}{llll}\begin{array}{l}\text { net rate of } \\ \text { change of } \\ \text { mass within } \\ \text { the element }\end{array} & =\begin{array}{l}\text { flux of } \\ \text { solute out } \\ \text { of the } \\ \text { element }\end{array} & \begin{array}{l}\text { flux of } \\ \text { solute into } \\ \text { the }\end{array} & \begin{array}{l}\text { loss or gain } \\ \text { ef solute mass } \\ \text { due to reac- }\end{array} \\ \text { tions and sinks } \\ \text { and sources.' }\end{array}$

The processes that control flux into and out of the elemental volume are advection (transport via the bulk motion' of the groundwater) and hydrodynamic dispersion (transport resulting from mechanical mixing ảnd molecular diffusion). Chemical reactions and radioactive decay will affect the loss or gain of solute mass (for the present analysis, phenomena such as Knudsen diffusion and coupled processes were considered of minor importance).

The transformation of the aforementioned qualitative statement into differential equation(s) typically involves a number of simplifying assumptions with respect to dimensionality, variability, and processes associated with the intended application. This section will review some of the processes associated with the pathways to be considered in this study.

\section{(a) Physical Processes}

It is assumed generally that the bulk movement of fluid will be the primary source of transport away from an HLW repository. In a porous medium, it is assumed commonly that the average rate of solute transport by advection is equal to the average linear velocity of the fluid multiplied by the concentration. The presence of a fracture system complicates the advective flow system by providing a high permeability flow path separate from, but interacting with, the matrix path.

In the unsaturated zone, water is.held in the pore space by surface tension. Geologic media-are comprised of a variety of pore space and fracture dimensions; therefore, these volumes will not empty at the same suction. During drainage, the large pores (or larger fractures) will empty at low suctions, whereas small pores (smaller radius of curvature) will 'empty at higher suctions. Most models of unsaturated flow in fractured media, therefore, assume that under high suction, the dominant groundwater pathway will be in the matrix (i.e., the fractures will be dry). However, it is worth pointing out that many factors (transient infiltration rates, fracture coatings, fracture dimensions,' and the presence of perched water) can dramatically influence the degree of fracture flow and validity of a single continuum model for unsaturated fractured media. Many assumptions that preclude fracture flow under unsaturated conditions have not been substantiated by laboratory or field data and, therefore, cannot be ruled out as a possible transport pathway in unsaturated, fractured rocks' (Parsons; et al., 1990).

Based on the lack of information to support a detailed fracture flow model, a steady-state flow model was assumed, where the fractures contribute to flow only when the infiltration rate exceeds the saturated conductivity. Further work will need to determine the degree of conservatism or pessimism in this assumption.

Whereas advection moves solute in the direction of flow, hydrodynamic dispersion and matrix diffusion affect solute concentration along its flow path. Hydrodynamic dispersion includes dilution due to mechanical mixing and mólecular diffusion. Mechanical mixing (a direct result of a tortuous path, variation in pore sizes or fracture apertures, and surface roughness) is related to the heterogeneity of the geologic media and is typically characterized by the dispersivity.

For the present analysis, it was assumed that dispersivity can be represented with a single dispersion length. This treatment was assumed adequate, because the performance measure of interest (cumulative release at the accessible environment over 10,000 years) would generally be insensitive to longitudinal dispersion, when the cumulative releases include a majority of the waste, and small cumulative releases are not as important as large releases: The degree to which this was or was not a conservative assumption will need to be examined in further work.:

Matrix diffusion couples the solute concentration in the fracture and matrix systems and is generally thought to provide a retardation of radionuclide transport in the fractures. As with the flow of water across the fracturematrix interface,' a large uncertainty in evaluating this phenomenon is determining the effect of fracture coatings on the diffusion rate. Quantification of the effect of fracture coatings will be needed to better determine the best approach for performance assessment. For the present study, matrix diffusion was assumed not to occur. This assumption should be conservative for the situation when contaminant being transported in the fractures is diffusing into the matrix. However; this assumption may not be conservative when contaminant is diffusing from the matrix into the fractures. 


\section{(b) : Chemical Processes}

There are several chemical processes that affect the movement of radionuclides in groundwater. One of the. most significant chemical processes that occurs is sorption (Parsons, et al., 1990). Solute species adsorb to the matrix or fracture surfaces by forming bonds with the molecules on the solid surface. The strength of these bonds and the kinetics depend on many chemical factors such as: (1) electric charge of solute and solid, (2) saturation of bonding sites, (3) $\mathrm{pH}$, (4) oxidation and reduction potential, and (5) temperature and pressure of the hydrogeologic system (Freeze, 1979).

Adsorption can be physical (generally considered a reversible process) or chemical (generally considered an irreversible process). At any moment, some of the solute particles are bonded to the solid surface and some are free to move with the groundwater. The adsorption-i desorption process has typically been represented in most groundwater transport models, using a retardation equation that employs a distribution coefficient. The assump: tions in this model include instantaneous and reversible adsorption and desorption (equilibrium), linear sorption isotherms, and single-valued sorption isotherms (i.e., no hysteresis effect) (Rasmussen and Evans, 1987). The distribution coefficient model was adopted for this study. Future work will need to perform supporting geochemical analyses, to determine the degree of validity of the present approach.

The model ignored precipitation of radionuclides along the flow path, although solubility was taken into account in the source term. This assumption is conservative because it would overestimate the cumulative release.

Table 6.1

Identification of Liquid Pathway Processes and Estimated Effect on Calculating' Cumulative Release from the Liquid Pathway

\begin{tabular}{ll}
\hline Processes & $\begin{array}{l}\text { Estimate of } \\
\text { Importance }\end{array}$ \\
\hline 1. Advection & High \\
2. Sorption & High \\
3. Radioactive Decay and Production & High \\
4. Fracture-Matrix Interactions & High \\
5. Matrix Diffusion & Medium \\
6. Precipitation of Radionuclides & Low \\
7. Dispersion & Low \\
\hline
\end{tabular}

\subsubsection{Gas transport}

The gas pathway is an alternative pathway for radionuclide transport to the accessible environment. Further- more, gas-phase source terms (i.e., carbon-14, tritium, " krypton-85, and iodine-129) could potentially be released from spent fuel buried at Yucca-Mountain. Gas-? phase carbon-14 in the form of carbon dioxide appears to be the most important for considerations of performance assessment. The half-lives of tritium and krypton-85 are relatively short (12.3 years'and 10.7 years, respectively), and it is possible that elemental iodine could quickly partition into the liquid phase. Because of the complexity of the issue and the relatively poor state of knowledge about gaseous release and transport, carbon-14 release to the atmosphere was not included in the total system analysis. An auxiliary analysis for carbon-14 release to the atmosphere is presented in Appendix D:

\subsubsection{Direct transport}

Potentially significant scenarios for the assessment of repository performance involve the possibility of volcanism" in the form of a disruptive event such as a magmatic eruption, or an intrusive event involving human drilling activities. Both scenario classes involve events whose estimated likelihood of occurrence and consequences are very uncertain over the regulatory period of performance for the repository (i.e., 10,000 years). Considerations for magmatic events and human intrusion are discussed next.' However, due to the complexity in understanding and predicting magmatic events, simulation work in this areä? was not performed in this study.

\section{(a) "Magmatic Events}

Basaltic eruptions are noted to have occurred near the Yucca Mountain site and west and south of it during the Quaternary period. Basalt flows and cinder cones have been observed on Crater Flat, and volcanic centers in Amargosa Valley have deposited ash falls as recently as 20,000 to 30,000 years ago. The consequences, assuming that a magmatic eruption occurs, are very uncertain; how-' ever, it is believed that this class of scenarios would need to consider the following in estimating consequences: (1) entrainment of the waste and deposition on the surface; for example, as a result of a physical (steam) explosion; (2) dispersal of fine-grained ash and radioactivity into the atmosphere; (3) mechanical and thermal loading that can affect rock stresses and permeabilities and flow conditions for radionuclide migration from the repository to the accessible environment, even if the event does not compromise the structural integrity of the repository; (4) the relative amounts of radioactivity that would be released due solely to the occurrence of this natural event; (5) potential barriers to flow or water table level changes; and (6) the source term.

The source term depends upon many factors, including:

- Mix of waste forms for the repository (spent fuel and high level waste from defense activities) . 
- Spent fuel inventory characteristics (reactor type and burn-up)

- Time of emplacement

- Emplacement configuration

- Rock geochemical properties

- Time of eruption or intrusion

- Extent, location, and geometry of volcanism

For scenarios involving the interception of waste packages by feeder dikes, estimates of the distribution and size of these dikes (resulting from the feeding of basaltic cinder cones) are needed, in addition to estimates of their times of occurrence (to account for radioactive decay).

\section{(b) Human Intrusion}

Human activities such as deep exploratory drilling of boreholes could potentially provide direct releases of radioactivity to the environment. It is believed that this issue, is primarily a source term issue which depends on the amount of radioactivity brought to the surface by drilling. In general, the waste package material, emplacement configuration, age of waste at time of interception by a drill bit, altogether contribute to estimating the radioactive source term. Estimates of radioactivity brought to the surface in contaminated cores from those boreholes that intercept the repository are also needed for a more complete consequence analysis. In order to estimate the risk, one needs to combine the consequence information with a probabilistic analysis of the drilling rate and penetration depth.

\subsection{Computer Program Review and Selection}

The analysis of any complex system often involves the use of computer-implemented mathematical models to assist the analyst in presenting an "adequate" description of the risk or performance of the system. The analysis of hydrologic systems has, over the last 20 years, created a number of computer programs for analyzing a variety of problems (until recently little attention has been paid to an unsaturated, fractured, and uneconomic rock such as tuff). Based on the pathway phenomena and types of scenarios anticipated for the analysis of a repository in unsaturated fractured tuff, computer programs were reviewed for their applicability in a performance assessment.

\subsubsection{Liquid Pathway}

The evaluation of the liquid pathway could involve-a suite of computer programs. The complexity of flow and transport in unsaturated fractured tuff could dictate the use of a set of models. A specific model could be used to evaluate a specific performance question, assist the assignment of model inputs, or justify the assumptions of simpler models used in a systems model. Some examples of the types of programs needed are: (1) two-phase flow program for analyzing thermal effects; (2) two- or threedimensional programs for simulating regional flow; (3) geochemical programs for assessing retardation phenomena; (4) a program that includes the influence of fractures' or allows for an interaction between fractures and matrix; and (5) an efficient transport program for use in the multiple simulations of a performance assessment.

The review - of computer programs is divided into the following four sections: (1) regional or far-field groundwater flow programs; (2) two-phase flow programs; (3) geochemical programs; and (4) transport programs. The ability of the various programs to deal with the presence of fractures will be discussed under the individual programs. A summary of the review and the selection rationale is provided in the subsequent'sections, whereas individual program summaries are provided in Appendix C.

$\therefore$

\subsubsection{Regional groundwater flow programs}

A number of unsaturated flow programs (e.g., FEMWATER and UNSAT2) were developed approximately 10 years ago, to analyze unsaturated flow in near- surface soils (Thomas, et al., 1982). NRC participation in the international project HYDROCOIN (Cole, et al., 1987) revealed significant numerical limitations in these programs in simulating unsaturated problems involving large non-linearities (e.g,, infiltration into a dry soil and large permeability contrasts). These and similar-type programs were not examined further due to their numerical deficiencies, which would be unacceptable in evaluating unsaturated fractured media. A new generation of unsaturated flow programs has been developed to better handle the non-linearities encountered in unsaturated flow.

The computer programs entitled SUTRA, VAM2D, and TRACER3D were selected as representative of the newer generation of unsaturated flow programs. The three programs employ similar Darcian approaches to simulating fluid flow in porous media. The ability to simulate fracture-flow could only be accommodated through a single-continuum, composite porous medium approach. $^{2}$ (Currently, there are no existing programs that simulate fracture-matrix interactions with an approach different from the single-continuum approach. SNL, under an NRC contract, is developing a flow program that will account for the fracture-matrix interactions in a more rigoroun fashion than is currently available. This program is scheduled for completion in April of 1990.)

The VAM2D program (Huyakorn, 1989) was selected for use in modeling regional flow because of the efficiency of the non-linear numerical techniques employed and the availability of the program for NRC staff use. 


\subsubsection{Two-Phase flow programs}

Assessing the thermal period of the HLW repository will require programs that can simulate the flow of air, liquid water, and water vapor. TOUGH, NORIA, and PETROS are existing programs that solve the two-phase flow and energy-transport problem. A detailed SNL review of these programs (Updegraff, 1989) discussed the difficulties of running two-phase flow models and the relative strengths and weaknesses of the individual programs. Overall, one program was not superior to the others. However, TOUGH successfully ran most of the test problems, whereas NORIA and PETROS could at best simulate approximately half the test problems.

The TOUGH program (Pruess, 1987) was selected to analyze two-phase flow problems because of its ability to handle a variety of problems (Updegraff, 1989), and the current availability of TOUGH to NRC staff. (Due to the complexity of two-phase flow problems, simulation work was not performed in this study.)

\subsubsection{Geochemical programs}

The geochemical behavior of the HLW repository could have a very strong effect on the movement of radionuclides. Unfortunately, current geochemical programs are not amenable to most performance-assessment systems programs because of their complexity. The primary use of the geochemical programs will be to aid the understanding of the geochemistry of the site and the assignment of lumped parameters in the simpler transport models.

The current study did not consider complex modeling associated with geochemical analyses. Summaries of various programs are included in Appendix C. Selection of a particular program was considered inappropriate until more specific performance issues or questions with respect to geochemistry could be made.

\subsubsection{Transport programs}

The use of a transport program in a systems code for the performance assessment will require a number of simplifications of the real system to accommodate the large number of simulations necessary for sensitivity and uncertainty analyses (see Appendix E, "Testing Statistical Convergence"). Some of the simplifications being considered are: use of a one- or two-dimensional analysis; limited (if any) interaction between fractures and matrix; steadystate flow; and limited geochemistry (typically a lumped retardation factor that is intended to account for all the geochemical interactions).

A number of existing programs, which employ many of the aforementioned simplifications, have been reviewed (see code summaries in Appendix $C$ ). The review included numerical solutions such as SPARTAN, NEFTRAN, and TOSPAC, as well as closed-form solutions such as the UCB programs. The NEFTRAN (Longsine, et al., 1987) program, developed at SNL under NRC funding, was selected because of: (1) availability on NRC computer systems; (2) ready access to the SNL developers; and (3) efficiency of the program, and compatibility with the LHS computer program for analyzing model sensitivity.

Although all the reviewed programs did not fully describe fracture-matrix interactions, SNL is currently modifying NEFTRAN to include fracture-matrix interactions (to be completed by March, 1990). Staff use of the current version of NEFTRAN will assist technology transfer of the new version of NEFTRAN in 1990.

\subsubsection{Gas Pathway}

The gas pathway was treated as an auxiliary analysis and is presented in Appendix D.

\subsubsection{Direct Pathway}

Computer programs for evaluating the consequences of drilling into a repository were not able to be acquired in a timely fashion. A model was developed that accounts for the anticipated important aspects of a drilling scenario. The model accounts for a drilling rate, radioactive decay, the areal extent of the repository, waste package emplacement orientation (horizontal versus vertical), and boreholes intercepting both the waste package and contaminated rock. A detailed discussion of the drilling model is provided in Appendix $\mathrm{H}$. 

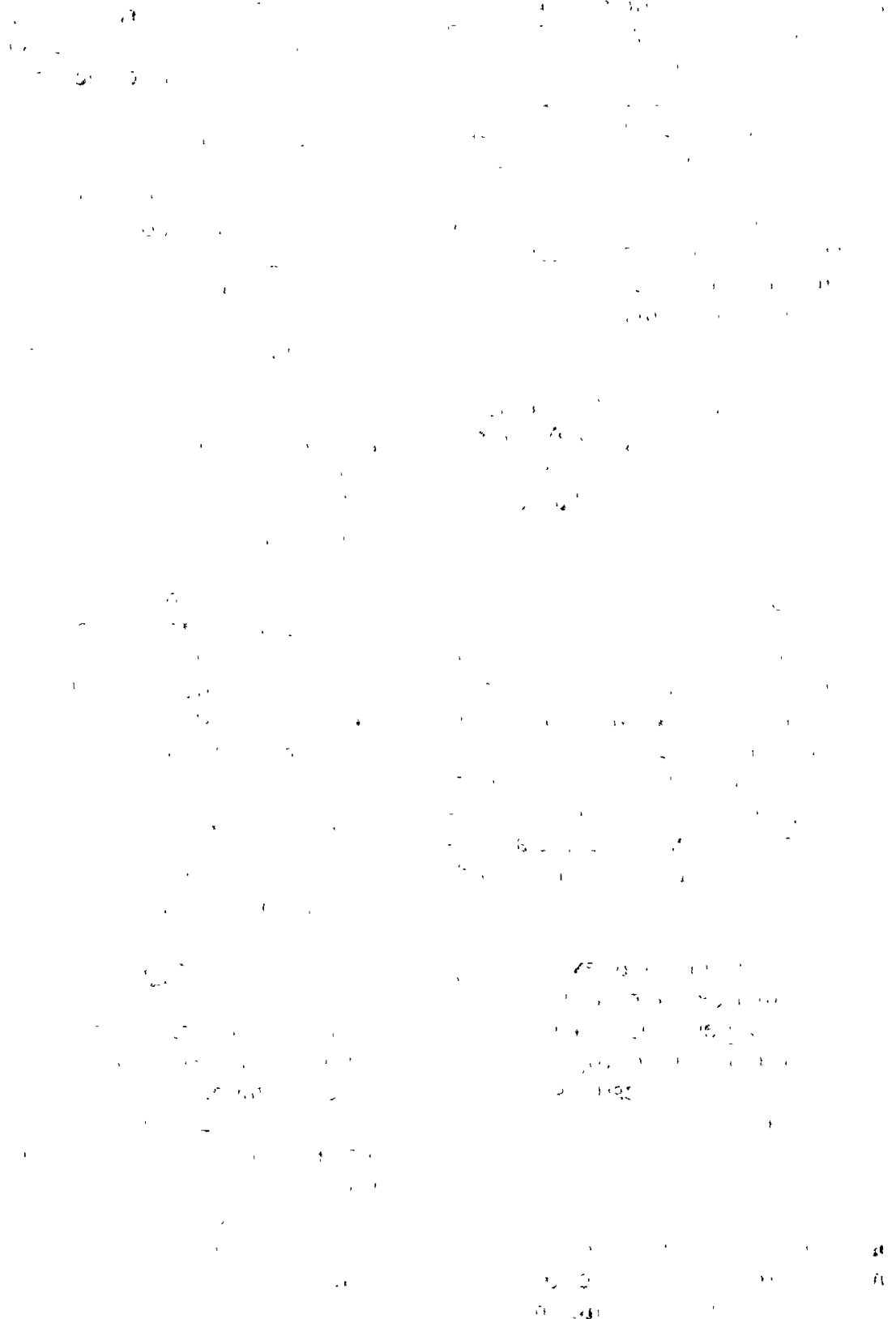


\section{METHODOLOGY FOR SCENARIO DEVELOPMENT}

\subsection{Introduction}

When this study was initiated, the staff intended to accomplish two objectives: (1)identify a methodology that could be used for scenario development, and (2) demonstrate the utility of the methodology by application to the Yucca Mountain site. Due to limitations on availability of staff resources, only limited progress was made on application of the methodology. This section is, therefore, primarily, a status report of on-going work, and consists primarily of a description of the selected methodology. Because application of this methodology to the Yucca Mountain site was not completed, there is no correlation between this section of the report and the scenario classes hypothesized for analysis in other sections of the report.

An important part of a performance assessment for an HLW repository is an evaluation of the uncertainties in projected performance. Two general approaches are available for analyses of uncertainties in repository performance. Such analyses can be carried out by incorporating the uncertainties directly into the model(s) and data base(s) describing the repository system, or uncertainties can be approximated as "scenarios"-i.e., descriptions of alternative ways.in which the repository system might perform in the future. Most analyses use a combination of the two approaches, although there are generally no explicit criteria for which way to treat a specific source of uncertainty. Thus, lists of processes and events to be included in scenarios often include phenomena such as waste-canister corrosion, even though such phenomena are likely to be evaluated directly within the repository model(s) and data base(s), rather than as scenarios.

This study distinguished two aspects of an uncertainty analysis:.(1) uncertainty about the characteristics of the repository system and its environment as they exist at the time of analysis, and (2) uncertainty, about the future evolution of the environment within which the repository will exist far into the future. For the purposes of this study, scenario analysis was limited to the second type of uncertainty. All uncertainties of the first type were assumed to be incorporated directly into the model(s) and data base(s) that describe the repository system.

The term "scenario" is defined here as a description of one of the many alternative ways in which the environment of a repository might evolve in the future. The goal of a scenario analysis is, then, to identify a set of such scenarios, to be used in uncertainty analyses, that is sufficiently complete to support a regulatory decision on the acceptability of the repository.

In this study, phenomena were considered to be either "internal" or "external," depending on the location where they were initiated. Those phenomiena initiated in the accessible environment were classified as external perturbations of the repository system, even if the effects of the phenomena occurred within the repository. Thus, fault movement within the controlled area of the repository was classified as an external event because the tectonic forces responsible for the movement were external. Similarly, drilling into a repository was classified as an external event because the drilling was initiated outside the controlled area. Phenomena internal to the repository system, such as corrosion of waste canisters, were assumed to be' addressed in the development of model(s) and data base(s) describing the repository system, and therefore were excluded from consideration for scenario development:

For this analysis, the boundary of the repository system was chosen to be coincident with the boundary of the accessible environment, for two reasons. First, many of the uncertainties within this boundary involve processes rather than discrete disruptive events. Simulation of processes and their associated uncertainties is often fairly simple, sometimes involving no more than specification of a range of values within the data base for the repository (e.g., a range of corrosion rates). On the other hand; phenomena outside this boundary are often rare, discrete events such as fault movement or volcanic activity. Simulation of such events within the model of the repository system may be awkward, especially when Monte Carlo or related simulation techniques are used. In such cases, the number of simulations needed to obtain a good representation of repository performance may be so large that accurate approximations of performance are not practical.

The second, and more important, reason for selection of the repository system boundary involved the way in which the repository is perceived by regulators and by the public. Both groups tend to view the repository system as ending at the accessible environment boundary and to visualize phenomena occurring outside this boundary as external perturbations of the repository. Scrutiny of repository safety tends to take the form of "What if" questions-e.g., What happens to the repository if a volcano erupts nearby? Evaluation of external phenomena through scenario analysis directly answers such questions, whereas incorporation of external phenomena into the repository system model(s) or data base(s) would tend to obscure the results of the analysis.

It is important to note differences between the approach adopted here for scenario development versus those proposed by other analysts., Hodgkinson and Sumerling (1989) describe an approach for scenario development in which no distinction is made between "internal". phenomena and those that occur outside the repository. In their 
approach, processes such 'as waste-canister corrosion would be treated as phenomena to be combined into scenarios for analysis. Because these authors combine internal with external phenomena, their list of "events, features and processes" to be combined into scenarios contains approximately 150 entries and, even after screening out unimportant entries, the number of scenarios that could be constructed from a list of this length would be quite large. Treatment of internal phenomena within the repository system imodel greatly reduces the potential number of scenarios, keeping the complexity of the repository analysis within manageable bounds.

Hodgkinson and Sumerling ălso describe "an alternative approach, referred to as "environmental simulation," in which an attempt is made to incorporate all identifiable uncertainties into the repository system model. As discussed previously, it appears that such an approach would have difficulty satisfying the information needs of regulators, and could require excessive numbers of simulations in order to provide accurate approximations of repository performance.

\subsection{Methodology'}

The scenario development approach adopted for this study is an adaptation of the event tree approach used in probabilistic risk analyses, and consists of the following steps:

1. Identification of Processes and Events. This step involves identification of a comprehensive set of processes and events that could adversely affect repository performance. Only "external" processes and events occurring (or initiated) in the accessible environment are included. Processes and events internal to the repository system are assumed to be treated as uncertainties within the model(s) or data base(s) describing the repository system, and therefore are not included. When the time of occurrence of a process or event (e.g., volcanic activity) is expected to have a significant effect on repository performance, the time is specified as part of the description of the event, and occurrences at "several different times could be listed as separate "subevents."

2. Estimation of Probabilities. Probabilities of the processes and events are estimated from historical data, models of the processes and events, or expert judgment.

3. Screening of Events and Procésses. Where possible, processes and events are eliminated from the list compiled in Step 1, using the following screening criteria: (a) lack of physical reasonableness; (b) low probability of occurrence; and'(c) insignificant effect 'on repository performance, if the process or event were to occur.

4. Scenario Construction. Processes and events surviving the screening of Step 3 are combined to form "scenario classẻs" using the event tree"approach described in NUREG/CR-1667 (Cranwell, et 'al., 1982). (Each "scenarió class" is a unique combination of processes and/or events without regard to the order in which they occur.) For this study, different permutations of events that comprise separate scenarios were not considered. Instead, judgment was used to select a permutation to be representative for the scenario class. For the illustrative purposes of this project, it was planned that the only scenarios to be formed would be those consisting of zero, one, or two processes or events-i.e., scenarios containing three or more èvents would not be formed.

5. Scenario Probabilities. Scenario probabilities âre estimated by combining the probabilities of the processes and events that comprise the scenarios. If the processes and events comprising a scenario are independent, the scenario probability is determined by multiplying the probabilities of the constituents. If the processes and events are not independent, correlations or causal relationships may be considered when determining scenario probabilities.

6. Scenario Screening. Scenarios are screened using the same criteria as for ścreening processes and events in Step 3.

\subsection{Application}

Application of the selected scenario-development methodology for Yucca Mountain was largely limited to the first step-identification of processes and events. The primary source' of information used to compile a list of processes and 'events was the staff's knowledge of the Yucca Mountain site, although limited references to literature describing similar scenario development efforts for Yucca Mountain were also made. Some progress was also made on the third step, involving screening processes and events. However, because probability assignments were not completed, screening was conducted only on the bases of physical reasonableness and insignificant conse'quences: Combination of processes and events into scenarios, development of scenario probability estimates, and scenario screening (Steps 4 to 6) must await development of probability estimates for the phenomena comprising the scenarios. Table 7.1 summarizes the candidate list of processes and events identified, including those that were later screened from the list. (As additional knowledge about the site is acquired, it will obviously be - necessary to periodically review both the completeness of the list and the specific descriptions of processes, and 
events making up the list.) Table 7.2 provides a more detailed description of each process and event and, where appropriate, the basis for screening.

\subsection{Conclusions}

Although only limited progress was made in applying the selected methodology for scenario developmenit, several tentative conclusions have been reached.

1. The methodology appears to be workable. The distinction between "internal" and "external" processes and events appears to have merit for determining which uncertainties are to be incorporated directly into the model(s) and data base(s) describing the repository system and that are to be addressed in scenario descriptions. This distinction also appears to be capable of limiting the number of processes and events in the scenario analysis to a manageable level.

2. Scenario descriptions are necessarily only approximate descriptions of future repository performance, and must incorporate significant conservatisms in order to limit the number of scenarios to be evaluated. In particular, the time at which a process or event is assumed to disrupt a repository may be highly conservative. If such conservatism is exces- sive, definition of "subevents," as was done for volcanism in this analysis, provides a way to remove conservatism and to generate a more realistic approximation of expected repository performance.

3. As for other risk analyses, no way has been found to ensure completeness of the initial list of processes and events from which scenarios are formed. An approach similar to fault tree analysis, in which the repository system is examined to identify potential failure modes, seems a useful way to check on the completeness of process and event identification.

4. Alternative approaches to scenario analysis, such as those described by Hodgkinson and Sumerling (1989), appear to differ primarily in the degree to which they address uncertainties in the model(s) and data base(s) describing the repository system or in scenario descriptions. The approach selected for this study was intermediate between the extremes proposed by others, and appears to be a reasonable trade-off between the desire for a highly detailed simulation of repository performance and the need to limit resources expended on the simulation. The selected approach also appears to have advantages over alternatives for producing information in a form that corresponds to the needs of NRC's regulatory process. 
I. Tectonic

A. Volcanic

1. " Extrusive

a. On-site

i. Years 0-100

ii. Years 101-1;000

iii. Years 1,001-10,000

b. Off-site

2. Intrusive
a. Upgradient
b. Downgradient
c. Intersecting repository;

B. Regionai Uplift \& Subsidence

1. Increased rate of uplift

2.. [Subsidence]

C. Fault Movement

1. Fault within controlled area :

a." Within underground facility

b. Outside underground facility

2. Fault outside controlled area.

a. Location alters groundwater flow

b. Effects limited to ground motion

II. Climatic

A. [Current climate-extreme weather phenomena]

B. [Increase in frequency or intensity of extreme weather phenomena]

C. [Glaciation]

1. [Covers site with ice]

2 [Causes sea level change]

D. Change in precipitation

1. Pluvial period

2. Drier period

III. Human-initiated

A. Greenhouse effect

1. Increased precipitation

2. Reduced precipitation

B. [Climate control]

C. [Weapons testing at Nevada Test Site (NTS)]

D. Drilling

1. Intersects canister

2. Misses canisters 
Table 7.1 List of Processes and Events* (continued)

E. Mining

1. [Above underground facility]

2. At or below underground facility

F. Withdrawal well(s) at or beyond controlled area

1. .. Small, single-family drinking water well

2. Large drinking water well (addition to Las Vegas supply)

3. Agricultural irrigation well

IV. Other

A. [Meteorite impact]

B. ????

"Processes and events enclosed in square brackets are screened from further analysis. 
Table 7.2. Descriptions of Procešses and Events**

\begin{tabular}{cl}
\hline Process or Event & Description \\
\hline 1 & On-site extrusive volcanic activity. A basaltic volcano erupts through the underground \\
facility. The volcano is fed through a dike. Waste canisters within the dike mix with the \\
magma, and their contents are erupted. The size of the dike is assumed to be \\
of the originally emplaced waste. This size is the worst credible, and is taken to be \\
representative of all less disruptive events. Three "subevents" are defined, based on the \\
assumed time of occurrence. (a) Subevent 1a, occurring immediately after repository \\
closure, represents all occurrences during the first century after closure, (b) Subevent \\
1b, occurring at year 101, represents all occurrences between year 101 and year 1,000, \\
and (c) Subevent 1c, occurring at year 1,001, represents all occurrences between year \\
1,001 and year 10,000 . Screening on the basis of likelihood is done only on the overall \\
probability of occurrence of the event during 10,000 years-not on the probabilities of \\
the subevents. The probability of Event 1 is estimated to be
\end{tabular}

2

(I.A.1.b)

3

(I.A.2.a)

4

(I.A.2.b)

5

(I.A.2.c)

6

(I.B.1)

(I.B.2)

7

(I.C.1.a)
Off-site extrusive volcanic activity. Off-site activity is a likely candidate for screening from the list because potentially detrimental effects seem unlikely. However, the event was retained pending a more thorough consideration of potential effects such as alterations of regional or on-site hydrological or geochemical conditions.

Upgradient intrusive volcanic activity. An igneous intrusion at

(location) upgradient from the underground facility forms in a way that alters groundwater flow downgradient from the location of the intrusion. The intrusion is in the form of a dike with dimensions of , and reaches to a depth of below the ground surface. The location and dimensions are the worst credible values, in terms of effects on repository performance, and are taken to be representative of all less disruptive intrusions. The temperature of the intrusive material is , causing thermal alterations of surrounding groundwater flow conditions. The probability of Event 3 is estimated to be

Downgradient intrusive volcanic activity. An igneous intrusion forms at (location) downgradient from the underground facility. Except for location, this intrusion is identical to that of Event 3. The probability of Event 4 is estimated to be

Volcanic intrusion intersects underground facility. An igneous intrusion identical to that of Event 3 forms beneath the underground facility, intersecting emplaced waste, but not reaching the ground surface. The probability of Event 5 is estimated to be

Increased regional uplift. The existing rate of uplift at the repository site increases to a rate of immediately after repository closure and then remains constant for 10,000 years. This same uniform rate of uplift also occurs within a surrounding area of dimensions . The probability of Process 6 is estimated to be

Subsidence. Subsidence was screened from the list because potentially disruptive effects could not be identified.

Fault movement within underground facility. A fault intersecting the underground facility moves immediately after repository closure, resulting in an offset of along the fault. (Should the type of fault, dimensions, etc, be specified? Is simultaneous movement on a series of faults within the underground facility possible and, if so, should that be the description here?) This event is taken to be representative of all similar events with less detrimental effects on waste isolation. 
Table 7.2 Descriptions of Processes and Events**.(continued)

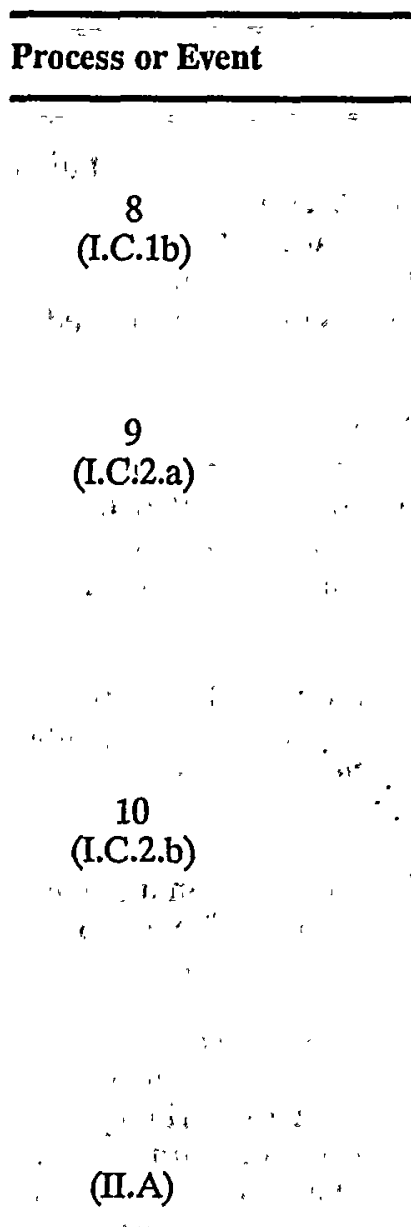

(II.B)

(II.C)

11

(II.D.1)

.,

12

(II.D.2)

\section{Description}

The probability of Event 7 is estimated to be

Fault movement within controlled area. A fault intersecting the controlled area, but not the underground facility, moves immediately after repository closure, resulting in an offset of along the fault. This event is taken to be representative of all similar events with less detrimental effects on repository performance. The probability of Event 8 is estimated to be

Fault móvement outside controlled area alters groundwater flow. A fault located outside the controlled area moves immediately after repository closure, altering groundwater flow characteristics in a way that potentially influences waste isolation. The location of the fault is '___ and the offset along the fault is . This event is taken to be representative of all similar events with less detrimental consequences. The probability of Event 9 is estimated to be . (NOTE: If both upgradient and downgradient locations of fault movement capable of altering groundwater flow are credible, separate events might need to be defined analogous to Events 3 and 4, previously mentioned.)

Fault movement outside controlled area causes ground motion. A fault located outside the controlled area moves, causing ground motion at the underground facility and shaft and borehole seals. The maximum acceleration and the frequency of motion are ? This event is taken' to be representative of all similar events with lower acceleration or less detrimental frequencies. The probability of Event 10 is estimated to be _. (NOTE: It might be possible to combine Events 9 and 10 although, in general, these events will be different since-Event 9 depends strongly on the location of . the fault movement, whereads Event 10 is concerned with the ground motion produced by an event at any location.).

Current climate-extreme weather phenomena. Extreme weather phenomena, such as tornados; hurricanes, etc., were screened from the list because potentially detrimental effects on waste isolation could not be identified.

Increased frequency or intensity of extreme weather phenomena. These phenomena were also screened from the list because potentially detrimental effects on waste isolation could not be identified.

Glaciation coyering site with ice or causing sea-level change. Glaciation causing the site to be covered with ice was screened from the list because of lack of evidence of 'occurrence during previous glacial episodes. Sea-level changes caused by glaciation were screened from the list because potentially detrimental effects on waste isolation could not be identified.

Pluvial period. A period of increased precipitation begins immediately after repository closure and continues for 10,000 years. Precipitation at the site and throughout the surrounding region is increased by 50 percent compared to current levels. This event is taken to be representative of all similar events of later onset, shorter duration, or smaller changes in precipitation. The probability of Event 11 is estimated to be $\therefore$

Drier period. A period of reduced precipitation begins immediately after repository closure and continues for 10,000 years. Precipitation at the site and throughout the surrounding region is reduced by 50 percent compared to current levels. This event is taken to be representative of all similar events of later onset, shorter duration, or smaller changes in precipitation. The probability of Event 12 is estimated to be 
Table 72 Descriptions of Processes and Events** (continued)

\begin{tabular}{|c|c|c|}
\hline Process or Event & & Description \\
\hline (III.A.1) & ' & $\begin{array}{l}\text { Greenhouse effect-increased precipitation. The greenhouse effect causes precipitation } \\
\text { to increase by } 30 \text { percent above levels that would have otherwise prevailed. The } \\
\text { increase begins immediately after repository closure.and continues for } 10,000 \text { years. } \\
\text { This event is taken to be representative of all similar events of later onset, shorter } \\
\text { duration, or smaller changes in precipitation. The probability of Event } 13 \text { is estimated } \\
\text { to be }\end{array}$ \\
\hline$\stackrel{14}{\text { (III.A.2) }}$ & $\cdot$ & $\begin{array}{l}\text { Greenhouse effect-reduced precipitation. The greenhouse effect reduces } \\
\text { precipitation by } 30 \text { percent compared to levels that, would have otherwise prevailed. } \\
\text { The decrease begins immediately after repository closure and continues for } 10,000 \\
\text { years. This event is taken to be representative of all similar events of later onset, } \\
\text { shorter duration, or smaller changes in precipitation. The probability of Event } 14 \text { is } \\
\text { estimated to be }\end{array}$ \\
\hline (III.B) & & $\begin{array}{l}\text { Climate control. This event was screened from the list because of low likelihood. It is } \\
\text { presumed that the institutional controls required by } 10 \text {.CFR Part } 60 \text { will be sufficiently } \\
\text { effective to prevent any events of this type that could detrimentally affect waste }\end{array}$ \\
\hline & & isolation. , " " \\
\hline (III.C) & & $\begin{array}{l}\text { Weapons testing at NTS. This event was also screened from the list by presuming that } \\
\text { the institutional controls required by } 10 \text { CFR Part } 60 \text { will be sufficiently effective to } \\
\text { prevent any events of this type that could detrimentally affect waste isolation. }\end{array}$ \\
\hline $\begin{array}{c}15 \\
\text { (III.D.1) }\end{array}$ & & $\begin{array}{l}\text { Drilling intersects a canister. Wildcat drilling for petroleum breaches a canister } \\
\text { allowing part of the canister contents to be brought to the surface in drilling fluids. } \\
\text { Wildcat drilling for petroleum is taken to be representative of all potential drilling at } \\
\text { the depth of the underground facility. The frequency of drilling at the repository site is } \\
\text { estimated to be } \\
\text { a canister is estimated by the geometric relationship between the area of the waste } \\
\text { canisters and the total area of the underground facility. }\end{array}$ \\
\hline
\end{tabular}

16

(III.D.2)

(III.E.1)

17

(III.E.2)
Drilling misses canisters. Wildcat drilling for petroleum penetrates the underground facility, but misses all canisters. This type of drilling is taken to be representative of all potential drilling at the depth of the underground facility. The frequency of drilling at the repository site is estimated to be , and the probability that any one drilling event will miss all canisters is estimated by the geometric relationship between the area of the waste canisters and the total area of the underground facility.

Mining above the underground facility. This event was screened from the list because effects potentially detrimental to waste isolation could not be identified.

Mining at or below the underground facility. Construction of shafts and other mining activities are assumed to be carried out only if direct contact with wastes does not occur. If wastes are directly contacted, it is assumed that their character will be recognized, mined openings will be sealed, and mining activities will be abandoned. The frequency of mine construction is estimated to be , and the probability that mining activities will contact waste canisters is estimated by-the geometric relationship between the area of the waste canisters and the total area of the underground facility. 
Table 7.2 Descriptions of Processes and Events** (continued)

\begin{tabular}{|c|c|}
\hline Process or Event & Description \\
\hline $\begin{array}{c}18 \\
\text { (III.F.1) }\end{array}$ & $\begin{array}{l}\text { Small water well. A small, single-family drinking-water well is assumed to be located } \\
\text { at the downgradient boundary of the controlled area and is used as a year-round } \\
\text { domestic water supply. The well is assumed to be drilled } 100 \text { years after repository } \\
\text { closure, and is used continually for the next } 9900 \text { years. Use of the well enhances the } \\
\text { hydrologic gradient within the controlled area, potentially affecting transport of } \\
\text { radionuclides to the accessible environment. The probability of Event } 18 \text { is estimated } \\
\text { to be }\end{array}$ \\
\hline $\begin{array}{c}19 \\
\text { (III.F.2) }\end{array}$ & $\begin{array}{l}\text { Municipal drinking-water well. A municipal drinking-water well is assumed to be drilled } \\
\text { at the boundary of the controlled area at year } 100 \text { after repository closure, and the well } \\
\text { is assumed to be used until year } 10,000 \text { after closure (or until depletion of available } \\
\text { groundwater supplies). The effect of this well on repository performance is limited to } \\
\text { potential alterations of regional groundwater flow characteristics. It is assumed that } \\
\text { current requirements for monitoring the quality of municipal water supplies will } \\
\text { continue, so that remedial actions will be taken if radioactive contamination of water } \\
\text { supplied by the well occurs. The probability of this event is estimated to be }\end{array}$ \\
\hline $\begin{array}{c}20 \\
\text { (III.F.3) }\end{array}$ & $\begin{array}{l}\text { Agricultural irrigation well. The assumptions regarding this well are identical to those } \\
\text { for Event } 19 \text { except that monitoring for potential radioactive contamination of the } \\
\text { water is not assumed to occur. Therefore, remedial actions will not be taken to stop } \\
\text { potential releases of waste via this well. Because no monitoring of water quality is } \\
\text { assumed, both releases of radionuclides and alterations of hydrologic gradients within } \\
\text { the controlled area may be more severe than for Scenario } 19 . \text { The probability of this } \\
\text { event is estimated to be }\end{array}$ \\
\hline (IV.A) & $\begin{array}{l}\text { Meteorite impact. This event was screened from the list because of low probability. } \\
\text { Several references in the technical literature demonstrate that the probability of impact } \\
\text { by a meteorite large enough to disrupt a repository is extremely small. }\end{array}$ \\
\hline
\end{tabular}

* Blanks indicate information to be developed later. 


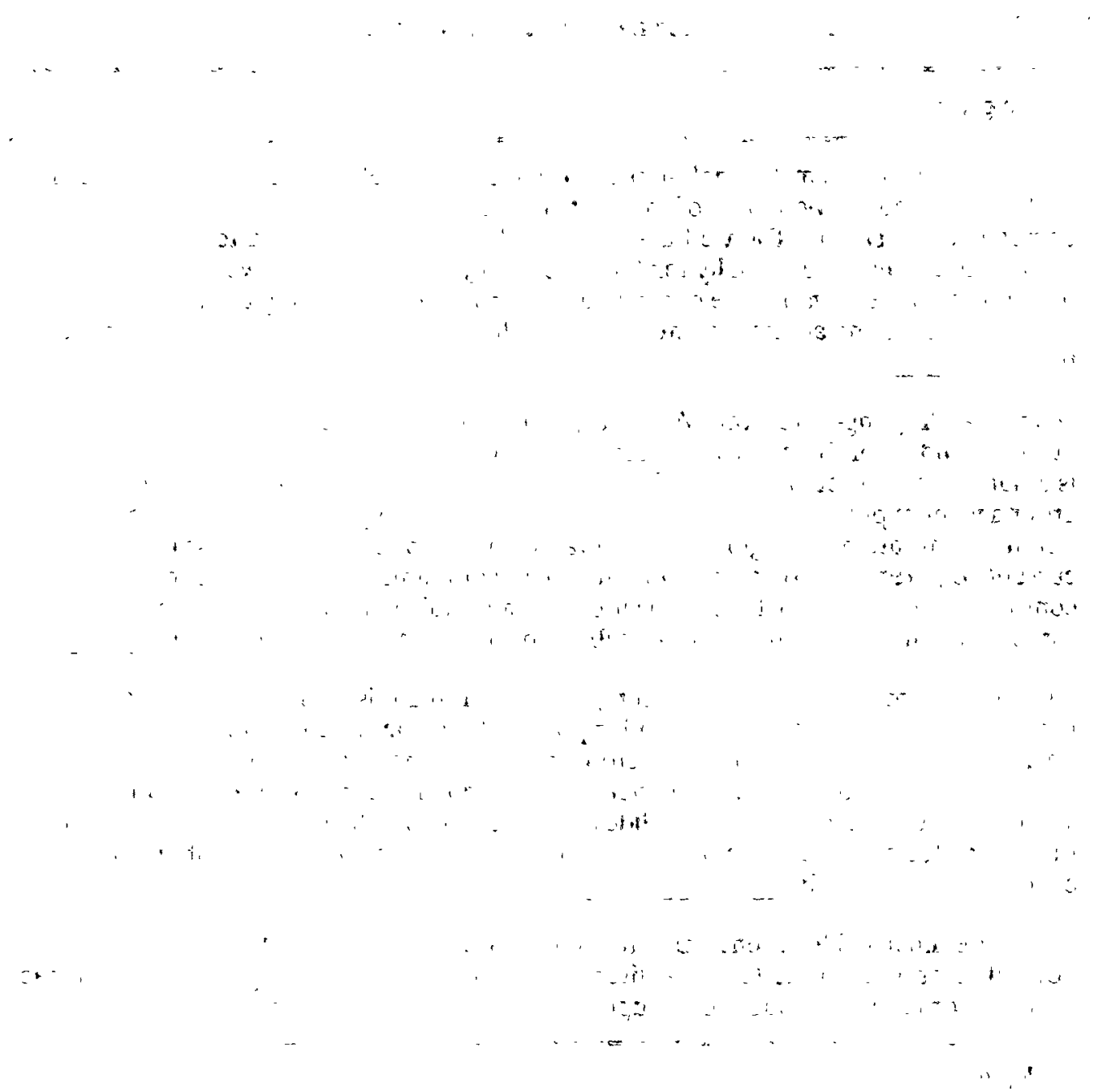




\section{AUXILIARY ANALYSES SUMMARIES}

\subsection{Introduction}

In general, the auxiliary analyses conducted for this demonstration were directed toward the evaluation of the appropriateness and limitations of various computational approaches and the analysis and interpretation of data used in this study. These analyses included: the twodimensional cross-sectional flow simulation of a layered porous site, the analysis of hydrologic data, and the analysis of statistical convergence for a CCDF. Additionally, a separate analysis of carbon-14 releases was performed to supplement the liquid and direct pathway analysis. The aforementioned auxiliary analyses are discussed in detail in the appendices. A brief description of the analysis are provided next.

\subsection{Carbon-14 Analysis (Appendix D)}

The release of carbon-14 from waste packages is a potential concern for a repository located in the unsaturated zone because of the presence of a fast pathway (gas through the fractures) to the accessible environment. Due to the complexity of the source term considerations of this problem, the analysis was not considered appropriate to be included in the total CCDF. However, it was considered important to perform some simple calculations to obtain a better appreciation and understanding of the magnitude of the problem and some of the concerns.

The analysis identified release mechanisms and the geochemistry of calcite precipitation as areas where data collection and further investigation would be most fruitful.

\subsection{Statistical Convergence (Appendix E)}

There are rules of thumb for determining the number of Monte Carlo simulations to perform to provide statistically representative results. Because of the highly nonlinear problems currently being tackled, it was deemed appropriate to investigate the number of simulations required to obtain statistical convergence.
Approximately an order of magnitude more simulations than the rule of thumb would indicate were required for the current problem. The most likely reason for this result, was the very few simulations that provided a nonzero result in the high consequence part of the CCDF.

\subsection{Analysis of Hydrologic Data (Appendix F)}

An auxiliary analysis of hydrologic data was conducted to determine if spatial correlations could be identified for porosity and hydraulic conductivity parameters. A large scale trend of decreasing porosity with increasing depth was identified in data from three holes drilled into the Topopah Spring unit, and a small-scale correlation length of less than 40 meters was identified in data from two holes drilled into the Topopah Spring unit. However, this analysis did not identify any spatial correlation with depth for Calico Hills porosity data or for saturated hydraulic conductivity in either the Calico Hills or the Topopah Spring units. This was relevant to the flow and transport modeling, because long correlation lengths lead to a broad travel time distribution for each column (see Section 9.3.1.4). Very short correlation lengths lead to the conclusion that there is a single groundwater travel time per column and little likelihood of long, fast, groundwater flow paths. In the flow and transport modeling, it was assumed that there was no apparent spatial correlation for saturated hydraulic conductivity beyond 10 meters separation (see Section 9.3.1.5).

\subsection{Two-Dimensional Flow Simulation (Appendix G)}

A two-dimensional flow simulation was conducted to examine the potential for flow diversion at unit interfaces or the propensity for non-vertical flow. The analysis, which considered only matrix flow, showed that considerable non- vertical flow would occur at interfaces where the saturated conductivity of the lower unit was 75 percent or less of the infiltration rate. Future work will need to consider the effect of fractures on non-vertical flow. 


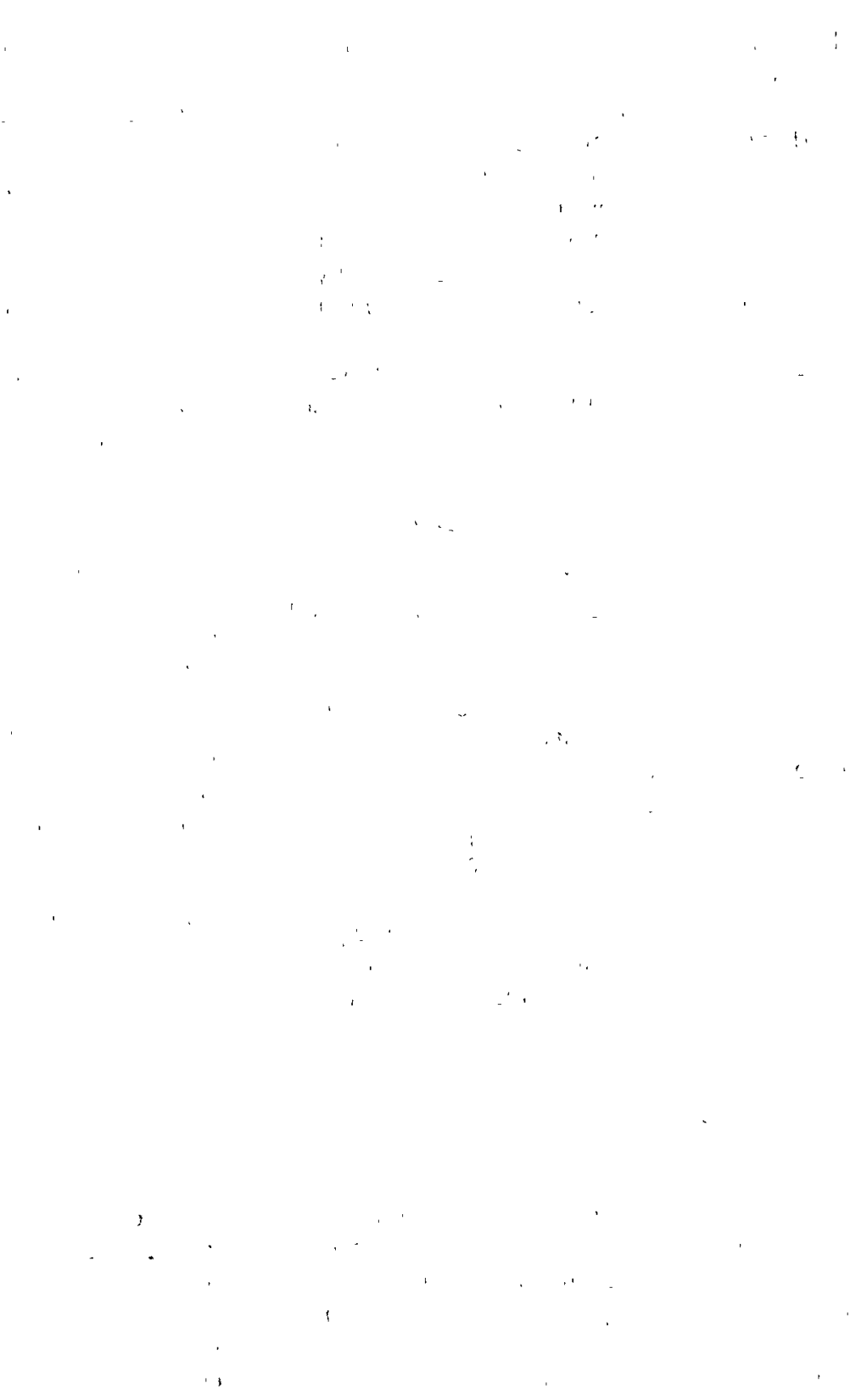




\section{ANALYSIS AND RESULTS}

Previous sections have described the methods and approaches for estimating performance and the evaluations used to select the various methods and approaches. This section describes the implementation of the methods and the results obtained. The following correspondence exists, between the previous sections and the current section:

\begin{tabular}{|c|c|c|c|}
\hline \multicolumn{2}{|c|}{ Previous (Methods) } & \multicolumn{2}{|c|}{ Current (Implementation) } \\
\hline Section 4 & System Code & Subsection 9.6 & Total CCDF \\
\hline Section 5 & $\begin{array}{l}\text { Source } \\
\text { Term }\end{array}$ & Subsection 9.2 & $\begin{array}{l}\text { NEFTRAN } \\
\text { Source '" } \\
\text { Term } \\
\text { Model }\end{array}$ \\
\hline Section 6 & $\begin{array}{l}\text { Flow and } \\
\text { Transport } \\
\text { Models }\end{array}$ & $\begin{array}{c}\text { Subsection } 9.3 \\
+\end{array}$ & $\begin{array}{l}\text { Flow and } \\
\text { Transport } \\
\text { Models }\end{array}$ \\
\hline Section 7 & $\begin{array}{l}\text { Methodology } \\
\text { for Scenario } \\
\text { Development }\end{array}$ & $\begin{array}{l}\text { Subsection } 9.1 \\
\cdots\end{array}$ & $\begin{array}{l}\text { Treatment } \\
\text { of Scenarios }\end{array}$ \\
\hline
\end{tabular}

Two additional subsections are added to this section to complete the exposition of implementing the methodology. Subsection 9.4, Parameters, describes values used in the analysis, and Subsection 9.5, Sensitivities and Uncertainties for Liquid Pathway Analysis, describes a demonstration of analytic methods.

\subsection{Treatment of Scenarios}

\subsubsection{Introduction}

A general approach for analysis of scenarios is discussed in Section 7 of this report. Because work on this part of the performance assessment was delayed, a less systematic approach to the treatment of scenarios was taken' in the interest of expediency. In particular, the steps of: (1) identification of processes and events; (2) estimation of probabilities; (3) screening of events and processes; (4) scenario class construction; (5) scenario class probability estimation; and (6) scenario class screening, were collapsed into a more direct approach. Because of the limited time available to perform the Phase 1 analysis, significant new modeling initiatives were not possible. With this in mind, a small number of interesting scenario classes were chosen for incorporation into the CCDF to demonstrate how this is done and how results from various scenario classes are combined.

\subsubsection{Discussion}

Two classes of fundamental events were selected. These events were: (1) changes in climate at Yucca Mountain, and (2) human intrusion by drilling exploratory boreholes.
These types of events were selected, in part, because they would demonstrate interesting aspects of repository performance and because the modeling variations needed to accommodate these events were not excessive. Thus treatment of the scenario classes involving climate changes, called pluvial conditions in this study and repressented by increased infiltration and a rise in the water table at Yucca Mountain, were accommodated by slight modifications to the data used as input to the model representing groundwater transport. Excavation of radioactivity contained either in the repository or in contaminated host rock could be relatively easily modeled to what is believed to be an acceptable degree of accuracy. In addition, excavation of radioactivity is an archetypical direct-release event, representative of the type of modeling anticipated for similar direct-release mechanisms like volcanism.

The two classes of fundamental events were combined to form four classes of scenarios:

Scenario \# 0 : Base case conditions and no drilling Scenario \# 1 : Pluvial conditions and no drilling

"Scenario \# 2 : Base case conditions with drilling Scenario \# 3 : Pluvial conditions with drilling.

Consequences for the base-case scenario were estimated by the output of the NEFTRAN code, as described in Sections 6 and 9.2 of this report. The pluvial case was estimated by the NEFTRAN code, but with input modified to simulate a higher water table and greater infiltration rate. Because the drilling removed so little radioactivity from either the repository or the host rock, the consequences of drilling, to a first approximation, could be calculated independently of the details of the migration of radionuclides. However, some of the same factors, such as the removal of waste from the repository, influenced both the groundwater and direct-release pathways, so parameters important to these factors were used in calculating releases from both pathways.:For Scenario Classes 2 and 3 , consequences from these two pathways were calculated and subsequently added together by the system code.

The probability of occurrence of drilling was considered to be independent of the occurrence of pluvial conditions (see Figure 9.14; and discussion in Subsection 9.6). Although drilling boreholes for purposes of aquifer detection or water exploration and extraction probably would depend on the climatic conditions at the site, drilling for purposes of mineral exploration probably would not. Following the guidance provided by EPA in Appendix B of 40 CFR Part 191, a constant drilling rate of 0.0003 boreholes per square kilometer per year, a repository area of 5.1 square kilometers gave 15.3 as the expected number of boreholes over 10,000 years. This means that 
the probability of no boreholes at the site over the same time period is very small. Using a Poisson distribution to describe drilling, the probability of no boreholes was estimated to be $2.3 \times 10-7$. Thus, the probability of drilling was very close to 1.0 . This probability may be overestimated, because exploratory drilling may be done preferentially in more level terrain (which is not accounted for in the average drilling rates) and because the repository's markers may be more effective than was assumed for this stidy: Because there were no readily available data, the probability of occurrence of pluvial conditions was assumed to be 0.1 , and the non-occurrence of pluvial conditions was assumed to be 0.9 .

Had the scenario analysis procedure discussed in Section 7 of this report been followed for this Phase 1 demonstration, the event of no drilling probably would have been screened out, because of low probability of occur rence. Alternatively, the two scenarios involving no drilling probably would have been screened out for the same reason. These non-drilling scenarios were retained in this analysis for demonstration purposes, and because the scenario analysis effort had not progressed sufficiently to use the scenario screening procedure. An interesting result shown in Section 9.6 is that these non-drilling scenarios had a negligible effect on the total CCDF, which is dominated by the scenarios with drilling.

The two fundamental events selected for treatment here illustrate the striking differences in the importance of various scenarios to the CCDF that are to be expected when the probabilities of occurrence or non-occurrence of a particular event (such as drilling or pluvial conditions) are nearly equal or are orders of magnitude different. Also note that the treatment of drilling consequences, in combination with consequences from liquid-pathway releases, as a separate pathway depended on the viability of the assumptions that: (1) the amount of radioactivity released by drilling is small compared to the total inventory in the repository and host rock, and (2),drilling boreholes had no substantial effect on the mechanisms important to liquid-pathway releases. Had these assumptions not been good approximations, a far more complex treatment of the combination of fundamental events would have been necessary.

\subsection{NEFTRAN Source Term Model}

NEFTRAN (Longsine, et al., 1987) has three built-in source term models; solubility-limited, leach-limited, and mixing cell. The solubility-limited and leach-limited models were adopted for the demonstration.

The engineered barrier lifetime $\left(\mathrm{T}_{\mathrm{eb}}\right)$, a randomly sampled variable in the calculation, was the time before which no radionuclides would be released. Beyond that time, the waste was assumed to be fully accessible to the environment and could be leached and dissolved. Upon exposure to the environiment, the radionuclides in the waste were assumed to be contained in the uranium dioxide matrix and to be. released at a rate determined by the leach time, $T_{L}$, i.e., the time for the matrix to be totally dissolved at a constant rate. The leach time is simply the reciprocal of the leach rate $\lambda_{L}$. The leach rate was estimated on the basis of the total inventory of the matrix $M_{0}$ (in grams), the infiltration rate I (in $\mathrm{m} / \mathrm{yr}$ ), the total surface area of the site, $A$ (in $\mathrm{m}^{2}$ ), the fraction of infiltrating water contacting the waste $f$ (unitless), and the solubility of the matrix $S_{0}$ (in grams per cubic meter of water):

$$
\lambda_{L}=I^{\prime} \mathrm{A} \text { f } S / \mathrm{M}_{0} \text {. }
$$

The rate of radionuclide release was governed by either the dissolution rate of the $\mathrm{UO}_{2}$ matrix or the solubility of the individual radionuclides. Most of the radionuclides must first be released from the matrix before their solubilities become limiting. Since more-oxidized fuel is likely to be more soluble, this solubility may be a function of time. The rate of fuel dissolution might be.controlled either by the amount of water entering the canister, or if there is ample water, by the solubility of the fuel determined by its oxidation state.

Once released from the waste matrix, the NEFTRAN program determines if the concentration of the radionuclide exceeds its solubility limit. If so, then the "undissolved inventory" for that radionuclide increases, and the flux leaving the source is limited by the solubility. The undissolved inventory can be released later if the concentration of radionuclides leaving the source term drops below the solubility limit. All variables for the source term model, except the initial radionuclide inventories in the spent fuel, were random, generated externally to the program by the LHS routine.

Several of the radionuclides, notably C-14, I-129, and cèsium, are known to collect outside of the uranium dioxide matrix (SCP, Section 8:3.5.9), and could be treated as being solubility-limited rather than leach-limited. The inventory fraction of these radionuclides available for immediate release was assumed not to be sufficiently great enough: to affect cumulative releases over 10,000 years; thus; 'no't changes to the NEFTRAN code were needed to accommodate this quick release. For this study, the entire inventory of these radionuclides was assumed to be contained in the $\mathrm{UO}_{2}$ matrix. However, the variation in the location of the $\mathrm{C}-14$ inventory was considered in the gaseous pathway auxiliary analysis (Appendix D). In Phase 1 , the gaseous releases of $C=14$ were treated separately from the groundwater release.of radionuclides, including C-14. 


\subsection{Flow and Transport Models}

The movement of radionuclides could occur in the liquid, gas, and direct pathways. As discussed in Section 6, the liquid pathway was simulated with the NEFTRAN computer program (Longsine, et al., 1987), and a computer code was developed by the staff to simulate the direct release of radionuclides due to exploratory drilling. The gas pathway was analyzed as an auxiliary analysis, as discussed in Appendix D.

\subsubsection{Liquid Pathway}

Yucca Mountain is a complicated, multilayered system in three dimensions. NEFTRAN can represent the site only as an interconnected series of flow tubes. Although capable of: representing a two-dimensional flow situation, NEFTRAN is further restricted to having only a single flow path for radionuclide migration. Because much important detail would be lost in the analysis of the complicated site with a one-dimensional analysis, the NEFTRAN code was modified and run in a manner to partially overcome the limitations of the one-dimensional structure (i.e., simulate the spatially varying and uncertain conditions at Yucca Mountain). This specialized implementation can be divided into the following areas: (1) geometry or network set-up, (2) phenomena, and (3) data input.

\subsubsection{NEFTRAN network implementation}

For this study, the design of the one-dimensional network for NEFTRAN was based on current information on hydrogeologic units and theories of flow at Yucca Mountain. In the SCP (DOE, 1988), the flow at Yucca Mountain is conceptualized as essentially vertical and under steady-" state conditions within the matrix for fluxes less than the matrix-saturated conductivity, $\mathrm{k}_{\mathrm{s}}$, and as fracture flow at higher fluxes. (The potential for lateral flow at the contact between hydrologic units when a higher-conductivity unit is underlaid by a lower-conductivity unit was examined as an auxiliary analysis in Appendix G.)

Based on the assumption of vertical flow and the fact that the repository is envisioned to have a slope similar to the surrounding geologic unit (see Figure 9.1), the analysis was comprised of four separate networks. The network, designed to represent the hydrologic units existing below a portion of the repository and extending to the water table, is depicted in Figure 9.2. This representation took into account the assumption that one end of the repository is 299 meters above the water table whereas the other end is $\mathbf{1 5 5}$ meters above the water table and that different units exist below these two extremes. Additionally, the areal extent of the repository is rather complex (see Figure 9.3). The percentage of waste inventory was partitioned among the four columns, based on the areal per-' centage of the repository determined to be above each column (see Figure 9.4). Table 9.1 presents the hydrogeologic units within the columns (labeled A through D), the thicknesses of the units, and thus the distance from the repository to the water table for each column, and the fraction of waste present in the repository areas represented by the columns.

There are 6 hydrogeologic units in Column A, 5 in Column B, 4 in Column C, and 2 in Column D. Note that in Column $D$, the only layers present have very small average $\mathrm{k}_{\mathrm{S}}$, and that for high infiltration rates, the transport might be dominated by fracture flow, and therefore contribute to potentially high radionuclide releases to the water table. Column Cis only slightly better, with two thin layers of the Calico Hills Vitric and Prow Pass Welded units present.

Some limitations of this one-dimensional network modeling approach (i.e., simulating the groundwater release pathway as four distinct columns of vertical flow; with radionuclide transport to the water table) are:

1. Lateral flow caused by the diversion of water along interfaces between units and/or obstructions of flow near faults is not taken into account.

2. Flow and transport of radionuclides in the saturated zone from the water table beneath the repository to the accessible environment is conservatively neglected.

The source term was conservatively considered to start at the boundary of the disturbed zone, 25 meters lower than the plane of the waste emplacement, and therefore closer to the water table (NRC Draft Technical Position on the Disturbed Zone, 1986).

\subsubsection{Implementation of matrix and fracture flow in NEFTRAN}

The NEFTRAN code was developed primarily for repositories located in saturated media (e.g.,in bedded salt and basalt). It represents groundwater flow and solute transport through a network of flow tubes. The groundwater flux and transport within each flow tube are considered to be fully saturated and at steady state, with each steadystate velocity determined by Darcy's Law. In this form, it was not well-suited for the present unsaturated flow calculations, because steady-state saturated conditions are not anticipated.

The guidelines for the present phase of this work limited the staff to using currently existing computer codes wherever possible. Rather than develop a new code capable of simulating the Yucca Mountain case, modifications were made to the NEFTRAN code to facilitate the simulation of unsaturated flow and transport. First, all çoding within 


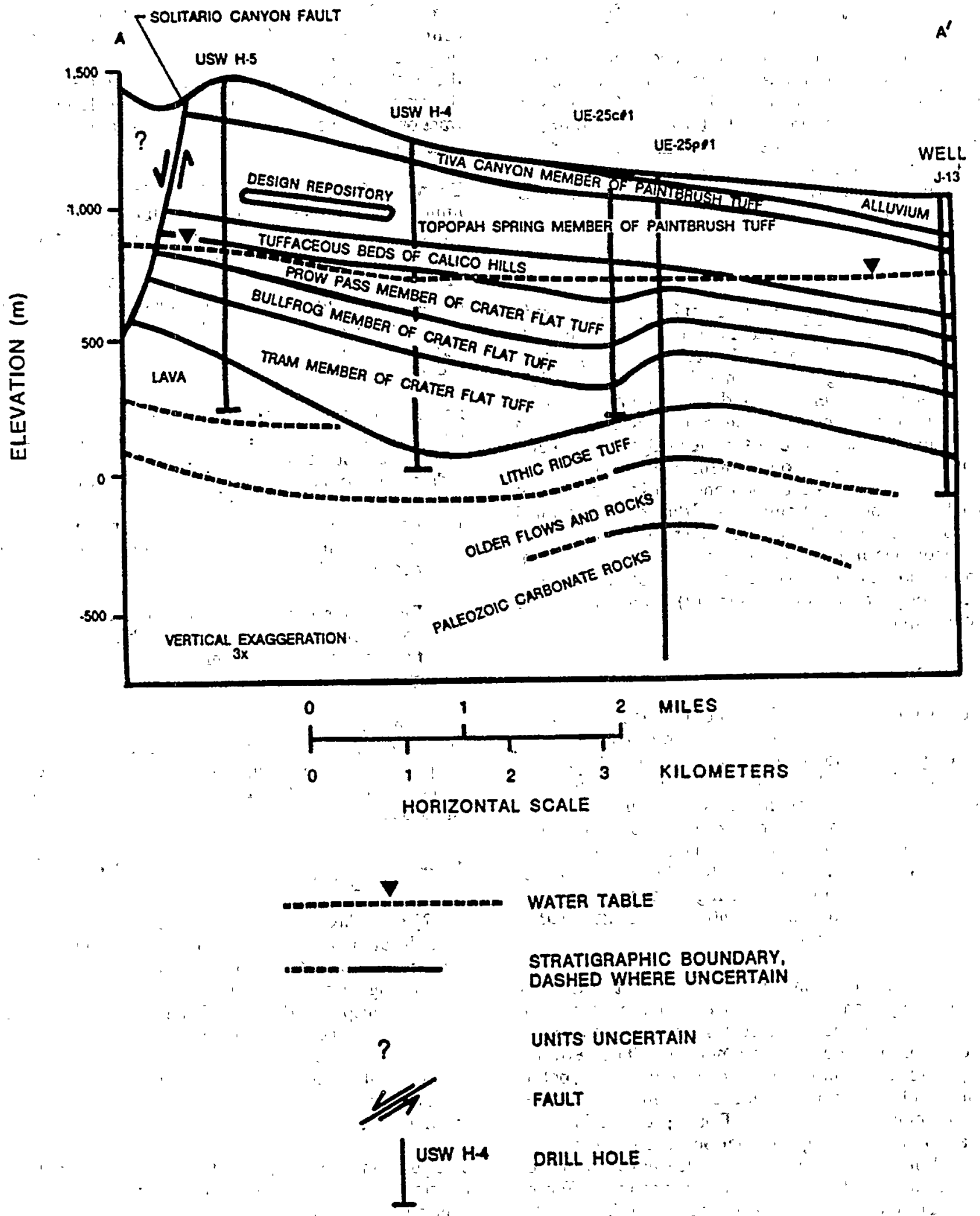

Figure 9.1. Conceptualization of a hydrogeologic cross-section through the unsaturated zone at Yucca Mountain (after DOE, 1988) 

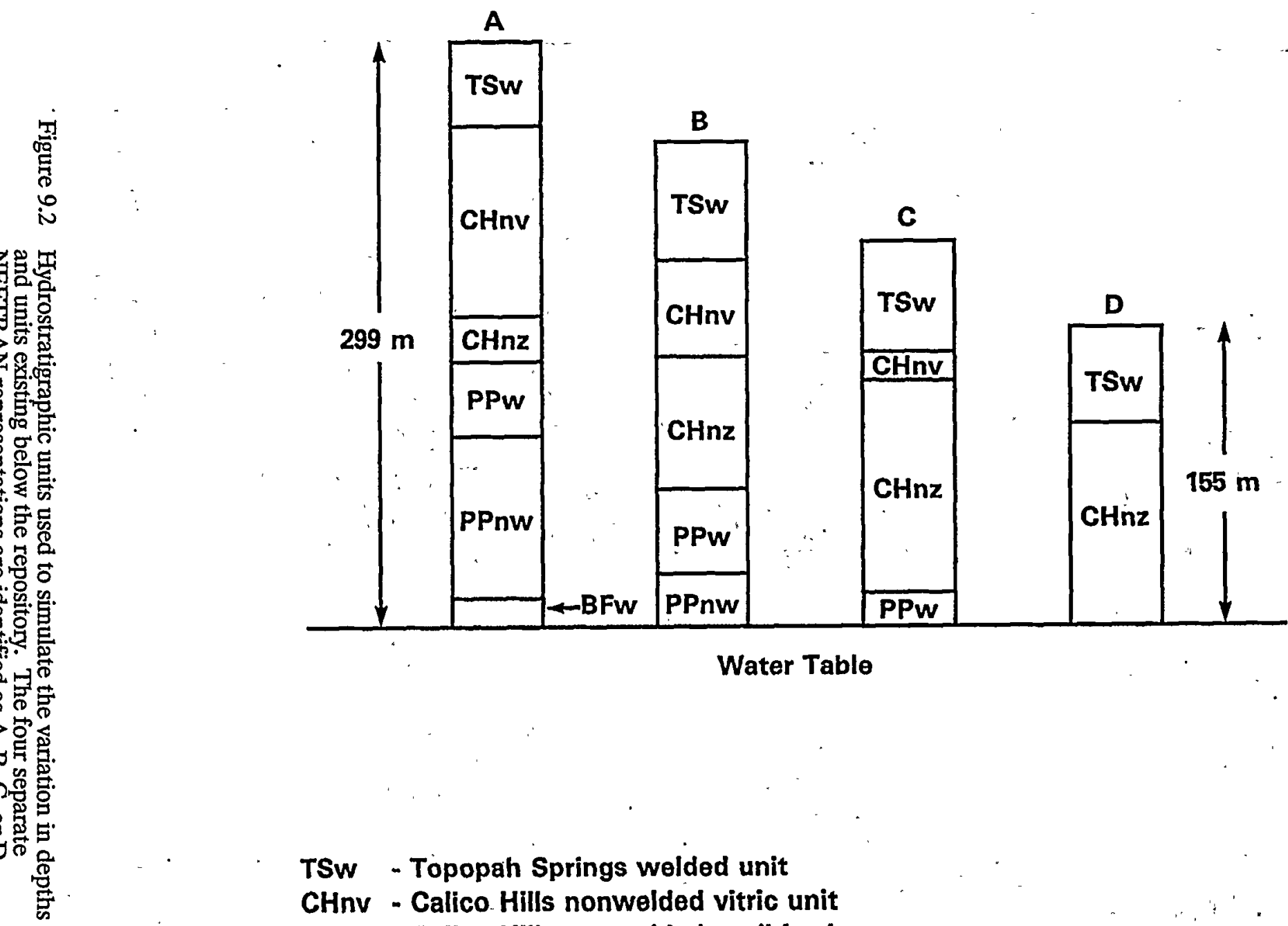

Water Table

TSw - Topopah Springs welded unit

CHnv - Calico Hills nonwelded vitric unit

CHnz - Calico Hills nonwelded zeolitized

PPw - Prow Pass welded member

PPnw - Prow Pass nonwelded member

BFw . Bullfrog welded member 


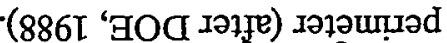

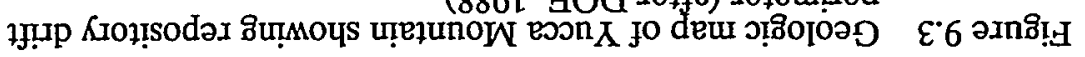
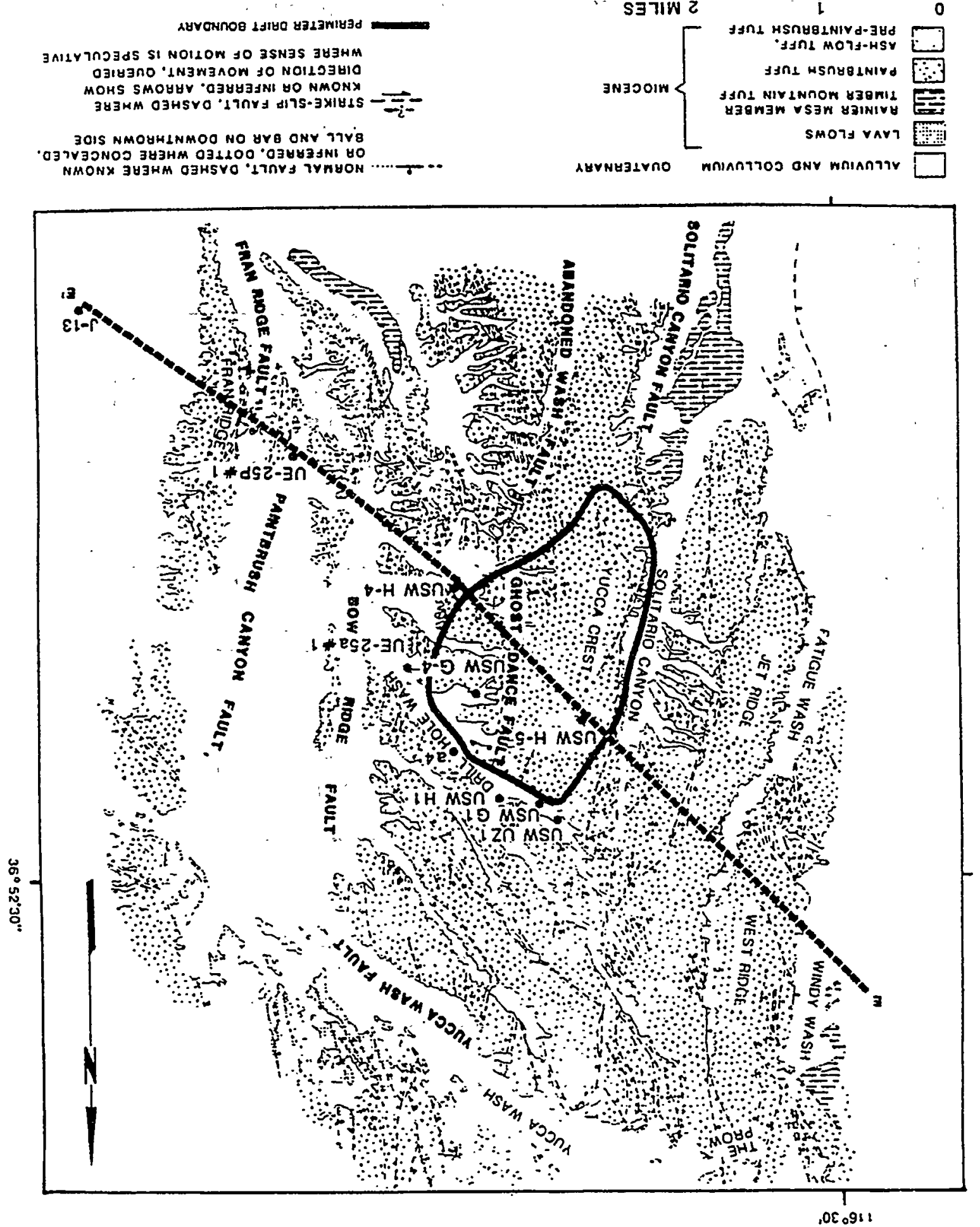

słnnsəy pur ș̣אTeur $\cdot 6$ 


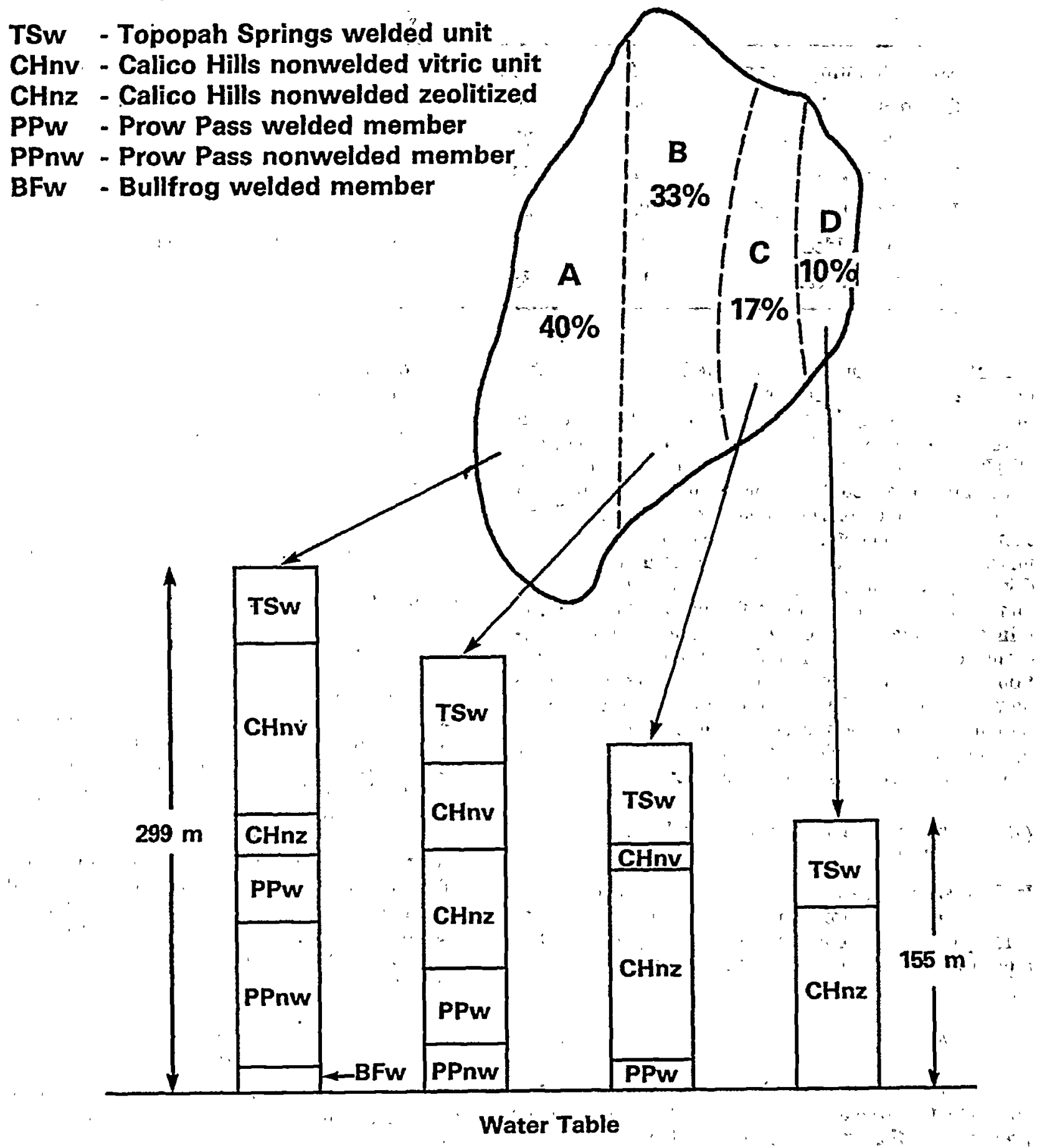

Figure 9.4 Representation of the allocation of repository area and radionuclide inventory of the four NEFTRAN simulations. ' 
Table 9.1 Columns Representing the Yucca Mountain Repository

\begin{tabular}{lccccc}
\hline Column & A & B & C & D & $\begin{array}{l}\text { Average Matrix } \\
\text { Saturated } \\
\text { Conductivity }\end{array}$ \\
\hline Topopah Spring Welded & $45 \mathrm{~m}$ & $60 \mathrm{~m}$ & $55 \mathrm{~m}$ & $55 \mathrm{~m}$ & $0.72 \mathrm{~mm} / \mathrm{yr}$ \\
Calico Hills Vitric & 100 & 50 & 10 & 0 & 107 \\
Calico Hills Zeolitic & 20 & 70 & 120 & 100 & 0.54 \\
Prow Pass Welded & 34 & 45 & 10 & 0 & 88 \\
Prow Pass Nonwelded & 90 & 20 & 0 & 0 & 22 \\
Bullfrog Welded & 10 & 0 & 0 & 0 & 118 \\
Fraction of waste & 0.4 & 0.33 & 0.17 & 0.10 & - \\
\hline
\end{tabular}

NEFTRAN that calculated saturated flux through the flow tubes was eliminated. Instead, the flow rates through the network along the path of radionuclide migration were calculated from the infiltration flux. Second, the NEFTRAN code was modified to examine predominantly downward bifurcated flow. Flow occurred either through the matrix or fractures, depending on the rate of infiltration relative to the saturated hydraulic conductivity of the matrix, $k_{s}$. Flow through a vertical column would be driven by the infiltration rate. Since the column is onedimensional, all flux must pass through each layer. If the infiltration rate is greater than the matrix-saturated hydraulic conductivity of an individual unit, then the fraction of the infiltration exceeding the saturated conductivity was assumed to flow in the fractures (in this case, all radionuclide transport occurred through the fractures, ignoring any radionuclide transport thirough the matrix). The possible subcases for this flow are:

\section{(a) Infiltration Lower Than Saturated Hydraulic Conductivity}

In this case, it was assumed that because of matrix suction, water will flow entirely within the matrix, so that the velocity of a non-sorbing tracer without dispersion will be equal to the infiltration rate I divided by the water content $\phi ;$ i.e.

$$
\mathrm{v}=\mathrm{I} / \Phi
$$

The water content is related to the unsaturated hydraulic conductivity through a constitutive relationship. In the present case, the Brooks-Corey formula was assumed:

$$
\Phi=\mathrm{n}_{\mathrm{e}}\left(\mathrm{I} / \mathrm{k}_{\mathrm{S}}\right)^{1 / \varepsilon},
$$

where $\epsilon$ is the Brooks-Corey factor for each hydroge- 1 . ologic unit and $\mathrm{n}_{\mathrm{e}}$ is the saturated effective porosity (Lin, 1986).

\section{(b) Infiltration Exceeding Saturated Hydraulic Conductivity}

In this case, the matrix will be incapable of carrying all the flow; therefore, a part of the flow will be carried by the interconnected fractures in the tuff. The matrix portion of the flow would have a transport velocity defined by:

$$
\mathrm{v}=\mathrm{k}_{\mathrm{s}} / \mathrm{n}_{\mathrm{e}} .
$$

The fracture portion of the flow would be:

$$
\mathrm{v}^{\prime}=\left(\mathrm{I}-\mathrm{k}_{\mathrm{s}}\right) / \mathrm{n}_{\mathrm{f}},
$$

where $n_{f}$ is the effective porosity of the fracture. This parameter should also depend on the infiltration rate. However, for the present set of calculations, $n_{f}$ will be taken as a constant, 0.0001 , representative of a small value leading to short travel times in fractures ( $\mathrm{Lin}, 1986)$. Since most of the potential for retardation and long travel times is in the matrix, a relatively small fraction of flow in the fracture may completely dominate the transport for bifurcated flow. Therefore, only the fraction of the infiltration carried in the fractures affected radionuclide transport for cases when both matrix and fractures should occur. The reasons for this choice are covered in the next section.

\subsubsection{Implementation of transport phenomena within NEFTRAN}

Radionuclides will be transported in the matrix or in the fractures, if infiltration exceeds the saturated conductivity. If flow occurs in the fractures, the matrix and the fractures would be coupled by hydraulic and chemical processes. The effect of matrix diffusion on the transport through the system would depend on the transfer rate of radionuclides between the fractures and the matrix. The net effect of this transfer can be characterized in three ways, depending on the rate: 


\section{High transfer rate}

At one extreme, transfer between the matrix and fractures would be high, leading to the concentration in the fractures being identical to that in the matrix. For plug flow (i.e., no longitudinal dispersion in the direction of flow) the rate of radionuclide movement would be the flux divided by the total water content $\Phi_{\mathrm{T}}$, i.e., the total volume of the void water-filled void space:

$$
\mathrm{v}=\mathrm{I} / \mathbf{\Phi}_{\mathrm{T}}
$$

\section{Partial transfer}

For the intermediate case, the concentrations of the matrix and fracture would be coupled by a process allowing the transfer of radionuclides from the higher to lower potential; i.e., if the concentration of radionuclides in the fracture was greater than in the matrix, there would be transport of the radionuclide into the matrix by molecular: diffusion. This phenomenon is generally called matrix diffusion.

By judicious choice of parameters, the NEFTRAN code can be made to approximate matrix diffusion using a simple two-zone model (Van Genuchten and Wierenga, 1976). The staff assumed that the water contained in the matrix is essentially immobile, because fracture flow is so much faster. The model accounts for the loss of the radionuclide from the mobile fluid to the immobile fluid by transfer across a boundary between the fracture and matrix. The concentration in the matrix and fracture is assumed to be uniform, and does not vary with distance: from the interface. The model is only a rough approximation of true matrix diffusion, because it ignores concentration gradients lateral to the direction of flow. It may capture salient features of matrix diffusion for our present purposes, however, and maintains the high efficiency of the code.

Transport due to matrix diffusion is proportional to a coefficient $B$. The NEFTRAN manual suggests that $B$ can be approximated from the average fracture spacing, $a$, and effective diffusion coefficient, D':

$$
B=2 D^{\prime} /(a / 2)^{2} .
$$

The model does not account for the additional resistance that could be caused by the presence of surface coatings on the fracture. Since fracture coatings are common, the coefficient $B$ should be reduced to take into account the reduction in transfer caused by these barriers.

\section{No transfer}

At the other extreme, no coupling, the transport in the matrix and fracture pathways would be separate.
For the preliminary analyses of the Phase 1 effort, the effects of matrix diffusion are ignored (the transport strategy is expressed by the "No Transfer" case). The reasons for the choice of this approach are:

1. The approach is conservative. Transfer from the fractures to the matrix would likely retard radionuclide transport.

2. Preliminary screening analyses showed that, for cases where fracture flow was important, the greatest contribution to dose was likely to come from transuranic elements, such as plutonium and americium. These elements are known to have a tendency to form colloids (Thompson, 1989). The molecular diffusion coefficient of colloids is much less than that for dissolved molecules and ions, so matrix diffusion may not be effective (colloid transport is not modeled explicitly in the present exercise, however).

3. Fracture coatings would lead to a diminished effectiveness of both the diffusive transfer of radionuclides and water flow from the fractures to the matrix (Carlos, 1985).

Lacking experimental data on the actual magnitude and rates of matrix diffusion at Yucca Mountain, this process was not included in this initial demonstration. This was believed to be a conservative assumption.

\subsubsection{Spatial variability of flow and transport parameters}

To maintain a high degree of efficiency in the Monte Carlo analyses with NEFTRAN, the complicated, spatially varying repository was represented as four vertical columns, each with a small number of hydrogeologic units through which all the radionuclides must pass, Existing data on tuff layers at the Yucca Mountain site indicate that there are considerable variations in the material properties. Available data do not support long correlation lengths for the transport parameters at the Yucca Mountain site. The data in many cases suggest small spatial correlation, or none at all, on the scale for which they were collected (see Appendix F). Using constant values of transport parameters in the models therefore would be inappropriate. Assuming perfect spatial correlation within a unit could lead to a false conclusion that conditions leading to short travel time would apply over the whole unit. In actuality, short travel time might apply only to a small segment of the column and be countered by the presence of a barrier elsewhere in the column. This applies to a one-dimensional analysis only in which the flow must pass through each segment in series.

Previous studies have recognized the importance of spatial correlation in the assessment of arrival-time distributions. Lin and Tierney (1986) estimated the arrival-time distribution for releases at the Yucca Mountain site by 
calculating the travel time of particles confined to a series of one-dimensional columns that represented the pathways from the repository to the water table. For each column, they varied the correlation length by changing the spatial step size, but keeping the hydraulic properties constant within a given step. They found from this analysis that longer step sizes lead to a wider arrival-time distribution:

"The implicit vertical correlation' length (10 feet) of the baseline case is much less that the thickness of any of the hydrogeologic units. This results in a large number of independent random variables (travel times through each of the calculational elements) which are added together to obtain a travel time through a column. Consequently there is a low probability that fracture flow will occur through a large number of elements in any single column from the disturbed zone to water table. ...

....Longer correlation lengths affect the travel time distribution, especially at the tail ends of the distribution, because of the increasing probability of fracture flow through a significant number of elements that make up each of the columns... These results indicate high sensitivity of the travel time distribution to the as yet undetermined correlation length for velocity in each hydrogeologic unit. Generally the sensitivity of the travel times to the correlation lengths suggest how prudent it is to perform a carefully designed testing program for determining the correlation length of all key parameters influencing flow velocities."

Long correlation lengths led to an overly broad distribution for arrival time, with some very short travel times at the tail of the distribution. At the other extreme, the assumption of zero correlation length led to the conclusion that there is only a single groundwater travel time per column. The aforementioned conclusions apply equally well to radionuclide transport; and therefore, the determination of spatial correlation scales, especially for $\mathrm{k}_{\mathrm{S}}$, was important to this demonstration.

\subsubsection{Effective values of flow and transport coefficients}

The NEFTRAN code simulates flow and transport through a network of connected tubes. For the present case, the flow and transport model was represented by up to six tubes in series, with each tube representing a major hydrogeologic unit; for example, the Topopah Spring welded, unit. Within each tube, the unit was represented by coefficients expressing its physical properties for flow and transport, namely hydraulic conductivity, porosity, cross-sectional area, and the retardation coefficients for each of the radionuclides considered in the present analysis.

As described in Section 9.3.1.2, groundwater transport was assumed to be either entirely in the matrix at low rates of infiltration, or entirely in the fractures at infiltration rates that exceed $\mathrm{k}_{\mathrm{S}}$. Since vertical flow under unsaturated conditions was assumed, the primary factor for determining whether the flow in the present analysis is in the matrix or the fracture was the saturated hydraulic conductivity, $\mathrm{k}_{\mathrm{s}}$. If infiltration exceeded $\mathrm{k}_{\mathrm{S}}$, then the excess flowed in the fractures.

Geostatistical analyses of the $\mathrm{k}_{\mathrm{S}}$ data presented in Appendix $F$ indicate that there was no apparent spatial correlation beyond about 10 meters separation distance, the smallest interval evaluated. As longer correlation lengths are more conservative, $\mathrm{k}_{\mathrm{S}}$ was assumed to be completely correlated at a distance of $\mathrm{L}$ meters. Each tube in the column was represented by a connected series of subtubes, each of length L. Each sub-tube had uniform properties, but was uncorrelated to the next subtube in the series. The value of $\mathrm{k}_{\mathrm{S}}$ for each sub-tube was picked by the Monte Carlo method from the lognormal distribution derived from the available core data presented in Table 9.5.

The analysis was based on the assumption that the flux of infiltrating water passed through each of the sub-tubes. The travel time across each sub-tube depended on whether the flux was greater or less than $\mathrm{k}_{\mathrm{s}}$ :

for $\mathrm{I}>\mathrm{k}_{\mathrm{S}}$,

$$
\begin{aligned}
\Delta \dot{t}_{\mathrm{i}} & =\mathrm{n}_{\mathrm{f}} \Delta \mathrm{l} /\left(\mathrm{I}-\mathrm{k}_{\mathrm{S}}\right) \\
\Delta \mathrm{t}_{\mathrm{ij}} & =\Delta \mathrm{t}_{\mathrm{i}} R_{\mathrm{dj}, \mathrm{f}} ;
\end{aligned}
$$

for $I<k_{S}$,

$$
\begin{aligned}
& \Delta t_{i}=\Phi_{j} \Delta l / I \\
& \Delta t_{i, j}=\Delta t_{i} R_{d j},
\end{aligned}
$$

where $\Delta t_{i}=$ the water travel time for subtube $i$

$\Delta t_{i, j}=$ the travel time for radionuclide $j$ in subtube $i$

$n_{f}=$ the effective porosity of the fractures (taken to be 0.0001 )

$\Phi_{i}=$ the water content of the matrix of subtube $i$

$\Delta \mathrm{l}=\quad$ the length of the subtubes

$I=$ the infiltration rate 
$\mathrm{R}_{\mathrm{dj}}=$ the matrix retardation coefficient for radionuclide $\mathbf{j}$

$R_{\mathrm{dj}, \mathrm{f}}=$ the fracture retardation coefficient for

1. $:$ radionuclide $\mathrm{j}$.

In this analysis, flow was considered to be either totally matrix or totally fracture flow for each sub-tube of length $\Delta \mathrm{l}$. Even though there will be matrix flow in parallel with the fracture flow, in practice the fracture transport properties generally overwhelm the contributions of the matrix flow and can therefore be safely left out of the analysis.

Then, the individual travel times and radionuclide travel times were summed to determine effective values of porosity, $\Phi_{e}$, and retardation coefficients, $R_{\text {dej }}$ for the main tubes representing the hydrogeologic units: ....

$$
\begin{gathered}
\Phi_{e}=\frac{I_{i=1}^{N} \Delta t_{i}}{N \Delta l} \\
R_{d e j}=\frac{\sum_{i=1}^{N} \Delta t_{i j}}{N} \\
\underset{i=1}{N} \Delta t_{i}
\end{gathered}
$$

where $\mathrm{N}$ is the number of sub-tubes.

There are two levels of sampling:

1. Within each sub-tube, a Monte Carlo method was used to sample for the values of $\mathrm{k}_{\mathrm{s}}$, from a lognormal distribution, to determine tube-averaged properties of effective porosity and retardation coefficients, and

2. From realization to realization, the IHS method was used to sample the mean and standard deviation of the logs of $k_{S}$ and the sub-tube length $L$, to represent the uncertainty in their values from borehole to borehole.

\subsubsection{Gas Pathway}

The discussion of this pathway is presented in Appendix D.

\subsubsection{Direct-release (Drilling) Pathway}

The analysis for the direct-release pathway (via exploratory drilling) is presented in Appendix $\mathrm{H}$. The drilling analysis used parameters specific to drilling (i.e., fre- quency of drilling), but all other parametric values were obtained by reading the NEFTRAN input files.

\subsection{Parameters}

This section presents the ranges of parameters used in the liquid and direct pathways. Parameter values used for the gas pathway analysis are presented in Appendix D. Ranges were used by the LHS program to generate data for the source term and transport programs.

\subsubsection{Liquid Pathway}

Using NEFTRAN to simulate the liquid pathway requires the assignment of the following parameters:

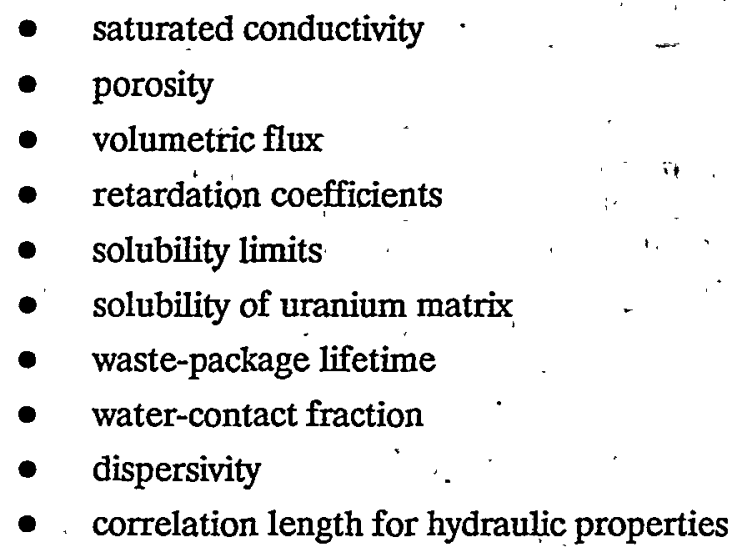

For the liquid pathway analysis, the geologic medium was represented as a series of four vertical columns, each with up to six hydrologic units through which all of the radionuclides must pass. Each segment represented a single hydrogeologic unit. Subroutine GETRV in the NEFTRAN program contained all the definitions of source term and transport parameters necessary to make the code emulate the unsaturated flow and transport model.

Inputs to NEFTRAN were generated using the LHS program, which selects random values from the input parameter ranges. Several known or suspected correlations are provided in Table 9.2. Formal inclusion of correlations between variables should be performed in subsequent phases of this study.

\subsubsection{Sampling Parameters for NEFTRAN' Analysis}

The parameters necessary for this preliminary analysis of the Yucca Mountain repository came from a variety of sources, but primarily, from published DOE reports, including previous performance assessments for the Yucca Mountain and other repositories. Many of these data are highly uncertain; nevertheless, they represented the best data available for the demonstration. Sensitivity analyses 
Table 9.2

Examples of Known and Suspected Correlations

- Retardation coefficients for similar elements

- Solubilities of similar elements

- Solubilities with temperature

- Temperature of canisters with engineered barrier failure time

- Uranium-matrix decomposition (i.e., oxidation, spallation, dissolution) with waste-package failure time

- Leach rate with infiltration rate and fraction of water contacting waste

- Infiltration rate with fraction of water contacting waste form

performed after the calculations pointed out areas where improvement in data would be important in narrowing the ranges of calculated performance. Table 9.3 shows the input ranges and distributions of parameters for the NEFTRAN and other analyses, as generated by the LHS program LHSVAX. The following sections describe the basis for choosing the ranges appearing in Table 9.3.

\subsubsection{Waste-package lifetime}

No readily available models were accessible to assist in the choice of the waste-package lifetime in the unsaturated zone. The NEFTRAN code is simplistic and able to accept only' a single value of lifetime for each run, even though it is likely that waste-package failure would occur in a highly distributed' manner.

Waste-package lifetime will affect the source term in several ways. First, the package must fail for anything to be released at all (although failure does not alone imply that there will be contact between the waste and the water). Second, if the package fails in an essentially dry environment, oxygen from the unsaturated zone will enter, which might allow oxidation of the $\mathrm{UO}_{2}$ to proceed for a fraction of the fuel rods that have defects. The more-oxidized uranium would have increased solubility over the less-oxidized form (Grambow, 1989). Furthermore, oxidation could cause an increase in volume of the pellets, causing splitting of the cladding and spallation of the pellets and thus possibly increasing surface area. Oxidation might also take place in some of the unfailed canisters, because of the presence of small amounts of oxygen, or the dissociation of water caused by ionizing radiation (Reed, et al., 1987). This radiation could form hydrogen peroxide or nitric oxide, which are powerful oxidants. The time-to-failure of the canister would impact directly on fuel oxidation, because the reactions are sensitiye to temperature and radiation, both of which decrease with time:
For the initial phase of this study, it was assumed that the fuel solubility was fixed and not a function of time and temperature. Refinements to account for timedependent oxidation state and temperature may be incorporated into the modei in later phases of this effort. A possible subject for further study would be the potential isolation afforded the waste by the drying out of the rock.

The waste-package failure for the liquid pathway analyses was chosen as normally- distributed, with 'a 0.001 - to 0.999-fractile range for 100 and 1000 years; respectively. For the gas pathway, two distributions were chosen to demonstrate the sensitivity of the release of $\mathrm{C}-14$ to waste-package lifetime (see Appendix D).

\subsection{2: "Solubility of uranium dioxide matrix}

Assuming the canisters and cladding have failed and water penetrates the canister, the bulk of the radionuclide release is likely to be from the dissolution of the uranium dioxide waste matrix. The solubility of the waste will be controlled by several factors. Among the more important factors will be the oxidation state of the fuel, which is, in turn, a function of temperature, oxygen availability, and time. It was assumed that the dissolution rate of the waste was controlled by the rate of disintegration of the uranium dioxide matrix, as characterized by a solubility limit (the disintegration of the fuel matrix may not actually be-limited by solubility, but by the rate of oxidation). For the present case, the solubility has been chosen to be independent of waste-package failure time and temperature and uniformly distributed between 0.0001 and 0.001 grams $\mathrm{UO}_{2}$ per gram of water.

\subsubsection{Dispersivity}

The dispersivity is a measure of the spatial variance in the transport speed, particularly that caused by variability in material properties, which causes the arrivali-time distribution to spread. It is not likely to be an important consideration in most analyses for cumulative releases. The dispersivity was chosen to be normally distributed, between 0.1 and 10 feet, for the 0.001 and 0.999 fractiles, respectively

\subsubsection{Infiltration rate}

One of the key variables in the analysis was the rate of infiltration, which is the main influence on the speed of water movement in the vertical column, as well as the amount of water coming into contact with the waste.

\section{(a) Base-case Infiltration}

At this time, there are no direct measurements of infiltration at Yucca Mountain. Estimates of present day infiltration rates have been calculated from: (1) heat flow measurements, (2) precipitation and elevation data, and 
Table 9.3 Input to Latin Hypercube Sampling Program :

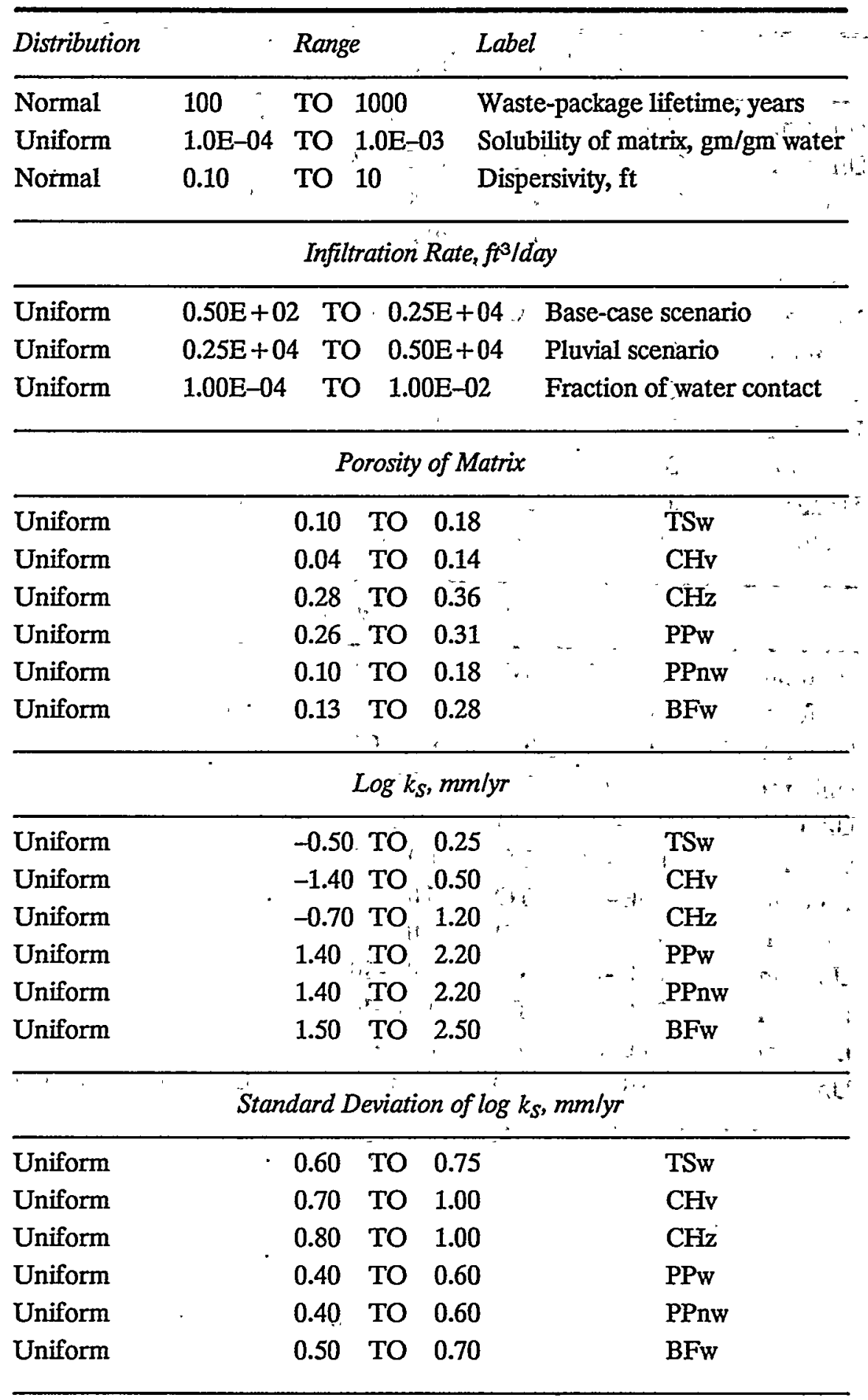


Table 9.3 Input to Latin Hypercube Sampling Program. (continued)

\begin{tabular}{|c|c|c|c|c|c|}
\hline \multicolumn{6}{|c|}{ Retardation Coefficients for Matrix } \\
\hline Uniform & 100 & TO & $1.0 \mathrm{E}+04$ & Am & \\
\hline Uniform & 3000 & TO & $3.0 \mathrm{E}+04$ & $\mathrm{Cm}$ & \\
\hline Uniform & 3 & TO & 2000 & $\mathbf{N i}$ & \\
\hline Uniform & 5 & TO & 100 & $\mathrm{~Np}$ & \\
\hline Uniform & 10 & TO & 100 & $\mathrm{Pu}$. & \\
\hline Uniform & $0.1 E+04$ & TO & $3.5 \mathrm{E}+04$ & $\mathrm{Ra}$ & 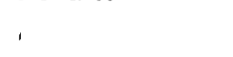 \\
\hline Uniform & $0: 2 \mathrm{E}+04$ & TO & $0.4 \mathrm{E}+04$ & $\mathrm{Sn}$ & \\
\hline Uniform & 5 & TO & 10 & Tc & \\
\hline Uniform & 200 & TO & $0.5 \mathrm{E}+04$ & Th & . \\
\hline Uniform & 5 & TO & 30 & U & \\
\hline Uniform & $1.0^{--}$ & TO & $1.0 \mathrm{E}+04 \cdots$ & $\mathrm{Zr}$ & \\
\hline Uniform & 20.0 & TO & $0.1 \mathrm{E}+04$ & $\mathrm{~Pb}$ & \\
\hline \multicolumn{6}{|c|}{ Solubilities, gm/gm water } \\
\hline Uniform & $2.0 \mathrm{E}-10$ & TO & $2.0 \mathrm{E}-07$ & $\mathrm{Am}$ & \\
\hline Uniform & $1.0 \mathrm{E}-09$ & TO & $2.0 \mathrm{E}-07$ & $\mathrm{Cm}$ & \\
\hline Uniform & $2.0 \mathrm{E}-04$ & TO & $1.0 \mathrm{E}-03$ & $\mathrm{Ni}$ & \\
\hline Uniform & $2.0 \mathrm{E}-05$ & TO & $3.0 \mathrm{E}-04$ & $\mathrm{~Np}$ & \\
\hline Uniform & $5.0 \mathrm{E}-08$ & TO & $3.0 \mathrm{E}-06$ & $\mathrm{Pu}$ & - \\
\hline Uniform & $1.0 \mathrm{E}-08$ & TO & $1.0 \mathrm{E}-07$ & $\mathrm{Ra}$ & \\
\hline Uniform & $5.0 \mathrm{E}-12$ & TO & $5.0 \mathrm{E}-10$ & $\mathrm{Sn}$ & \\
\hline Uniform & 0.5 & TO & 1.0 & $\mathrm{Tc}$ & \\
\hline Uniform & $1.0 \mathrm{E}-11$ & TO & $5.0 \mathrm{E}-10$ & Th & \\
\hline Uniform & $2.0 \mathrm{E}-11$ & TO & $1.2 \mathrm{E}-10$ & $\mathrm{Zr}$ & $"$ \\
\hline Uniform & $1.0 \mathrm{E}-04$ & TO & $2.0 \mathrm{E}-03$ & $\mathrm{~Pb}$ & \\
\hline Üniform & $20.0^{-}$ & TO & 50.0 & Corre & lation length, $\mathrm{ft}$ \\
\hline
\end{tabular}


(3) hydrologic parameters measured from core and within site boreholes. Table 9.4 contains a summary of infiltration estimates cited in the literature: Estimates of infiltration rates range from less than $0.1 \mathrm{~mm} / \mathrm{yr}$ to $10 \mathrm{~mm} / \mathrm{yr}$.

Most of the previous DOE analyses have employed infiltration rates in the range of 0.1 and $0.5 \mathrm{~mm} / \mathrm{year}$. However, because of the considerable uncertainty in the estimates presented in Table 9.4, a considerably wider range of infiltration rates than previous DOE analyses was chosen. For the base case scenario, the infiltration rate was considered to be uniformly distributed between 0.103 and $5.14 \mathrm{~mm} /$ year (500 to 2500 cubic feet per day over the total repository area). This range was considered to be a sufficient representation of available data for the purposes of this demonstration.

\section{(b) Pluvial Scenario}

Czarnecki (1985) estimated infiltration for a future pluvial climate scenario to calculate the potential rise in the water table. Estimates of future precipitation were based on descriptions of paleoclimates, which indicated that annual precipitation 12,000 to 9,000 years before present, in the modeled area, may have been 100 percent greater than modern day annual precipitation. This 100-percent increase with respect to modern-day precipitation was assumed to be the probable maximum increase in the next 10,000 years. Czarnecki doubled the rainfall estimate of Rush (1970), and then multiplied by the percentage of precipitation occurring as recharge that is associated with that higher precipitation range. He assumed that the increased flux across the northern boundary of the modeled area occurred because of the increased precipitation in recharge areas to the north. Vertical infiltration into Fortymile Wash increased because of surface-water runoff from its drainage basin. Czarnecki calculated that increased recharge from a 100-percent increase in annual precipitation would be 13.7 times greater than estimates of modern-day recharge, corresponding to about $7 \mathrm{~mm} /$ year infiltration. He alșo predicted a rise in the water table of 130 meters.

For the purpose of this study, the range of infiltration for the pluvial scenario was chosen to be 5 to $10 \mathrm{~mm} / \mathrm{year}$, with an increase in the water table height of 100 meters.

\subsubsection{Fraction of water contacting waste}

The ratio of water infiltrating the site to the water actually coming into contact with the waste was characterized as a constant. Simple calculations were performed to estimate the fraction of the waste canisters exposed to purely vertical infiltration by taking the ratio of the cross-sectional area of the canisters to the total area of land surface projected by the repository. This ratio was approximately equal to 0.00078 . In most cases, infiltrating water could flow around the canisters because of the matrix suction of the unsaturated rock, so this figure derived from this simple approach does not capture the true nature of water contact.

DOE plans to emplace the canisters in the host rock in a manner that it considers would reduce the likelihood of water coming into contact with the waste. These precautions include vertical storage and an air gap between the canister and the rock walls. Furthermore, DOE considers that the heat generated by the waste may create a significant zone of dry rock around the canisters, thus isolating them until cooling of the rock at a later time allows water to rewet the rock (SCP, Section 8.3.5.9). Water may still come into contact with the canisters by other mechanisms, including:

1. Infiltrating water flowing through fractures and dripping onto the canisters

2. Loss of the air gap caused by failure of the emplacement holes through mechanical and thermal stresses, or mineral and sediment infilling

Two additional and potentially important sources of water could be (1) lateral inflows from areas of perched water, and (2) liquid water circulation caused by heatdriven evaporation and condensation. Lateral inflows were assumed unlikely to affect more than a few of the canisters, since the water necessary for this phenomenon to be viable would be diverted from the vertical infiltration available for all canisters. If such a diversion were possible, some canisters might receive a greater share of the overall infiltration at the expense of the remaining canisters being exposed to le'ss water. Liquid water circulation caused by heat is potentially important, and is discussed further in Section 5 of this report, "Source Term."

For this preliminary analysis, the water contact fraction was chosen to be 0.002 to 0.01 , based on the assumed wetting of a small fraction of the canisters.

\subsubsection{Saturated hydraulic conductivity}

Water flow in the unsaturated fractured rock could proceed through both the matrix of the rock at low rates of infiltration or through the fractures and the matrix at higher rates of infiltration. The switchover from matrix flow to flow in the fractures may be related to the saturated hydraulic conductivity of the rock matrix $\left(\mathrm{k}_{\mathrm{S}}\right)$. Statistical evaluation of the data, presented in Appendix $F$, indicated that $\mathrm{k}_{S}$ was lognormally distributed. Table 9.5 summarizes the available data on saturated hydraulic conductivities from rock cores at the Yucca Mountain site in terms of $\log$ means and standard deviations, where there are sufficient data available. 
Table 9.4 - Infiltration Estimates

\begin{tabular}{|c|c|c|c|}
\hline Estimate & Location & Methodology & Source \\
\hline $4 \mathrm{~mm} / \mathrm{yr}$ & Yucca Mt. & $\begin{array}{l}\text { precipitation. and } \\
\text { elevation data }\end{array}$ & $\begin{array}{ll}\text { Rice, } & 1984 \\
\text { Rush, } 1970 \\
\end{array}$ \\
\hline $1-10 \mathrm{~mm} / \mathrm{yr}$ & Yucca Mt. & drill hole thermal data & Sass; 1982 \\
\hline $2 \mathrm{~mm} / \mathrm{yr}$ & Yucca Flat & hydrogeologic parameters & winograd, 1981 \\
\hline $0.5 \mathrm{~mm} / \mathrm{Yr}$ & Yucca Mt. & $\begin{array}{l}\text { precip. and elevation } \\
\text { data }\end{array}$ & Czarnecki, 1985 \\
\hline$=0.5 \mathrm{~mm} / \mathrm{yr}$ & Yucca Mt: & $\begin{array}{l}\text { core and insitu } \\
\text { hydrogeologic parameters }\end{array}$ & wilson, $1985 \%$ \\
\hline $0.5 \mathrm{~mm} / \mathrm{yr}$ & Yucica Mt. & maximum for matrix $\mathrm{k}_{\mathrm{s}}$ data & Sinnock, 1984 \\
\hline $0.1-0.5 \mathrm{~mm} / \mathrm{yr}$ & USW Uz-1 & $\begin{array}{l}\text { core and insitu } \\
\text { hydrogeologic parameters }\end{array}$ & Montezar, 1985 \\
\hline $10^{-7}-0.2 \mathrm{~mm} / \mathrm{yr}^{-}$ & USW UZ-1 & $\begin{array}{l}\text { core and UsW UZ-2 insitu } \\
\text { hydrogeologic parameters }\end{array}$ & Montezar, 1984 \\
\hline
\end{tabular}


Table 9.5

Mean and Standard Deviation (S.D.) of $\log \mathbf{k}_{S}$

\begin{tabular}{|c|c|c|c|c|c|}
\hline Unit & $\therefore$ & i & $\underset{\mathrm{mm} / \mathrm{yr}}{\text { Mean of } \log \mathrm{k}_{\mathrm{S}}}$ & & $\begin{array}{l}\text { S.D. of } \log _{\mathrm{S}} \\
\mathrm{mm} / \mathrm{yr}\end{array}$ \\
\hline BFnw & & ? & $\begin{array}{l}2.22 \\
1.38 \\
1.71\end{array}$ & & $\begin{array}{l}\overline{-} \\
\overline{0} .59\end{array}$ \\
\hline BFw & & & 2.08 & & - \\
\hline CHny & $\because$ & 1 & $\begin{array}{r}-1.32 \\
0.47 \\
0.07\end{array}$ & & $\begin{array}{l}- \\
\overline{-}\end{array}$ \\
\hline $\mathrm{CHnz}$ & , & & $\begin{array}{r}1.16 \\
-0.65\end{array}$ & & $\overline{0} .87$ \\
\hline $\mathrm{PP}$ & & & $\begin{array}{l}1.44 \\
2.09\end{array}$ & . & $=$ \\
\hline TSw & $\because$ & , & $\begin{array}{r}0.22 \\
-0.45\end{array}$ & & $\begin{array}{l}0.72 \\
0.61\end{array}$ \\
\hline
\end{tabular}

\subsubsection{Spatial correlation of saturated hydraulic
conductivity}

Geostatistical analyses of the $k_{S}$ data, presented in Appendix $\mathrm{F}$, indicated that there was no apparent spatial correlation of the core data on $\mathrm{k}_{\mathrm{s}}$ above the minimum separation distance of 10 meters used in the analyses. Since larger correlation scales are conservative, a correlation scale between 20 and 50 feet was assumed. There were insufficient data to determine the distribution of the mean and standard deviation of $\mathrm{k}_{\mathrm{S}}$, so it was assumed that the mean and the standard deviation of $\log \mathrm{k}_{\mathrm{S}}$ were uniformly distributed. The mean, standard deviation and correlation length of $\mathrm{k}_{\mathrm{S}}$ were used to choose representative hydraulic coefficients for each hydrogeologic unit as described in Section 9.3.1.

\subsubsection{Porosity}

There are probably more porosity data available from core taken at the Yucca Mountain site than for any other type of data used in this study. As used in this study, water velocity and radionuclide transport speed in the matrix were tied closely to the average value of porosity for the columns. The porosity ranges were chosen from available data averaged over each unit. There were insufficient data to determine the distributions of the average properties, so the averages were assumed to be uniformly distributed. Representative values of porosity for each hydrogeologic unit were sampled from the distribution of arithmetic mean porosities shown in Table 9.6.
Table 9.6 Mean Porosity for Hydrogeologic Units

\begin{tabular}{|c|c|c|c|c|}
\hline Unit & & Arithmetic & c Meañ & Porosity \\
\hline BFnw & $\begin{array}{l}\cdot: \\
\cdots\end{array}$ & & $\begin{array}{l}0.20 \\
0.22 \\
0.25\end{array}$ & $\therefore$ \\
\hline BFw & , &. & $\begin{array}{l}0.13 \\
0.28\end{array}$ & \\
\hline $\mathrm{CHn}$ & & $\begin{array}{l}\ddots \\
\ddots\end{array}$ & $\begin{array}{l}0.36 \\
0.20 \\
0.28 \\
0.34 \\
0.29\end{array}$ & \\
\hline PPn & & & 0.29 & \\
\hline PPw & $\because$ &.$\quad \vdots$ & $\begin{array}{l}0.31 \\
0.31 \\
0.26\end{array}$ & 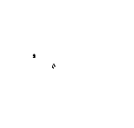 \\
\hline TSw & . & 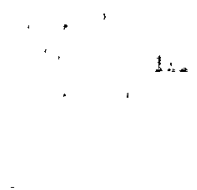 & $\begin{array}{l}0.11 \\
0.13 \\
0.10 \\
0.11 \\
0.18\end{array}$ & \\
\hline
\end{tabular}

\subsubsection{Brooks-Corey coefficients}

The Brooks-Corey coefficients are used to determine the fraction of saturation fora given infiltration rate, as described in Section 9.3. The values used in the demonstration were taken from Lin and Tierney (1986) and are presented in Table 9.7.

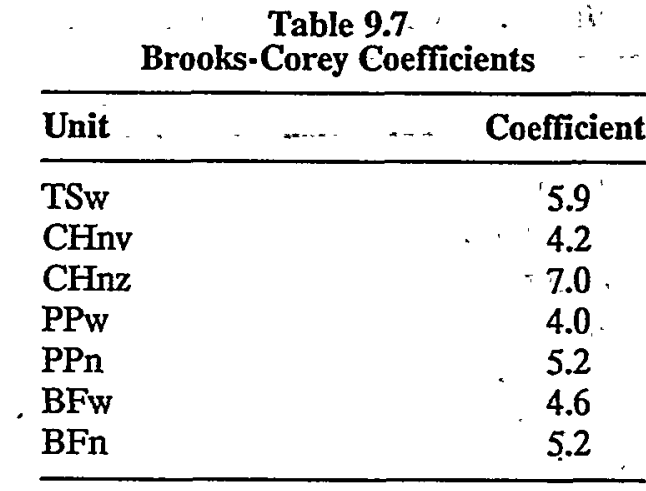

\subsubsection{Retardation coefficients}

Values of retardation coefficients for the matrix were chosen to reflect reported values for batch and column tests performed. For the key radionuclides plutonium and americium, values were chosen at the low end of the range to account partially for data that indicate that these substances do not behave simply, tend to form colloids, and may be difficult to predict under repository conditions (Thompson, 1989). However, it should be noted that much of the data in column experiments that indicated low retardation for some elements was collected for flow 
rates 3 to 4 orders of magnitude greater than those used in this demonstration, and therefore may be pessimistic. Furthermore, the-results of sensitivity studies presented in Section 9.5 indicate that, in the present study, retardation coefficients for plutonium and americium are relatively unimportant, indicating that factors such as low solubility and long half-life may be more important than retardation for these nuclides. Values used in this study are typical of those used previously in Yucca Mountain performance studies ( $\mathrm{Lin}, 1986)$. Although most of the retardation coefficients are sampled by LHS from the distributions presented in Table 9.3, the retardation coeffients for a few of the elements were taken to be constants. These retardation coefficients are 1.0 for iodine, 10,000 for cesium, 1,000 for strontium, and 1.0 for carbon.

Retardation coefficients for the fractures were taken from the study by Lin (1986), and are orders of magnitude smaller than the matrix retardation coefficients. The values of retardation coefficients for fractures were not sampled, but remained fixed for all realizations. The values used are given in Table 9.8. For both the matrix and fractures, no distinction was made for the variation in retardation between different hydrogeologic units. However, those units that have low values of saturated hydraulic conductivity will tend to have lower effective retardation coefficient values because of the greater proportion of the flow to be expected in the fracture zone (as calculated by the procedure presented in' Section 9.3.1.5).

Table 9.8

Retardation Coefficients for Fractures

\begin{tabular}{|c|c|c|c|c|c|c|c|}
\hline Element & $\cdots$ & & & $\cdots$ & $\cdots$ & $\mathbf{R}_{\mathbf{d f}}$ & \\
\hline Curium - & $\cdots$ & & & - & & 1.4 & \\
\hline Plutonium & & & & & & 1.1 & \\
\hline Uranium & & & & & & 1.0 & - \\
\hline Americium & & & & & & 1.4 & \\
\hline Neptunium & & & & & & 1.0 & \\
\hline Thorium & & & & & & 2.2 & \\
\hline Radium & & & & & & 2.8 & \\
\hline Lead & & & & & & 1.0 & \\
\hline Cesium & & & & & • & 100 & \\
\hline Iodine & & . & & $\therefore$ & & 1.0 & - ar. \\
\hline $\operatorname{Tin}$ & & & & & $\therefore$ & 1.3 & $=$ \\
\hline Technetium & & & & . & : & 1.1 & in \\
\hline Zirconium & & & & l: & & $2: 0$ & $\cdot$ \\
\hline Strontium & & & & & & 10.0 & $=$ \\
\hline Nickel & & & & & & 1.2 & . . \\
\hline Carbon & & & & & & 1.0 & $\ldots$ \\
\hline
\end{tabular}

\subsubsection{Solubilities}

Values for the solubilities of radionuclides were taken primarily from DOE references, including several preliminary performance assessments. They reflect those reported in previous performance assessments from Yucca Mountain (Lin, 1986).

\subsubsection{Direct-Release (Drilling) Pathway}

The drilling program was developed to calculate the consequences from an expected number of boreholes intercepting the repository (see Appendix $\mathrm{H}$ ). The following values were needed: drilling rate, size and number of waste packages, area of repository, time of drilling, and radius of the borehole. Additionally, the following data from the liquid pathway were used: time of waste-package failure, volumetric flux, water contact fraction; and solubility limits (these values were discussed in the previous section and will not be discussed here).

Based on conceptual repository designs, the dimensions used for the repository system were: area of repository = 5.1. square $\mathrm{km}$, number of waste packages $=18,000$, borehole radius $=6 \mathrm{~cm}$, waste-package radius $=0.34 \mathrm{~m}$, and waste-package length $=4.8 \mathrm{~m}$. The time for commencement of drilling was set to a arbitrary value of 100 years, and the drilling rate to .0003 drillings per square $\mathrm{km}$ per year, based on EPA average drilling rates (EPA, 1985).

\subsection{Sensitivities and Uncertainties for Liquid-Pathway Analysis}

\section{5:1 Introduction}

This section covers the sensitivity and uncertainty analyses of the liquid-pathway calculations on a scenario by scenario basis. It does not cover either the drilling or gas pathway analyses. The CCDFs presented in this section for the base-case and pluvial scenarios take into account the uncertainty in the values of the coefficients for each scenario, but not the scenario probabilities. The sensitivity to variations in parameters using rank regression and ad hoc variations of single parameters (including those parameters relating to the NRC guidelines of $10 \mathrm{CFR}$ 60.113) are also presented. Total system results; which incorporate the probabilities of the scenarios, are covered in Section 9.6. Formal sensitivity and uncertainty analyses on these total system results were not performed.

\subsubsection{Statistical Uncertainty Analysis}

An important part of conducting a performance assessment for an HLW repository is quantifying the uncertainties associated with the probabilities of occurrence of credible scenarios and those associated with the offsite 
and onsite consequences (both radiological and nonradiological).

Many risk and environmental impact assessments apply single or best-estimate values for model parameters and assert that these valuations are reasonable and conservative (i.e., lead to overpredictions) without quantifying the degree of conseryatism inherent in the assessments. $A$ variety of techniques is available, to quantify the uncertainty in complex models for assessing radiological impact on man and the environment that may include nonlinearities and time-varying phenomena. These include: the Monte Carlo method (Helton, 1961); fractional factorial design (Cochran, 1963); LHS (Cranwell and Helton, 1981; Iman and Conover, 1979; McKay, et al., 1979); response surface (Meyers, 1971); differential sensitivity analysis (e.g., adjoint (Baybutt, et al., 1981, Oblow, 1978, Cacuci, et al., 1980)); and Fast Probabilistic Performance Assessment (CNWRA, 1988) methodologies. A preferred technical approach would be flexible, economical to use, easy to implement, provide a capability to estimate an output distribution function, and rank input variables by different criteria.

\subsubsection{Latin Hypercube Sàmpling (LHS) ' ' ' " \\ In this study, the.LHS scheme was chosen to be used on the flow and transport model in the performance assess- ment of the HLW repository. The advantages and proper- ties of the LHS techniques are:}

- The full range of each input variable is sampled, and correlation coefficients between all pair-wise input variables can be specified.

- It provides unbiased estimates of the parameters (means and variances) of cumulative distribution functions and means for model output, under moderate assumptions.

The LHS method is a member of the class of sampling techniques that includes Monte Carlo and stratified random sampling. Several risk assessments for nuclear waste repositories (Campbell, et al., 1979) have applied LHS techniques. Furthermore, LHS has been applied to the model for atmospheric transport of reactor accident consequences and'recently used for the severe reactor accident calculations in NUREG-1150 (NRC, 1989).

Different'types of uncertainty associated with the modeling of physiochemical processes can be distinguished-in particular:

- The statistical uncertainty due to inherent random nature of the processes, and

- The state of (perhaps "lack-of") knowledge uncertainty.
This latter state-of-knowledge uncertainty may be subdivided further into model and parameter uncertainty. $\mathrm{Pa}$ rameter uncertainty is because of insufficient knowledge about what the input to the code should be. Modeling uncertainty is because of simplifying assumptions and the fact that the models used may not accurately model the true physical process. This study deals primarily with $\mathrm{pa}_{-}$ rameter uncertainty.

As shown in Table 9.9, a set of key parameters in the model under study must be identified first. For each chosen variable, a set of quantitative information is developed regarding the range of variation and probability distribution, as well as correlations among the variables:

Table 9.9

Steps to Perform Uncertainty and Sensitivity Analysis

1. Specify Maximum-Minimum Ranges of Probabilities

2. Specify Correlation Matrix

3. Run Latin Hypercube Sampling Code

4. Run Source Term and Flow and Transport Models

5. Statistical Analysis (fitting distributions; regressión analysis; graphical display and analysis) ,

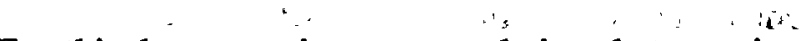

For this demonstration, no correlations between input variables were used. The data input to the LHS program is provided in Table 9.3, which shows the distribution and range of input for each variable. The basis for choosing these inputs was discussed in Section 9.4. This information was used as input to the LHS code (Iman and Shortencarrier, 1984; Iman and Davenport, 1.984). LHS is used to generate what is called a design matrix. Specifically, if $\mathrm{N}$ computer runs are to be made with $\mathrm{k}$ parameters under study, the design matrix has dimensions Nx k. Each row of this matrix contains the input valuations of each of the c chosen $\mathrm{k}$ parameters (independent variables) for the $\mathrm{N}$ computer runs. The sample size $N$ is specific to the problem being investigated (Iman, '1980). Appendix D presents a sensitivity study on the sample size for one scenario.

\subsubsection{Ad Hoc Sensitivities}

In this section, results of the NEFTRAN runs for the base-case and pluvial liquid-pathway scenarios are presented, with the intent of demonstrating the effects of individual variables on the resultant cumulative radionuclide releases to the accessible environment. . . ....

The NEFTRAN computer code, as modified for this demonstration, calculated cumulative releases, for the basecase scenario, over either 10,000 years or 100,000 years, 
and for the pluvial scenario, over $10 ; 000$ years: For each simulation, a list of 47 variables was generated, using LHS. The list of variables for each simulation is called a "vector." The input constants, ranges and distributions for generating the vectors are presented in Table 9.3:

\subsubsection{Sensitivity to infiltration}

Figures 9.5 and 9.6 show the resultant conditional CCDFs for the base-case scenario at 10,000 and 100,000 years, respectively. Also plotted on these figures are CCDFs composed only from vectors having infiltration rates less than limits set at 2.0 or $1.0 \mathrm{~mm} / \mathrm{yr}$, to demonstrate the particular significance of this parameter to repository performance.

The great sensitivity to infiltration rate can be partially explained by the next two figures. Figures 9.7 and 9.8 show the CCDFs for the base-case scenario at 10,000 and 100,000 years, respectively, comparing the contribution of Column $\mathrm{D}$ to the contribution from all four columns. Column D contains just 10 percent of the waste, but has the shortest pathway to the water table. In addition, Column D contains just two units; the Topopah Spring welded and Calico Hills zeolitic. Both of these units have relatively low, saturated hydraulic conductivities, which would make them prone to fracture flow for higher infiltration rates. Fracture flow can lead to short radionuclide travel times along the liquid pathway, because the overall radionuclide retardation is low. Figure 9.7 shows the effect most dramatically, as virtually all the contribution to the high-consequence portion of the curve is caused: by Column D, alone; retarded radionuclides have not yet started to arrive from the other columns. Travel times through the other three columns. would be too long to contribute much to the CCDF within 10,000 years. Figure 9.8 shows that more of the contribution to the CCDF comes from the other three columns over the 100,000 -year period, because the long-lived radionuclides begin to arrive.

Figure 9.9 shows the CCDF for the pluvial scenario. In this case, the water table is shallower and infiltration rates are higher than for the base-case 'scenario, - so radionuclide travel times are shorter for all columns. A relatively larger portion of the cumulative radionuclide releases comes from Columns $A, B$, and $C$ than in the base-case scenario. These two scenarios are not directly comparable, however, because long computer-run times led to the necessity of reducing the number of vectors from 500 to 98 for the pluvial scenario. It should also be pointed out that the 98 vectors for the pluvial case were generated from a truncated run originally intended to contain 200 vectors. The desirable property of statistical independence in the LHS procedure can only be ensured when the final sample size matches the intended sample size. When this is not the case, as with the pluvial scenario,' statistical independence cannot be ensured, as the potential for spurious correlations between parameters is much greater.

\subsubsection{Sensitivity Analysis Using Regression}

As shown in Täble 9.9, following the execution of the LHS program and the source term and flow and transport models, the next step involves performing a sensitivity analysis on the calculated results. The aim of this analysis 'is to determine and quantify the relative contributions of a particular variable toward the output variability. Sensitivity analyses can be very fruitful in preliminary studies such as this one, since-sensitivity analyses can help to identify which parameters and models should be refined in future studies. In addition, sensitivity analyses may allow the analyst to check his intuition about the importance of the parameters and phenomena of the model.

Sensitivity can be determined by performing step-wise linear regression analyses on either the raw results of the model analysis (i.e., the EPA ratios) or the ranks of the raw results (i.e., replacing the "raw" data values with their ranks). Ranks may be preferred when highly nonlinear relationships are present between the model outputs and inputs, but the correlations obtained have less significance than those obtained from the raw data. Both graphical analyses and statistical-distribution fitting procedures may also be useful in identifying patterns in the data. The present report shows only the regression analyses on raw results; i.e., the EPA release ratios.

The sensitivity of the cumulative release was analyzed for several cases using a modified version of the STEPWISE program from SNL (Iman, 1980). The STEPWISE program was modified to read the data file of input vectors generated by the LHS procedure and the combined results for Columns A through D generated by NEFTRAN for those input vectors. The regression coefficients are presented in Table 9.10 for both the base-case and pluvial scenarios. There were 500 vectors for the base-case scenario, but because of excessively long computer-run times, only 98 vectors for the pluvial scenario. The paucity of vectors led to more equivocal results for the pluvial scenario. Only the most significant regresșion coefficients or, in some cases, those regression coefficients pointing to an apparent lack of sensitivity to particular parameters.

The sensitivity analyses proved to be very revealing, both for the sensitivities to some parameters and apparent lack of sensitivities to others. The parameters consistently influencing to the EPA ratio were: contact fraction, infiltration rate, solubility of the matrix, and saturated hydraulic conductivity of the Calico Hills vitric unit. Of these, high infiltration rates, combined with the low $\mathrm{k}_{\mathrm{s}}$, led to radionuclide release along fast fracture flow pathways with low retardations in Column D, which contributed most of the high-consequence releases in the base-case scenario. 
Table 9.10

Regression of Liquid Pathway Cumulative Releases (Raw data correlations)

\begin{tabular}{|c|c|c|c|}
\hline Variable & $\begin{array}{l}\text { Base-case } \\
10,000 \text { yrs }\end{array}$ & $\begin{array}{l}\text { Base-case } \\
100,000 \text { yrs }\end{array}$ & $\begin{array}{l}\text { Pluvial } \\
10,000 \text { yrs }\end{array}$ \\
\hline W.P. Lifetime & -0.045 & -0.049 & - \\
\hline Solubility $\mathrm{UO}_{2}$ & 0.09 & 0.13 & 0.32 \\
\hline Infiltration & 0.10 & 0.31 & 0.23 \\
\hline Contact Fraction & - & 0.18 & 0.44 \\
\hline Mean $\log \mathrm{k}_{\mathrm{S}} \mathrm{TSw}$ & - & -0.11 & - \\
\hline $\begin{array}{l}\text { Mean log, } \mathrm{k}_{\mathrm{S}} \\
\mathrm{CHnz}\end{array}$ & -0.14 & -0.22 & -0.28 \\
\hline $\begin{array}{l}\text { Retardation Coeff. } \\
\mathrm{Cm}\end{array}$ & - & - & -0.20 \\
\hline $\begin{array}{l}\text { Retardation Coeff. } \\
\mathrm{Pu}\end{array}$ & $\ddot{-}$ & -0.23 & -0.22 \\
\hline $\begin{array}{l}\text { Retardation Coeff. } \\
\text { Ra }\end{array}$ & - & - & 0.18 \\
\hline Solubility Cm & - & - & 0.17 \\
\hline Solubility $\mathrm{Pu}$ & - & - & -0.27 \\
\hline $\begin{array}{l}\text { Correlation } \\
\text { Length }\end{array}$ & 0.11 & - & - \\
\hline
\end{tabular}

\subsubsection{Average Importance of Radionuclides}

The average importance by radionuclide to the cumulative radionuclide release for the scenarios was calculated by taking their average contribution to the EPA ratio for all vectors. Table 9.11 shows this contribution for the base-case scenario at 10,000 and 100,000 years, and the pluvial scenario at 10,000 years. In addition, the base-case scenario results are broken down by infiltration rate, including only those vectors with rates less than $1.0 \mathrm{~mm} / \mathrm{yr}$, $2.0 \mathrm{~mm} / \mathrm{yr}$, or $5.14 \mathrm{~mm} / \mathrm{yr}$, to demonstrate the sensitivity of the results to this parameter. The isotopes $\mathrm{Pu}-239$ and $\mathrm{Pu}-240$ stand out as the most important contributors to the EPA ratio because of their large inventory in the source term, long half-lives and potentially low retardation in the rock. Nearly all the contribution of these radionuclides comes from the initial source-term inventory rather than from the chain decay of heavier radionuclides (e.g., Am-243). Other radionuclides are important in a few cases. For example, I-129 appears for the 100,000year base-case scenario, for infiltration rates of less than $1.0 \mathrm{~mm} / \mathrm{yr}$, because it has an exceedingly long half-life. The isotopes I-129, C-14, and Tc-99 would take on high relative importance if the groundwater flow were always restricted to matrix, rather than fracture, flow. This would have been the situation for the base-case scenarios, ex- cept for the influence of fracture flow in Column D, as the saturated conductivities of most of the. hydrogeologic units in the other columns was sufficient to ensure retention of most of the significant, but retarded, radionuclides.

\subsubsection{Sensitivity to NRC Performance Criteria}

NRC defines a set of performance criteria for particular barriers in 10 CFR 60.113:

"60.113(a)1(ii)(A) Containment of HLW within the waste packages will be substantially complete for a period to be determined by the Commission ... that such period shall not be less than 300 years nor more than 1,000 years after permanent closure of the geologic repository; ...."

“60.113(a)1(ii)(B) The release rate of any radionuclide from the engineered barrier system following the containment period shall not exceed one part in 100,000 per year of the inventory of that radionuclide calculated to be present at 1,000 years following permanent closure,...."

"60.113(a)2 The geologic repository shail be located so that pre-waste-emplacement groundwater travel time along the fastest path of likely radionuclide travel from the disturbed zone to the accessible environment shall be at least 1,000 years ...."

These limitations imposed by NRC have the intent of providing a set of criteria for the repository independent of the EPA release limits specified in 40 CFR Part 191, and prevent reliance on a single barrier to the release of ,radionuclides to the accessible environment.

\subsubsection{Effects of NRC performance criteria on CCDFs}

The relationship between compliance with the NRC " standards and the outcome of the performance-assessment calculations was examined in terms of compliance with the cumulative release limits. This was not intended to be a demonstration of the effectiveness or lack of effectiveness of the NRC subsystem performance criteria, but was instead a demonstration of the usefulness of performance-assessment modeling in making future decisions on regulations. The conditional CCDF for the basecase scenario was recalculated by using the original set of 500 input vectors and output releases, but screening out those vectors that did not comply with the NRC criteria stated previously: The subset of vectors that "passed" the criteria were then used to plot a CCDF and compared to the CCDF plotted from all of the vectors for the basecase scenario, unconditionally. The screening procedure is described next: 
Table 9.11 - Average Importance of Radionuclides to EPA Release Limits ${ }^{1}$

Time Infiltration

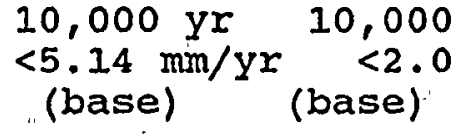

\section{Radionuclide}

\begin{tabular}{|c|c|c|c|c|c|c|c|}
\hline $\mathrm{Am}-241$ & 0.077 & $0.061=$ & 0.069 & & 0.014 & 0.017 & 0.069 \\
\hline Am-243 & 0.014 & 0.016 & 0.016 & - & 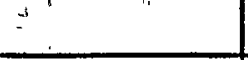 & 0.013 & \\
\hline $\mathrm{C}-14$ & 0.094 & 0.013 & & 0.015 & 0.031 & 0.061 & \\
\hline$I-129$ & 0.05 & - & & - & 0.037 & 0.229 & \\
\hline$N p-237$ & 0.01 & $1-$ & $\therefore \therefore \quad \therefore$ & 0.015 & $\therefore 0.014$ & $\therefore:$ & \\
\hline $\mathrm{Pu}-238$ & 0.01 & $\because$ & $\because \because \quad \therefore$ & $\therefore$ & $\therefore$ & $\vdots$ & $E$ \\
\hline Bu-239 & $\quad 0.39$ & 0.438 & $\therefore 0.438$ & 0.726 & $0.589^{\circ}$ & $0.18 \overline{3}$ & 0.543 \\
\hline Pu-240 & 0.41 & 0.463 & 0.465 & 0.069 & 0.281 & 0.142 & 0.459 \\
\hline $\mathrm{Pu}-241$ & $\therefore 0.02$ & $\therefore$ & $\vdots$ & & & & $\cdot$ \\
\hline $\mathrm{Pu}-242$ & $\therefore \quad: \quad \Xi$ & $\therefore$ & $i$ & 0.024 & 0.011 & & . \\
\hline$T c-99$ & . & $\because$ & & 0.016 & 0.022 & 0.013 & $!$ \\
\hline$T h-230$ & $\therefore \therefore$ & - & 1 & & 0.011 & 0.011 & \\
\hline $\mathrm{U}-233=$ & $\therefore:$ : & $\therefore$ & ' & 0.012 & & & 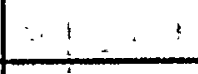 \\
\hline$=\quad U-234$ & 0.02 & & $\therefore$ & 0.048 & 0.034 & 0.010 & \\
\hline $\mathrm{U}-236$ & - & $\because$ & & 0.026 & 0.018 & & \\
\hline$U-238$ & 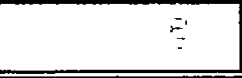 & & & 0.024 & 0.018 & & \\
\hline
\end{tabular}

\footnotetext{
'only presented if greater than 0.01 contribution. Bold if greater than 0.05 .
} 


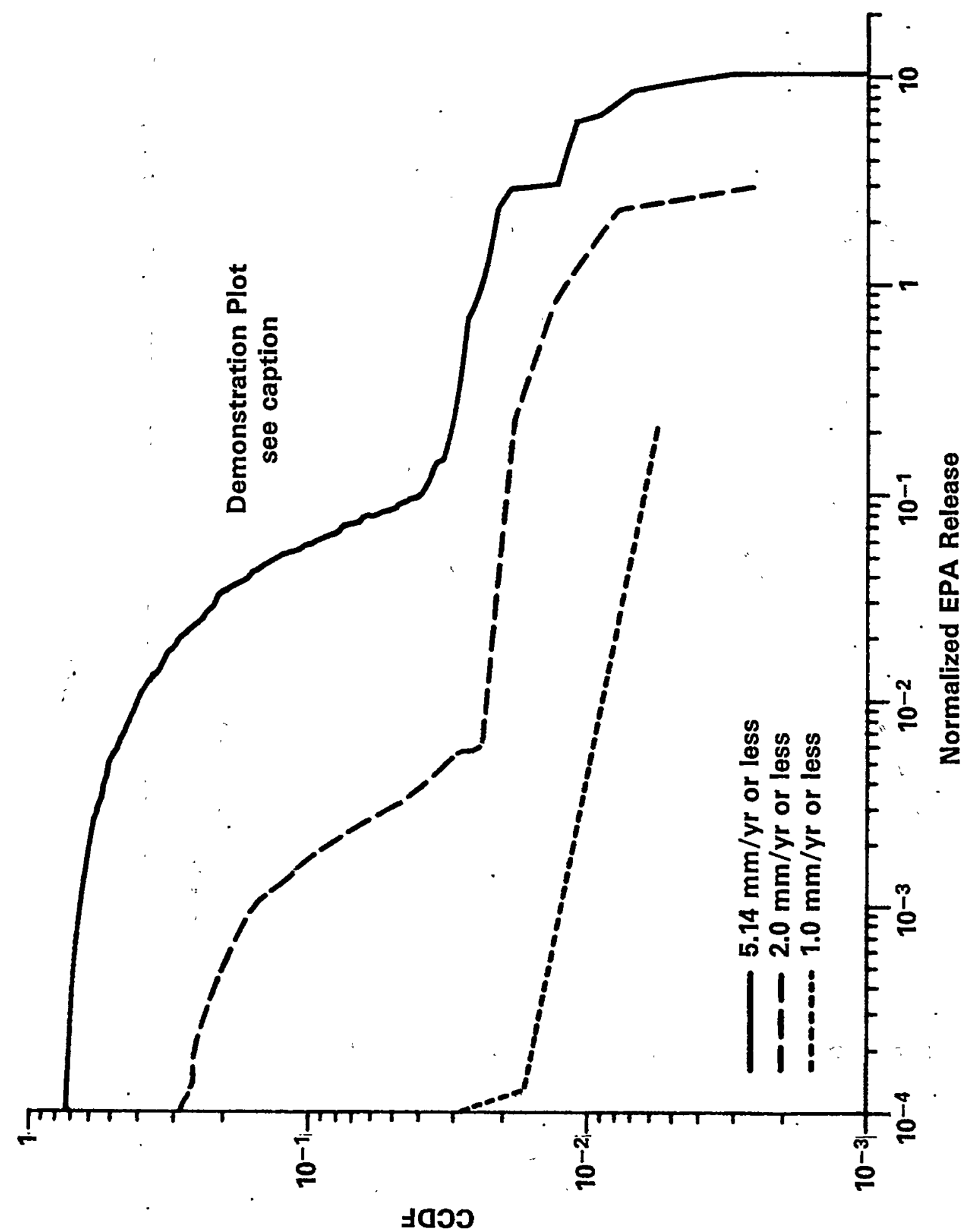

Figure 9.5 CCDF for Base Casé; 500 Vectors, 10,000 Years. This graph presents results from an initial demonstration of staff capability to conduct a performance assessment. The graph, like the demonstration, is limited by the use of many simplifying assumptions and sparse data. 


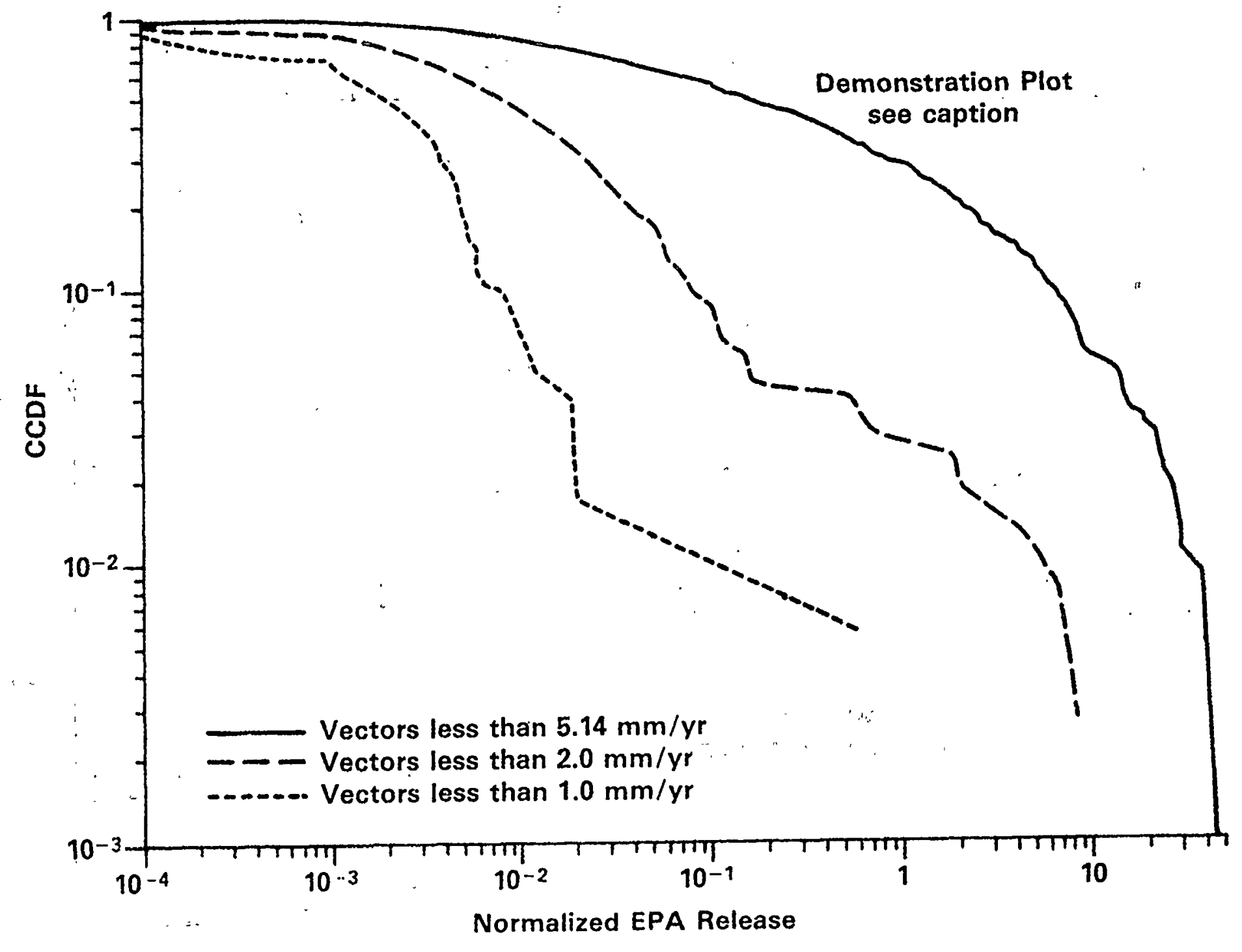




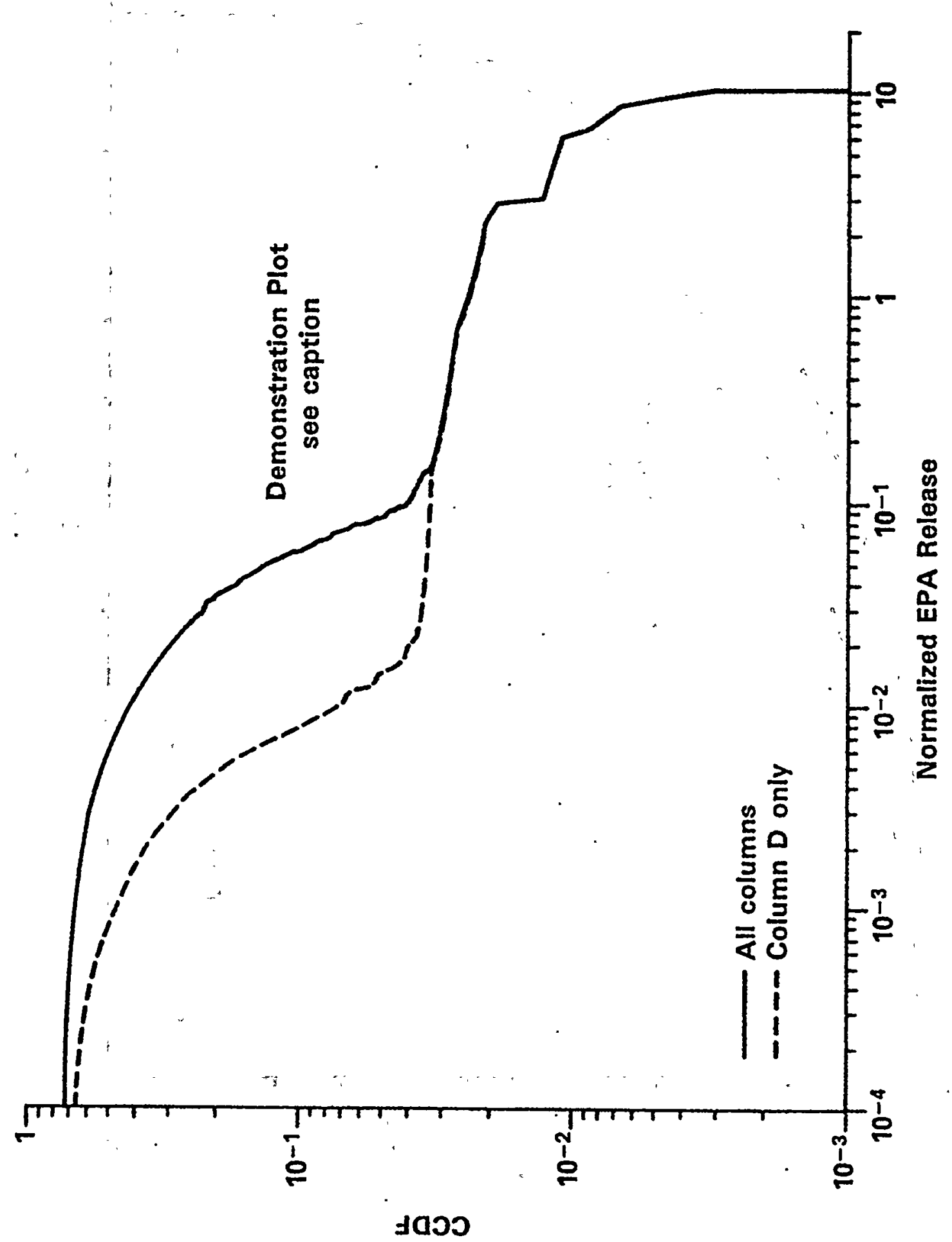

Figure 9.7 CCDF for 100,000 Years, 500 Vectors. This graph presents results from an initial demonstration of staff capability to conduct a performance assessment. The graph, like the demonstration, is limited by the use of many simplifying assumptions and sparse data. 

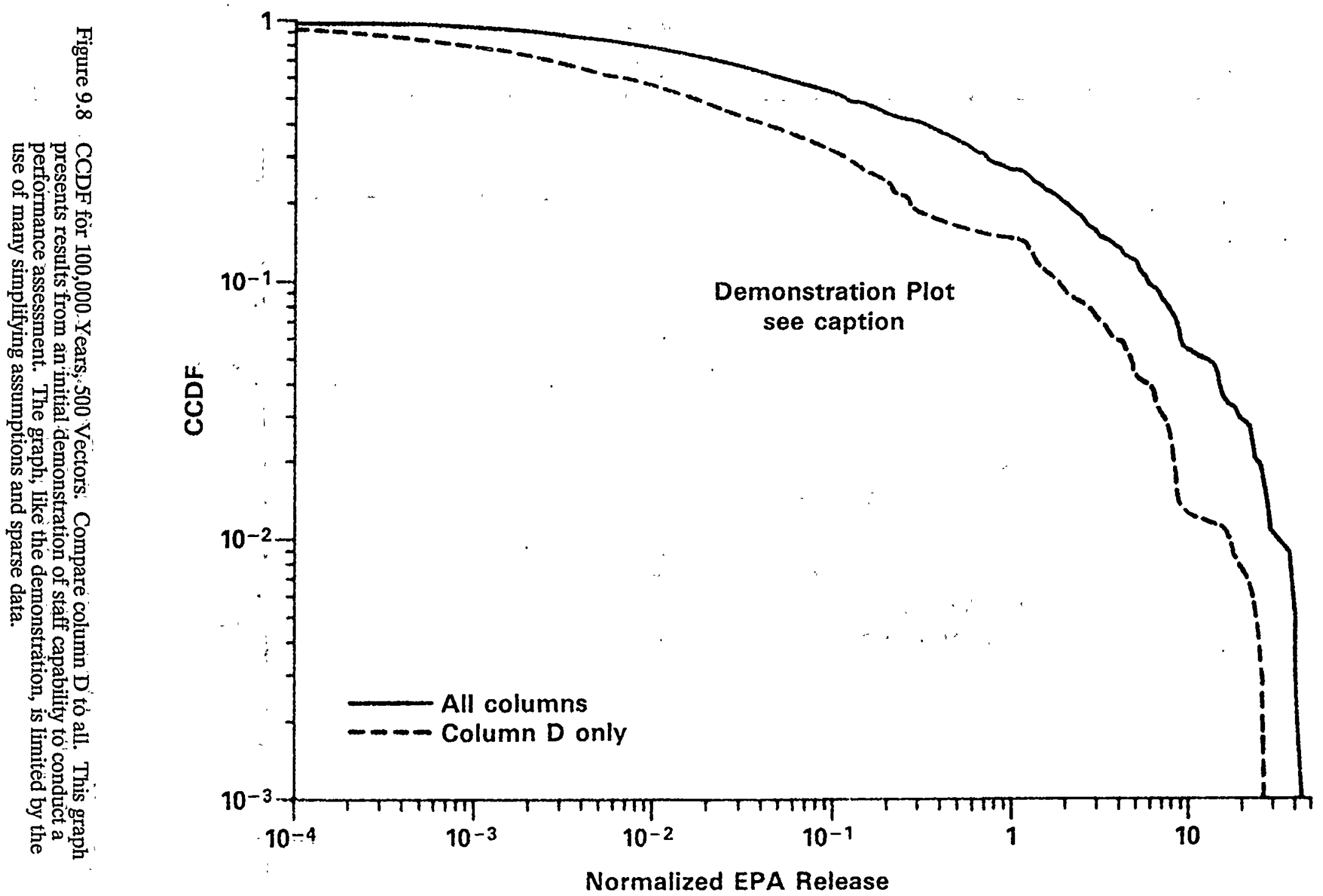

$\infty$

Normalized EPA Release 


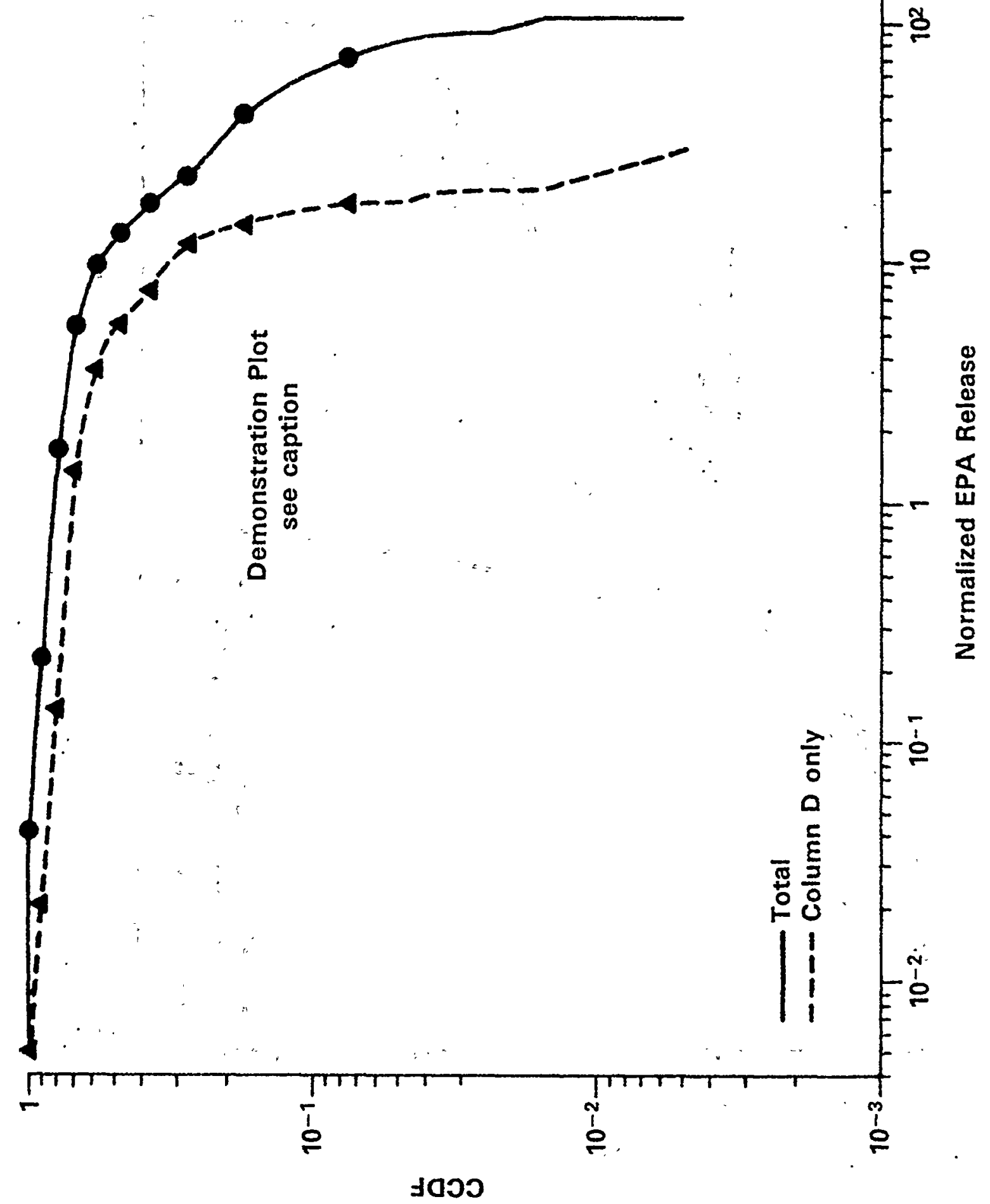

Figure 9.9. CCDF for Pluvial Scenario; 98 Vectors Only. This graph presents results from an initial demonstration of staff capability to conduct a performance assessment. The graph, like the demonstration, is limited by the use of many simplifying assumptions and sparse data. 


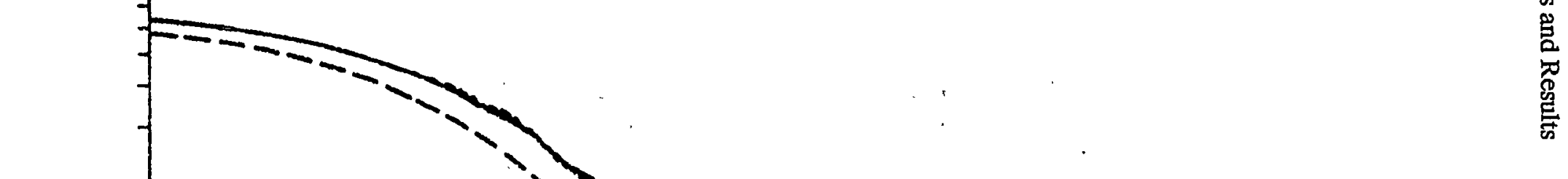

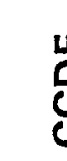

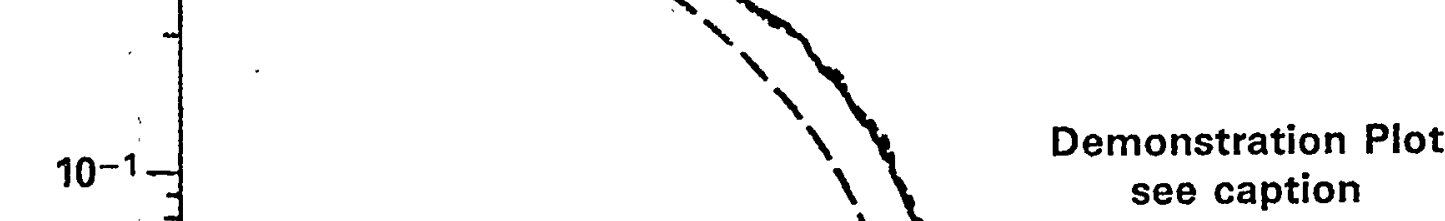

0

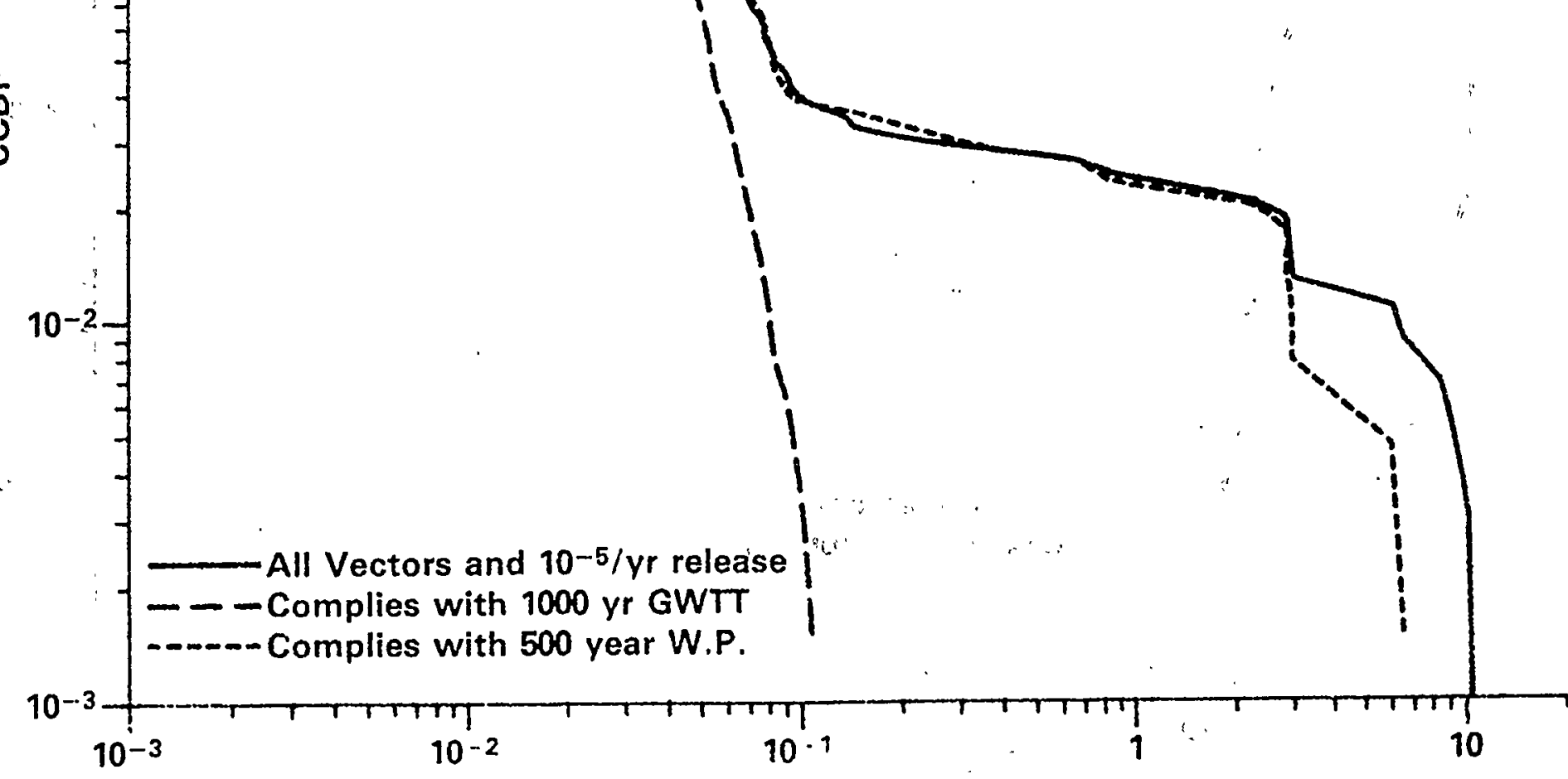

Normalized EPA Release 


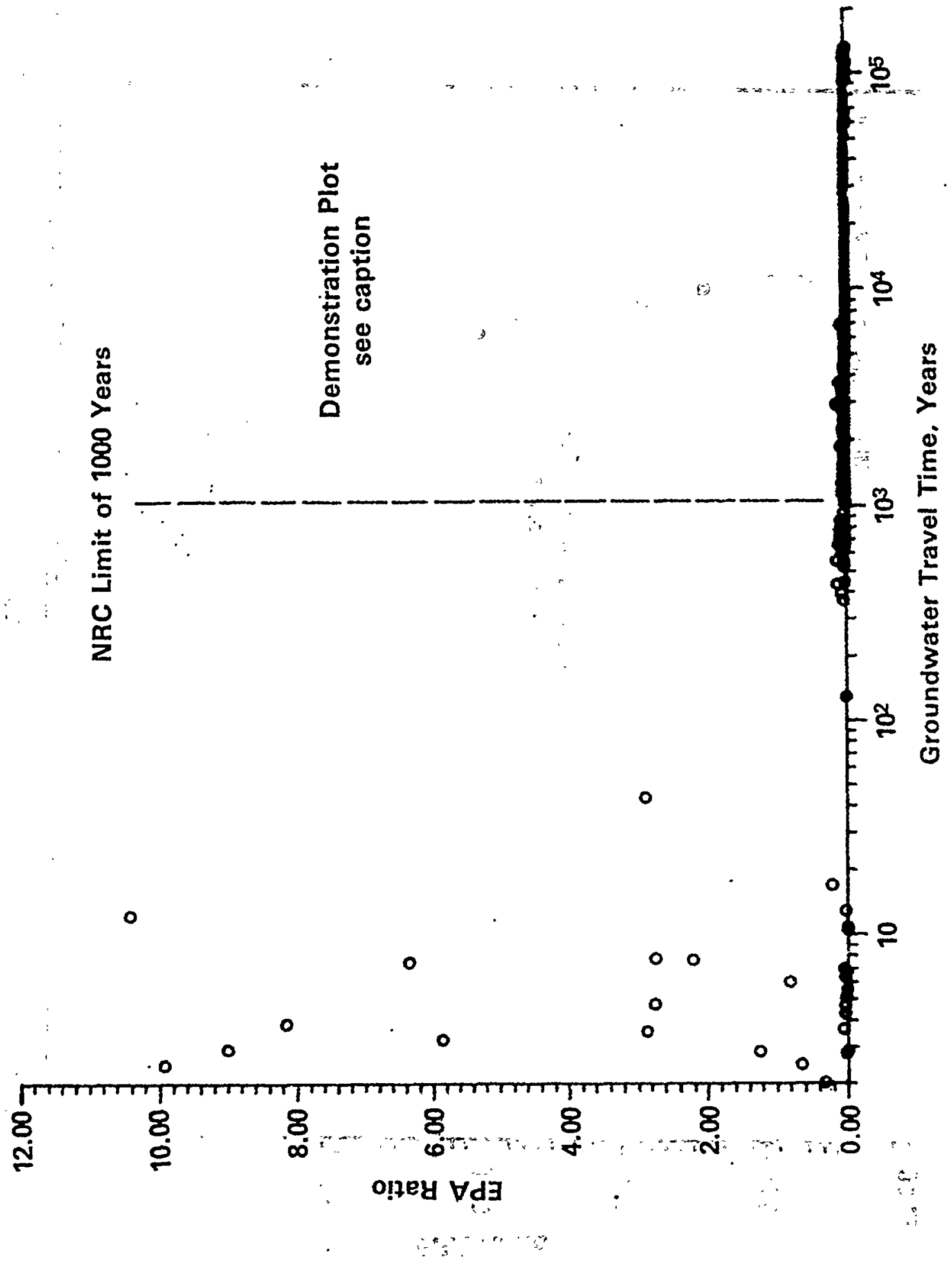

Figure 9.11 Base Case Liquid Pathway.Scenario; 10,000 Years. Effects of Groundwater Travel Time on EPA Release. This graph presents results from an initial demonstration of staff capability to conduct a performance assessment: The graph, like the demonstration, is limited by, the use of many simplifying assumptions and sparse data: 
9. Analysis and Results

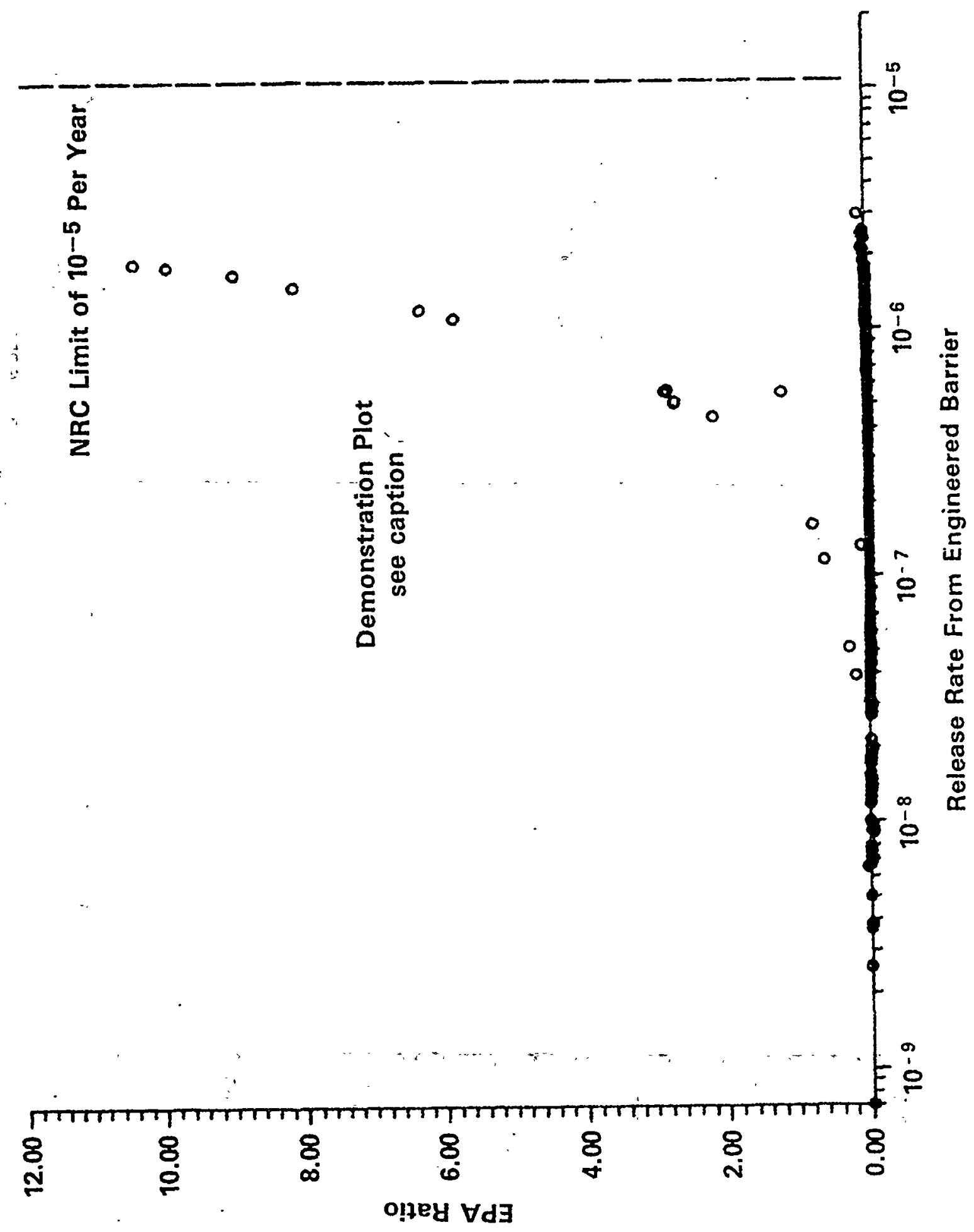

Figure 9.12 Base Case Liquid Pathway Scenario; 10,000 Years. Effects of Release Rate from Engineered Bárrier:. This graph presents results from an initial demonstration of staff capability to condúct a performance'assessment. 'The graph, like the demonstration, is limited by the use of many simplifying assumptions and sparse data. 


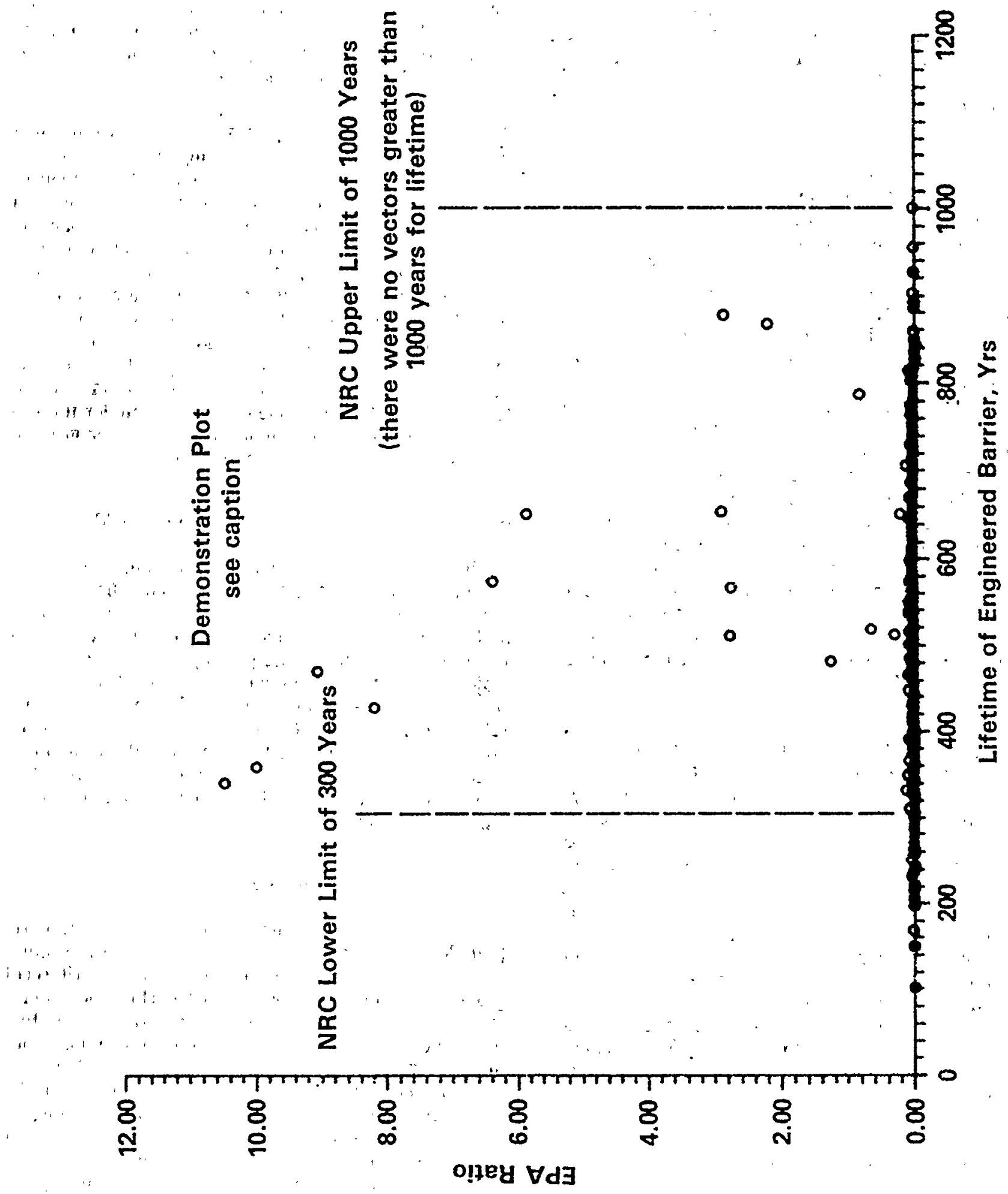

Figure 9.13 Base Case Liquid Pathway Scenario; 10,000 Years. Effects of Engineered Barrier Lifetime. This graph presents results from an initial demonstration of staff capability to conduct a performance assessment. The graph, like the demonstration, is limited by the use of many simplifying assumptions and sparse data. 
- Substantially complete containment-Vectors with a waste-package lifetime less than a specified time were screened out. For this demonstration, only a single representative cutoff time of $\mathbf{5 0 0}$ years was chosen.

- Release rate limitation-The release rate model in NEFTRAN accounts only for the congruent release of radionuclides contained in the uranium dioxide fuel. The maximum rate is controlled by the dissolution rate of the matrix. For this demonstration, the release rate was assumed equivalent to the dissolution rate of the matrix. Releases of some of the radionuclides might actually be smaller than the congruent dissolution rate because they are solubility-limited; thus, the screening criterion might be slightly over-restrictive. The dissolution rate calculated in NEFTRAN is a function of uranium solubility, infiltration rate, and water-contact fraction. It should be noted that, for this demonstration, the assumptions used do not correspond precisely to the rule. Specifically, the rule states a limit of "one part in 100,000 per year of the inventory of that radionuclide present at 1,000 years," with a limitation on those radionuclides that might have decayed to very low levels at 1,000 years. The demonstration was therefore only an approximate comparison to the limitations of this subsystem requirement.

- Groundwater travel-time limitation-For this demonstration, radionuclide transport was assumed to occur along four separate liquid water pathways: Columns $A, B, C$, and $D$, in part to simulate the spatial variability inherent in the Yucca Mountain repository. Column D was the shortest pathway, and contained hydrogeologic units that would saturate more quickly at increased infiltration rates, thus leading to fracture flow. Therefore, the mean travel time along Column D was taken to be the "groundwater travel time along the fastest path of likely radionuclide travel". In this demonstration, groundwater travel time is defined as the average time for plug flow through the column and is a function of infiltration rate, porosity, saturated hydraulic conduc-. tivity, and correlation length.

Figure 9.10 shows the conditional CCDF for the basecase scenario for all vectors, and for vectors limited by the EBS release rate, the waste-package lifetime, or the groundwater travel-time restrictions. No relationship was assumed between waste-package lifetime and the EBS : release rate. In this demonstration, all ' 500 'vectors had release rates less than $10-5 / y$, 'so the CCDF curve for vectors under that restriction was coincident with the curve for all vectors. Screening based on a waste-package lifetime of 500 years or greater caused a shift toward lower radionuclide releases, but only for the lowprobability, high-consequence releases.

Screening on the basis of groundwater travel times had the most dramatic effect. All the high-consequence releases were essentially eliminated when vectors leading to travel times shorter than 1,000 years were eliminated from the CCDF. This is because flow (and accompanying radionuclide transport) along Column $\mathrm{D}$ was controlled by the fractures, for infiltration rates higher than the $\mathrm{k}_{\mathrm{S}} \mathrm{s}$ of the units in the column. Fracture flow was faster than flow through the rock matrix, and, because retardation in the fractures was less than in the matrix, radionuclides could be transported more quickly. Therefore, eliminating the vectors. with higher infiltration rates allowed transport only through the matrix under unsaturated conditions, with commensurately longer groundwater travel times and slower transport.

\subsubsection{Average contributions by radionuclide}

Table 9.12 illustrates the average contribution by radionuclide for the unrestricted vectors and for those vectors meeting with: (1) the 500-year waste-package lifetime, and (2) the groundwater travel time of 1,000 years. For the unrestricted and waste-package lifetime cases, the major contributors to cumulative radionuclide release are the isotopes $\mathrm{Pu}-239$ and $\mathrm{Pu}-240$. However, for those releases with groundwater travel times of 1,000 years or greater, the radionuclides $\mathrm{C}-14$ and $\mathrm{I}-129$ are the main contributors. These radionuclides were unretarded in this demonstration and therefore could move relatively quickly through the matrix.

\subsubsection{Ad Hoc Sensitivities to NRC Criteria}

The results of the 500 runs for the base-case scenario (liquid-pathway analysis) were plotted against the values of the individual NRC subsystem performance criteria of groundwater travel time, waste-package lifetime, and release rate from the EBS. The results, presented in Figures $9.11,9.12$, and 9.13, show that, for the assumptions inherent in this demonstration, imposing the NRC performance criteria could have a favorable impact on the total radionuclide releases to the accessible environment. For the scenario considered, imposing the 1000 year groundwater travel time limitation virtually eliminated any non-compliance with the EPA containment requirement in 40 CFR Part 191. Additionally, none of the vectors yielded release rates, from the EBS, greater than 10-5/yr, although it was noted that cumulative release s. increased with an increase in the release rate. Finally, "there was also a noticeable decrèase in cumulative radionuclide release, with increasing waste-package lifetime. 
Table 9.12

Fractional Contribution by Radionuclide to EPA Release Ratio for Unrestricted Vectors and Those Restricted by NRC Performance Criteria

\begin{tabular}{|c|c|c|c|c|c|}
\hline Radionuclide & & . & $\begin{array}{l}\text { Unrestricted } \\
\text { vectors }\end{array}$ & $\begin{array}{l}\text { Restricted to } \\
\geq 500 \text { yr. W.P.* } \\
\text { Lifetime }\end{array}$ & $\begin{array}{l}\text { Restricted to } \\
\geq 1000 \text { yr. GWTT** }\end{array}$ \\
\hline $\mathrm{Pu}-240$ & & $\because$ & 0.41 & 0.40 & 0.0 \\
\hline $\mathrm{Pu}-239$ & & 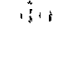 & 0.39 & 0.37 & 0.0 \\
\hline$C-14$ & & & 0.094 & 0.13 & 0.94 \\
\hline Am-241 & $\because$ & & 0.077 & 0.062 & 0.0 \\
\hline Am-243 & ' & & 0.014 & 0.014 & 0.0 \\
\hline I-129 & & & 0.005 & 0.007 & 0.05 \\
\hline
\end{tabular}

*W.P. is waste-package.

**GWTT is groundwater travel time.

\subsection{Total System Results}

\subsubsection{Introduction}

The results presented here can only be considered as a demonstration of a performance-assessment capability and should not be taken as representative of the performance of a repository at Yucca Mountain, Nevada. Among the most important limitations of the study were:

1. the lack of sufficient site data,

2.' the large uncertainties in the data now in use,

3. the use of only four scenarios to characterize future states at the site,

4. uncertainties in the site conceptual model, and

5. uncertainties in modeling the physicochemical processes leading to radionuclide release and migration in the geosphere.

For this demonstration, four scenario classes were considered:

1. Undisturbed or base-case conditions,

2. Pluvial conditions,

3. Drilling under undisturbed conditions, and

4. Drilling under pluvial conditions.

As shown in Figure 9.14, these particular scenarios arose from the possible combinations of two fundamental events: a pluvial period (or not) and drilling at the site (or not). Probabilities for each of the scenario classes were determined by multiplying the probabilities of their independent constituent events. The likelihood of each event was based upon staff judgment in the case of the pluvial/ nonpluvial events, and 40 CFR Part 191, Appendix B, for the human-intrusion events. 40 CFR Part 191 assumes a likelihood of drilling at the site as a set number of boreholes per unit area over 10,000 years, based on the geologic formations in which the repository is located.

There are two important points to note in Figure 9.14. First, given the scenarios and probabilities chosen for this demonstration, the case in which conditions at the repository over the next 10,000 years remain as they are today appears highly unlikely. Secondly, the two humanintrusion scenario classes have probabilities orders-ofmagnitude greater than the base-case and pluvial scenarios, which do not incorporate the possibility of drilling events. This difference is due to the high probability of drilling, as opposed to not drilling, as shown in the figure.

The consequences of each scenario and of all scenarios combined can be expressed in terms of normalized cumulative releases of radionuclides to the accessible environment over a specified period of time. These results, displayed as curves of consequences versus the probability that such consequences will be exceeded (i.e. a complementary cumulative distribution function, or CCDF), can in turn be compared with the curve of the EPA containment requirements in 40 CFR Part 191(Figure 9.15). The EPA standard requires summed normalized cumulative releases to the environment equal to: (1) 1.0 not to exceed a probability of 0.1 , and (2) 10.0 not to exceed a likelihood of 0.001 .

Compliance with the containment requirements cannot be determined solely on the basis of the strict numerical results of a performance assessment. As recognized in 40 .CFR Part 191, substantial uncertainties are.inherent in 
projecting future disposal-system performance, and thus the bias towards this uncertainty in component performance must also be taken into account. For example, in Figure 9.16, a portion of the empirical CCDF lies above the EPA containment requirement and is therefore labeled a "possible violation." If the bias in component performance was consistently toward more pessimistic performance, then the results expressed in the CCDF may be too conservative, and thus this portion of the curve may be judged to be not a violation. If, on the other hand, component performance was viewed optimistically, the CCDF may well be found to be in violation of the EPA standard. Since definitive proof of future system performance cannot be provided, 40 CFR Part 191 only requires a "reasonable expectation" that compliance will be achieved.

The partial CCDFs for each of the scenario classes are shown in Figures 9.17 through 9.20. These curves differ from the distribution of consequence figures shown earlier in Section 9.5, in that these partial CCDFs incorporate the probabilities of the scenarios themselves. For this reason, the cumulative probability of any single scenario presented here never reaches 1.00 , as it will for the total CCDF, which is a composite of all four scenario classes.

\subsubsection{Partial CCDF Results}

\subsubsection{Undisturbed or base-case conditions}

The $\log -\log$ plot of summed normalized EPA release versus cumulative probability for undisturbed conditions (Figure 9.17) shows the characteristic concave downwards shape for a CCDF. As will be the case for each CCDF, the curve intersects the $y$-axis at the likelihood of the scenario; here, the likelihood is equal to $2.3 \times 10-7$. For this scenario, EPA ratios of 1.0 and 10.0 have corresponding cumulative probabilities of approximately $4.9 \times 10-9$ and $4.1 \times 10-10$, both of which are well below the EPA criticalpoint likelihoods of 0.1 and 0.001 for these same EPA ratios.

\subsubsection{Pluvial conditions}

Consequences from the pluvial case scenario (Figure $9.18)$ equal to an EPA ratio of 1.0 have an aggregate probability of $1.9 \times 10-8$, while an EPA ratio of 10.0 has a cumulative likelihood of $1.3 \times 10-8$. These results, combined with an overall scenario probability of $2.0 \times 10-8$, leave the $\mathrm{CCDF}$ for the pluvial case orders-of-magnitude below the EPA containment requirement.

The reader should be aware that an inordinate amount of computer time limited the pluvial and the drilling-underpluvial-conditions scenarios to only 98 input vectors. Furthermore, because a sample of 200 input vectors was planned and generated with the LHS sampling routine to represent this release pathway and these scenario classes, a a subset of 98 vectors might have led to spurious correla"tions and an inatequate representation of the partial CCDFs.

\subsubsection{Drilling under undisturbed conditions}

The CCDF for drilling under undisturbed conditions (Figure 9.19) shows a slight step-in the low consequence/ high probability end of the curve. This is attributable to consequences from the drilling. The rest of the CCDF curve is dominated by releases via the liquid pathway.

More importantly though, with the addition ${ }_{2}$ of drilling events to the base-case, the overall probability of the scenario is increased to 0.9 . Thus, for this scenario, although the sum probability of an EPA ratio of 1.0 is below - the EPA standard at 0:022, the EPA ratio/cumulative probability pair of 10.0 and 0.0036 falls above the standard, which appears as a step function in this and the following fịgures.

\subsubsection{Drilling under pluvial conditions}

The shape of the partial CCDF for drilling under pluvial conditions (Figure 9.20) does not exhibit the effects of the drilling. This is because the consequences due to drilling are in the range of .0001 , and are therefore negligible when factored into overall scenario consequences of .01 to 100 .

With the overall likelihood of drilling under pluvial conditions equal to 0.1 , the $1.0 / 0.082$ consequence/aggregate probability pair falls just below the EPA containment requirement, whereas an EPA ratio of 10.0 for this scenario has a cumulative probability of approximately 0.06 , which lies above the standard.

\subsubsection{Results for the Total CCDF}

Figure 9.21 demonstrates how each of the four individual scenarios contributes to the total CCDF. It is readily apparent that releases from the two human-intrusion scenario classes dominate the CCDF, under the given probabilities and conditions. Contributions to the total consequences-from the undisturbed and pluvial scenarios are negligible, because their respective scenario probabilities are too low.

The total CCDF for the four scenario classes modeled is plotted against the EPA standard in Figure 9.22. This comparison shows that, for this demonstration, the empirical CCDE ilies above the EPA standard at both containment-requirement break points, with cumulative probabilities of approximately 0.104 and 0.06 for EPA ratios of 1.0 and 10.0 , respectively.

The results of this demonstration should not be taken as representatiye of the performance of a repository at Yucca Mountain, Nevada. Rather, they should be used to 
9. Analysis and Results

indicate the importance of: (1) the assumptions in modeling phenomena, such as fracture/matrix interactions; (2) the data used in the total system modeling, e.g.; infil- tration rate; and (3) the consistency of the bias, whether pessimistic or optimistic, toward the performance of the various disposal-system components. 


\section{DETERMINATION OF SCENARIO PROBABILITIES FROM THE PROBABILITIES OF FUNDAMENTÁL EVENTS}

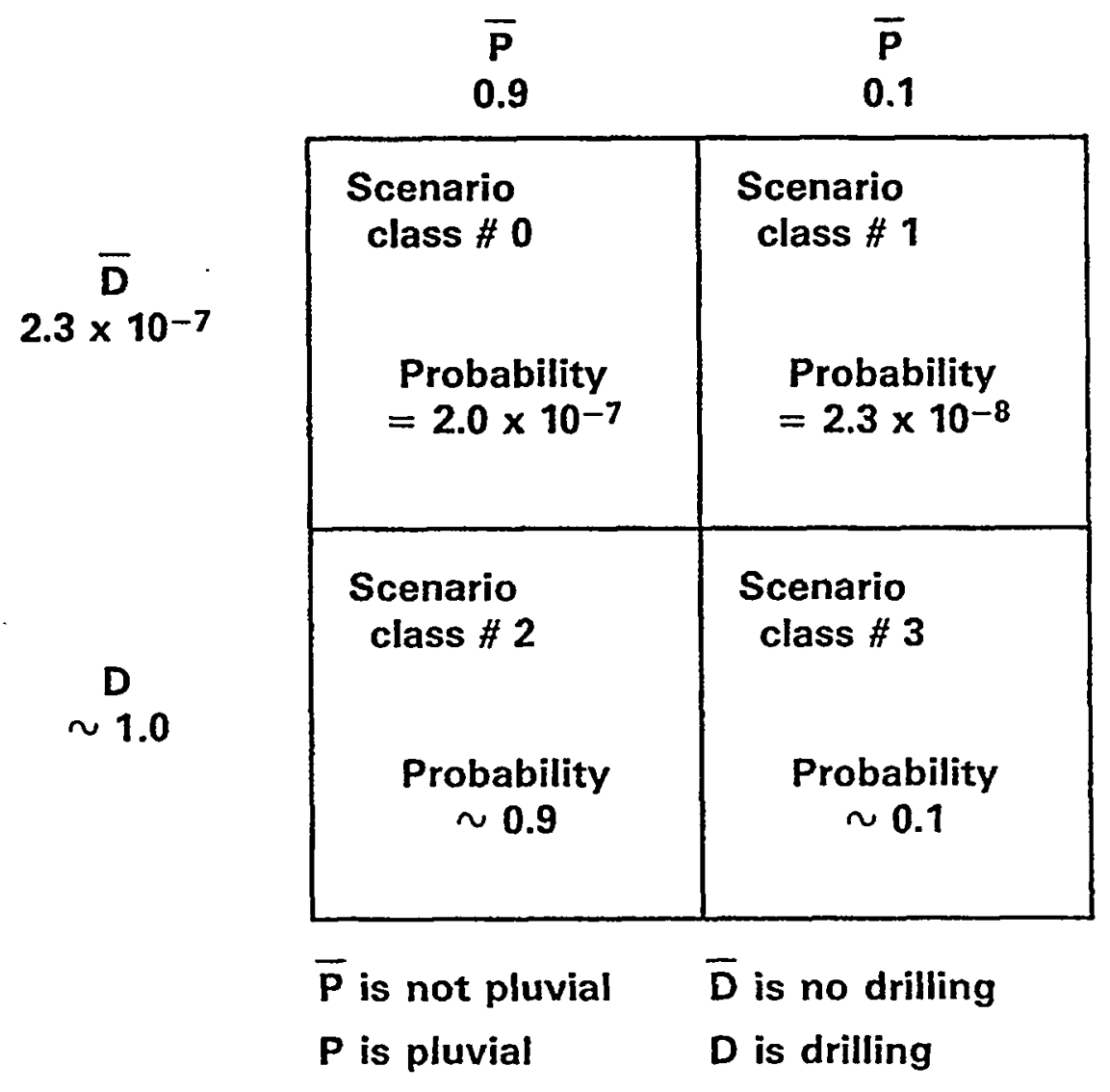

Scenario class \# 0 is no drilling, not pluvial Scenario class \# 1 is no drilling, with pluvial Scenario class \# 2 is drilling, not pluvial Scenario class \# 3 is drilling and pluvial

Note: Probability combinations assume that fundamental events have independent probabilities of occurrence; this is not a general restriction.

Figure 9.14 Determination of scenario probabilities from probabilities of fundamental events. This figure presents results from an initial demonstration of staff capability to conduct a performance assessment. The figure, like the demonstration, is limited by the use of many simplifying assumptions and sparse data. 

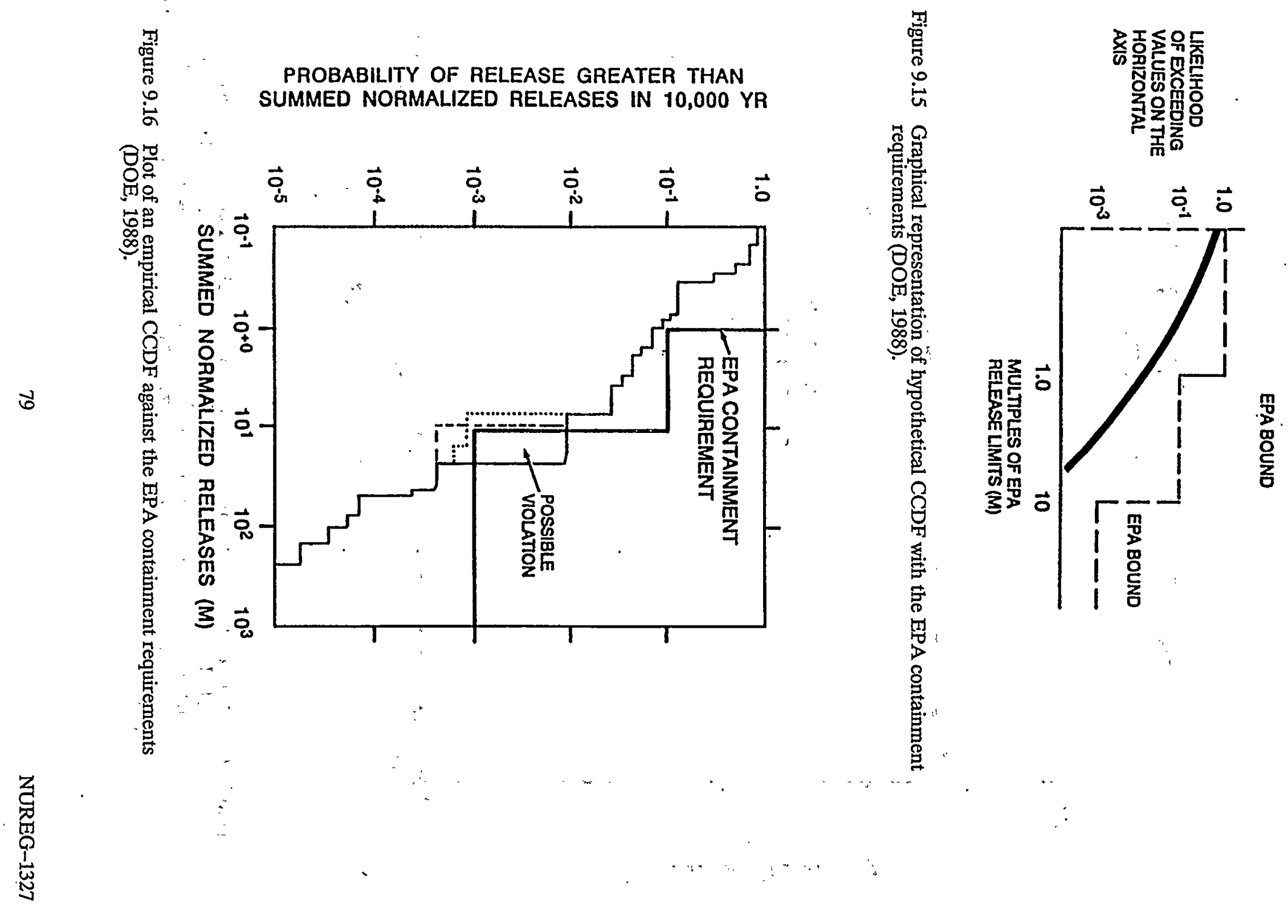


\section{CCDF FOR UNDISTURBED CONDITIONS $(10,000$ years $)$}

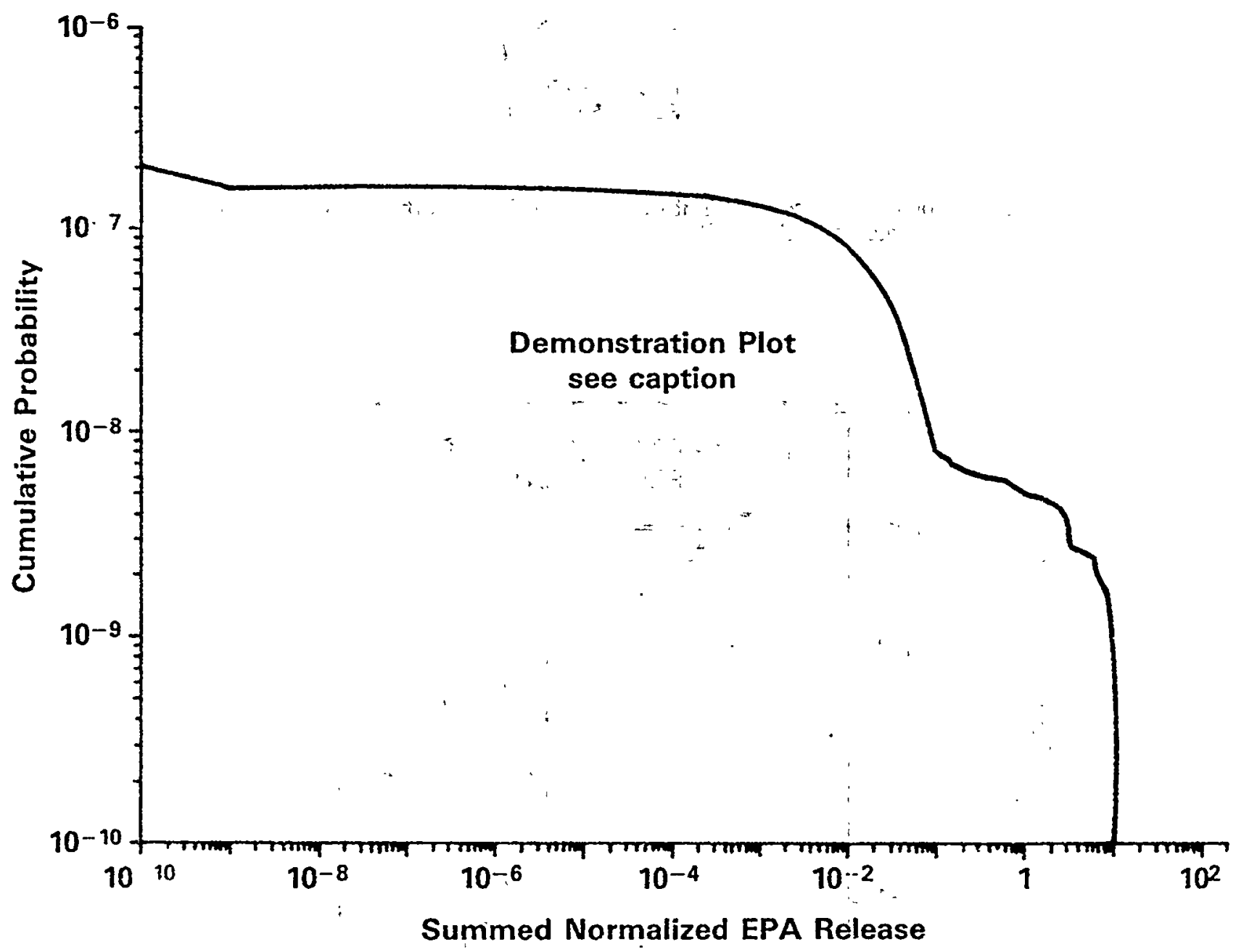

Figure 9.17 Partial CCDF for Undisturbed Conditions. Phase 1 of the Iterative Performance Assessment. Results based on 500 vectors, yielding 398 values aftèr duplication. This graph presents results from an initial demonstration of staff capability to conduct a performance assessment. The graph, like the demonstration, is limited by the use of many simplifying assumptions and sparse data. 


\section{CCDF FOR PLUVIAL CONDITIONS $(10,000$ years $)$}

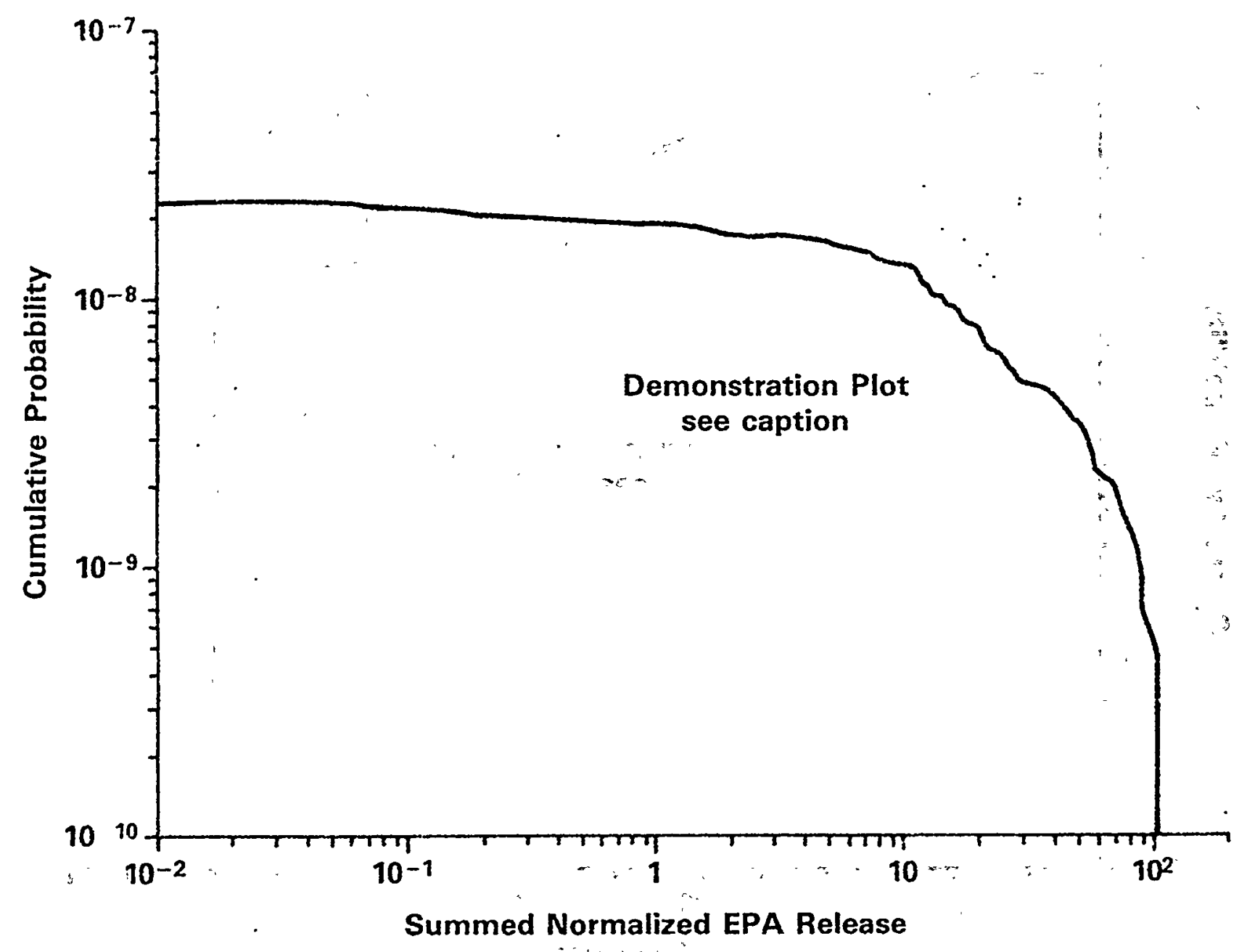

Figure 9.18 Partial CCDF for Pluvial Conditions. Phase 1 of the Iterative Performance Assessment. Results based on 98 vectors, yielding 98 values after duplication. The graph presents results from an initial demonstration of staff capability to conduct a performance assessment. The graph, like the demonstration, is limited by the use of many simplifying assumptions and sparse data. 


\section{CCDF FOR DRILLING UNDER UNDISTURBED CONDITIONS $(10,000$ years $)$}

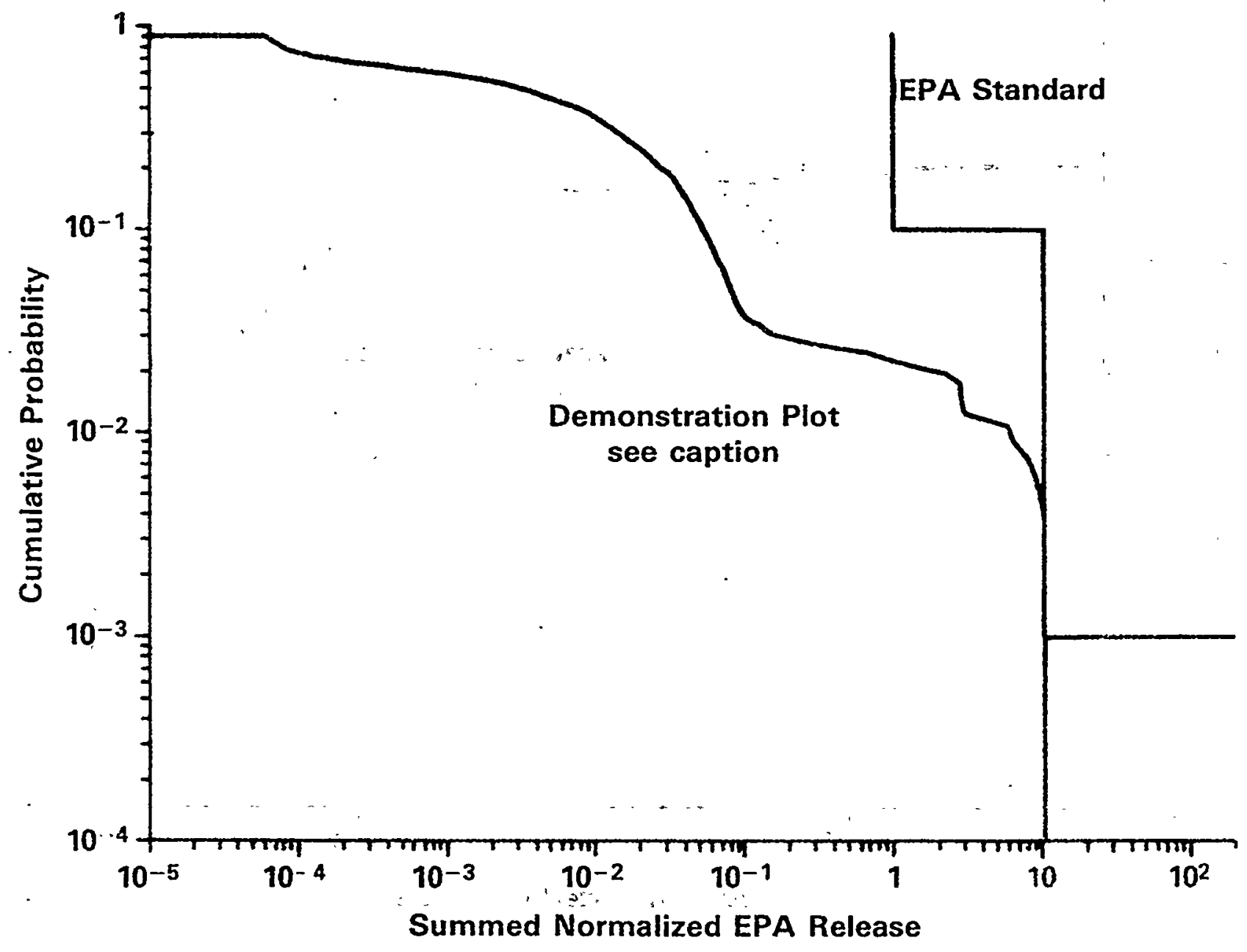

Figure 9.19 Partial CCDF for Drilling Under Undisturbed Conditions. Phase 1 of the Iterative Performance Assessment: Results based on 500 vectors, yielding 500 values after duplication. This graph presents results from an initial demonstration of staff capability to conduct a performance assessment. The graph, like the demonstration, is limited by the use of many simplifying assumptions and spärse datá." 


\section{CCDF FOR DRILLING UNDER PLUVIAL CONDITIONS $(10,000$ years $)$}

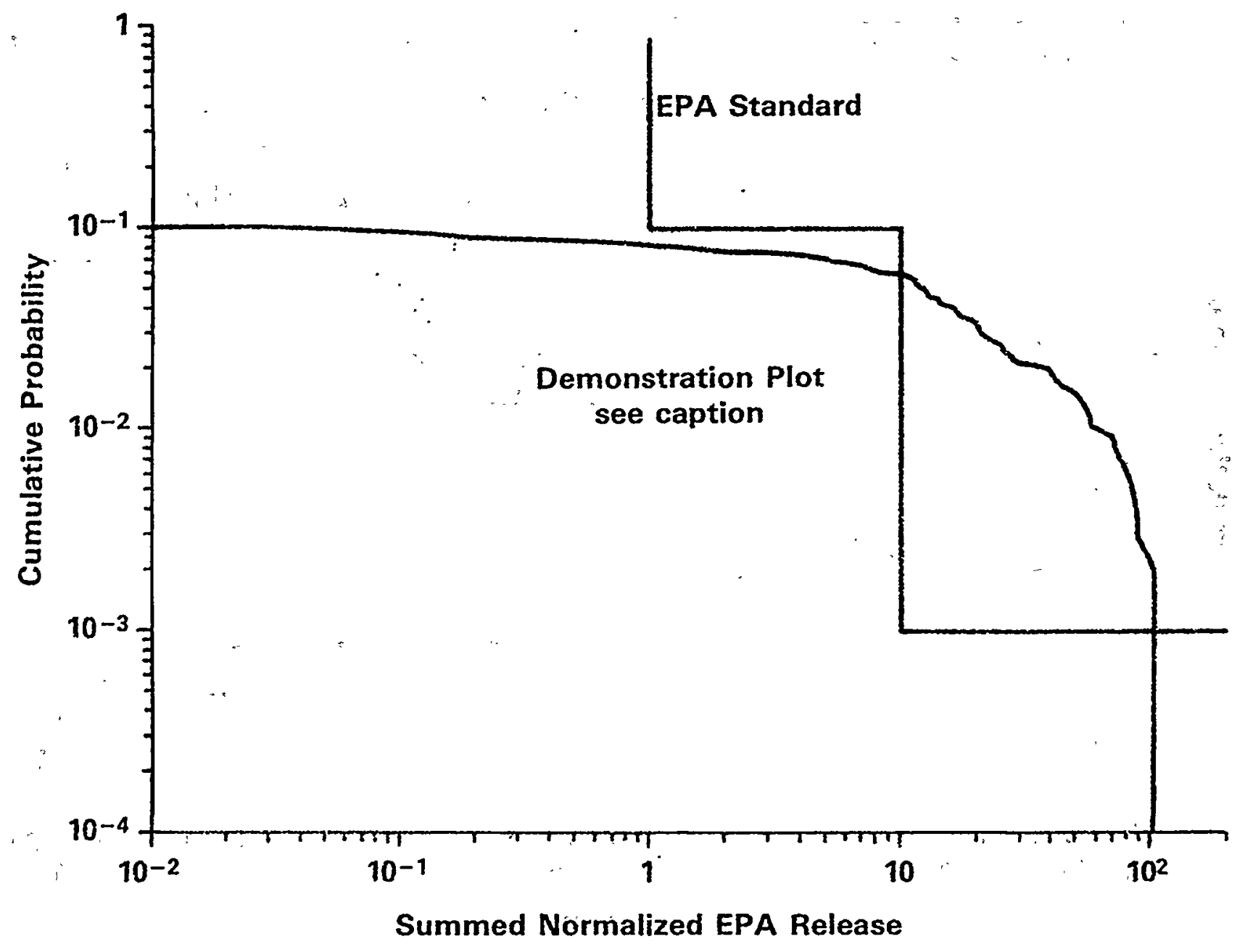

Figure 9.20 Partial CCDF for Drilling Under Pluvial Conditions. Phase 1 of the Iterative Performance Assessment. Results based on 98 vectors, yielding 98 values after duplication. This graph presents results from an initial demonstration of staff capability to conduct a performance assessment. The graph, like the demonstration, is limited by the use of many simplifying assumptions and sparse data. 
9. Analysis and Results

\section{TOTAL CCDF \\ $(10,000$ years $)$}

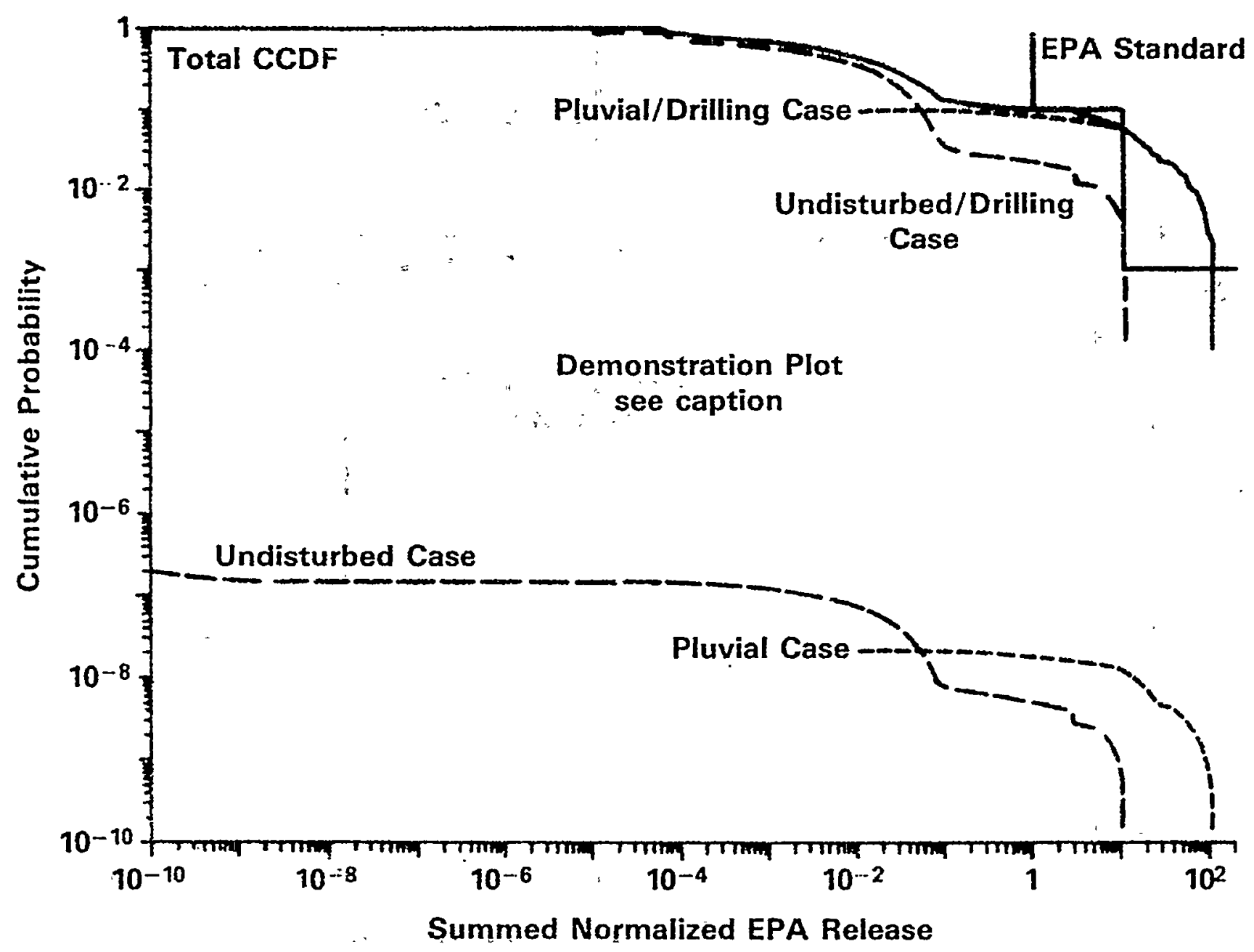

Figure 9.21 Composite CCDF Curve for the Scenario Classes Considered in Phase 1 of the Iterative Performance Assessment: Results based on 598 vectors, yielding 1196 values, 1094 after duplication. This graph presents' results from an initial demonstration of staff capability to conduct a performance assessment. The graph, like the demonstration, is limited by the use of many simplifying assumptions and sparse data. 


\section{$(10,000$ years)}

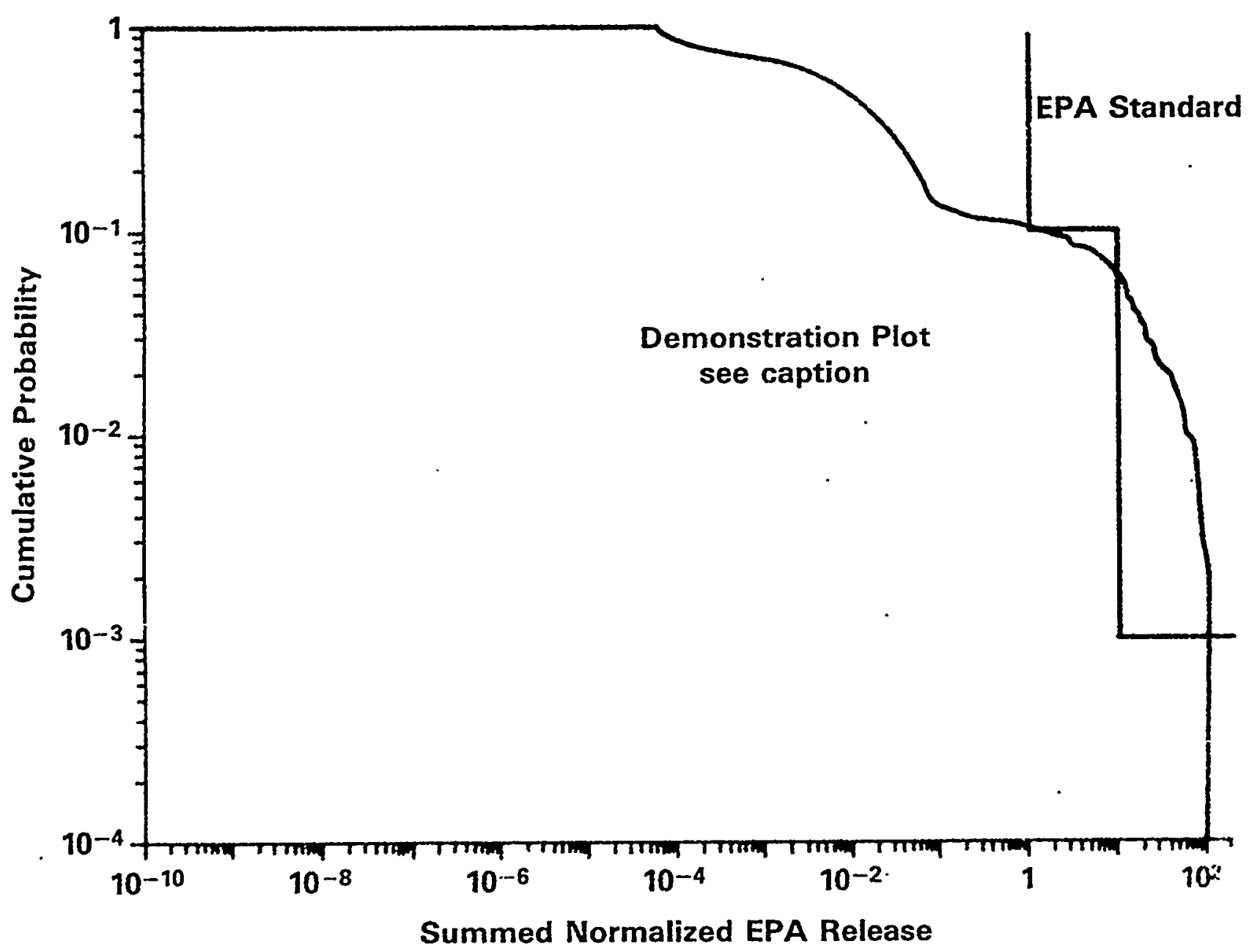

Figure 9.22 Total CCDF for Phase 1 of the Iterative Performance Assessment. Results based on 598 vectors, yielding 1196 values, 1094 after duplication. This graph presents results from an initial demonstration of staff capability to conduct a performance assessment. The graph, like the demonstration, is limited by the use of many simplifying assumptions and sparse data. 



\section{PRELIMINARY SUGGESTIONS FOR FURTHER WORK}

Based on this preliminary analysis and the limitations noted, some preliminary recommendations regarding the directions for further tecchnical work can be made. These suggestions are based on insights gained during the Phase 1 effort. Although these suggestions were derived from this work, they are not necessarily unique to this work, are generally consistent with scientific intuition, and are largely consistent with planning documents such as the DOE SCP. The suggestions relate to this report and are not intended to indicate an evaluation of the DOE program outlined in the SCP. These recommendations have all the limitations inherent in the analyses on which they are based. These suggestions presented are in the spirit of providing some ideas to guide further work and are not intended to be definitive. Some of this suggested work is clearly the responsibility of DOE; other items could be performed by NRC, DOE, or a third party. Most of the recommendations of this type reflect the general lack of data available for executing an analysis of this type. The suggestions for technical improvements can be grouped into three categories:

1. Suggestions to improve or extend the modeling used to obtain preliminary estimates of performance;

2. Suggestions for refining or adding auxiliary analyses to help better evaluate the performance estimates obtained; and

3. Suggestions for refinements or additions to the scientific bases, including the methodologies available, for arriving at estimates of repository performance.

\subsection{Improvements and Extensions to Modeling}

The following are recommended improvements to modeling of performance. These are considered to be ideas for further work that could improve the current preliminary assessment and might be suitable first steps in generally upgrading the methodology.

\section{General}

1. Add the capability for modeling additional scenario classes. :

In this Phase 1 demonstration, the staff used a readily available computer code, NEFTRAN, to model the release of radionuclides by the groundwater pathway. This code was able to treat both the "basecase" for current climate conditions and the "pluvial case" for a wetter climate. A simple model and computer code were developed to treat the release of radionuclides directly to the environment through exploratory drilling. However, there did not appear to be any readily available models and computer codes to estimate consequences from volcanism, faulting, subsidence, uplift, and other tectonic events and processes and other types of scenarios. The consequences from these scenarios do not appear to be readily treatable by extensions of models currently in use (such as the way the pluvial case was treated by extending the base-case treatment). Therefore, the capability for modeling the consequences of additional scenario classes must be added to the methodology, if such scenario classes are to be treated explicitly in the CCDF.

2. Test the system code, using the consequence codes as subroutines, instead of generating data sets external to the system code.

In the Phase 1 effort, the consequence modules were run separately from the system code, and the resulting files were manipulated to generate the total system CCDF: An attempt to run the consequence modules as subroutines of the system code was not made. Such an attempt would indicate whether such an approach may be practicable and would provide an important insight into the direction for further development of the NRC independent performance-assessment capability.

3. Acquire, test, and evaluate codes that SNL developed for a repository in the unsaturated zone.

SNL, under contract to NRC, has been developing an extension of the SNL performance-assessment methodology, to treat an HLW repository in partially saturated tuff. At the beginning of the Phase 1 demonstration, it was recognized that the SNL tuff methodology would not be ready to use in the Phase 1 effort. This tuff methodology also will incorporate the ability to treat transient conditions by a multiple steady-state approximation. Because this methodology was developed specifically for the NRC waste management program, it has the potential to greatly improve the accuracy and adequacy of the performance assessment capability. By acquiring and evaluating this methodology, the NRC staff can determine what improvements or additions, if any, may be needed.

4. Evaluate additional computer codes, which could not be acquired and evaluated during the Phase 1 effort, to determine whether existing codes can meet the NRC modeling needs, or whether additional code development is needed. 
Several computer codes, which appeared to be promising in terms of providing missing parts of the analysis or which might offer improved treatment of certain aspects of modeling, were not available for use in the Phase 1 demonstration. Several of these codes should be evaluated in subsequent iterations to determine how relevant and useful they are for the NRC iterative performance assessiments. Some of the codes that might be worthwhile investigating are: TOSPAC, AREST, NEFTRAN 2, and EBSPAC.

5. Explore, with the CNWRA, the adaptation of the Fast Probabilistic Performance Assessment (FPPA) methodology to generate the total system CCDF.

During the Phase 1 demonstration, questions arose regarding the number of vectors required for an adequate representation of the distribution of consequences for a given scenario class. This question usually arises in studies of this type where performance is estimated using an "empirical distribution" derived from models of system performance using multiple samples of input data. Appendix $\mathrm{E}$ discusses some of the concerns about ensuring that enough samples are used to obtain a sufficiently accurate representation of performance. A concern in this study is that several vectors yielded zero cumulative releases; although this outcome increased confidence in the probability estimates of the lowconsequence/high-probability end of the CCDF, less confidence wäs available for the highconsequence/low-probability end of the CCDF, which may be the critical region for assessing regulatory compliance. Therefore, the use of an importance sampling technique, such as the FPPA methodology, if made applicable for the total CCDF, may combine an increase in accuracy and confidence in results with a saving in computational cost and time.

6. Perform a sensitivity analysis, using both drilling and groundwater transport parameters.

During the Phase 1 analysis, the sensitivity analysis was performed only on the liquid-pathway model (because the drilling model and code were not available at the time the sensitivity analysis was done), using the variables and distributions germane to that model. Some of these same variables were important for the model of direct.releases by drilling. However, some of the variables that could have a significant effect on the consequences of drilling were not included in the sampling procedure used to perform the sensitivity analysis, but were fixed in the model. As a consequence, the variability in the output of the drilling model inappropriately may have been kept small, and the importance of some of the variables may not have been revealed by the sensitivity analysis.

\section{Flow and Transport :}

1. Refine groundwater modeling (e.g., by considering more dimensions).

$x$. The âssumptions used as the bases for flow modeling, which are then the bases for transport modeling, greatly simplify the complexity of the structure, boundary conditions, and physical processes considered in modeling flow at Yucca Mountain. Among the more significant simplifying assumptions used in the Phase 1 effort were that: (1) flow was onedimensional and vertically downward; (2) flow was steady-state; (3) surface infiltration was assumed to be constant over time; and (4) fracture flow was initiated when the infiltration rate exceeded the saturated hydraulic conductivity of the matrix. A more precise and complete treatment of the hydrology at the site could treat some of these aspects by using two-or three-dimensional models, incorporating a better treatment of fracture flow, considering the coupling to regional hydrology, and removing additional simplifying assumptions. Additional site hydrologic data could be incorporated, if available.

2. Incorporate a model of gas-pathway transport in the calculation of the CCDF.

In Phase 1, the only release pathways implemented in the model used to generate estimates of performance were the liquid pathway and the direct-release pathway (i.e., release by exhumation of waste or contaminated rock). A more complete treatment would explicitly use the concepts discussed in Appendix D, "Gaseous Releases of Carbon-14," to formulate a model that quantitatively estimates releases by the gas pathway and then incorporates these estimates into the total system CCDF, as discussed in Section 4." "System Code." In addition, it might be necessary to couple the liquid and direct-release pathway calculations of releases to those from the gaseous pathway to ensure conservation of mass (currently, the models used assumed all C-14 was released in dissolved groundwater) and to characterize correctly the interactions between the various pathways.

3. Include flow and transport through the saturated zone.

In the Phase 1 demonstration, flow and transport of radionuclides in the saturated zone was not incorporated into the estimations of total system performance. Instead, the radionuclide releases were calculated at the water table (i.e., the boundary between the unsaturated and saturated zones), 
although estimating consequences in this manner was probably conservative, because retardation and travel time in the saturated zone were neglected. Adding consideration of transport in the saturated zone is recommended because: (1) a more realistic model of system performance will result and (2) synergistic effects will be portrayed with increased confidence. For example, the impact of releases from the vertical columns, used in the Phase 1 effort to describe the geometry of the repository, may be substantially different when the effect of transport through the saturated zone on those releases is included in the model.

4. Use a more sophisticated computational model for transport through partially saturated, fractured rock.

The NEFTRAN code was used to calculate transport in the Phase 1 demonstration. It was developed to simulate radionuclide migration in saturated rock. The following analytical steps were used to simulate radionuclide migration in partially saturated rock using the NEFTRAN code:

i. 'The saturated flow solver incorporated in the NEFTRAN code was bypassed, and the flow was calculated assuming partially saturated flow in four one-dimensional columns.

ii. If the calculated conductivity of any segment of a column was less than the saturated hydraulic conductivity for that segment, then the porosity was multiplied by the degree of saturation (to account for partially saturated conditions), and this modified porosity was used in the NEFTRAN code to calculate radionuclide migration.

iii. If the calculated conductivity of any segment of a.column was greater than the saturated hydraulic conductivity for that segment, then all the transport was assumed to occur in the fracture, and the properties of the fracture were used in the NEFTRAN code, to calculate radionuclide migration.

Improvement in the transparency, accuracy, and robustness of the modeling of transport through unsaturated, fractured rock could be achieved by taking a more direct approach to modeling phenomena such as: (1) flow in the partially saturated rock; (2) the transition from matrix flow to matrix plus fracture flow; (3) transport in the partially saturated matrix; and (4) the exchange of mass between the fractures and matrix.

5. Explicitly model fracture/matrix coupling.
In the Phase 1 demonstration, the coupling between groundwater flow in the fractures and the matrix was modeled by assuming that: (1) flow was entirely in the matrix, if the infiltration was less than or equal to the $\mathrm{k}_{\mathrm{S}}$ of that segment; and (2) flow greater than the $\mathrm{k}_{\mathrm{S}}$ was carried by the fractures, if the infiltration through the segment was greater than the $\mathrm{k}_{\mathrm{s}}$. Although the NEFTRAN code has the capability to treat matrix diffusion, this capability was not exercised for the Phase 1 demonstration. A more complete, precise treatment of the coupling between the rock matrix and the fractures, for both groundwater flow and radionuclide transport, would improve the completeness of the model and would provide further insight into the importance of these couplings and the parameters influencing the couplings.

\section{Source Term}

1. Attempt to develop or use a previously developed mechanistic model of waste-package failure.

In the Phase 1 demonstration, a distribution was assumed to describe the time of waste-package failure, and all waste packages were assumed to fail at the same time. The assumed distribution was not related to any of the parameters that are usually thought to influence waste-package failure, such as: repository temperature as a function of time, the rate and manner of water contacting the waste packages, the geochemistry of the groundwater, and the stress field to which the packages are subject. These factors can be a function of the repository design, the evolution of repository conditions with time (primarily thermal and hydrologic conditions), and the occurrence of substantially changed conditions produced by various scenarios. A mechanistic model of wastepackage failure would relate the source term to these factors. Incorporation of such a mechanistic model can help to reveal the interactions between the source-term behavior and the behavior of other parts of the repository system.

2. Develop a mechanistic model of contact between groundwater and the waste.

In the Phase 1 demonstration, the fraction of groundwater contacting the waste (and thereby brought up to the appropriate limiting concentration for each radionuclide) was assumed to be a random variable, selected from an assumed distribution. A mechanistic model for the fraction of groundwater raised to the limiting concentration of radionuclides could relate this fraction to parameters generally thought to influence such mass transfer; e.g., the nature of flow near the repository (including, the flow rate, the degree of saturation, and the flow profile near the waste packages), the degree of mixing 
induced by the repository design, the thermal conditions in the repository and the potential for thermally driven flow. An even more direct approach would dispense with the concept of the fraction of groundwater contacting, the waste and instead, would calculate mass transfer from the ensemble of waste packages to the geosphere, based on the appropriate physical and geometrical parameters.

3. Treat the repository as a source of radionuclides distributed in time and space.

In the Phase 1'demonstration, all the waste packages were assumed to fail at a single time, rather than the more realistic assumption of waste-package failures distributed in time; and 'therefore, space. The release rate of the inventory from the containers was assumed also to be limited by the solubility of the $\mathrm{UO}_{2}$ matrix. Some of the spatially distributed nature of the repository was treated in Phase 1 by partitioning the waste into four groups of packages overlying four columns for radionuclide transport. However, because all waste packages were assumed to fail simultaneously, the variance in radionuclide releases may have been underestimated. ' $\mathrm{A}$ more inclusive and mechanistic model of the repository distributed in space and time should provide a more realistic picture of the dependence of repository performance on various parameters and on various components. Improved modeling could be accomplished by extending some of the methods used' in 'the Phase 1 demonstration.

\subsection{Improvements and Extensions to Auxiliary Analyses}

The following are recommended improvements to and extensions of the auxiliary analyses. These appear to be important aspects of a performance assessment, requiring more detailed study, which were not within the scope of Phase 1.

1. Perform detailed geochemical analyses to investigate:

a. The use of $K_{D}$ (distribution coefficients) in estimating radionuclide transport.

In the Phase 1 demonstration, $K_{D} s$ were used in estimating the transport of radionuclides. Because of the complex and time-consuming nature of detailed geochemical analyses, which are an alternative to the $K_{D}$ approximation, additional modeling efforts are likely to use the $\mathrm{K}_{\mathrm{D}}$ approximation. Therefore, an auxiliary analysis to show how appropriate this approxi- mation is and under what conditions it is more or less accurate would be useful.

b. The effects of spatially varying saturation on radionuclide migration.

In the Phase 1 demonstration, the effects of spatially varying saturation were assumed to be limited to changing the amount of groundwater available for advection and dispersion, as the groundwater moved through various hydrogeologic units. The possibility of a more complex influence of the variation in saturation along the migration path on radionuclide transport was not considered. For example, some reactions, such as those resulting in precipitation, may depend on the amount of water available. An auxiliary analysis to determine how well approximations useful in fully-saturated flow can be extended to model partially-saturated flow would be useful.

c. The waste form/groundwater/tuff interactions.

In the Phase 1 demonstration, the dissolution of the waste form was based on a simple model of the solubility of a particular radionuclide in the groundwater. A more complex, comprehensive, realistic treatment of the dissolution of the waste form, that considers the complex interactions of the waste form, the host rock, and the groundwater, would help to determine the accuracy of the simpler modeling approaches.

d. The degradation of the waste package.

In the' Phase: 1 demonstration, a nonmechanistic model of waste-package degradation was used. An essential ingredient of a more realistic treatment would be to consider the geochemical interactions among the canister,' host rock; and groundwater. An auxiliary analysis of this type could indicate important parameters, outstanding questions regarding phenomenology, and the directions for additional work to take.

$\therefore$ The oxidation of the spent fuel matrix.

In the Phase 1 demonstration, oxidation of the spent fuel matrix was a phenomenon important in determining the behavior of the source term, especially the gaseous phase releases of C-14. Various empirical and semi-empirical approaches were,employed to describe this phenomenon. Detailed geochemical analyses of the rate of spent fuel matrix oxidation and its dependence on temperature and geochemical 
conditions'would help to determine how well this phenomenon is understood and whether the modeling should be improved.

f. The geochemical behavior of plutonium.

In the Phase 1 demonstration, plutonium appeared to be a major contributor to the total system performance measure, the CCDF. An auxiliary analysis, to evaluate the adequacy of the modeling of plutonium transport and to determine whether the geochemical data base for plutonium interactions with tuff is adequate, would be useful. The geochemical behavior of plutonium in the near field would also: be a useful subject of study.

2. Evaluate heat effects at early times and estimate the thermal, hydrologic, and geochemical environment of the repository at early times.

In the Phase 1 demonstration; the calculated performance did not explicitly take into account the thermal, hydrologic, and geochemical conditions of the repository at early times, and how such conditions might affect performance. Consequently, the design, environmental, and site conditions that influence these conditions were not explicitly modeled. An auxiliary analysis of these complex interactions could help to determine which phemomena and parameters should be included in improved models of repository performance.

3. Evaluate the importance of thermally- and barometrically-driven air flow on repository performance at Yucca Mountain.

is

if: In the Phase 1 demonstration, the flow of groundwater was calculated using a simple; onedimensional flow approximation that did not include interaction with fluids in the gaseous phase. The SCP, NRC's Site Characterization Analysis (NRC, 1989), and other documents (including several reviewed as part of the Phase 1 effort) indicate that the , barometrically- and thermally-driven flow of air and water vapor at Yucca Mountain may have a significant impact on the movement of groundwater and, therefore, may have a potential impact on repository performance. An auxiliary analysis on the nature of such gas flows and theirimpact on the movement of groundwater at Yucca Mountain could indicate whether these effects should be included explicitly in models of repository performance:

4. Perform detailed -hydrologic analyses for Yucca L. Mountain, to provide a better input to the transport analysis and to examine, in more detail, various al- ternative hypotheses regarding hydrology at Yucca Mountain.

In the Phase 1 demonstration, the hydrologic analysis consisted of a one-dimenisional, steady-state approximation of the unsaturated flow conditions at . Yucca Mountain. Detailed hydrologic analyses that èvaluate the applicability of these and otherassumptions (e.g., vertical flow downward, a fixed watertable location) and the effects of regional flow conditions could suggest ways to improve modeling of repository performance.

\subsection{Recommendations for Additional Scientific Input}

The following are recommendations for additional scientific input, some of which could be performed by either DOE or NRC, whereas others are clearly the responsibil-: ity of DOE). These suggestions were clearly: beyond the scope of the Phase 1 effort, but were identified as gaps in knowledge, as the work in Phase 1 progressed.

1. Develop and demonstrate a mathematically rigorous, scientifically robust method for scenario analysis.

In the Phase 1 demonstration, an attempt was made to follow the methodology for scenario analysis developed by SNL. Conceptual and logical problems were encountered when attempting to define, enumerate, and screen scenarios. A more mathematically rigorous, scientifically robust approach to sceniario analysis would streamline the interactions between modelers and various scientific disciplines and would permit a more transparent, direct deriva-

i. tion and presentation of results.

2. Obtain geoscience input for modeling volcanism.

During the Phase 1 demonstration, some consideration and evaluation was given to the scientific bases available to model the occurrence and manifestation of volcanism. Although some information was identified regarding previous occurrences of volcanism at Yucca Mountain, the physical mechanisms for predicting site-specific volcanism at Yucca Mountain appear to be poorly understood. Additional information was identified regarding how different types of volcanic events might be manifested within or near to a repository. It would be useful to perform a comprehensive review of potentially valuable literature, as well as to consider what additional general and site-specific information and original research are needed to estimate the likelihood and consequences of volcanism at Yucca Mountain. 
3. Obtain geoscience and hydrologic input for modeling faulting, uplift, and subsidence at Yucca Mountain.

During the Phase 1 demonstration, tectonic events and processes such as faulting, uplift, and subsidence were identified as potentially important fundamental events that should be consideredin defining and selecting scenarios for a performance assessment of á Yucca Mountain repositöry. Although some-substantial information has been compiled (e.g., in the SCP) on these processes and events in the tectonic province and in the immediate vicinity of Yucca Mountain, additional field data and other original research may be needed. A more comprehensive review of applicable literature and the identification of additional data needs would be useful.

4. Obtain laboratory chemical analyses to determine the partitioning of radionuclides in various compartments of the spent fuel waste form.

During the Phase 1 demonstration, an important issue regarding the behavior of spent fuel as a waste form was the quantity, of various radionuclides in various compartments of this complex waste form. Spent fuel can be considered to consist of at least five different compartments (proceeding from outside in): (1) crud adhering to the outer surface of the cladding, (2) the cladding, (3) the gap between the cladding and fuel pellets, (4) the intergranular spaces in the fuel matrix, and (5) the fuel matrix itself. The rate of release of a particular radionuclide depends on the compartment in which it is located, because of the physical and chemical form it may be in and because compartments closer to the geosphere may release their radionuclide inventory first. This consideration appears to be important in determining the rate and quantity of $\mathrm{C}-14$ release. However, very little data on the inventory of various radionuclides in these different compartments were identified. This lack of data limited the Phase 1 analysis.

5. Obtain field and laboratory data on phenomena important to the near-field behavior of the repository, especially the effects of heat.

(...

Although the Phase 1 demonstration explicitly took into account, the thermal, hydrologic, and geochemical conditions in the near-field of the repository and how such conditions might affect performance, considerations of such complex, near-field interactions was limited to rudimentary, frequently nonmechanistic, modeling. Although an auxiliary analysis of these complex interactions could help to determine which phemomena and parameters to include in im- proved models of repository performance, execution of such auxiliary analyses appears to be limited by the lack of phenomenological information and data available for tuff. Additional field and laboratory experiments could provide needed data.

6. Obtain more data on plutonium geochemistry.

In the Phase 1 demonstration, plutonium was a major contributor to the total system CCDF. An expansion of the geochemical data base for plutonium interactions with tuff may be useful.

7. Obtain a better understanding of waste-package corrosion in the unsaturated zone.

is In the Phase 1 demonstration, a selected distribution of waste-package failure was used, in large part because few analyses and data exist that treat the corrosion of waste packages in a partially saturated re: pository. On the. basis of the literature review performed as part of Phase 1, it appears that additional phenomenological data are needed before waste-package corrosion in the unsaturated zone can be modeled.

8. Obtain field and laboratory data and perform analyses to investigate the issue of non-vertical flow at 'Yucca Mountain.

An assumption used in the Phase 1 demonstration transport calculations was that flow moved vertically downward in four columns underlying the repository: An auxiliary analysis; performed in Phase 1 to evaluate the potential for non-vertical flow (Appendix G), indicated that non-vertical flow might occur, under certain conditions. Nonvertical flow could affect radionuclide transport and groundwater travel times. Therefore, it appears that additional field and laboratory data and additional analyses on the potential for non-vertical flow would be useful.

9. Obtain field and laboratory data on the transport of gaseous radionuclides, especially C-14, at Yucca Mountain.

In the Phase 1 demonstration, the release of $\mathrm{C}-14$ and other gaseous radionuclides along the gas path"way was not explicitly incorporated into the total sys$\because$ tem CCDF. An auxiliary analysis executed in Phase 1 (Appendix D) indicated that the release of these radionuclides in the gas phase may be important. An obstacle to the realistic modeling of such releases is the lack of general and site-specific data on gaseous radionuclide transport. Additional data would be useful. 


\section{R. REFERENCES}

Amter, S., et al., 1988, "Carbon-14 Travel Time at Yucca Mountain," Appendix to "An Example Postclosure Risk Assessment Using the Yucca Mountain Candidate Site," P. Doctor, et al., 1992, PNL-8081, Pacific Northwest Laboratories, Richland, Washington.

Anderson, L.A., 1981a, "Rock Property Analysis of Core Samples From the Calico Hills UE25a-1 Borehole, Nevada Test Site, Nevada," USGS OFR 81-1337, U.S. Geological Survey, Reston, Virginia.

Anderson, L.A., 1981b, "Rock Property Analysis of Core Samples From the Calico Hills UE25a-1 Borehole, Nevada Test Site, Nevada," USGS OFR 81-1338, U.S. Geological Survey, Reston, Virginia.

Anderson, L.A., 1984, "Rock Property Measurements on Large-Volume Core Samples From Yucca Mountain USW GU-3/G3 and USW G-4 Boreholes, Nevada Test Site, Nevada," USGS OFR 84-0552, U.S. Geological Survey, Reston, Virginia.

Baybutt, P., D.C. Cox, and R.E. Kurth, 1981, "Methodo1ogy for Uncertainty Analysis of Light Water Reactor Meltdown Accident Consequences," Topical Report from Battelle Columbus Laboratories to U.S. Nuclear Regulatory Commission. $\rightarrow$

Beahm, E.C., W.E. Shockley and O.L.Culberson, 1985, "Organic Iodide Formation Following Nuclear Reactor Accidents," NUREG/CR-4327, U.S. Nuclear Regula-! tory Commission, Washington, D.C. ,,

Bear, J.', 1979, Hydraulics of Groundwater, McGraw-Hill, New York, New York.

Bixler; N.E., 1985, "NORIA-A Finite Element Computer Program for Analyzing Water, Vapor, and Energy Transport in Porous Media," SAND84-2057, Sandia National Laboratories, Albuquerque, New Mexico.

Bonano, E.J., et al., 1989, "Demonstration of a Performance Assessment Methodology for High-Level Radioactive "Waste Disposal in Basalt Formations," NUREG/ CR-4759, U.S. Nuclear Regulatory Commission; Washington, D.C.

Boyars, C., et al., 1985, "Demonstration of Methodology for Waste Package Performance Assessment," WPR-86 (6810-01)-81, Aerospace Corporation.

Cacuci, D.G., et al., 1980, "Sensitivity Theory for General System of Nonlinear Equations," Nuclear Science and Engineering 75, 88.
Campbell, J.E., R.L. Iman, and M. Reeves, 1979, “Risk Methodology for Geologic Disposal of Radioactive Waste: Transport Model Sensitivity Ảnalysis."

Campbell, J.E. and D. Longsine, 1989, "Application of Generic Risk Assessment Software to Radioactive Waste Disposal (Draft)," SAND89-1419C, Sandia National Laboratories, Albuquerque, New Mexico.

Carlos, B., 1985, "Minerals in Fractures of the Unsaturated Zone from Drill Core USW-G-4, Yucca Mountain, Nye County, Nevada," LA-10415-S, UC-70, Los Alamos Láboratories, Los Alamos, New Mexico.

Center for Nuclear Waste Regulatory Analyses, 1988, "Fast Probabilistic Performance Assessment (FPPA) Methodology Evaluation," CNWRA88-004, San Anțonio, Texas.

Cochran, W. G., 1963, Sampling Techniques,'John Wiley and Sons.

Cole, C.R., et al., 1987, "Lessons Learned from" the HYDROCOIN Experience," Proceedings of GEOVAL 1987 Symposium, Swedish Nuclear Power Inspectorate, Stockholm, Sweden.

Cox, D.C. and P. Baybutt, 1981, Risk Analysis, Vol. 1 No. 4, p. 251.

Cranwell, R.M. and Helton, J.C., March 9-13, 1981, "Uncertainty: Analysis for Geologic Disposal of Radioactive Waste," Proceedings of Symposium on Uncertainties Associated with the Regulation of the Geologic Disposal of HighLevel Radioactive Waste, Gatlinburg, Teninessee, March 9-13, 1981, Conf-810372, ed. D.C. Kocher, pp. 131-144.

Cranwell, R.M., et al., 1982, "Risk Methodology for Geologic Disposal of Radioactive Waste: Scenario Selection Procedure," NUREG/CR-1667, U.S. Nucleat Regulatory Commission, Washington, D.C.

Czarnecki, J.B., 1985, "Simulated Effects of Increased Recharge on the Ground-Water Flow System of Yucca Mountain and Vicinity, Nevada-Californiä," WaterResources Investigations Report, USGS WRI 84-4344; U.S. Geological Survey, Reston, Virginia.

Doctor, P., et al., 1992; “An Example Postclosure Risk Assessment Using the Potential Yucca Mountain Site," PNL-8081, Pacific Northwest Laboratories, Richlánd, Washington.

Dudley, A.L., et al., 1988, "Total System Performance Assessment Code (TOSPAC), Volume 1: Physical and 
Mathematical Bases," SAND85-0002, Sandia National Laboratories, Albuquerque, New Mexico.

Einsiger, R.E. and R.E. Woodley, 1985a, "Evaluation of the Potential for Spent Fuel Oxidation under Tuff Repository Conditions", HEDL-7452, Hanford Engineering Development Laboratory, Richland Washington.

Einsiger, R.E. and R.E. Woodley, 1985, "Low Temperature Spent Fuel Oxidation under Tuff Repository Conditions," HEDL-SA-3271, Hanford Engineering Development Laboratory, Richland Washington.

Einsiger, R.E., and R.E. Woodley,' 1987; "Predicting Spent Fuel Oxidation States in a Tuff Repositóry," HEDL-SA-3267, Westinghouse Hanford Company, Richland, Washington.

Einziger, R., and R. Kohli, 1984, "Low Temperature Rupture Behavior of Zircalloy-Clad Pressurized Water Reactor Spent Fuel Rods under Dry Storage Conditions," Nuclear Technology, vol. 67, pp. 107-123.

Engel, D.W., et al., 1989, "The AREST Code: User's" Guide for the Analytical Repository Source-Term Model," PNL-6645, Pacific Northwest Laboratories, Richland, Washington.

Englund, E. and A. Sparks, 1988, "GEO-EAS (G' 'Mostatistical Environmental Assessment Software) User's Guide," EPA/600/4-88/-33a, U.S. Environmental Protection Agency, Washington, D.C.

Fischer, F. and J. Ehrhardt, 1985, "Uncertainty Analysis with a View Towards Applications in Accident Consequence Assessments," Kernforschunqszentrum Karișruhe, kfk 3906.

Freeze, R.A. and J.A. Cherry, 1979, Groundwater, Prentice-Hall, Englewood Cliffs, New Jersey.

Gelhar, L.W. and C.L. Axness, 1983, "Three-" Dimensional Stochastic Analysis of Macrodispersion in Aquifers," Water Resources Research, Vol. 19, no. 1, pp. 161-180.

Gelhar, L.W. and A. Mantoglou, 1987, "Stochastic Modeling of Large-Scale Transient Unsaturated Flow Systems," Water Resources Research, Vol. 23, no. 1, pp. 37-46.

Grambow, B., 1989, "Spent Fuel Dissolution and Oxidation-An Evaluation of Literature Data," SKB 89-13, Swedish Nuclear Fuel and Waste Management Company, Stockholm, Sweden.

Hadley, G.R., 1985, "PETROS-A Program for Calculating Transport of Heat, Water, Water Vapor, and Air
Through Porous Material," SAND84-0878, Sandia National Laboratories, Albuquerque, New Mexico.

Hayden, N.K., 1985, "Benchmarking NNWSI Flow and Transport Codes: Cove 1 Results," Sandia National Laboratories, SAND84-0996, Albuquerque, New Mexico.

Helton, J.H., 1961, SLAM Review, 12, 1.

Hodgkinson, D.P., and T.J. Sumerling, 1989, “A Review of Approaches to Scenario Analysis for Repository Safety Assessment," paper presented at NEA Symposium on Safety Assessments for Repositories, Paris, France.

Huyakorn, P.S.; 1989, "VAM2D-Variably Saturated Analysis Model in Two Dimensions," NUREG/CR-5352, U.S. Nuclear Regulatory Commission, Washington, D.C.

Iman, R.L., 1980, "Stepwise Regression with PRESS and Rank Regression," SAND80-1472, Sandia ,National Laboratories, Albuquerque, New Mexico.

Iman, R.L. and W.J. Conover, 1979, "The Use of Rank Transform in Regression," Technometrics 21, pp. 499-509.

Iman, R., W. Conơver, and J. Campbell, 1980, "Rísk Methodology for Geologic Disposal of Radioactive Waste: Small Sample' Sensitivity Analysis Techniques for Computer Models, with an Application to Risk Assessment," NUREG/CR-1397, U.S. Nuclear Regulatory Commission,' Washingtoni,' D.C.

Iman, R., J: Davenport, and D. Zeigler, 1980, "Latin Hypercube Sampling (Program User's Guide)," SAND79-1473, Sandia National Laboratories, Albuquerque, New Mexico.

Iman, R.L. and J.M. Davenport, 1984, "An Iterative Algorithm to Produce a Positive Definite Correlation Matrix from an Approximate Correlation Matrix (with a Program User's Guide)," SAND81-1376, Sandia National Laboratories, Albuquerque, New Mexico.

Iman, R.L. and M.J. Shortencarier, 1984, “A FORTRAN 77 Program and User's Guide for the Generation of Latin Hypercube and Random Samples for Use with Computer Models," NUREG/CR-3624 (SAND83-2365), U.S. Nuclear Regulatory Commission, Washington, D.C.

International Formulation Committee, 1967, A Formulation of the Thermodynamic Properties of Ordinary Water Substance, IFC Secretariat, Dusseldorf, Germany.

Katz, J.J., and E. Rabinowitz, 1951, The Chemistry of Uranium-The Element, Its Binary and Related Compounds, National Nuclear Energy Series, Division VIII, Vol.5, Dover Publications Inc, New York. 
Killough, G.G.; and J.E. Till, 1978, "Scenarios of ${ }^{14} \mathrm{C}$ Releases from the World Nuclear Power Industry and Estimated Radiological Input," Nuclear Safety, Vol.18, no.5, pp. 602-17.

Knapp, R., 1987, "An Approximate Calculation of Advective Gas Transport of C-14 at Yucca Mountain, Nevada," UCRL-97805 (preprint), Lawrence Livermore National Laboratory, Livermore, California.

Lahoud, D.H., et al., "1984, "Geohydrology of Volcanic Tuff Penetrated by Test Well UE25b\#1, Yucca Mountain, Nye County, Nevada," USGS WRI 84-4253, U.S. Geological Survey, Reston, Virginia.

Lee, W., April 6, 1989, Letter to Dr. N. Eisenberg, detailing codes developed at UCB on file at the National Energy Software Center.

Liebetrau, A, et al., 1987, "The Analytic Repository Source Term Code for Waste Package Performance," PNL-6346, Pacific Northwest Laboratories, Richland, Washington.

Lin, Y.T., 1985, "SPARTAN-A Simple Performance Assessment Code for the Nevada Nuclear Waste Storage Investigations Project," SAND85-0602, Sandia National Laboratories, Albuquerque; New Mexico.

Lin, Y.T. and M.S. Tierney, 1986, "Preliminary Estimates of Groundwater Travel Time and Radionuclide Transport at the Yucca Mountain Repository Site," SAND85-2701, Sandia National Laboratories, Albuquerque, New Mexico.

Lóngsine, D.E., E.J. Bonano, and C.P. Harlan, 1987, "User's Manual for the NEFTRAN Computer Code," NUREG/CR-4766, U.S. Nuclear Regulatory Commission, Washington, D.C.

McKay, M.D., W.J. Conover, and R.J. Beckman, 1979, "A Comparison of Three Methods for Selecting Values of Input Variables in the Analysis of Output from a Computer Code," Technometrics 21, pp. 239-245.

Meyers, R.H., 1971, Response Surface Methodology, Allen and Bacon, Inc., Boston, Massachusetts.

Miller, C.W., 1983, "CHEMTRN .User's Manual," Pub-3031, Lawrence Berkeley Laboratory, Berkeley, California.

Montazer, P. and W. Wilson, 1984, "Conceptual Model of Flow in the Unsaturated Zone, Yucca Mountain, Nevada," USGS WRI 84-4345, U.S. Geological Survey, Reston, Virginia.
Montazer, P., et al., 1985, "Monitoring The Vadose Zone in Fractured Tuff, Yucca Mountain, Nevada," Proceedings, National Water Well Association Conference on Characterization and Monitoring of the Vadose (Unsaturated) Zone, Denver, Colorado, November 19-21, 1985.

Oblow, E.W., 1978, Nuclear Science and Engineering, Vol. 65, p. 187.

Ogard, A., et al., 1983, "Are Solubility Limits of Importance to Leaching?," Scientific Basis for Nuclear Waste. Management, Material Research Society Proceedings, Vol.3, pp. 331-337.

Parkhurst, D.L., D.C. Thorstenson, and L.N. Plummer, 1980; "PHREEQE-A Computer Program ifor Geochemical Calculations," Water-Resources Investigations Report 80-96, U.S. Geological Suryey, Reston, Virginia.

Parsons, A.M., et al., 1990, "Conceptualization of a Hypothetical High-Level Nuclear. Waste Repository Site in Unsaturated, Fractured Tuff," NUREG/CR-5495, U.S. Nuclear Regulatory Commission, Washington, D.C.

Peters, R.R., et al., 1984, "Fracture and Matrix Hydrologic Characteristics of Tuffaceous Materials From Yucca Mountain, Nye County, Nevada," SAND84-1471, Sandia National Laboratories, Albuquerque, New Mexico.

Plummer, L.N., B.F. Jones, and A.H. Truesdell, 1976, "WATEQF-A Fortran IV Version of WATEQ, A Computer Program for Calculating Chemical Equilibrium of Natural Waters," Water-Resources Investigations Report 76-13, U.S. Geological Survey, Reston, Virginia.

Prindle, R.W., 1987, "Specification of a Test Problem for HYDROCOIN Level 3 Case 2: Sensitivity Analysis for Deep Disposal in Partially Saturated, Fractured Tuff,". SAND86-1264, Sandia National Laboratories, Albuquerque, New Mexico.

Pruess, K., 1987, “TOUGH U̇ser's Guide," NUREG/ CR-4645, U.S. Nuclear Regulatory Commission, Washington, D.C.

Rasmussen, T.C., and D.D. Evans, 1987, "Unsaturated Flow and Transport Through Fractured Rock Related to High-Level Waste Repositories, Final Report-Phaśe II," NUREG/CR-4655, U.S. Nuclear Regulatory Commission, Washington; D.C.

Reda, D.C., 1987, "Influence of Transverse Microfractures on the Imbibition of Water into Initially Dry Tuffaceous Rock," Geophysical Monograph 42, American Geophysical Union, Washington, D.C., 187 p.

Reed, D.T., et al., 1987, "Effects of Ionizing Radiation on Moist Air Systems", UCRL-97936, Lawrence Livermore National Laboratory, Livermore, California. 
Reed, D.T., and R.A. van Konynenburg, 1987, "Effects of Ionizing Radiation on Moist Air Systems,". Material Research Society Symposium on the Scientific Basis for $\mathrm{Nu}$ clear Waste Management XI; Boston, Massachusetts.

Rice, W.A., 1984, "Preliminary Two-Dimensional Regional Hydrologic Model of the Nevada Test Site and Vicinity," SAND83-7466, Pacific Northwest Laboratory.

Robinson, P.C. and D.P. Hodgkinson, 1986, "Exàct Solutions for Radionuclide Transport in the Presence of Parameter Uncertainty," AERE R 12125, United Kingdom Atomic Energy Authority (Harwell Laboratory), Oxfordshire, England.

Ross, B., 1988, "Gas-Phase Transport"of Carbon-14 Released from Nuclear Waste into the Unsaturated Zone," Material Research Society, Symposium Proceedings, vol. 112.

Rush, F.E., 1970, "Regional Ground-Water Systems in the Nevada Test Site Area, Nye, Lincoln, and Clark Counties, Nevada," Water Resources Reconnaiśsance Series Report 54, Department of Conservation and Natural Resources, State of Nevada, Carson City, Nevada.

Sass, J. and A. Lachenbruch, 1982, "Preliminary Interpretation of Thermal Data From the Nevada Test Site," USGS OFR 82-973, U.S. Geological Survey, Reston, Virginià.

Sinnock, S., Y.T. Lin, and J.P. Brannen, 1984, "Preliminary Bounds on the Expected Postclosure Performance of the Yucca Mountain Repository Site," Southern Nevada," SAND84-1492, Sandia National Laboratories, Albuquerque, New Mexico.

Sinnock, S., et al., 1986, "Preliminary Estimates of Groundwater Travel Time and Radionuclide Transport at the Yucca Mountain Repository Site," SAND85-2701, Sandia National Laboratories, Albuquerque, New Mexico.

Stumm. W., and J. Morgan, 1970, Aquatic Chemistry, Wiley-Interscience, New York.

Thomas, K., 1987, "Summary of Sorption Measurements Performed with Yucca Mountain Tuff Samples and Water from Well J-13," LASL LA10960MS, Los Alamos National Laboratory, Los Alamos, New Mexico.

Thomas, S.D., et al., 1982, "A Summary, of Repository Siting Models," NUREG/CR-2782, U.S. Nuclear Regulatory Commission, Washington, D.C.

Thompson, J.L., 1989, "Actinide Behavior on Crushed Rock Columns," Journal of Radioanalytical and Nuclear Chemistry, Vol. 130, no.2, pp. 353-364.
Travis, B.J., 1984, "TRACR3D: A Model of Flow and Transport in Porous/Fractured Media," LA-9667-MS, Los Alamos National Laboratory, Los Alamos, New Mexico.

Tsang, Y.W. and K. Preuss, 1987, "A Study of Thermally Induced Convection Near a High-Level Nuclear Waste Repository in Partially Saturated Fractured Tuff," Water Resources Research, vol. 23, pp. 1958-1955.

Updegraff, C.D., 1989, "Comparison of Strongly HeatDriven Flow Codes for Unsaturated Media," NUREG/ CR-5367, U.S. Nuclear Regulatory, Commission, Washington, D.C.

U.S. Code of Federal Regulations, "Environmental Radiation Protection Standards for Management and Disposal of Spent Nuclear Fuel, High-Level and Transuranic Radioactive Wastes," Part 191, Subchapter F, Title 40.

U.S. Code of Federal Regulations, "Disposal of HighLevel Radioactive Wastes in Geologic Repositories," Part 60, Chapter I, Title 10, "Energy."

U.S. Department of Energy, 1986, "Environmental Assessment, Yucca Mountain Site, Nevada Research and Development Area, Nevada,"' DOE/RW-0073.

U.S. Department of Energy, 1988, "Site Characterization Plan, Overview, Yucca Mountain Site, Nevada Research and Development Area, Nevada," DOE/RW-0198.

U.S. Department of Energy, 1988, "Site Characterization Plan: Yucca Mountain Site, Nevada Research and Development Area, Nevada," DOE/RW-0199.

U.S. Environmental Protection Agency, 1983, "REPRISK Code Documentation," prepared by Arthur D. Little, Inc., Cambridge, Massachusetts.

U.S. Nuclear Regulatory Commission, Draft Generic Technical Position "Interpretation and Identification of the Extent of the Disturbed Zone in the High-Level Waste Rule (10 CFR 60)," Notice of Availability in Federal Register, Vol. 51, No. 132, 25125 (July 10, 1986).

U.S. Nuclear Regulatory Commission, 1989. "Severe Accident Risks: An Assessment for Five U.S. Nuclear Power Plants," NUREG-1150, Washington, D.C.

van Genuchten, M., and P.J.'Wierenga, 1976, "Mass Trànsfer Studies in Sorbing Porous.Media," Soil Science Society of America Joumal, 40 (4), pp. 473-480.

yan Konynenberg, R., et al., 1984, "Behavior of C-14 in Waste Packages for Spent Fuel in a Repository in Tuff," UCRL-90855, Lawrence Livermore National Laboratory, Livermore, California. 
van Konynenberg, R., et al., 1987. "Carbon-14 in Waste Packages for Spent Fuel in a Tuff Repository," in Scientific Basis for Nuclear Waste Mangement, Material Research Society Proceedings, ed.J.K. Bates and W.B. Seefeldt, Vol. 84, pp. 185-196.

Voss, C.I., 1984, "SUTRA Saturated-Unsaturated Transport-A Finite Element Simulation Model for SaturatedUnsaturated, Fluid-Density-Dependent Groundwater Flow with Energy Transport or Chemically-Reactive Single-Species Solute Transport," USGS WRI 84-4369, U.S. Geological Survey, Reston, Virginia.

Weeks, E.P. and W.E. Wilson, 1984, "Preliminary Evaluation of Hydrologic Properties of Cores of Unsaturated
Tuff, Test Well USW H-1, Yucca Mountain, Nevada," USGS WRI 84-4193, U.S. Geological Survey, Reston, Virginia.

Wilson, W.E., 1985, Letter from W.E. Wilson (USGS) to D.L. Vieth (DOE/NVO), December 24, 1985; regarding unsaturated zone flux.

Winograd, I., 1981, "Radioactive Waste Disposal in Thick Unsaturated Zones," Science, Vol. 212, No. 4502, June 26, 1981.

Wolery, T.J., 1979, "Calculation of Chemical Equilibrium between Aqueous Solution and Minerals: The EQ3/6 Software Package," UCRL-52658, Lawrence Livermore National Laboratory, Livermore, California. 


\section{APPENDIX A - SYSTEM CODE REVIEW : \\ A.1 Introduction \\ standard. The code does not take into account various}

The following discussion provides summaries of several programs evaluated by the staff to determine their suitability, as a whole or in part, for use as a system code for the Phase 1.demonstration. Not all the programs. pre-" sented are system codes per se, but each contained elements considered necessary to the approach used in this. effort.

\section{A.2 Program Summaries}

\section{A.2.1 AREST}

The AREST code (Engel, et al., 1989) was developed by Pacific Northwest Laboratory for the U.S. Department of Energy (DOE). The program takes a modular approach to the problem of making preliminary, quantitative performance assessments of the engineered barrier and near-field systems. Input variables to the code include values assigned to the spent fuel waste package, as well as to variables describing the physical and chemical environments of the repository/near-field system and the waste package.

AREST models the performance of the assemblage of individual waste packages from repository closure to the failure of the canister, the release of radionuclides from the failed packages, and the subsequent movement of the radionuclides away from the waste packages. Average release rates and cumulative releases over time can be calculated from successive waste-package simulations.

The code cannot be considered as a total system code, since it treats only various failure mechanisms for the waste packages and not the possible scenario classes creating the conditions for failure.

\section{A.2.2 SPARTAN}

SPARTAN (Lin, 1985) is a simple performanceassessment model developed by Sandia National Laboratories to support DOE's Environmental Assessment of a potential repository at Yucca Mountain, Nevada. Input, consisting of repository, hydrogeologic, waste-package, and spent fuel characteristics, is used to simulate the one-dimensional, dispersionless transport of radionuclides in both a porous matrix and a fractured media.

Radionuclide release rates and cumulative curies released are calculated. From this, the performance of the repository can be measured relative to the U.S. Nuclear Regulatory Commission's (NRC) performance objectives and to the U.S. Environmental Protection Agency (EPA) scenarios.

\section{A.2.3 TOSPAC}

Sandia National Laboratories developed TOSPAC(Dudley, et al., 1988) for DOE, specifically for the Yucca Mountain, Nevada site. The model considers the onedimensional, transient, unsaturated flow and transport of. soluble waste materials with coupling between the matrix and fractures.

The code is a FORTRAN 77 program that uses various modules to manage the input and output tasks and to model the differential equations governing water flow, radionuclide transport, and liquid-phase mass transport. A management driver oversees the interactions between these modules. Input to the code covers the material properties of the geologic strata, the radionuclide properties, and different boundary conditions. Output consists of release over time, radionuclide concentrations in the matrix and fractures versus time, and three-dimensional plots of concentration versus time versus distance.

\section{A.2.4 REPRISK}

REPRISK (EPA, 1983) is an EPA program that models the long-term radionuclide release and population health effects associated with the disposal of high-level radioactive wastes in mined geologic repositories. It was originally developed for a repository located in a saturated, porous salt media and can address variations in geologic setting, radionuclide inventories, radionuclide-release mechanisms and pathways, time frames, and dose-uptake pathways.

The code handles four designated "release mechanisms:" (1) direct impact of a waste package with release to air and land; (2) direct impact of a waste package with release to an aquifer; (3) disruption of the repository with release to land; and (4) disruption of the repository with release to an aquifer. REPRISK does not treat radionuclide decay chains and does not incorporate a random sampling program (like Latin Hypercube Sampling (LHS)) or any sensitivity and uncertainty analyses.

Consequences of a release to the accessible environment can be expressed as somatic or genetic health effects, a ratio of release amount to limits set in 40 CFR Part 191, and/or total curies released per radionuclide.

\section{A.2.5 SUNS}

The Sensitivity and Uncertainty Analysis Shell (SUNS) (Campbell and Longsine, 1989) is a Sandia National Laboratories generic software shell created to perform 
Monte Carlo and LHS analyses. It is a modular, menu driven code with a flexible input editor that can incorporate a variety of application models suitable for such analyses. The user provides replacement statements to equate model variable names to locations in the various SUNS arrays. The program is designed for parametric analyses and correlation studies.

SUNS performs all file-management operations. Output is available in both statistical and graphical formats:

\section{A.2.6 Code Coupler Programs}

Sandia National Laboratories developed the Code Cou- pler programs (Bonano, et al., 1989) to provide linkage between a suite of Sandia codes for a total system performance assessment. This linkage is given on two scales: (1) between the regional and local flow models; and (2) between the local flow model and the radionuclide transport model.

aic $\therefore, \ldots$

LHS is used to create a common database for input in order to maintain a consistent description of the system for each of the models. Programs are available to plot. estimated flow paths, discharge rates (in curies per day) versus time (in years), and complementary cumulative distribution functions (CCDFs). 


\section{APPENDIX B -SOURCE TERM CODE REVIEW}

\section{B.1 Introduction}

This appendix presents reviews of source term models used in previous U.S. Department of Energy (DOE) analyses of the Yucca Mountain repository, and of other models related to source-term considerations, in general. It covers both dedicated source-term codes such as AREST, as well as source-term routines in systems codes. This is not a comprehensive list, but represents a sampling of codes whose references were available to the staff.

\section{B.2 Review of Available Source-Term Models Used for Assessing the Yucca Mountain Project (YMP) Site}

\section{B.2.1 Early DOE Assessment Models for Yucca Mountain}

DOE performed several preliminary, simplified, scoping assessments of the Yucca Mountain site performance. Two models used in these assessments were the Environmental Assessment model and the TOSPAC model.

\section{B.2.1.1 The Environmental Assessment model}

The Environmental Assessment (DOE, 1986) model considered the repository to be composed of three components: the waste package, the engineered barrier, and the geological barrier. The lifetime of the waste package was 3000 to 30,000 years, before which time there would be no liquid releases of radionuclides.' The 3000-year lowerbound lifetime was adopted to achieve "some degree of conservatism." The source-term model used in this assessment assumes that there would be congruent dissolution of the uranium dioxide $\left(\mathrm{UO}_{2}\right)$ matrix, and that the radionuclide release rate is proportional to the water flow past the fuel and the solubility of the matrix. DOE estimated that for an infiltration rate of $0.5 \mathrm{~mm}$ per year, a fuel matrix solubility of 0.05 kilograms per cubic meter, and an infiltration area per canister of 0.33 square meters, there would be a fractional release rate by congruent dissolution of 2.5E-9 per year. The model does not take into account solubility limits for released radionuclides, but assumes that with the exception of carbon, cesium, technetium and iodine, all solubility values would be less than or comparable to the value of the $\mathrm{UO}_{2}$ matrix. The authors recognize that there are other sources of radionuclides, 'e.g., in the pellet-cladding gap, the hardware, and the cladding, but that except for $\mathrm{C}-14$, they argue that the radionuclide inventories would not significantly affect their results for cumulative release. All C-14 releases are assumed to be from the matrix also, neglecting contributions from the cladding. and gap compartments. Interestingly, a DOE screening analysis indicated that most of the radionuclides would never reach the accessible environment, except for carbon, technetium and iodine. Since these are the very elements that tend to collect outside of the $\mathrm{UO}_{2}$ matrix, neglecting the other compartments may be a weakness in this approach. This model appears to be virtually identical to that presented by Lin and Tierney (1986).

\section{B.2.1.2 The TOSPAC model}

The Total System Performance Assessment Code (TOSPAC) (Dudley, et al., 1985) is a more sophisticated one-dimensional model developed by Sandia National Laboratories that considers transient unsaturated flow and radionuclide transport, with coupling between the matrix and fractures. The source-term model considers either the complete dissolution of the $\mathrm{UO}_{2}$ matrix, with release of all radionuclides (an extremely conservative assumption) or the more realistic congruent release model. The congruent release model assumes that: (1) the fractional release rate of radionuclides from the spent fuel inventory is equal to the fractional leach rate of the uranium dioxide matrix; (2) the rate of the matrix dissolution is a function of the solubility limit of uranium dioxide and the availability of water; and (3) the transport of dissolved species to the source boundary is instantaneous, and the transport behavior in the near-field region of the waste package (where the rock is thermally and mechanically disturbed) is similar in the adjacent undisturbed rock. The authors neglect radionuclide releases from compartments other than the $\mathrm{UO}_{2}$ matrix, but acknowledge the potential importance of these compartments. The amount of radionuclide release is limited to being 'less than or equal to the nuclide's solubility in the water contacting the waste. The authors claim that, in most cases, the solubility limit would be greater than the concentration, therefore, the release is truly congruent. This model would not appear to treat daughter products for chain decay unless all daughters had the same solubility.

Dudley, et al. recognize that the assumptions about how liquid water contacts the waste to begin the release process is not well understood. They assume that all the water intercepted by a container (which is equal to the product of the infiltration rate and the cross-sectional area of the canister) becomes saturated with waste. They also recognize that additional mechanisms may limit the dissolution of the matrix, e.g., diffusion out of the waste container, and that the advection-only model may be pessimistic.

Waste canisters are assumed to fail at a uniform rate, for lack of any data on actual failures. 


\section{B.2.2 More Recent Modeling of YMP Site Performance}

Doctor, et al. (1992) conducted a preliminary risk assessment for the Yucca Mountain site, in which releases from the engineered barrier were evaluated using the AREST code (Liebetrau, et al., 1987). The AREST model consists of three major components: the Engineered System Release (ESR) model; the Waste Package Containmenit (WPC) model, and the Waste Package Release (WPR) model. The code treats waste packages individually, with no interactions between adjacent waste packagès. The WPC model simulates corrosion and degradation leading to waste-package failure. The WPR model simulates release of radionuclides and their migration outward through the waste-package barriers. The ESR model integrates the simulated releases from individual waste packages with respect to their failure-time distribution. There is also a geochemical model to provide in puts to the three major component models. The authors used the concept of support models external to the AREST code to perform site-specific calculations that are too timeconsuming or difficult to include in the overall simulation.

The AREST code uses detailed site-specific information about the physical and chemical environment of the waste package and the repository. The code describes the thermal, geochemical, and hydrological environments of the simulated waste package. The geochemical model determines the chemical environment of the waste package. The hydrologic model for the unsaturated case determines the time that the waste packages might be rewetted after they cool, although it appears that the authors only considered porous media and not the possibility of fracture flow near the waste package. For saturated conditions, the hydrologic model calculates the time to achieve resaturation after repository closure. For unsaturated media, the thermal model calculates the time for the waste package to cool to a point where liquid water can come into contact with it.

Several mechanistic models of uniform and pitting corrosion, as well as empirical models derived from sitespecific testing, are assumed in the WPC model. The model does not differentiate between canister and cladding containment. In this risk assessment for the Yucca Mountain site, the authors did not use a mechanistic code for waste-package containment. Instead, they chose arbitrarily a normal distribution of failure times, with a mean of 1000 years and a standard deviation of 200 years, and the lower tail of the distribution truncated at 300 years.

The WPR model takes separate approaches for the saturated and unsaturated cases. The saturated model assumes low oxygen levels (leading to low dissolution rate for the $\mathrm{UO}_{2}$ matrix), low radionuclide solubilities, and low groundwater flow rates, so that releases are based on diffusive mass transfer. For unsaturated media, the model assumes that the environment is oxidizing, and that transport is likely to be convective rather than diffusive. Radionuclides are released from the waste matrix congruently at a rate given by the forward-matrix dissolution and the fractional inventory of the nuclide in the matrix. The model chooses the larger of the diffusive/solubility release rate or the convective release rate. The release rate may be solubility-limited if the rate of congruent release is high, and the solubility of the released species is low. The model also looks at the non-matrix components of the source term, and treats those radionuclides accumulated in the, interstices and cladding gap as solubility/ transport-limited, until the inventory is depleted. The modelers recognize that the $\mathrm{UO}_{2}$ matrix dissolution may not be truly controlled by solubility, but, rather, by the instability in an oxidizing environment, so that the rate could remain non-zero even when the solution becomes saturated with respect to the matrix. The modelers limited the release of the matrix radionuclides on the basis of an oxidized and more-soluble uranium silicate mineral.

Even if release rate is not controlled by the solubility of the matrix, and the radionuclide in question is not solubility-controlled, the rate of release might still be controlled by diffusion away from the waste form, rather than by convection, if the latter is very small. The models allows for certain of the radionuclides to form colloidal species. Diffusion of colloids might also limit their release for very low flow rates. Since colloids have much smaller diffusion coefficients than molecular species, this rate must be very small when the release is diffusion-limited. It is not likely that both diffusion and convection need to be considered simultaneously for the Yucca Mountain càse for any single species.

The WPR model makes no special provision for release of gaseous radionuclides, such as ${ }^{14} \mathrm{CO}_{2}$. It assumes that all this inventory is released upon failure of the canister. The non-volatile radionuclides that are not contained in the matrix generally have high solubilities and do not form colloids in oxidizing environments.

The geochemical model is used to determine the chemical environment of the waste packages. The model calculates the steady-state equilibrium concentration of J-13 water in equilibrium with the tuff at different temperatures and in a saturated condition. It does not treat radiolysis reaction between the water and the corroding canister material, the sorption of radionuclides, and water vaporization or rewetting. These may be serious omissions that should be tested with support models. In particular, the consequences of corrosion products of the canister and other materials on the rate of corrosion and dissolution of radionuclides, and the effects of mineral concentrations in the near field, resulting from the effects of heat and drying, should be tested. 


\section{B.2.3 Other Models Not Developed Specifically for the YMP Site.}

\section{B.2.3.1 NEFTRAN}

NEFTRAN (Longsine, et al., 1987) implements a Network Flow and Transport Model developed by Sandia National Laboratories primarily for the modeling of repository performance at saturated sites. NEFTRAN contains models for solubility-limited and leach-limited cases. If so desired, the program will determine whether a particular release is limited by leaching or solubility. A third model, mixing cell, assumes that the radionuclides are released into a well-mixed cell. The concentrations of the radionuclides in the cell are governed by flowrate through the cell, volume of the cell, and solubility of the radionuclide species.

The source-term model follows three radionuclide inventories. The first tracks the total mass of radionuclides remaining in the waste and is called the "unleached inventory." The second inventory is "undissolved," and it is that portion which has been released from the matrix by leaching, but whose release to the geosphere is limited by solubility. The third inventory represents dissolved radionuclides. Releases of radionuclides from the matrix depend on the leach rate of the matrix, that is, upon congruent dissolution. Releases become part of the soluble compartment if their solubility is greater than the concentration, or part of the undissolved compartment if vice versa. Concentrations of different isotopes of the same element are taken into consideration for solubility limits by specifying the fraction of the inventories for each isotope.

\section{B.2.3.2 Exact and asymptotic solutions}

The University of California, Berkeley (UCB), Earth Sciences Division has published a number of computer codes dealing mainly with the closed-form solution of flow and diffusive transport from waste packages and through the geosphere (Lee, 1989). Some of these solutions have been incorporated into the AREST code and the Pacific Northwest Laboratory (PNL) assessment of Doctor, et al. (1992). Some of the codes that may prove to be useful for defining the source term releases are:

UCBNE-101-Calculates the concentration of solubility-limited species as a function of space and time, and the mass flux rate from a waste sphere buried in a nuclear waste repository in water-saturated rock.

UCBNE-107-Calculates the fractional release rate of soluble radionuclides that are released from nuclear waste emplaced in water-saturated porous media. UCBNE-106-A time-dependent version "of
UCBNE-107.

UCBNE-106D-Calculates the time history of the diffusion coefficient.

UCBNE-106N-Calculates the species concentra-" tion in the void water, as a function of time.

UCBNE-106F-Calculates the fractional release rate of the species at the void/rock interface, as a function of time.

UCBNE-108-Calculates the mass flux rate and the fractional release rate at the interface between the first layer of porous material and the next layer of porous material of soluble species released in water-saturated porous media.

UCBNE-102-Calculates the mass flux of the nondecaying contaminant outward from a spherical waste form, when there is stationary precipitation at a prescribed distance from the waste separating an inner region of higher solubility and an outer region of lower solubility.

In addition to these codes that are specifically for nearfield phenomena, there are a set of UCB codes that integrate the source-term and the transport models. To get analytical solutions, the source term part of these models must be simple, either an impulse (i.e., instantaneous release), a step function in concentration or flux (band release), or a concentration boundary. None of these models can handle solubility limits, because these are inherently non-linear and cannot usually be solved in closed form. The models can treat the releases of chaindecaying radionuclides in the source, provided that their concentrations can be expressed by the Bateman equations and are not distorted by preferential removal of daughters.

\section{B.2.3.3 CONVO}

CONVO is a code developed for the U.S. Nuclear Regulatory Commission (NRC) to model the performance of the waste canisters and engineered barrier system (Boyars, et al., 1985). The code was primarily developed for demonstrating compliance with the NRC annual release criteria in $10 \mathrm{CFR}$ Part 60.113, rather than the cumulative release criteria of EPA, as embodied in 10 CFR Part 60.112. CONVO has three models for release of radionuclides:

1) a one-dimensional, dual-media model,

2) a three-dimensional, single-medium model, and

3) a two-dimensional, cylindrical, dual-media model.

These models assume that the radionuclides are released at the surface of the waste package through a porous 
packing material, and that releases are limited by diffusion and by solubility. There is no consideration given to radioactive decay and the rate at which the radionuclides are released from the $\mathrm{UO}_{2}$ matrix, or to compartments in the fuel other than the matrix. Release events are considered by two approaches:

1) The convolution approach, in which the time of peak releases is considered to be independent of the time of canister failures.
2) The cascade approach, in which the sequential failures of the canister packing are considered.

The code was targeted mostly to a saturated, zerovelocity, low solubility groundwater system, in which diffusion rather than advection was assumed to be the dominant transport mechanism for the release of radionuclides from the waste packages. It appears that, in its present form, CONV.O would be of little use as a sourceterm model for the Yucca Mountain site. 


\section{APPENDIX C-FLOW AND TRANSPORT CODE SUMMARIES}

\section{C.1 Regional Flow Program Summaries}

\section{C.1.1 SUTRA}

SUTRA (Voss, 1984), solves the equations for fluid density-dependent saturated or unsaturated groundwater flow, and either transport of a solute in the groundwater or transport of thermal energy in the groundwater and solid matrix. Solute transport in groundwater includes equilibrium adsorption on the solid matrix, and radionuclide production and decay. Additionally, SUTRA may be used to examine variable-density leachate movement and salt-water intrusion. Although energy-transport simulations can be performed with SUTRA, the program only simulates the liquid phase, without any consideration for phase changes.

The program uses an integrated finite-difference method to approximate the governing equations. The finite element mesh can accommodate arbitrary geometries employing quadrilateral finite elements in Cartesian (one or two dimensions) or radial-cylindrical (quasi-three dimensions) coordinate dimensions.

Explicit treatment of fractures is not accounted for in the model. However, a dual-porosity type of treatment for simulating fracture-matrix interactions would be possible through the use of a composite characteristic curve.

\section{C.1.2 VAM2D}

VAM2D (Huyakorn, 1989) is a two-dimensional, finite element program developed to simulate moisture movement and solute transport in variably saturated porous media. In solving the governing equations for groundwater flow, the program can take into account hysteretic moisture characteristics and variable (due to moisture content) anisotropy in the hydraulic conductivity of the unsaturated media. The program is capable of simulating the transport of chains of radionuclides that account for retardation phenomena, via a linear equilibrium isotherm.

VAM2D uses a finite element method to solve the flow and transport equations. Time integration is performed using implicit finite difference approximations, with nonlinearities being handled with either Picard or NewtonRaphson iteration schemes. Additionally, the iterative methods employs the Preconditioned Conjugate Gradient (PCG) for solving the matrix equations (The PCG method has recently emerged as a very promising technique for handling the numerical difficulties of groundwater modeling).
The current version of VAM2D has no capability to handle fracture-matrix problems. Future development (i.e., in 1990) of the program will include a capability to account for fractures via a composite characteristic curve.

\section{C.1.3 TRACER3D}

The TRACER3D program (Travis, 1984) simulates twophase mass flow and transport in a three-dimensional; deformable, heterogeneous, reactive porous medium. The program solves the equations for mass conservation of the liquid and gas and a reduced form of the momentum equation. The program has the flexibility to solve one-dimensional, single-phase flow problems, or to include features such as additional dimensions (up to three dimensions), the gas phase, and solute transport.

The partial differential equations are approximated using an integrated finite difference scheme. The iteration procedure is implemented using a Gauss-Seidel or successive over-relaxation method,

TRACER3D does not explicitly account for fractures, although the geometrically flexible, integrated finite difference approach would allow for discretizing very small elements that would tend to simulate fractures. However; the program represents the relative conductivity with the: Brooks and Corey expression that is reasonable for porous media, but may be unacceptable for fractures.

\section{C.2 Two-Phase Flow and Heat Transport Program Summaries}

\section{C.2.1 TOUGH}

TOUGH (Pruess, 1987) solves the equations for twophase flow of air and water in the vapor and liquid phases, and heat transport in a fully coupled way. The formulation used in TOUGH is analogous to that used in multiphase, multi-component, geothermal or steam-flooded hydorcarbon reservoir problems. The governing fluidflow equations account for gaseous diffusion, Darcy flow, capillary pressure, vaporization, and condensation with latent heat effects, and conduction and convention of heat are included in the energy equation. Water, air, and rock are assumed to be in thermodynamic equilibrium at all times: The flow domain can include liquid, gas, and two=phase regions, indicating that the code handles both saturated and unsaturated flow problems, either individually or simultaneously. The thermophysical properties of liquid and vaporized water are represented by the Interrnational Formulation Committee's (1967) steam-tables. Air is approximated as an ideal gas, and additivity of partial pressures is assumed for air-vapor mixtures. 
TOUGH solves three non-linear partial-differential equations simultaneously. These are the conservation equations for air, water, and heat. Air and water can be transported in either the liquid phase, the gas phase, or both. The dissolution of air in water is represented by Henry's law and flow (gas and liquid) by Darcy's law.

The code can simulate flow in one, two, or three dimensions, because the method of solution is based on a general integrated finite-difference method. Time-stepping is accomplished by a fully implicit procedure. The resulting non-linear difference equations are linearized by the Newton-Raphson technique.

The linearized equations are solved by the Harwell matrix solver, that stores only the non-zero elements of a matrix, thus reducing core storage requirements for the code.

\section{C.2.2 NORIA}

NORIA (Bixler, 1985) is designed to simulate liquid, vapor, air, and energy transport in partially saturated and fully saturated porous media. The following mechanisms are included in NORIA: (1) transport of water, vapor, and air due to pressure gradients; (2) transport of water, vapor; and air due to density gradients; (3) binary diffusion of vapor and air; (4) Knudsen diffusion of vapor and air; (5) thermo-diffusion of vapor and air; (6) conduction of sensible heat; (7) convection of sensible heat; (8) evaporation and condensation; (9) a nonequilibrium and equilibrium vapor pressure model; and (10) capillary. pressure. Nearly all the thermodynamic and constitutive properties in the code can be defined nonlinearly in terms of the remaining dependent or independent variables by the user.

NORIA solves four non-linear partial differential equations governing the flow of water, vapor, air, and energy. These equations consist of a water-pressure equation, a vapor partial-pressure equation, an air partial-pressure equation, and a heat equation. The equations are solved by the Galerkin finite-element method. Time-stepping is accomplished by a two-step time integrator with automatic time-step , selection:- The non-linear difference equations formed by application of the finite-element method are solved simultaneously by Newton-Raphson iteration. Normally, a one-step iteration is used; however, a multistep iteration is used if the correction on the first iteration is larger than a specified amount.

\section{C.2.3 PETROS}

PETROS (Hadley, 1985) is designed to simulate problems similar to those handled by NORIA. PETROS solves the same number and types of non-linear equations and handles the same physical processes as NORIA, but in a slightly different manner. The main difference between the two codes is that PETROS solves only one- dimensional problems, either in linear, radial, or spherical coordinates, and solves the equations with the finite-difference method. There are also some differences between the codes in the way the time integrations are performed. PETROS uses a modified version of the time integrator in NORIA.

PETROS solves three mass-conservation equations and a heat-conservation equation, just as NORIA. However, the liquid-conservation equation in PETROS is formulated with respect to saturation rather than pressure, as in NORIA. The characteristic curves and the thermal conductivity, as a function of saturation and temperature, are supplied to PETROS through user-written function subprograms. Other parameters such as diffusion coefficients, water viscosity, saturation vapor pressure of water, and default values of the characteristic curves and thermal conductivity are supplied internally in the code as function subprograms. Constants such as gas viscosity, specific heats, and water density can be set either at default values or supplied by the user. The user can also choose between equilibrium and nonequilibrium vaporpressure models.

The aforementioned equations are solved numerically by a finite-difference method. The equations are differentiated in both space and time. Differentiating in time results in fully implicit equations. The saturation and temperature equations are solved with a tri-diagonal algorithm. Because the vapor and air-pressure equations are strongly coupled, they are solved with a block tridiagonal algorithm.

\section{C.3 Geochemical Program Summaries}

\section{C.3.1 PHREEQE}

PHREEQE (Parkhurst, 1980) was developed to model geochemical reactions between water and rock material. Based on an ion-pairing aqueous model, the program calculates $\mathrm{pH}$, redox potential, and mass transfer as a function of reaction progress. The program performs a mass balance of elements in terms of their concentrations in the aqueous phase and uses electrical neutrality and electron balance relations to complete the set of equations needed to solve a given problem.

The program solves a set of non-linear algebraic equations, using a combination of a continued-fraction approach for mass balance and a Newton-Raphson iteration technique.

\section{C.3.2 $\mathbb{E Q 3 / 6}$}

EQ3/6 (Wolery, 1979) was developed to compute equilibrium models of aqueous geochemical systems. EQ3 performs distribution-of-species calculations for natural water compositions. EQ6 uses the results of EQ3 to 
predict the consequences of heating and cooling aqueous solutions and of irreversible reactions in rock-water sys-. tems. Reaction path modeling is useful in analysing complex systems where analytical data do not permit the definition of reactions by mass balance alone.

The program uses a Newton-Raphson method to solve the algebraic governing equations of chemical equilibrium.

\section{C.3.3 WATEQF}

WATEQF (Plummer, 1976) simulates the thermodynamic speciation of inorganic ions and complex species in solution for a given water analysis. The program provides a general capability to calculate chemical equilibria in natural waters at low temperatures.

WATEQF uses a successive approximation method to solve the mass action and mass balance equations.

\section{C.3.4 CHEMTRN}

CHEMTRN (Miller, 1983) was developed to simulate one-dimensional transport of chemical species in groundwater. Equilibrium is assumed in all chemical reactions, and thermodynamic activities of all reacting species are related by mass-action expressions. The program includes the effects of dispersion and diffusion, advection, sorption via ion exchange or surface complexation, aqueous complexation, precipitation and dissolution of solids, and the dissociation of water.

The governing equations are approximated using a finitedifference approach. A Newton-Raphson iteration technique is used to to solve the system of equations.

\section{C.4 Transport Program Summaries}

\section{C.4.1 SPARTAN}

1:i:

The SPARTAN code ( $\mathrm{Lin}, 1985)$ is a simple performance assessment code developed at Sandia National Laboratories. The model employs a simplistic hydraulic model for flow of water infiltrating the surface and reaching the water table. This model has little in the way of a mechanistic explanation for the way water would flow at Yucca Mountain. The rate of infiltration in the matrix is assumed to follow Darcy's law, with a gradient of unity, a fixed permeability and fixed effective porosity. For infiltration rates less than $1.0 \mathrm{~mm} / \mathrm{year}$, the speed of groundwater movement is proportional strictly to the infiltration rate and does not take into account the change of hydraulic conductivity with moisture content. For infiltration rates greater than $1.0 \mathrm{~mm} / \mathrm{yr}$, the model assumes that a fraction of the water infiltrating will move through the fracture zone faster than through the matrix, with trans- port properties typical of fractures. The transport model takes radioactive decay and a linear sorption $(\mathrm{Kd})$ into account. It allows different retardation factors for daughters and parents.

The SPARTAN code was used for śome very preliminary assessments of a proposed repository at Yucca Mountain: In the test cases that the authors demonstrated, there were either two or three pathways for radionuclide transport, which was'supposed to represent the different lengths from the repository to the water table, For an infiltration rate of $0.5 \mathrm{~mm} / \mathrm{yr}$, there were two pathways for matrix flow. In this case, only I-129, C-14, and Tc-99 reached the accessible environment within 100,000 years. For a rate of $5.0 \mathrm{~mm} / \mathrm{yr}$, it was assumed that the water in excess of what the matrix could carry would travel through a third pathway as fracture flow. Many more of the radionuclides were released to the accessible environment for this case.

\section{C.4.2, TOSPAC,}

TOSPAC (Dudley, 1987), the Total System Performance Assessment Code, is a computer program designed to simulate water flow and transport of soluble waste in fractured, porous unsaturated rock. The groundwater flow module solves either the transient or steady-state partial-differential equations for an equivalent porous, fractured medium, in which the properties of the matrix and fractures are combined into one constitutive relationship for saturation versus hydraulic conductivity (or matrix potential versus hydraulic conductivity). The site is represented as a series of one-dimensional flow tubes with no laterál interchange. Within any single flow tube, either the steady-state or transient flow equation for the equivalent matrix-fracture relationship is solved. For the steady-state situation, the solution is iterative, to allow for the self-adjustment of the hydraulic conductivity and saturation values to correspond to the constitutive relationships for each layer. Once the solution reaches steady-state, the hydraulic conductivity is known, and consequently so is the net downward flux and groundwater velocity that can then be used in the transport calculations. The transient solution solves for pressure head, with a numerical solution of Richard's equation using Pickard iteration.

The module for radionuclide transport uses the velocities calculated from the flow module. First, the code estimates the fraction of flow in the matrix and fracture flow paths. Concentrations of each radionuclide are calculated for the matrix and fracture compartments, with a dynamic coupling between them.

\section{C.4.3 NEFTRAN}

NEFTRAN (Longsine, et al., 1987) is a network flow and transport code developed by Sandia National 
Laboratories primarily for modeling the repository performance at saturated sites. The flow model in NEFTRAN consists of an arbitrary network of onedimensional pipes, connected at nodes. Boundary conditions of pressure are set on some of these nodes, and the hydraulic properties of transmissivity and porosity are set within the pipes. The network model then solves for the steady-state velocity and flux within the network. Radionuclides are transported in the network by the calculated flux. The model uses retardation factors to express the speed at which a particular species is transported. It also allows for transport between the actively flowing legs and immobile water adjacent to the leg, in order to simulate matrix diffusion. The program also can simulate the transport of radionuclide chains. There are two models for chain transport. The first assumes equal retardation coefficients and allows chains of up to three members. The other model allows arbitrary retardation coefficients for chains of up to six daughters. Calculations using the former model are much less time-consuming. NEFTRAN simulates dispersion along the legs using the Distributed Velocity Method (DVM), which assumes that-dispersion is caused by the distribution of velocities in the flow field.

In its present form, NEFTRAN is not ideally suited for performance assessment of a repository located in unsaturated, fractured tuff for the following reasons:

1. The model is set up for boundary conditions that are appropriate for a saturated site.

2. The flow model is for steady-state conditions. Transient recharge may be an important consideration in unsaturated, fractured tuff.

3. The model assumes that the source term is concentrated in one leg only, and cannot represent source terms highly distributed in time and space. This limitation may not be as important for saturated sites where flow is more horizontal than vertical, but it could be a limitation in situations where multiple travel paths are needed to adequately account for system performance.

Presently; NEFTRAN is being modified "specifically for the Yucca Mountain case, and some of these limitations should be overcome. Sandia is developing a multidimensional, finite-difference model to calculate steadystate and transient, unsaturated flow in porous media. Output from this model will be fed directly into a NEFTRAN modified to accept flux boundaries and transient flow conditions. However, the source term will continue to be represented by a single leg, and therefore will not be able to simulate a highly-distributed source.

\section{C.4.4 University of California, Berkeley (UCB) Programs}

There are a large number of analytical codes (i.e., closedform solutions) available that could serve to calculate flow and transport, particularly for one-dimensional, steady-state flow, in which there are really few considerations as to whether the flow is saturated or unsaturated. The UCB codes combine simple source-term models with analytical solutions for one-dimensional, steady-state flow, and radionuclide transport. These codes have been used in a number of important U.S. studies (e.g., WISP report and AREST code development). The programs are unique analytic solutions, because they provide explicit solutions for chain decay with differing retardation coefficients for each daughter radionuclide. However, the solution technique may not permit the incorporation of more than one hydrologic layer; this would make difficult the application of these codes to the Yucca Mountain site, where there are several distinct layers with different material properties.

\section{C.4.5 Laplace Transform Solutions}

Another class of analytical codes is Laplace Transform domain solutions (Robinson and Hodgkinson, 1986). The source term, transport model, and even stochastic solution can be set up using this method, solving the lineardifferential equations in the Laplace domain and obtaining the time-domain solution by numerical evaluation of the contour integral in the complex plane. This solution technique should be relatively easy to apply to the problem of transport through multiple layers. The recent development and progress of this solution technique in the United Kingdom needs to be followed for later use in performance assessment. 


\section{APPENDIX D-GASEOUS RELEASES OF CARBON-14}

\section{D.1 Introduction}

Carbon-14 (C-14) is produced in nuclear reactors by the activation of nitrogen impurities in the fuel cladding, and by the activation of oxygen-17.(O-17), particularly in the uranium dioxide fuel and in the circulating water of lightwater reactors. The release of $\mathrm{C}-14$ from the waste packages may be of concern because there is at least the possibility of a fast gas pathway to the accessible environment through the unsaturated: fractured rock, excavations, and tunnels. Although in this Phase 1 demonstration, the release of $\mathrm{C}-14$ was treated in the liquid pathway analysis by inclusion with the total release into the liquid phase, this treatment would not be conservative from the standpoint of the gaseous release pathway. This appendix presents models for the gaseous release of C-14 from the waste package and its transport to the accessible environment.

\section{D.2 Source Term}

C-14 is found in quantities an order of magnitude greater than would be allowed under 40 CFR Part 191, if all were released. For the 70,000 metric tons heavy metall assumed, the initial inventory of $\mathrm{C}-14$ for this study was 98,000 curies (Doctor, et al., 1992), whereas the allowed release under 40 CFR Part 191 is only 7,000 curies. C-14 has a half life of 5720 years. The majority of environmental C-14 comes from interaction of cosmic ray neutrons and nitrogen, although it is also created by activation of the rare $0-17$ isotope in the atmosphere (van Konynenberg, 1987). It is produced in great quantities in atmospheric nuclear explosions through neutron activation. Once in the atmosphere, $\mathrm{C}-14$ is removed from the environment mainly by absorption in the bicarbonate ions in seawater with an apparent relaxation time (i.e., time for half to disappear from the biosphere) of approximately 9 to 15 years (Killough and Till, 1978). A portion of the $\mathrm{C}-14$ recycles through the food chain and is very biologically active. The combination of biological activity and long half-life leads to relatively large population doses per curie released.

In reactor fuel, $\mathrm{C}-14$ is produced by the same mechanisms as in the atmosphere. The main routes to production are: (1) activation of nitrogen impurities in the metallic structure of the reactor and the fuel cladding, and (2) activation of $\mathrm{O}-17$ in the uranium dioxide fuel and in the circulating water of the reactor, with subsequent deposition onto the cladding and other structural material.

Measurements indicate that about one-third of the total C-14 inventory resides in or on the cladding of pressurized-water reactor (PWR) fuel, but similar meas- urements for boiling-water reactor (BWR) fuel are not available (van Konynenberg, 1987). It is expected that measurements for BWR fuel may be different because the oxidation potential is different in these reactors. The remainder of the $\mathrm{C}-14$ is dispersed in the fuel, cladding gap, and the intergrain boundaries. There is little or no information on C-14 inventories for other rion-fuel parts: of the reactor:

The two mechanisms for producing $\mathrm{C}-14$ in the reactor are important to understanding its availability. Presum-; ably, C-14 created by activation of nitrogen would be dispersed in the cladding, because the nitrogen may also be dispersed. Much of the C-14 appears to be from the oxygen-activation mechanism, and is adsorbed onto the cladding, fairly close to the surface. This fact may be important because it allows the C-14 to be more readily accessible to the environment than if it were uniformly dispersed in the cladding (SCP, Sections 8.3.5.9, 8.3.5.10) (DOE, 1988).

\section{D.2.1 Possible Release Modes from Spent Fuel}

Upon failure of the canister, gaseous $\mathrm{C}-14$ could be released to the geologic setting. Most of the C-14 in the canister is apparently in the form of elemental carbon, metal carbides, or oxycarbides (van Konynenberg, 1987). In inert nitrogen and helium atmospheres, spent fuel does not readily release its C-14. Upon exposure to air, however, some of the $\mathrm{C}-14$ oxidizes and is usually released to the immediate atmosphere as ${ }^{14} \mathrm{CO}_{2}$. About 1 to 2 percent of the available $\mathrm{C}-14$ inventory, mainly that portion deposited on the surface of the canisters as crud or collected on the intergrain boundaries of the fuel, could be released quickly by this mechanism (van Konynenberg, 1987). For elemental carbon, release could depend on oxidation to carbon dioxide and carbon monox ${ }^{3}$ ide, the rate of which is extremely slow at low temperatures. Elemental carbon is known to be extremely stable. under normal conditions, as is evidenced by the presence of graphite in schists exposed for thousands of years at the earth's surface. There is some experimental evidence to suggest, however, that carbon will oxidize to carbon dioxide at a temperature of $275^{\circ} \mathrm{C}$ within a radiation field of. 10,000 rads per hour (van Konynenberg, 1987). Temperatures of the fuel may be in this range for the first few decades after storage, but are likely to be considerably cooler near the time required for minimum canister life. Radiation levels of $10,000 \mathrm{rad} / \mathrm{hr}$ are likely to be present for up to about 100 years. Although the radiation field diminishes with time, no experimental evidence is avail= able to indicate that there is a threshold below which no oxidation would occur. For the sake of conservatism in this analysis, it was assumed that a mechanism is available 
to oxidize available carbon to gaseous carbon dioxide for the lifetime of the repository.

The more likely $\mathrm{C}-14$ release mechanisms from spent fuel are:

- Dissolution of the cladding and oxidation of the C-14 attached to the cladding, e.g., crud.

- Quick release of a small percentage of carbon dioxthe cladding.

- Diffusion of oxygen into the waste form, particularly the matrix, reaction of the carbon with the oxygen, and the subsequent diffusion of carbon dioxide out of the matrix.

Other possible mechanisms might also release C-14 (although little or no direct evidence is available to show that they apply):

- Galvanic reaction between elemental carbon in the cladding or metal carbides and the surrounding metal in the waste form.

- Reaction of metal carbides on the zirconium or uranium with water to form acetylene gas (Katz and Rabinowitz, 1951).

- Microbial action on carbon or carbon compounds in the waste.

- Release of methyl.iodide created from the reaction of carbon and iodine present in the fuel. This could be a potential release mechanism for I-129. Methyl iodide would be volatile around $200^{\circ} \mathrm{C}$, temperatures expected in the repository during the first few decades after site closure.

Little direct evidence is available to support a particular model for C-14 gaseous release, but a reasonable set of release mechanisms was chosen, based on the limited information, and applied in a release model for this auxiliary analysis. These mechanisms are discussed next in their order of expected importance. In addition, conservative ranges of parameter values were chosen for use in the models for these release mechanisms. However, it cannot be stated that the overall model is conservative.

\section{D.2.1.1 Releases due to oxidation of uranium dioxide}

For this study, the C-14 trapped within the uranium dioxide fuel was released at a rate coupled to the rate of oxidation of the fuel. Uranium dioxide is unstable in an oxidizing environment, and oxidizes to other forms, with corresponding increases in volume, porosity, and fracturing, in many cases. If the reaction proceeds fast enough, the $\mathrm{UO}_{2}$ will spall, becoming more porous and less dense. The increase in volume could promote continued cracking of the cladding, allowing more pellets to be exposed.

Spallation is an indication that significant oxidation has occurred and may also provide for increased exposure of the $\mathrm{C}-14$ to oxidants. Both $\mathrm{UO}_{2}$ and $\mathrm{C}$ will be competing for the oxidants. From thermodynamic considerations alone; carbon would be oxidized first at low oxygen activities, followed by oxidation of $\mathrm{UO}_{2}$ at higher oxygen activities. However, the relative rates of the competing reactions probably govern how the components of the spent fuel will be oxidized. Einsiger and Woodley (1985a) state that for irradiated fuel, the uranium dioxide crystalline structure is damaged and pellets are fragmented, thereby opening more surface area to oxidation. In addition, gas bubbles and fission products may migrate to the grain boundaries where the interconnected paths can form, making grain boundaries preferential sites for oxidation. The radiation field can ionize or excite atmospheric oxygen or water, possibly enhancing the oxidation rate.

Einsiger and Strain (1984) present two curves bounding the time to spallation, $t_{s}$, as a function of temperature $T$ :

$$
\begin{aligned}
& \log t_{\mathrm{s}^{\prime}}=(0.78 \times 10-4 / \mathrm{T})-13.01 \\
& \log \mathrm{t}_{\mathrm{s}^{2}}=(1.03 \times 10-4 / \mathrm{T})-15.9
\end{aligned}
$$

where $t_{s}$ is in given in hours, $T$ in degrees Kelvin, and log denotes the base 10 logarithm. Equations D. 1 and D.2 are not directly useable to determine the rate of release of C-14, because they are formulated with steady temperatures in mind. Since the fuel temperature changes with time, it is more convenient to convert spallation time to an oxidation rate. If it is assumed that the rate of oxidation, $\lambda_{s}$, is the reciprocal of the spallation time, $t_{s}$, then a time-dependent rate of $\mathrm{C}-14$ release can be defined:

$$
\lambda_{\mathrm{s}}=1 / \mathrm{t}_{\mathrm{s}}
$$

This model may be conservative from the standpoint that the time for the onset of spallation does not signal the total oxidation of the fuel pellets. On the other hand, the rate of release of $\mathrm{C}-14$ may not be as low as indicated for long spallation times that occur at lower temperatures.

\section{D.2.1.2 Oxidation of zirconium}

A large fraction of the C-14 inventory may be in or on the cladding, caused by neutron activation of $\mathrm{O}-17$ picked up from the circulating water, particularly in BWRs, or from nitrogen impurities in the metal itself. Corrosion of the zirconium may be the first step in releasing the C-14 to the atmosphere, although it is possible that this corrosion may not be necessary to initiate release. In addition, cladding corrosion leading to perforation could expose the $\mathrm{UO}_{2}$ to oxidation. 
Oxidation of the cladding has been studied for the case of dry-cask storage of spent fuel. Einziger and Kohli (1984) present a rate equation for zirconium cladding in terms of temperature:

$$
\mathrm{L}=3.68 \mathrm{E} 8 \times \mathrm{t} \times \exp (-15810 / \mathrm{T})
$$

where $L$ is the oxide thickness in millimeters, $t$ is the time in years, and $T$ is the absolute temperature, degrees Kelvin. To find the growth of the zirconium oxide layer with time, we first convert Equation D.4 to a rate, and integrate from the time of failure $t_{f}$, using the expected temperature of the waste:

$$
\mathrm{L}=\int_{\mathrm{t}_{\mathrm{f}}}^{\mathrm{t}} 3.68 \mathrm{E} 8 \exp (-15810 / \mathrm{T}(\mathrm{t})) \mathrm{dt}
$$

The calculated oxide thicknesses are presented in Table $\mathrm{D}: 1$ for a typical fuel temperature ranging from a high of $320^{\circ} \mathrm{C}$ to a low of $110^{\circ} \mathrm{C}$ over 10,000 years, and an assumed failure time of $t_{f}=0$.

\begin{tabular}{|c|c|c|}
\hline $\begin{array}{l}\text { Temperature } \\
\left({ }^{\circ} \mathbf{C}\right)\end{array}$ & $\begin{array}{l}\text { Time } \\
\text { (years) }\end{array}$ & $\begin{array}{l}\text { Thickness } \\
\text { (mm) }\end{array}$ \\
\hline 320 & 5 & $4.90 \mathrm{E}-3$ \\
\hline 300 & 25 & $1.25 \mathrm{E}-2$ \\
\hline 275 & 50 & $1.52 \mathrm{E}-2$ \\
\hline 250 & 75 & $1.59 \mathrm{E}-2$ \\
\hline 230 & 100 & $1.61 \mathrm{E}-2$ \\
\hline $200-110$ & 10000 & $1.62 \mathrm{E}-2$ \\
\hline
\end{tabular}

Table D.1 Calculated Zirconium Oxide Thickness

A typical cladding thickness is $0.61 \mathrm{~mm}$, so the maximum oxide growth is only about 3 percent of the total thickness. Most of the oxidation takes place when temperatures are highest, with, virtually none after about 100 years:

Einsiger and Woodley (1985a) also describe a possible condition that might affect the rate of cladding failure in the absence of oxygen. Canisters might contain a few tens of milliliters of water from rods stored in cooling pools. The radiolysis of the water could provide oxidants that could oxidize the cladding (Reed, 1987).

The ramifications of zirconium oxidation are not entirely clear. It appears that there would be relatively little oxidation of the zirconium in the repository. If the fuel is kept cool; e.g., in wet storage casks before being placed in the canisters, the reaction would not proceed very far. It would be more oxidized in dry storage, but might be inhibited by the presence of inert atmosphere in the canisters. Although the percent oxidation may be small, most of the C-14 might be close to the surface as crud, or attached to an existing oxide coating, since it might have been picked up externally from the circulating water. The fact that little if any oxidation of the zirconium alloy occurs at temperatures lower than about $230^{\circ} \mathrm{Cleads}$ to a tentative conclusion, for the purposes of this study, that there will be little additional zirconium oxidation after canister failure. It was assumed, therefore, that only the readily available portion of 'the $\mathrm{C}-14$, about one percent, will be driven off during the pre-canister-failure period, and that there will be no additional releases from the zirconium compartment. Corrosion of the cladding might be relatively more important if it causes perforation, allowing oxygen to reach and oxidize the spent fuel matrix...

\section{D.2.2 Proposed Source Term Model}

For the Phase 1 study, the following model was chosen for the release of gaseous carbon from the waste package, incorporating the mechanisms discussed previously:

- Canisters failed at a rate predicted by a normal probability distribution. Two different distributions were chosen to demonstrate the sensitivity of the C-14 release to the waste-package lifetime.

- At the time of canister failure, oxygen entered the canister and became available immediately to react with the uranium dioxide in the fuel rods. The model assumed that release rate was tied closely to the spallation rate of the fuel, and that there was sufficient oxygen available upon canister failure for the fuel oxidation to proceed. Although most fuel rods will have additional protection from oxidation based on resistance to corrosion of the zirconium alloy cladding, it was assumed, for the purpose of conservatism, that all fuel rods are available for release of their $\mathrm{C}-14$ inventories.

- On failure of the canisters, a small fraction of the C-14 inventory was released rapidly. This fraction represented the $\mathrm{C}-14$ inventory of the claddingpellet gap and the $\mathrm{C}-14$ close to the outside surface of the cladding or crud that would be readily oxidized.

The average fractional release rate of $\mathrm{C}-14, \mathrm{f}(\mathrm{t})$, was calculated based on the random failures and oxidations of a large number of canisters, to which was added the fractional prompt release, $\mathrm{f}_{\mathrm{p}}$, from the canisters at the time of failure, $t_{f}$ :

$$
f(t)=\frac{1}{N} \sum_{i=1}^{N}\left[H\left(\left(t-t_{f i}\right) f_{p}+\int_{t_{f i}}^{t} \lambda_{s i}(t) d t\right]\right.
$$

where $N$ is the number of canisters, and $H\left(t-t_{f i}\right)$ is the Heaviside unit step function at time $t=t_{f i}$. 


\section{D.2.3 Results of Source Term Predictions}

Figure D.1 illustrates the fraction of the total C-14 inventory released up to 10,000 years for two different assumed canister failure models. The higher release curve (solid) corresponds to canister failure with a mean failure time of 550 years, a standard deviation of 150 years, and an upper and lower limit of 100 and 1000-years, respectively. The lower (broken) curve corresponds to a mean failure time of 1000 years, with a standard deviation of 300 years, and an upper and lower limit of 200 and 1800 years, respectively. The maximum cumulative releases were approximately 13.2 percent and 2.5 percent, respectively, thus illustrating the strong dependence of $\mathrm{C}-14$ release on waste package lifetime.

\section{D.2.4 Limitations of the C-14 Source Term Model}

The $\mathrm{C}-14$ release model was based on the following limiting assumptions:

- A non-mechanistic failure of all canisters in a time short relative to the half-life of C-14 and the 10,000 year period of interest.

- An influx, upon canister failure, of sufficient oxygen to cause unimpeded fuel oxidation. Oxygen was not consumed by other reducing agents, such as the canister walls and metal components of the fuel assemblies.

- The highly corrosion-resistant cladding on the fuel ' offered no protection' from oxidation.

- A prompt release from the cladding and pellet-gap inventories for 100 percent of the fuel rods. (In actuality, the prompt release might occur only from failed fuel rods.)

- The rate of oxidation was equal to the reciprocal of the spallation time. In fact, spallation time may be more representative of the oxidation of only a fraction of the fuel. Based on this assumption, the release rate of $\mathrm{C}-14$ might be conservative at high temperatures, and may not be conservative at low temperatures.

\section{D.3 Gaseous Transport Model}

Once released from the fuel, the C-14 would probably be carbon dioxide or another gas, such as methane or acetylene. Van Konynenberg (1987) estimates that there would be no more than 22 kilograms of $\mathrm{C}-14$ in the repository, as contrasted to greater than 300,000 kilograms of dead carbon in the immediate vicinity of the repository, in the form of carbon dioxide and even more as carbonate and bicarbonate ions. Part of the dead carbon will be available to exchange with the $\mathrm{C}-14$ along the transport pathway. The effect of this exchange may be to retard the speed at which the $\mathrm{C}-14$ could be transported to the accessible environment. A potentially important reaction is the precipitation of calcite (calcium carbonate) by the reaction of calcium ions and carbon dioxide to form a low solubility precipitate (Ross, 1988). The significance of retardation of $C \perp 14$, or its removal by precipitation, will depend on the relative rates of exchange between the $\mathrm{CO}_{2}$ gas; the bicarbonate, and calcite, and the velocity of air flow through the rock.

Several reports propose C-14 transport models. Knapp (1987) describes a one-dimensional model for C-14 transport by advection, with exchange between the gas phase and the bicarbonate in the groundwater. The results of this study show that for Yucca Mountain, C-14 released as a pulse from the repository horizon at 2000 years after repository closure would reach the surface within 6000 years:

Amter, et al., (1988) expand on the concept of a C-14 transport model with more computational detail. Their model accounts for two-dimensional gas advection, with diffusion and exchange between liquid and gas compartments. They assume that gas and water are in equilibrium for carbonate species because of the rapid diffusion of carbon dioxide. Dissolved bicarbonate ions in the rock are considered to be essentially immobile because of the relatively high velocity of gas flow, as compared to liquid flow. Liquid-phase diffusion is also ignored because liquidphase diffusion constants are much smaller than gasphase diffusion constants. The presence of the C-14 components in the liquid will have the effect of reducing the speed of transport by a retardation factor.

\section{D.3.1 Chemical Modeling}

The chemical retardation of $\mathrm{C}-14$ depends on equilibrium between carbon dioxide, bicarbonate ion, and solid carbonate. The equilibrium between $\mathrm{C}-14$ as $\mathrm{CO}_{2}$ and bicarbonate is tied to several possible chemical factors, including the presence of calcite, $\mathrm{CO}_{2}$ partial pressure, and $\mathrm{pH}$ : Ross (1988) assumes that $\mathrm{CO}_{2}$ dissolved in water is immobile, a conservative assumption for atmospheric releases, since there is likely to be a net movement of groundwater to the water table from the ground surface. $\mathrm{CO}_{2}$ is produced naturally in plant roots. The decline in the concentration of $\mathrm{CO}_{2}$ with depth seems to indicate that it is being removed by some mechanism, possibly calcite precipitation. Ross speculates that this would require a source of calcium ions infiltrating the site. Although the groundwater is not saturated with calcium carbonate, and it does not appear that the calcite is precipitating naturally, an increase in repository temperature might cause precipitation both by evaporation and the decrease in calcite solubility. Calcite solubility is 


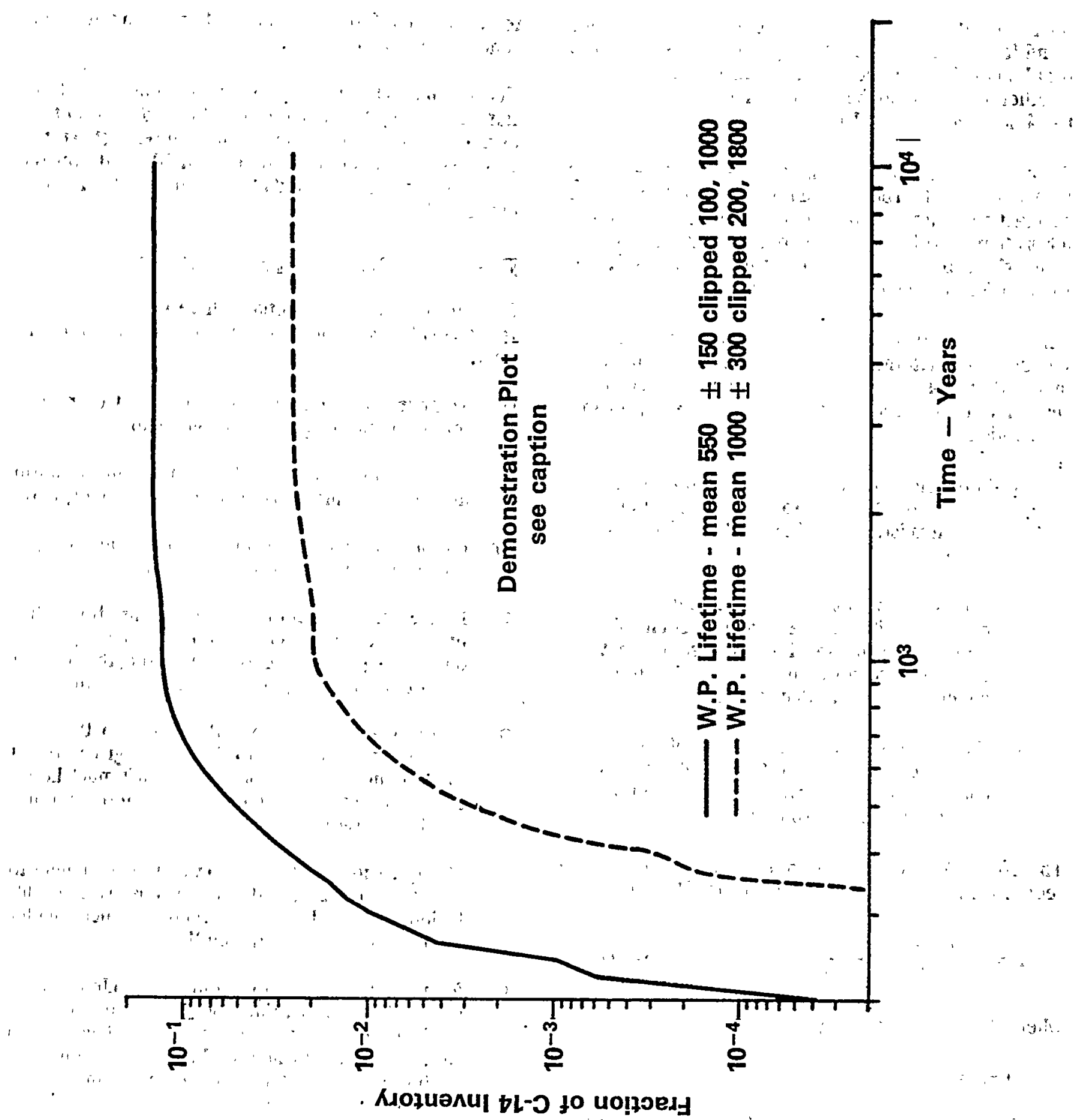

Figure D-1 Release of C-14 Inventory. This, graph presents results from an initial demonstration of staff capability to conduct a performance assessment. The graph, like the demonstration, is limited by the use of many simplifying assumptions and sparse data. 
retrograde, decreasing with increasing temperature. This trend leads to some interesting possibilities of how the bicarbonate ions in the heated area would react and whether there would be an irreversible deposition of C-14 in precipitating calcite.

Differences in the atomic weights of C-14 and C-12 may lead to fractionation because of the slightly different rates of reaction, evaporation, condensation, crystallization, adsorption, and diffusion. Fractionation was estimated by comparison to enrichment factors for stable $\mathrm{C}-13$, and found to be negligible (Amter, et al., 1988).

Amter, et al. (1988) present the results of geochemical modeling to determine the complicated equilibrium among the $\mathrm{C}-14 \mathrm{gas}$, liquid, and solid phases. The conceptual model of the geochemical system had three principal assumptions:

"1. Sufficient calcium carbonate is present in the unsaturated zone to dominate the aqueous chemistry and buffer the $\mathrm{pH}$ of the water.

2. A relatively minor amount of calcium is derived from silicaite weathering reactions. As a first approximation, it can be assumed that calcium concentrations are the result of equilibration with calcium carbonate.

3. Fractionation plays a negligible role in removing carbon-14. from the gas phase, and concentrations of carbon-14 are proportional to those of carbon-12."

The effect of isotopic equilibrium between phases is to reduce the speed of transport by $a$ factor $B$, defined:

$$
\mathrm{B}=1+\frac{\theta_{\mathrm{T}}-\theta_{\mathrm{D}}}{\theta_{\mathrm{D}}}, \frac{\mathrm{C}_{\mathrm{T}}^{*}}{\mathrm{C}_{\mathrm{T}}}
$$

where $\theta_{\mathrm{T}}=$ total porosity

$$
\begin{aligned}
\theta_{\mathrm{D}}= & \text { drained porosity } \\
\mathrm{C}_{\mathrm{T}}{ }^{*}= & \begin{array}{l}
\text { concentration of carbon ion in the liquid } \\
\text { phase at equilibrium }
\end{array} \\
\mathrm{C}_{\mathrm{T}}= & \begin{array}{l}
\text { concentration of carbon ion in the gas } \\
\text { phase at equilibrium }
\end{array}
\end{aligned}
$$

Ampter, et al. (1988) determine the equilibrium concentrations needed for Equation D.7 using the PHREEQE reaction path model. There are few data available on the chemistry of water in the unsaturated rocks of the reposi- tory, and therefore the data used in the analyses are somewhat subjective.

The results of the PHREEQE calculations were functions expressing the dependence of retardation on temperature for the hydrogeologic units. The expected retardation coefficients ranged from about 20 to 90 over the expected temperatures and concentrations of carbonate in the rock.

\section{D.3.2 Gas Phase Transport Modeling}

Several mechanisms potentially drive the gas flow, but Amter, et al. (1988) consider two mechanisms to be dominant:

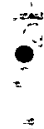

Temperature-driven circulation caused by repository heat and the geothermal gradient;

- The difference in density between the moist, warm air in the rock and the cooldry air in the atmosphere.

The authors considered and eliminated the following potential mechanisms for transport of $\mathrm{C}-14$ :

- Liquid phase advection-The downward flux of liquid water is likely to be about one tenth the gas flux during the period of repository heating that is most important to HLW performance assessment.

- Diffusion-Using a travel distance of 350 meters and a retardation factor for $\mathrm{C}-14$ of 70 gives a travel time for diffusion of $43,000 \mathrm{yrs}$, which is much larger . than either the ambient of heat-driven travel times for the repository.

- Binary diffusion-A mass flow of air from higher to lower temperatures in the rock will be driven by diffusion, but this flow was shown to be much smaller than the temperature-driven flow.

-. Mixing by seasonally alternating flow-Under ambient conditions, gas within Yucca Mountain will move upward in winter and to a lesser extent downward in summer, but would move C-14 molecules only a few centimeters per season, much smaller than even the molecular diffusion effect.

The authors' C-14 transport model relied on a temperature field developed by Tsang and Preuss (1987) that showed a gas phase velocity of meters to thousands of 'meters'per yeat resulting from the repository heat, as 'shown in Figure D.2. The model of Amter, et al. (1988) predicted travel times for $\mathrm{C}-14$ of several hundred years to several tens of thousands of years, depending on the location in the repository and the depth of the overburden, as shown in Figure D.3. 


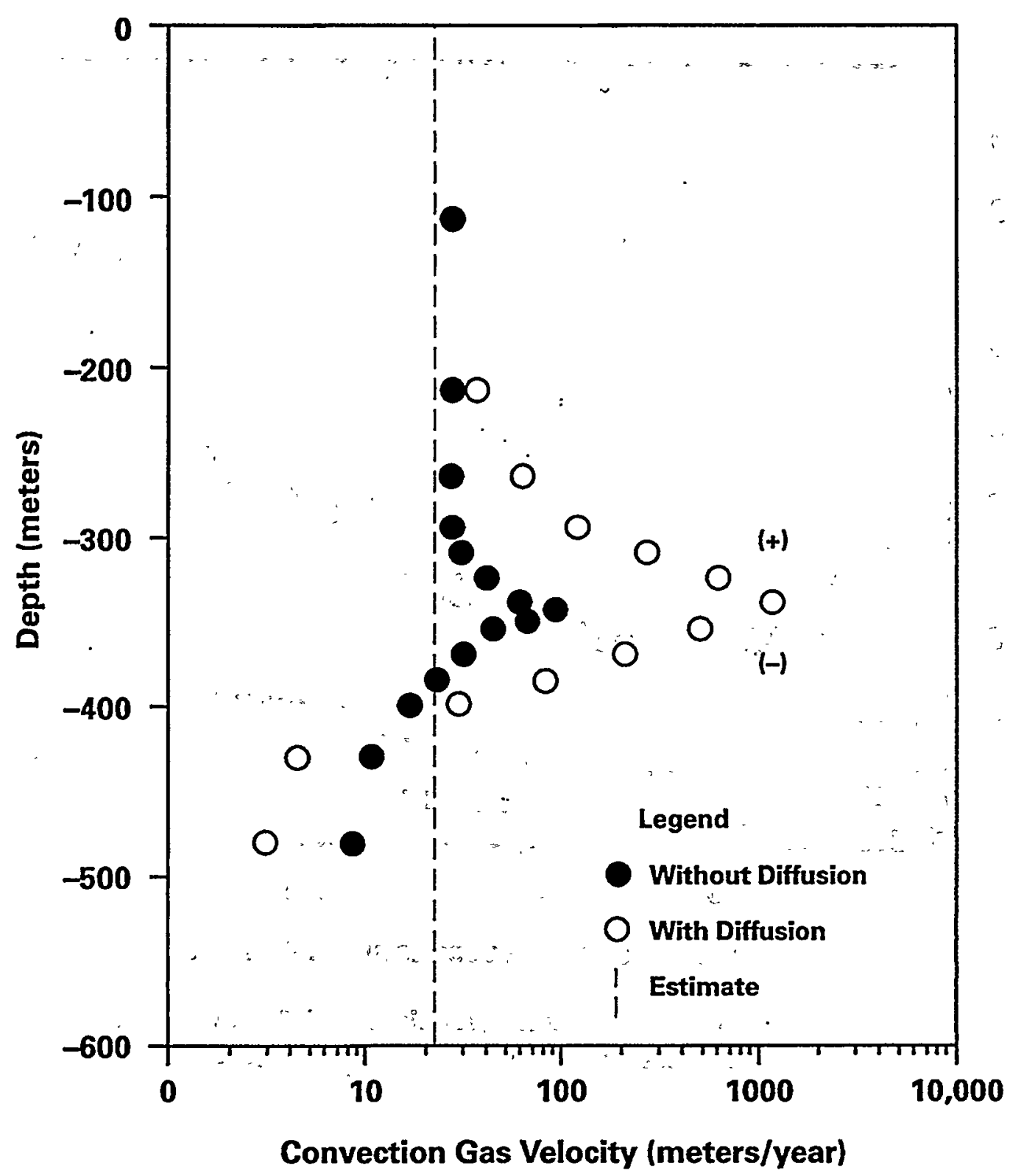

Figure D-2 Gas convection velocities along the repository center line at 100 years after waste emplacement. Plus and Minus signs refer to upward and downward fluxes at the repository depth for the case with binary diffusion (modified from Tsang and Preuss, 1987). 


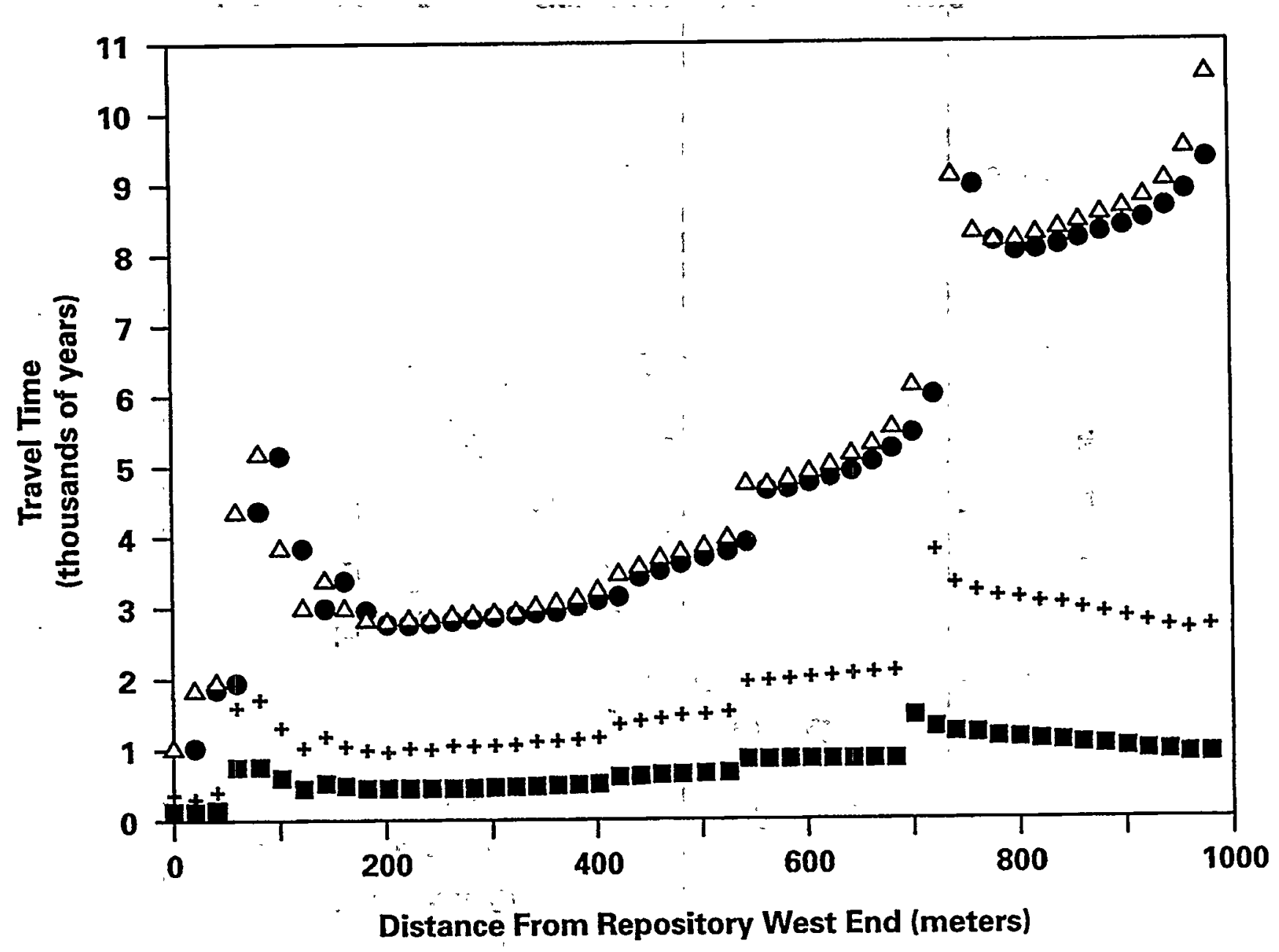

$\Delta$ Pre-emplacement; Ambient $\quad+10,000$ Yrs $T=314$

a 2,000 Yrs $T=330$

Figure $D=3$ Carbon-14 travel time from the repository to the surface for ambient conditions, $2,000,10,000$, and 50,000 years (modified from Ampter, et al:, 1988). 


\section{D.3.3 C-14 Transport Model}

In the Phase 1 demonstration, the staff used the estimated travel times calculated by Amter, et al. (1988), as shown in Figure D.3, to develop a scoping model that accounts for transport of carbon dioxide from the repository to the surface of the earth. The model considered radioactive decay using the average travel time for $\mathrm{C}-14$ from the repository to the surface. Amter, et al. (1988) calculated the travel times along a transect of the repository at zero, 2000 years, 10,000 years and 50,000 years. The fractional release, $f_{i}$, at the earth's surface for a parcel of $\mathrm{C}-14$ released at time $t_{0}$, was determined by integrating along the path from the repository to the surface, assuming that the velocity of the parcel would be everywhere equal, but varying with time according to a linear interpolation of the four times calculated by Ampter.

This is not necessarily a good assumption, because the velocity is known to vary in space within the complicated convection currents predicted by Tsang and Preuss, 1987):

$$
L(t)=\int_{\mathfrak{t}_{0}}^{\mathfrak{t}} v(t) d t
$$

where $L(t)$ is the normalized distance that the parcel has traveled relative to the distance to the surface, $v(t)$ is the normalized velocity, defined here as the reciprocal of the travel time at time $t$, and $t_{0}$ is the time of release. The integral was evaluated graphically to find the time $t$ when $L(t)=1$. The object of the integration was to find the travel time of the parcel and to determine whether it could reach the surface within the stated time limit, i.e., 10,000 years. Once the travel time, $t_{i}$, was determined for each parcel with release time $t_{0 i}$, the fraction, $f_{i}$, released at the earth's surface was determined by radioactive decay:

$$
f_{i}=\exp \left(-\lambda t_{i}\right)
$$

where $\lambda=\ln 2 / t_{1 / 2}$. The results of these calculations are summarized in Table D.2 for releases at 500 to 6500 years. The fractional release ranges from a maximum of 0.91 to a minimum of 0.65 . It is interesting to note that because the upward velocity approaches a maximum value, the earliest release shown in Table D.2 does not result in the highest fraction escaping. Releases after about 6500 years do not arrive at the surface of the earth before 10,000 years.
Table D.2 Release Fraction as Function of Release Time

\begin{tabular}{lll}
\hline $\begin{array}{c}\text { Time of release } \\
\text { years }\end{array}$ & \multicolumn{2}{c}{ Fraction Reaching } \\
Surface
\end{tabular}

\section{D.3.3.1 Limitations of $\mathbf{C}-14$ gas transport model}

Some of the limitations of the transport model are:

- There is the possibility that gaseous releases from the repository level may follow the shortest path, and that there may be ample ground transport between one part of the repository and another because of the network of drifts, shafts, and fractures. The effective travel time for $\mathrm{C}-14$ released anywhere in the repository may therefore be more characteristic of the shortest travel time calculated.

- There is evidence that in natural waters, $\mathrm{CO}_{2}$ is not in equilibrium with the atmosphere, partially because of unfavorable mixing conditions and the slowness of the gas transfer reaction (Stumm and Morgan, 1970). The chemical model for C-14 behavior was based on the assumption of equilibrium. Failure to attain equilibrium would have the effect of reducing the retardation of $\mathrm{C}-14$.

- In their transport and chemical models, Ampter, et al. (1988) assume intimate contact between the gas and water phases. Such contact is unlikely at Yucca Mountain, because, under unsaturated conditions, water would be present primarily in the smallest rock pores, and the flow of air would be most prevalent in the largest rock pores and fractures. Therefore, the potential for close air-water contact would be diminished, having the effect of reducing the retardation of C-14.

\section{D.4 Conclusions and Recommendations}

The results of Amter, et al. (1988) and Knapp (1987) for transport of C-14 from the Yucca Mountain repository to the surface of the earth predict travel times ranging from a few hundred to a few thousand years, and are shortest during the period where there is significant heating from the radioactive decay. This period of short travel times 
coincides roughly with the period when the demonstration model predicted most of the $\mathrm{C}-14$ releases to occur; however, any release depends on the failure of the waste canisters. The release of $\mathbf{C}-14$ is very sensitive to the waste-package lifetime in the modeling approach chosen for this study, particularly because early failure timeslead to faster and more complete oxidation of the uranium dioxide. Considering the 5720 year half-life of C-14, there would be relatively little attenuation of the cumulative release of $\mathrm{C}-14$ at the earth's surface because of holdup in the geologic barrier.

The release and transport models for this auxiliary analysis were formulated using assumptions believed to be conservative, although there is little direct evidence-to support these assumptions. The following areas were identified as the most fruitful for the collection of additional data:

- Investigate the mechanisms for $\mathrm{C}-14$ release, including the available information on dry-cask storage, and the investigations to be performed as part of site characterization. There is considerable scatter in the data on spallation of the uranium dioxide fuel, and this could be a potential source of uncertainty. Direct measurements of $\mathrm{C}-14$ releases from the various compartments of the fuel would be more reliable than models based indirectly on effects such as fuel spallation.

- Investigate the geochemistry of calcite precipitation at the Yucca Mountain site, under repository conditions, to determine whether the released C-14 is removed effectively before reaching the accessible environment. There are several counteracting factors involved in the effectiveness of this mechanism for removing C-14. Knapp (1987) states that "Waterrock interaction is probably insignificant due to the low abundance of calcite at the Nevada site and due to the prediction that calcite will not precipitate." However calcite solubility diminishes with increasing temperature, leading to the possibility that repository-induced heating would cause calcite precipitation. 


\section{APPENDIX E-TESTING STATISTICAL CONVERGENCE}

\section{E.1 Discussion}

The Latin Hypercube Sampling (LHS) method is an efficient method for performing Monte Carlo analyses (Iman, 1980a). As with all Monte Carlo analyses, increasing the number of samples increases the convergence of the statistical results. Minimizing the number of repetitions is usually of interest to the analyst, particularly for complicated, time-consuming calculations. A rough "rule of thumb" for LHS analysis is that the minimum number of samples should be $4 / 3$ the number of independent variables for good statistical convergence (Bonano, et al., 1989). It is not clear however whether the rule of thumb is meant to apply both to the generation of the Complementary Cumulative Distribution Function (CCDF) curve and the sensitivity análysis, or just to the latter. The following example was designed to test whether this "rule of thumb" applies to highly nonlinear problems, such as the present calculation.

47 independent variables were sampled in the present analysis. The rule would predict therefore, that about 63 samples would be sufficient to generate an acceptable output distribution; i.e., the CCDF of radionuclide release. To test this hypothesis, the 10,000-year CCDF for the base-case scenario was generated from $500 \mathrm{LHS}$ samples, to provide a smooth benchmark curve representing a statistically converged distribution. Next, 5 CCDF curves were generated for the same distribution, but using only 100 LHS samples each, with each case employing a new random seed for the LHS sampling. The results are shown in Figure E.1. Only one of the five CCDF curves generated with the 100-point samples was close to the 500-point CCDF curve. Convergence was best in the lowconsequence region, and generally poor in the highconsequence region. The 100-point case led to a spread in the release in the high-consequence portion of the curve of about two orders of magnitude. This result indicates that the "rule of thumb" in this case is inadequate, and many more samples would be required. This analysis, however, used only a single scenario, and the statistical convergence treating all scenarios, along with their respective scenario probabilities, might behave differently.

The probable explanation for the inadequacy of the "rule of thumb" in this case is that there were relatively few samples giving high radionuclide releases, and many cases in which there was no release at all within 10,000 years. For this analysis, the low-consequence samples were far more prevalent, as demonstrated by the generally good agreement in that portion of the curve. The result of this exercise points to the need for care in using the LHS method to ensure that enough samples are generated for statistical convergence. Iman, in fact, warns that the sample size is highly problem-specific (Iman, 1980b). In future demonstrations, some of the more sophisticated sampling methods, such as Fast Probabilistic Performance Assessment methods and Importance Sampling (Center for Nuclear Waste Regulatory Analyses, 1988), should be pursued. 


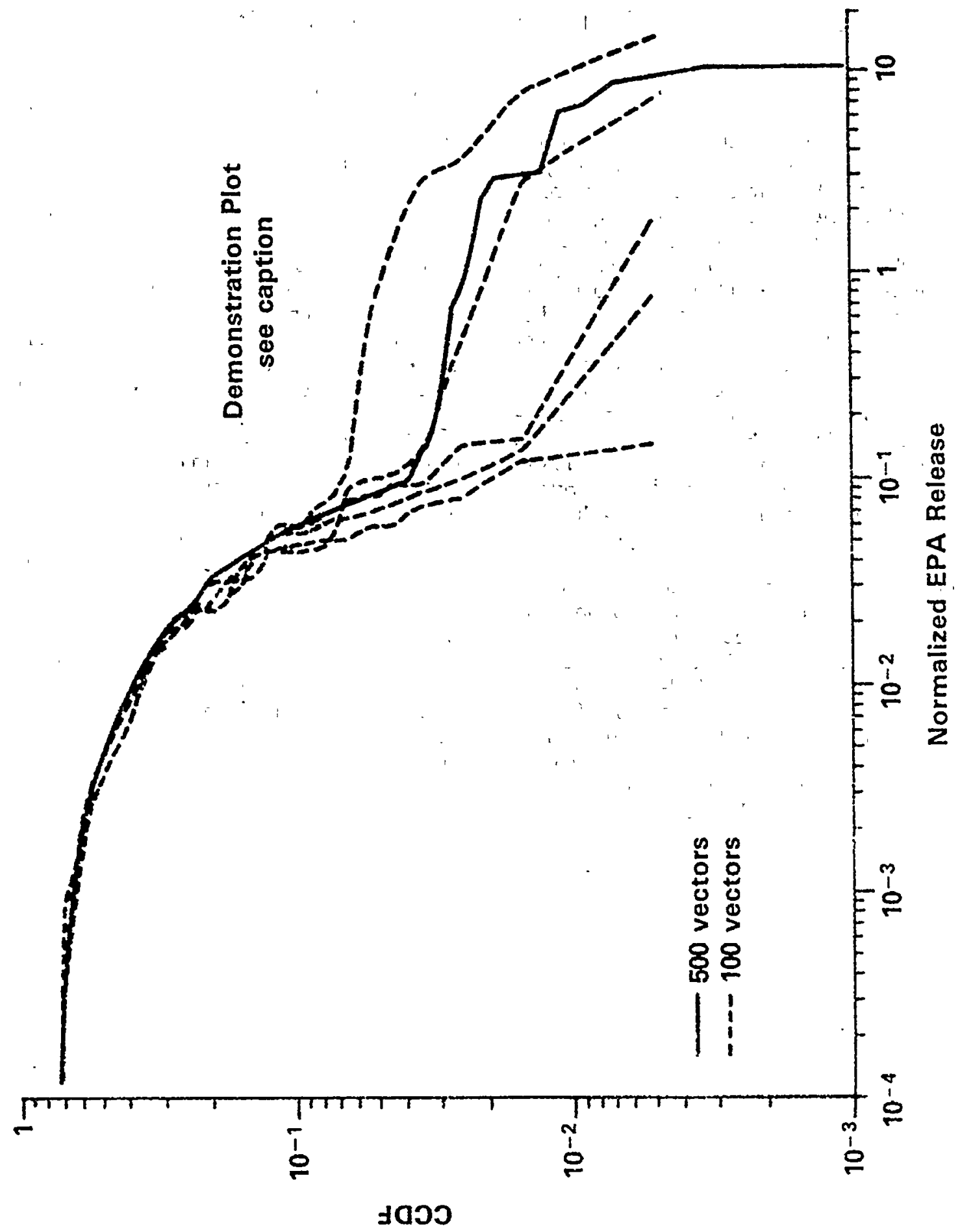

Figure E.1 Statistical Convergence; 100 vs. 500 Vectors, 10,000 Years, Base Case. This graph presents results from an initial demonstration of staff capability to conduct a performance assessment. The graph, like the demonstration, is limited by the use of many simplifying assumptions and sparse data. 


\section{APPENDIX F - ANALYSIS OF HYDROLOGIC DATA}

\section{F.1 Introduction}

An auxiliary analysis of hydrologic data was conducted to determine if spatial correlations could be identified for porosity and hydraulic conductivity parameters. This analysis did not identify any spatial correlation with depth for saturated hydraulic conductivity data or for Calico Hills unit-porosity data. A large-scale trend of decreasing porosity with increasing depth was identified for the Topopah Spring unit, and a small-scale correlation length of less than 40 meters was identified in data from two holes in the Topopah Spring unit.

\section{F.2 Discussion}

The identification of spatial correlation is important to performance-assessment modeling, because longer correlation lengths increase the probability that contaminated groundwater pathways will be encountered that might provide quicker transport of radionuclides to the water table. To look for correlation lengths, the program GEO-EASS (Geostatistical Environmental Assessment Software) (Englund, 1988) was used to generate scatter plots, histogram 'plots, cumulative distribution plots (probability plots), and variograms of depth, porosity, and. saturated hydraulic conductivity data for the Calico Hills and Topopah Spring units. A variogram is a means of quantifying the commonly observed relationship that samples close together will tend to have more similar values than samples far apart. In this analysis, the scatter plots were used to look for trends with depth, whereas the variograms were used to look for spatial correlation in the vertical distance between pairs of measurements.

Since unsaturated zone hydrology parameters were of interest, this study only used core data. The data input files were generated,from Department of Energy data (Anderson, 1981a, 1981b, 1984; Hayden, 1985; Lahoud, 1984; Peters, 1984; Sinnock, 1986; Weeks, 1984). In all runs, depth was in meters, porosity was unitless, and saturated hydraulic conductivity was in meters per second.

Histogram plots of Topopah Spring and Calico Hills porosity data were prepared using all the porosity data from these units in the database. The histogram plot of the Topopah Spring porosity values was made from six wells and 200 samples. The histogram plot of the Calico Hills porosity values was made from six wells and 174 samples. From the histograms, it was concluded that: (1) the Topopah Spring unit tends to have lower porosity values than the Calico Hills unit; (2) the distributions of Topopah Spring porosity data are skewed to the lower porosity values; and (3) the Calico Hills porosity data are skewed to higher porosity values and are bimodal (Figures F.1 and F.2). These results may reflect the difference in matrix porosity values between the nonwelded Calico Hills unit and the welded Topopah Spring unit.

Scatter and variogram plots were generated only for holes which had enough data to conduct these types of analyses. Data from five holes (USW GU-3, USW G-1, USW G-4, USW H-1, and UE25a-1) were used in the analysis (Figure F.3). Separate plots of saturated hydraulic conductivity, porosity, and distance were made for each hole for the Calico Hills and Topopah Spring units.

No correlations with depth could be identified in scatter plots and variogram plots of saturated hydraulic conductivity from either the Topopah Spring or Calico Hills units. In addition, no correlations with depth could be identified in plots of porosity data from the Calico Hills unit.

However, a trend of decreasing porosity with depth was identified in scatter plots of some of the holes in the Topopah Spring unit (UE25a-1, USW GU-3, and USW G-4) (Figures F.4, F.5, and F.6). This trend may be the result of increasing welding with depth, resulting in decreased porosity with depth. Porosity variogram plots of the Topopah Spring unit for two holes (USW GU-3 and USW G-1) contained a pattern, which could be due to the trend noticed in the scatter plots. When the trend was removed, there appeared to be spatial correlation displayed in variograms for holes USW G-4 and UE25a-1 (Figures F.7 and F.8). In both cases, the variogram has a sill of 40 meters or less, indicating that beyond a 40 -meter separation distance, there is no spatial correlation for porosity.

In summary, a large-scale trend of decreasing porosity with increasing depth was identified in data from three holes drilled into the Topopah Spring unit, and a smallscale correlation length of less than 40 meters was identified in data from two holes drilled into the Topopah Springs unit. However, this analysis did not identify any spatial correlation with depth for Calico Hills porosity data or for saturated hydraulic conductivity in either the Calico Hills or the Topopah Spring units. This result was relevant to the flow and transport modeling, because long correlation lengths lead to a broad travel-time distribution for each column (Section 9.3.1.4). Very short correlation lengths lead to the conclusion there is a single groundwater travel time per column and little likelihood of long, fast, groundwater flow paths. In the flow and transport modeling, it was assumed that there was no apparent spatial correlation for saturated hydraulic conductivity beyond 10 meters separation (Seçtion 9.3.1.5). 


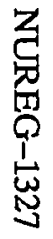

HISTOGRAM OF TOPOPAH SPRINGS UNIT

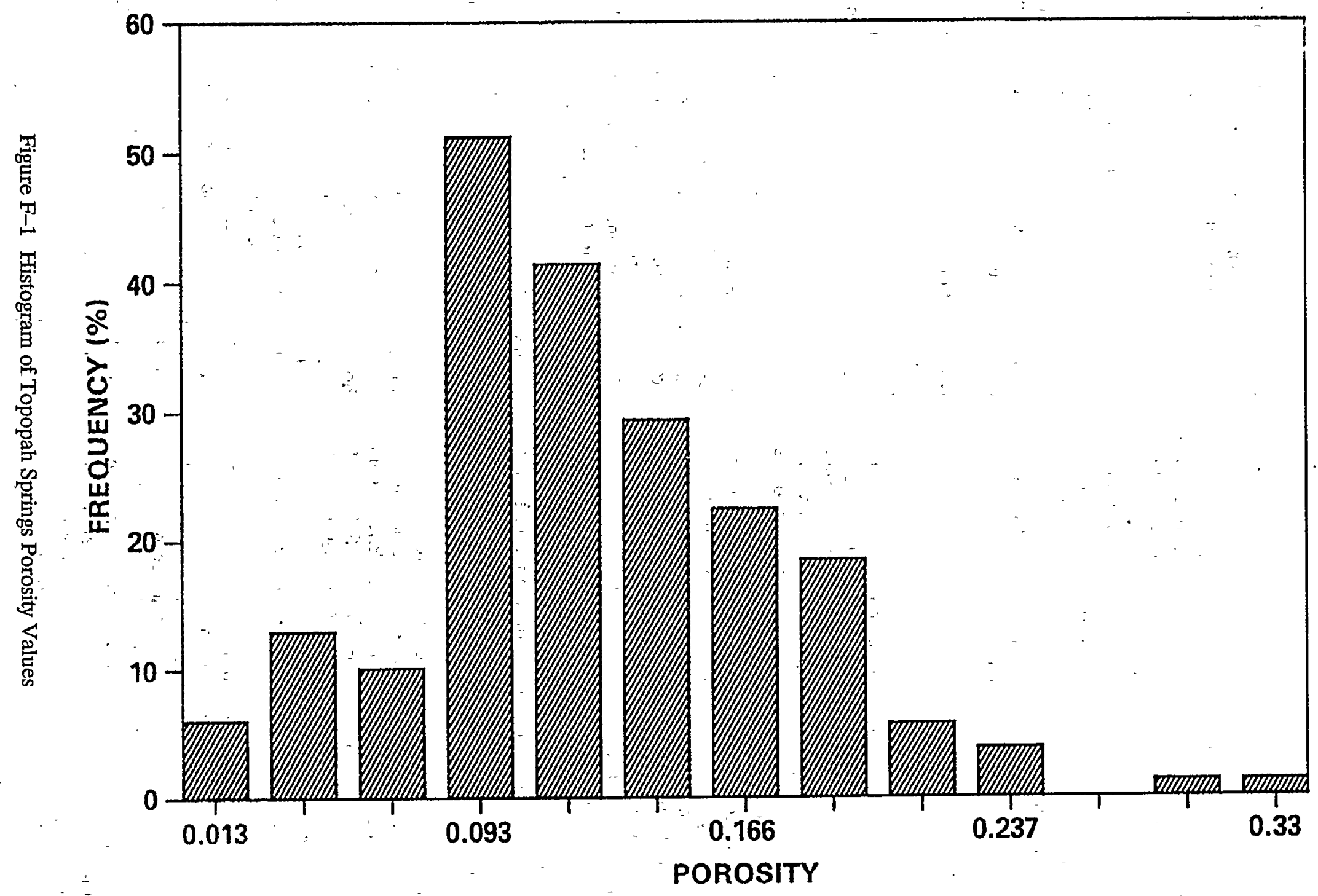


Appendix F

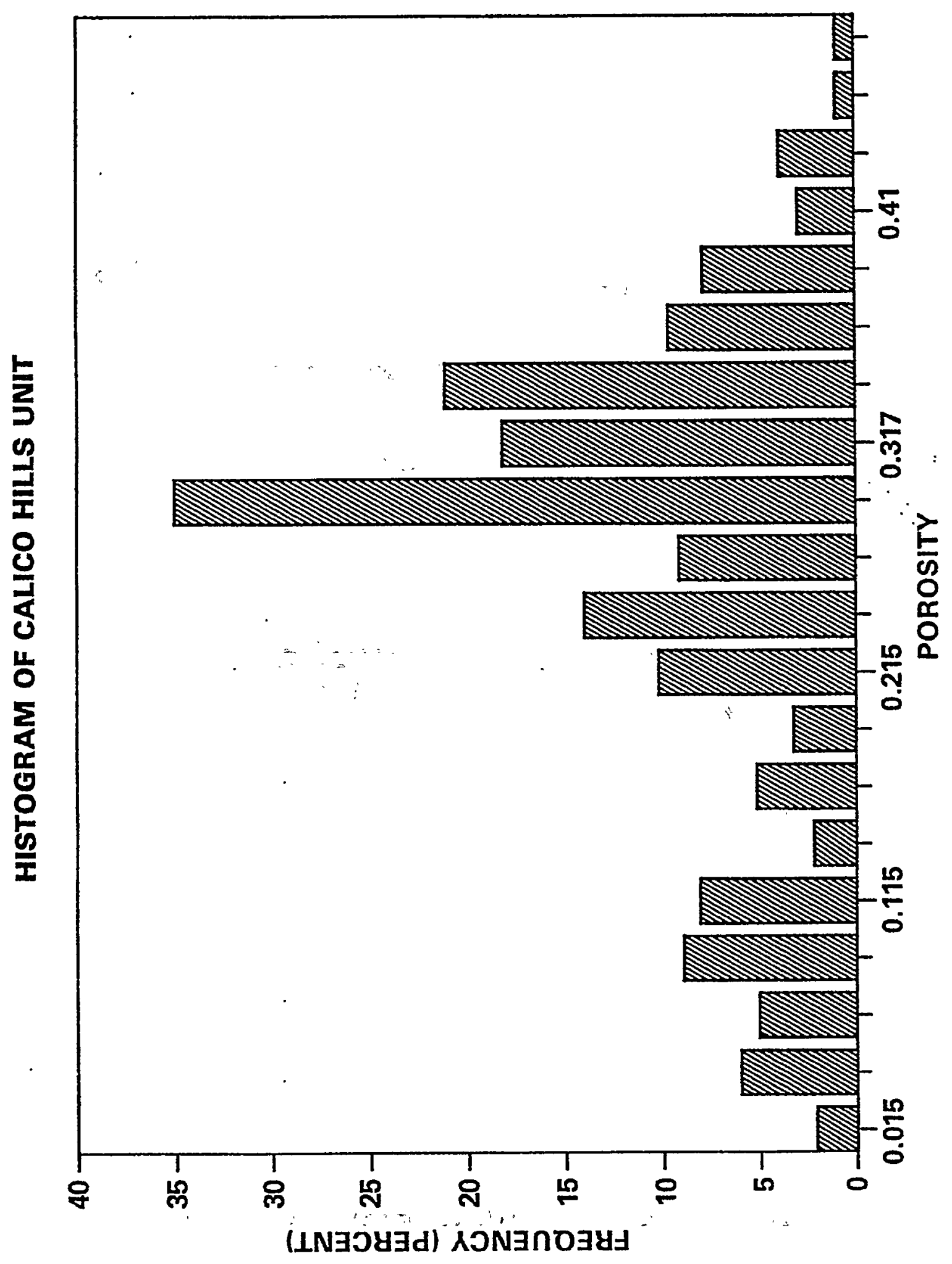

Figure F-2 Histogram of Calico Hills Porosity Values 


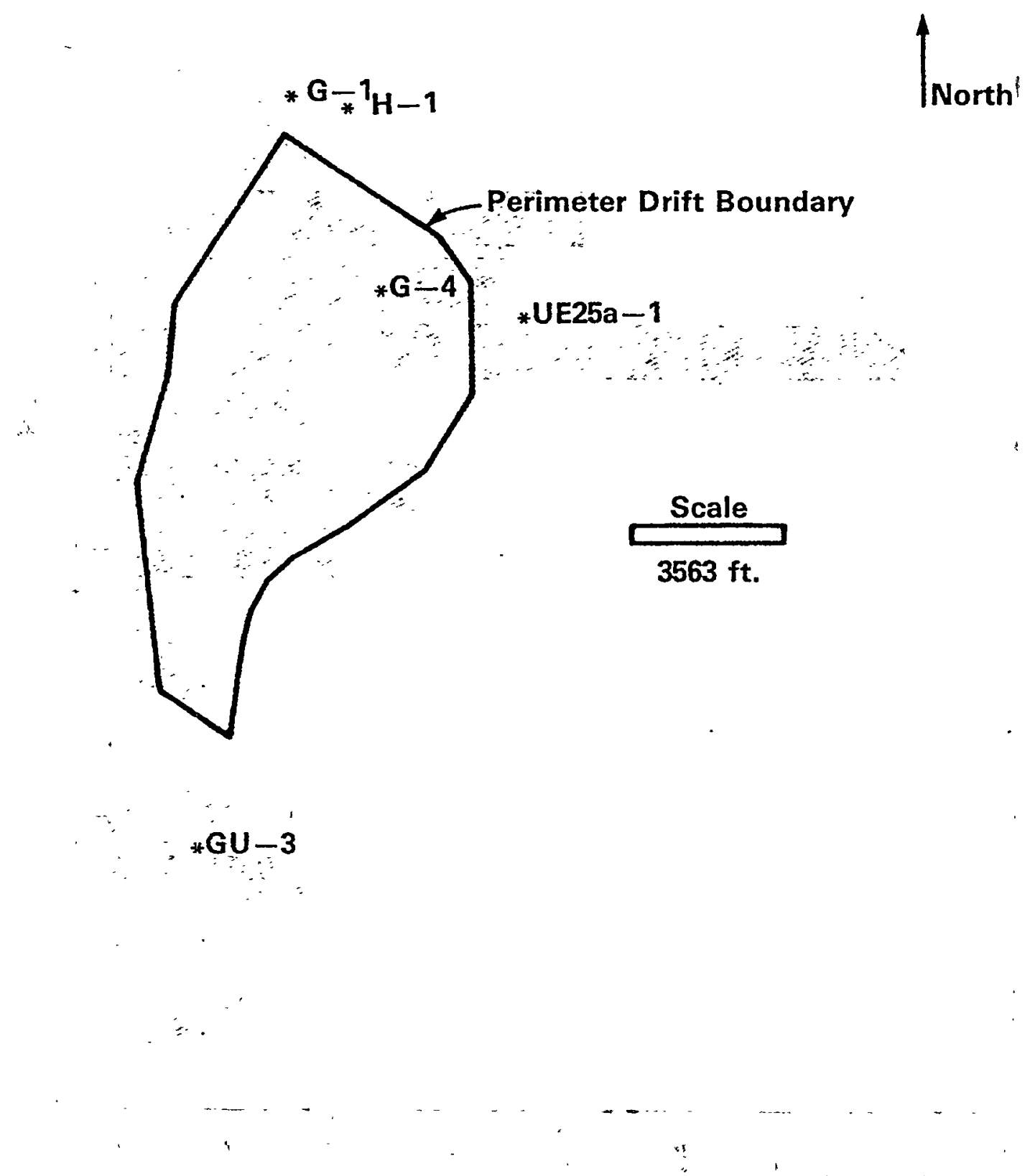

Figure F-3 Location map of holes used in Scatter and Variogram Plots. 


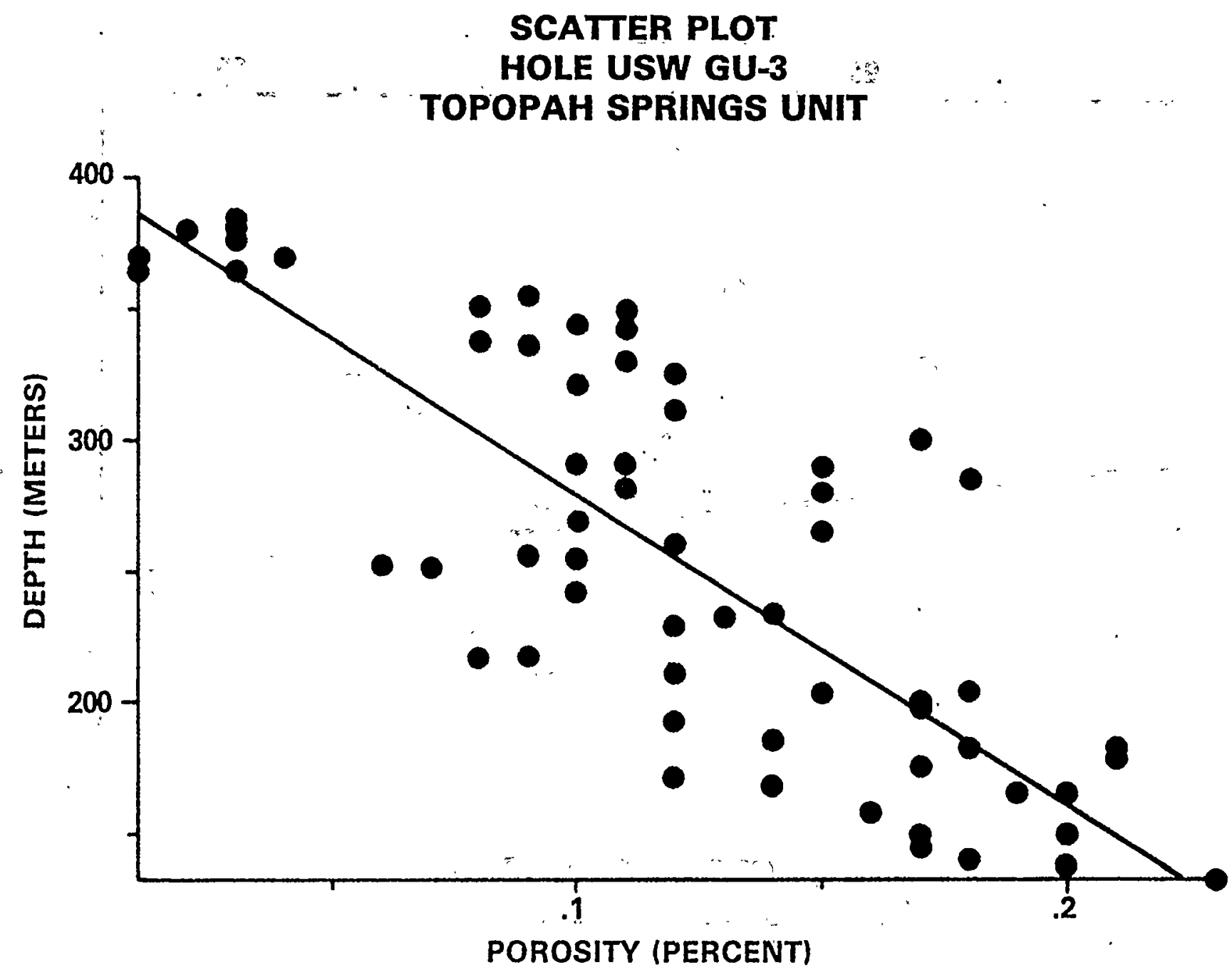




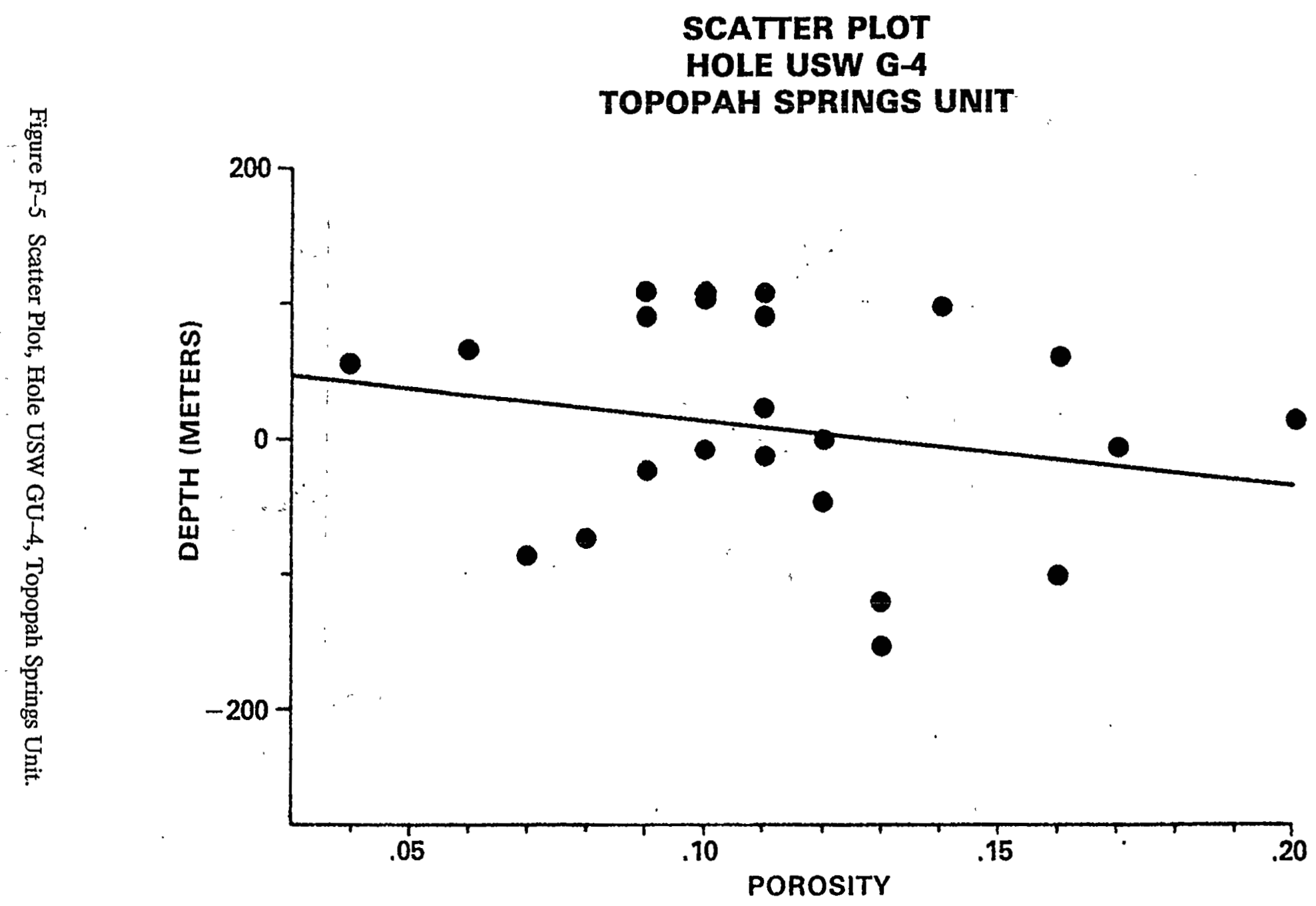




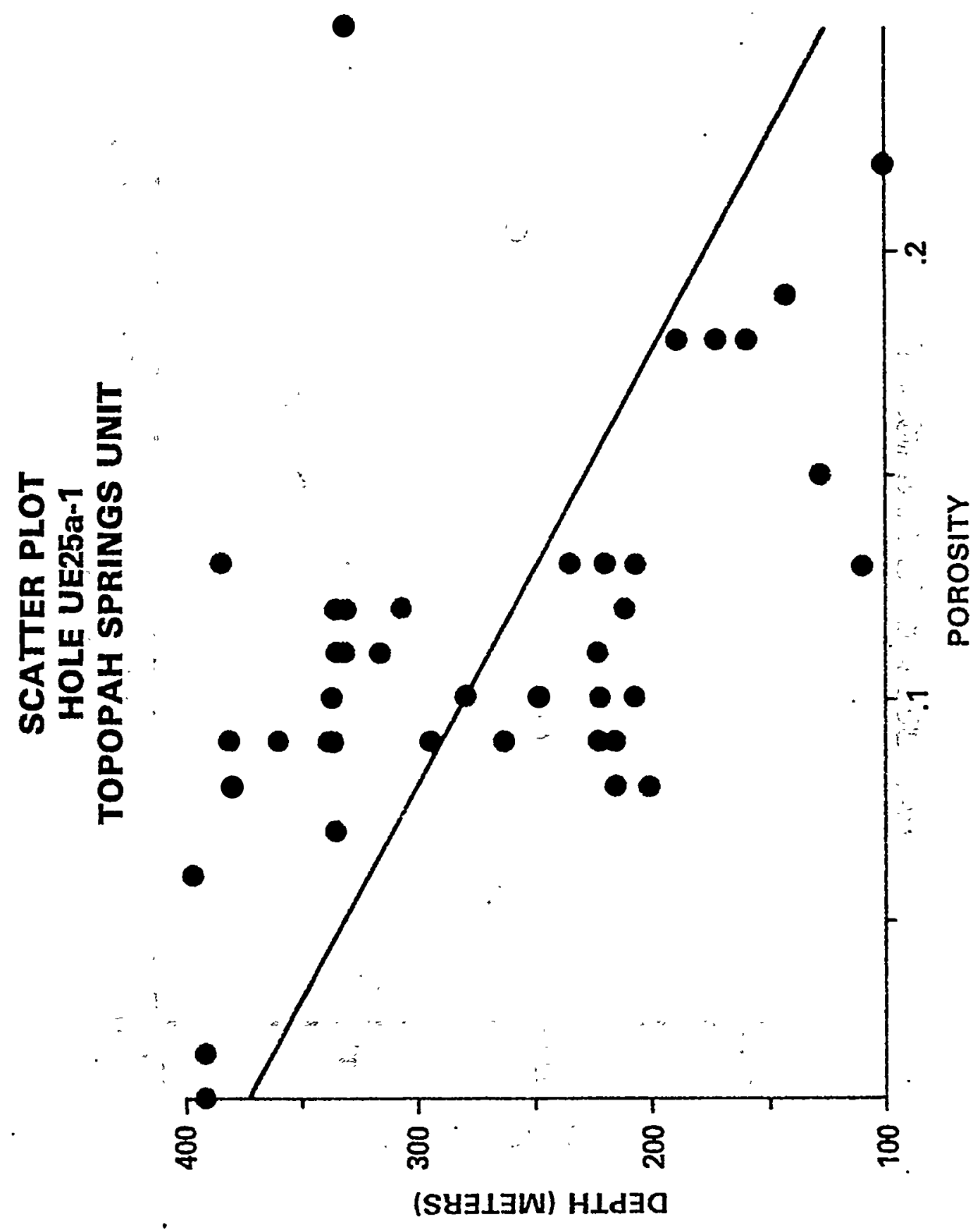

Figure F-6 Scatter Plot, Hole UE25a-1, Topopah Springs Unit. 


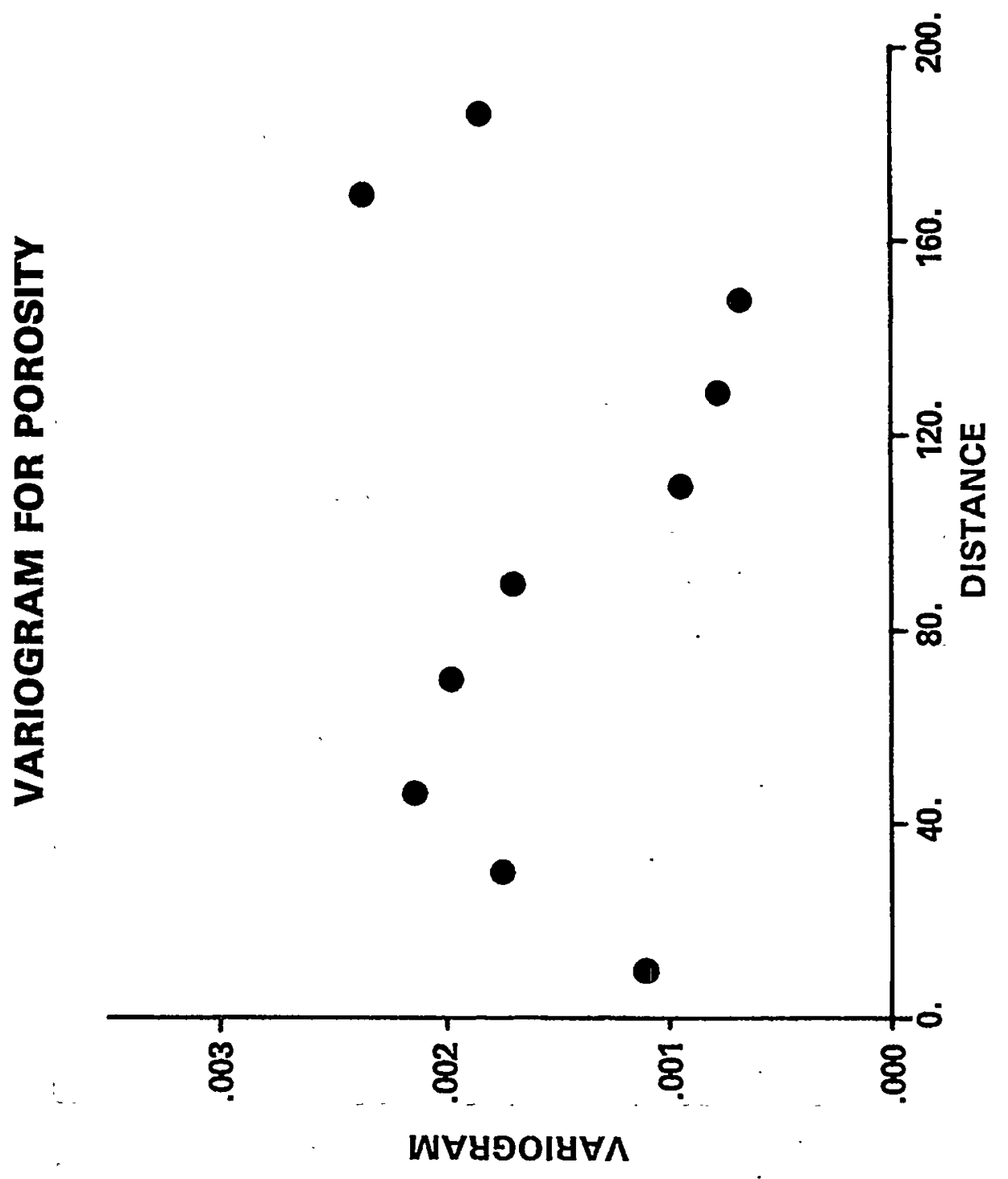

Figure F-7 Porosity Variogram, Hole USW G-4, Topopah Springs Unit. 
VARIOGRAM FOR POROSITY

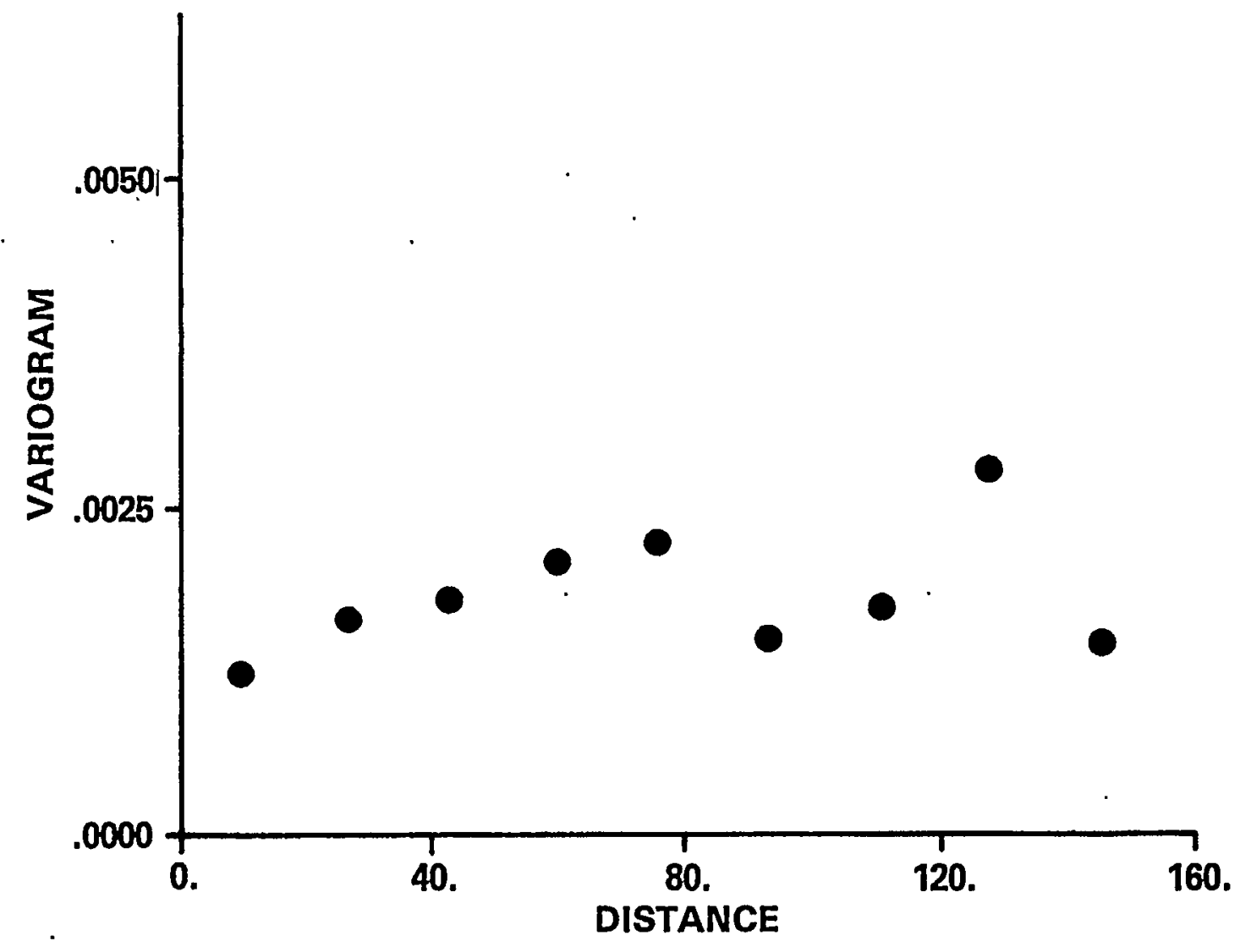




\section{APPENDIX G-TWO-DIMENSIONAL CROSS SECTIONAL FLOW MODEL}

\section{G.1 Introduction}

The HYDROCOIN unsaturated fractured tuff test case described a hydrogeologic system comprised of layers whose matrix properties varied over many orders of magnitude. Due to contrasts in properties at unit interfaces and a dip (average dip of 6 degrees) of the units, it could be expected that water would perch or preferentially move down-gradient with a horizontal velocity component rather than move only vertically.

The degree of horizontal flow is an important consideration because: (1) above the repository, flow diversion could lead to a reduction in flux through the repository; and (2) below the repository, horizontal flow could lead to a shorter path to the water table. Hydrologic modeling can be useful in identifying the conditions (e.g., flux rate) that lead to horizontal flow and the influence these conditions have on flux through a repository and the geometry of travel paths.

\section{G.2 Purpose}

Hydrologic modeling of unsaturated fractured tuff currently is generally limited to a single-continuum composite porous approach for the treatment of fracture/matrix interaction and is computationally intensive. However, some relatively simple modeling of layered systems can be done to: (1) gain insights into the flow diversion issue and how this affects the fluid flux through the repository and the validity of the vertical flow path assumption, (2) understand the numerical limitations better, and (3) provide simple initial simulation studies as the basis for understanding the effects of further modeling refinements.

\section{G.3 Problem Set-up}

This initial analysis assumed matrix flow only and used the description of the tuff site as defined by Department of Energy in the HYDROCOIN Project (Prindle, 1987). In addition, the VAM2D computer program was used to simulate the matrix flow problem. The analysis involved a steady-state simulation using the layering and parametric values presented in Figure G.1 and Table G.1, respectively. The boundary conditions were: a constant infiltration rate on the upper surface, a constant head at the lower (water table) boundary, and no-flow conditions on the sides. Additionally, all the layers were tilted $6 \mathrm{de}$ grees.

\section{G.4 Results and Conclusions}

The diversion of flow at the interfaces was investigated by simulating the HYDROCOIN test case with different infiltration rates of $0.1,0.2$, and $0.5 \mathrm{~mm} / \mathrm{yr}$ (for the 0.5 $\mathrm{mm} / \mathrm{yr}$ simulation, the low conductivity upper layer was not included, because the infiltration rate was greater than the saturated conductivity of the layer). The results of the simulations, presented as the ratio of horizontal to vertical flow immediately above an interface, are presented in Table G.2. Vertical flow dominated in all units when the infiltration rate was $0.1 \mathrm{~mm} / \mathrm{yr}$. When infiltration was $0.2 \mathrm{~mm} / \mathrm{yr}$ or more, horizontal flow was at least an order of magnitude higher than vertical flow above the low conductivity unit (Layer C). The horizontal gradient, a result of the tilted bedding of the layers, and the low hydraulic conductivity of the unit underlying Layer $\mathrm{C}$ are the primary reasons that a significant component of velocity was in the horizontal direction in the lower portion of Layer C. Although the nonwelded unit (Layer E) shows a large component of horizontal flow, this result was due to the imposed boundary condition and to the tilt of the layers, rather than to increased infiltration.

These simulations indicate that infiltration rates greater than $0.2 \mathrm{~mm} / \mathrm{yr}$, combined with the 6-degree slope in unit bedding, could produce a significant amount of horizontal flow. If similar conditions existed at Yucca Mountain, these flows could result in perched zones or localized fracture flow. However, a conclusion on what effect horizontal flow would have on overall performance cannot be made by this analysis. It is very important to note that this analysis did not account for the presence of fractures, heterogeneities, or anisotropy in hydraulic parameters. Future modeling efforts should examine the influence of these additional complications. 


\section{INFILTRATION}

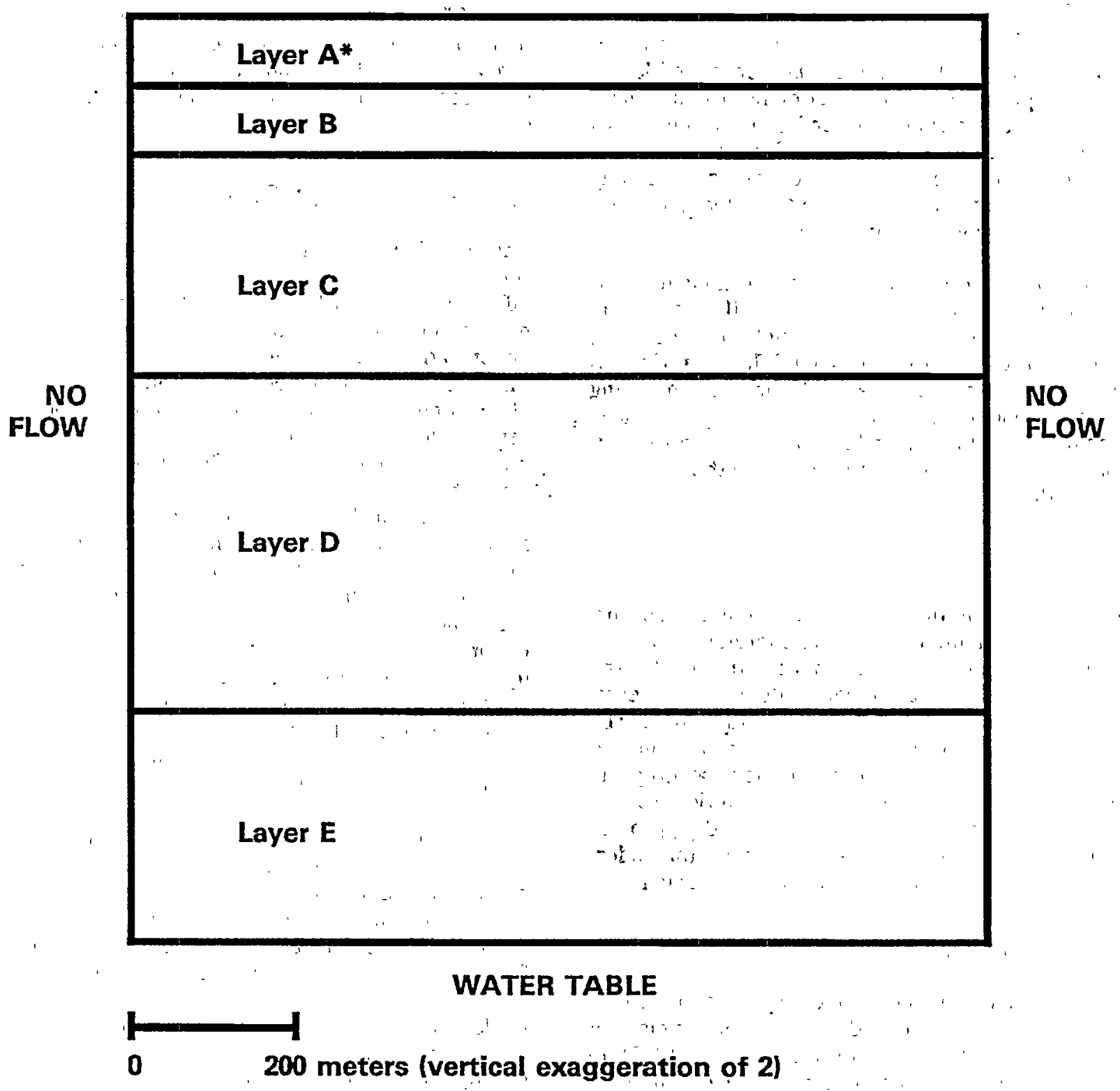

Figure G.1 Hydrogeologic units and boundary conditions used in the cross setional simulation using the VAM2D computer program (note: the figure does not show the six degree incline that was included in the simulation).

*see Table G.1 for Layer descriptions. 
Table G.1

Hydraulic Properties Used in the

Two-Dimensional Simulation of a Layered Tuff Site (Prindle, 1987)

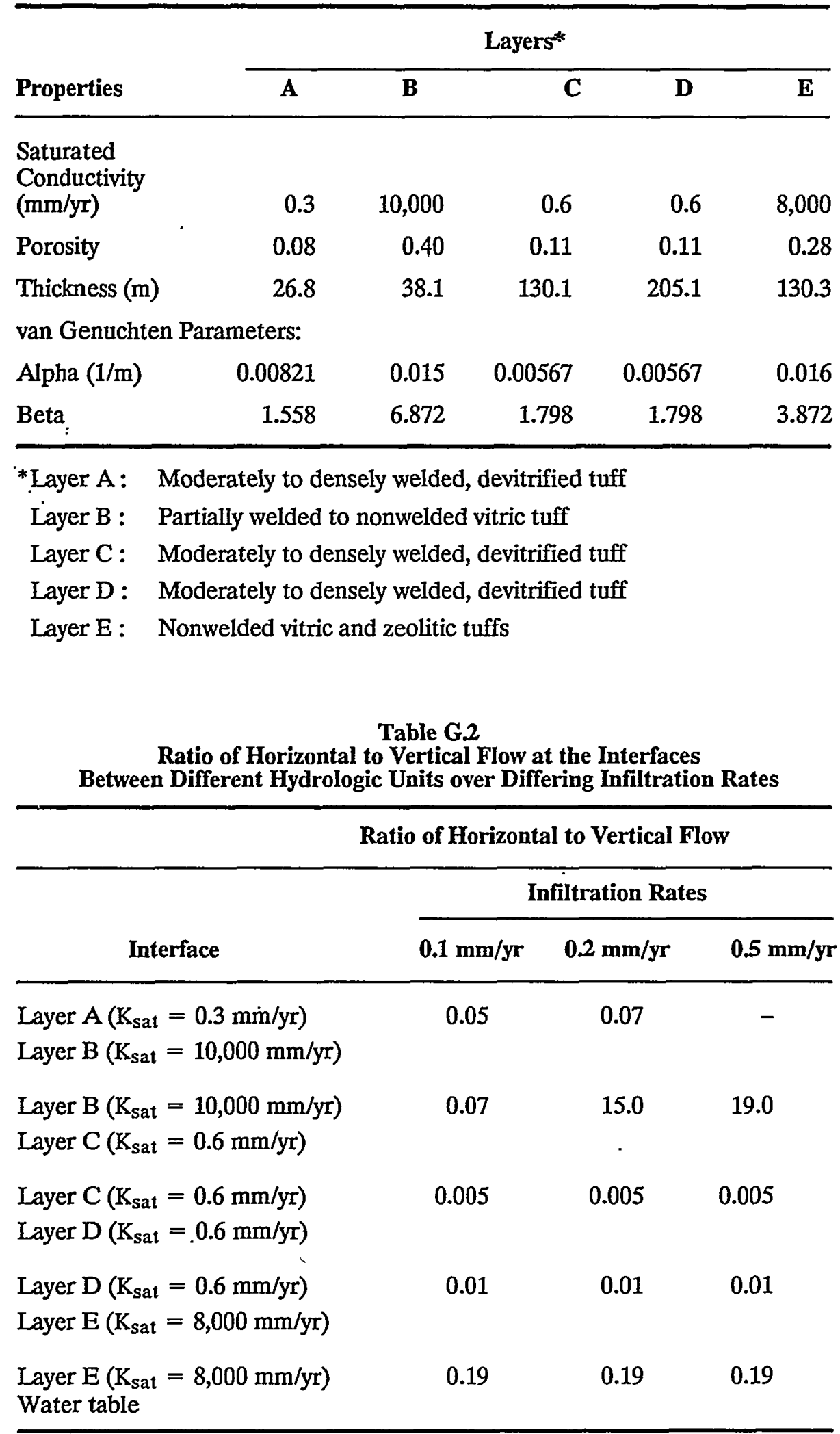




\section{APPENDIX H-ANALYSIS FOR DRILLING SCENARIO}

\section{H.1 Introduction}

The analysis for the drilling scenario largely followed the concepts discussed in the U.S. Department of Energy's (DOE) Site Characterization Plan (SCP) (DOE, 1988), which were used to make an estimate of the expected partial performance measure (EPPM) in that document. However, the analysis in the SCP was expanded upon and modified in some significant ways. The drilling scenario was, in some ways, the archetypical direct release scenario, and it was anticipated that many of the approaches to analyzing both the probabilities and the consequences of this scenario could be extended to similar scenarios, with appropriate modifications.

\section{H.2 Scenario Probability}

To analyze this scenario, many of the concepts used in formulating Appendix B of 40 CFR Part 191 were used. Although Appendix B is offered as guidance and is not binding on either the DOE or the U.S. Nuclear Regulatory Commission, the concepts expressed were a useful starting point for this initial analysis. Two fundamental ideas behind the drilling analysis were: (1) that the institutional memory and control preventing disturbance of the repository fail after some period of time; and (2) that the permanent markers at the site fail in their function after some time. After the greater of these times, it was assumed that drilling for economic resources commenced. It was assumed that this drilling occured at the same rate of drilling as today, for the type of rock involved. Because of these assumptions, a natural approach to the analysis was to assume that drilling occured randomly in space and time, and that it could be effectively described as a Poisson process. Although these are rather sweeping assumptions, viable competing hypotheses appear to be at least as speculative or arbitrary. Furthermore, the purpose of the analysis was to reveal any weaknesses in the design or siting of the repository, so if these assumptions preserved important relationships between the important variables affecting the performance of the repository, then their inherent truthfulness may not be important.

\section{H.2.1 Probability Analysis}

To begin the analysis, one assumes that exploratory drilling takes place at a constant rate, $r$ (in units of per year per. square kilometer); therefore, the rate of drilling over the repository area is:

$$
\mathrm{R}=\mathrm{rA}_{\mathrm{r}}
$$

where $R$ is the rate of drilling into the repository, and $A_{r}$ is the area of the repository.
If it is assumed that this drilling occurs in a random fashion, with no memory of previous drilling, then a Poisson distribution may be used to describe the probability of $N$ boreholes being drilled into the repository over a period of time, $8 \mathrm{t}$, such that:

$$
\mathrm{P}(\mathrm{N})=\frac{(\mathrm{R} \delta \mathrm{t})^{\mathrm{N}} \exp (-\mathrm{R} \delta \mathrm{t})}{\mathrm{Nl}}
$$

In general, under this set of assumptions, there can be any number of boreholes over a particular period of time; however, the form of the distribution given in Equation H.2 ensures that the expected value of the number of boreholes, $\hat{N}$, is equal to Rot. Without too much diffi- culty at this stage of the analysis, a somewhat more general" approach to drilling probability could be taken by assuming a Weibull distribution, rather than a Poisson distribution. For the Weibull distribution,

$$
\mathrm{F}(\mathrm{t})= \begin{cases}\frac{\beta}{\delta}\{(\mathrm{t}-\Gamma) / \delta\} \exp \left\{-[(\mathrm{t}-\Gamma) / \delta]^{\beta}\right\}, & \mathrm{t}>\Gamma \\ 0 & \mathrm{t}<\Gamma\end{cases}
$$

For this analysis, the location parameter, $\Gamma$, would be taken to be the time at which drilling is assumed to commence, $T_{d}$. The scale parameter, $\delta$, would be taken to be $1 / \mathrm{R} \delta \mathrm{T}$. The shape parameter; $\beta$; could be chosen to represent a gradual change from a zero rate of drilling to the constant value $R$ used in the Poisson distribution (Equation H.2). Of course, the distribution would need to be suitably modified to account for the finite number of boreholes, $N$. However, this refinement was not used in the drilling analysis for Phase 1.

For the purpose of this scenario class, the time period of interest was the time between the commencement of drilling, $T_{d}$, and the time duration of the simulation (i.e., the period of time over which the performance of the repository was to be estimated, e.g., 10,000 years), $T_{p}$. That is:

$$
\delta \mathrm{t}=\mathrm{T}_{\mathrm{p}}-\mathrm{T}_{\mathrm{d}}
$$

By combining Equations H.2 and H.3, one obtains the probability of $\mathrm{N}$ boreholes penetrating the site as:

$\mathrm{P}(\mathrm{N})=\frac{\left(\mathrm{R}\left(\mathrm{T}_{\mathrm{p}}-\mathrm{T}_{\mathrm{d}}\right)\right)^{\mathrm{N}} \exp \left(-\mathrm{R}\left(\mathrm{T}_{\mathrm{p}}-\mathrm{T}_{\mathrm{d}}\right)\right)}{\therefore \mathrm{N} !}$

and the probability that no boreholes penetrate the site from Equation $H .4$, by setting $N=0$,

$$
P(O)=\exp \left(-R\left(T_{p}-T_{d}\right)\right) \quad \because .
$$


Both of these probabilities assume that $T_{p}>T_{d}$; that is, that drilling started sometime before the end of the period of consideration. If drilling started at a later time, then Equations H:4 and H.5 must be répláced by,

$$
P(N)=0
$$

and

$$
P(0)=1
$$

The probability of the drilling scenario, $P_{s}$, that is, that some drilling into the repository occured, is given by:

$$
P_{S}=1-P(0)
$$

or

$$
P_{S}=1-\exp \left(-R\left(T_{p}-T_{d}\right)\right)
$$

For the assumptions used in the SCP, $(r=0.0003$ boreholes per square $\mathrm{km}$ per year, $A_{\mathrm{r}}=5.1$ square $\mathrm{km}$, $\mathrm{T}_{\mathrm{p}}=10,000$ years, and $\mathrm{T}_{\mathrm{d}} \doteq 0$ ) (DOE, 1988, $\mathrm{p}$. 8.3.5.13-83), $\mathrm{P}(0)=2.27 \mathrm{E}-07, \mathrm{P}_{\mathrm{s}} \approx 1$, and $\hat{\mathrm{N}}=15.3$. This means that the likelihood of no drilling is very small and that, on average, at least 15 boreholes will be drilled at the site over the 10,000 -year period of consideration.

The previous discussion establishes the probability for the drilling scenario overall and for the probability of $N$ boreholes being drilled on the repository site. However, the analysis of this scenario is more complex, because a borehole could either penetrate the emplaced waste or merely excavate some of the surrounding host rock. In effect, embedded in this scenario is a two-branch event tree:

drilling occurs
on site

If only host rock, and therefore, no waste, is excavated, then some radiological consequences may occur, because, in general, the host rock will be contaminated to some level by the movement of contaminated groundwater from the repository. The probabilities and consequences of these two event-tree branches need to be considered in this analysis.

First, one considers the probability of the excavation of waste, given that drilling occurs on the repository site, $P_{e}$. Assuming that the interception area of drilling is small compared to the repository area, then one finds:

$$
\mathrm{P}_{\mathrm{e}}=\frac{\text { intercept area }}{\text { repository area }}
$$

or

$$
P_{e}=\frac{N_{T} A_{p}}{A_{r}}
$$

where $A_{p}$ is the projected intercept area of a waste package on a horizontal plane and $\mathrm{N}_{\mathrm{T}}$ is the total number of waste packages.

For vertical emplacement of the waste packages in the repository, the projected intercept area is a circle, with a radius equal to the sum of the package radius and the drill radius (Figure H.1a). Thus, for vertical emplacement:

$$
A_{p}=\pi\left(r_{p}+r_{d}\right)^{2}
$$

where $r_{p}$ is the radius of the waste package and $r_{d}$ is the radius of the drill.

For horizontal emplacement of the waste canisters, the projected intercept area is a rectangle, with height equal to the sum of the package diameter and the drill diameter and width equal to the sum of the package length and drill diameter (Figure H.1b). Thus, for horizontal emplacement:

$$
A_{p}=\left[2\left(r_{p}+r_{d}\right)\right]\left[L+2 r_{d}\right]
$$

where $L$ is the length of the waste package.

For the current repository and waste package design $\left(\mathrm{r}_{\mathrm{p}}\right.$ $=0.34 \mathrm{~m}, \mathrm{~L}=4.3 \mathrm{~m}, \mathrm{~N}_{\mathrm{T}}=18,000, \mathrm{~A}_{\mathrm{r}}=5.1$ square $\mathrm{km}$, and assuming the drill diameter is $6.0 \mathrm{~cm}$ ), the possibility of waste excavation for vertical emplacement is:

$$
{ }_{1 .} \mathrm{Pe}_{\mathrm{e}}=0.001518
$$

and for horizontal emplacement:

$$
\mathrm{Pe}=\underset{\mathrm{R}^{5}}{0.01139}
$$

\section{H.3 Consequence Analysis}

With such small target-strike probabilities, the usual outcome would be to excavate contaminated host rock rather than waste. Therefore, it is important to estimate the consequences of excavating contaminated host rock.

\section{H.3.1 Volume of Waste Excavated}

First, one considers the volume of waste that would be excavated if a borehole penetrated a waste package. Taking into account the manner in which the probability of excavation was calculated, a conservative assumption can be used; i.e., if the waste package is touched by the drill, then the entire cylinder of material excavated from the horizon of the waste-package top to the horizon of the waste-package bottom is assumed to be solid waste. For 


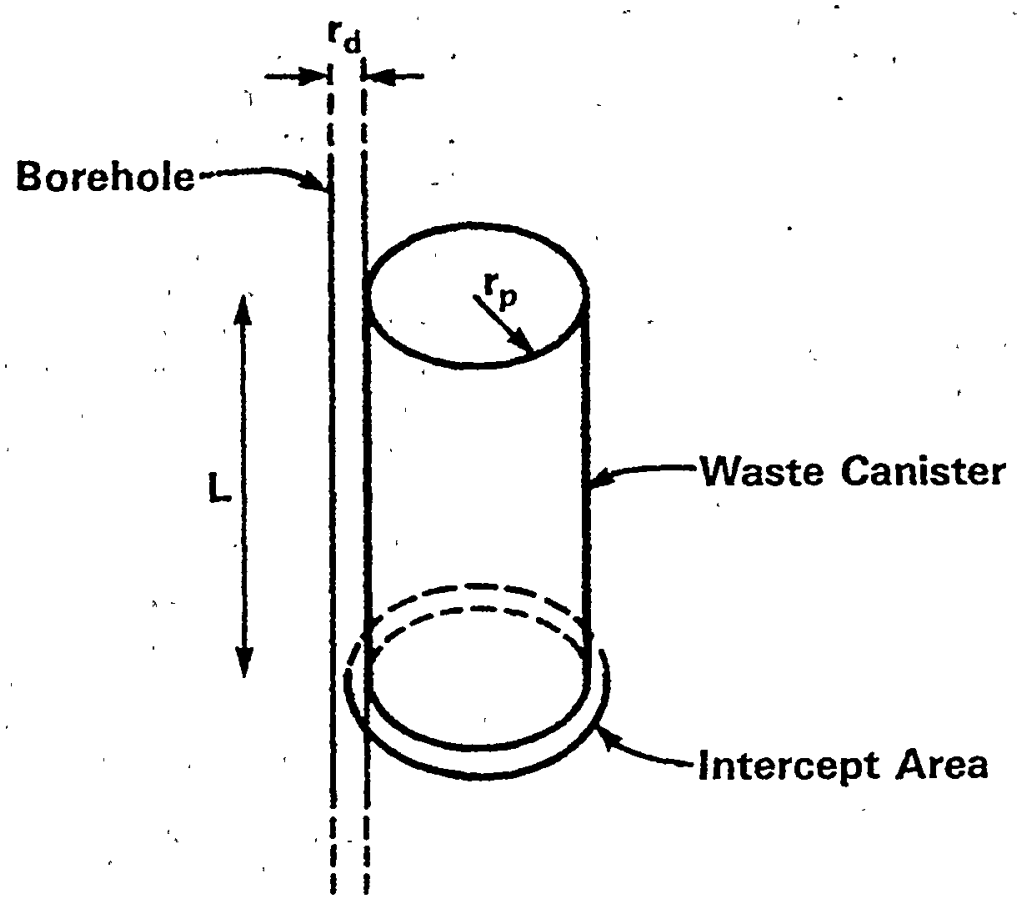

Figure H-1a Intercept geometry for vertical emplacement.

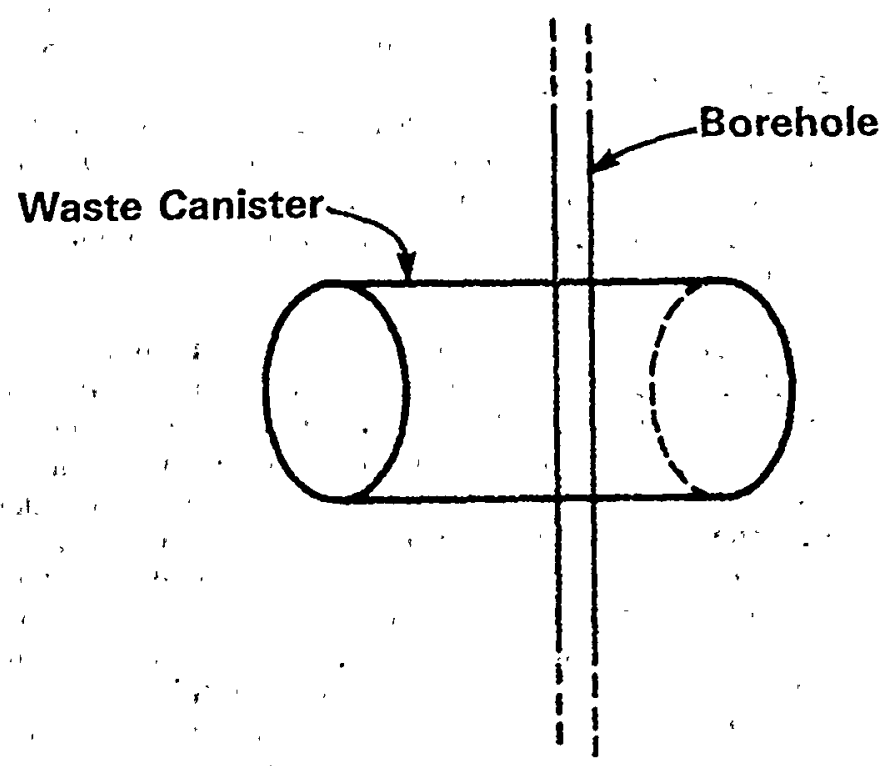

SIDE VIEW

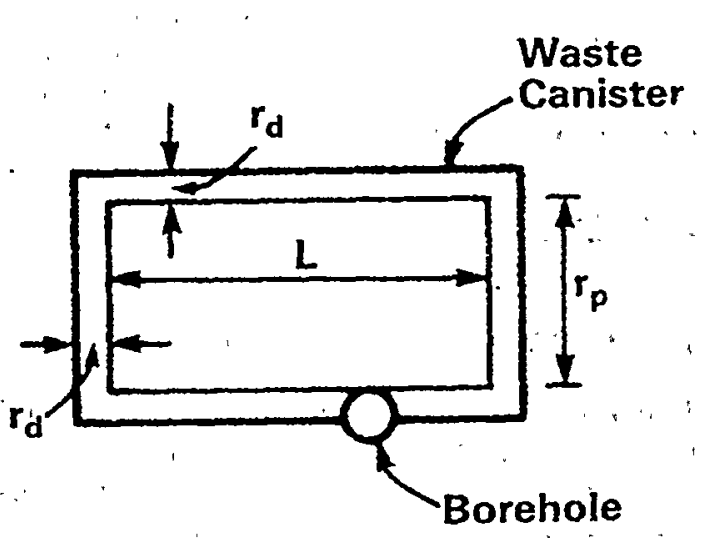

TOP VIEW

Figure $\mathrm{H}-1 \mathrm{~b}$ Intercept geometry for horizontal emplacement. 
boreholes just touching the perimeter of the waste package, or only partially overlapping it, this is clearly a conservative assumption. For this assumption, the volume of excavated waste, $V_{e}$, for vertical emplacement is given by:

$$
\mathrm{V}_{\mathrm{e}}=\pi \mathrm{r}_{\mathrm{d}}^{2} \mathrm{~L}
$$

For horizontal emplacement, the situation is somewhat more complicated, because the length of the column of excavated waste depends on the location on the package at which the drill impinges (Figure H.2). If $h$ is the height of the column of waste and $x$ the distance from the center of the drill to the midpoint of the waste package, then

$$
h=2\left(r_{p}^{2}-x^{2}\right)^{1 / 2}
$$

where $\mathrm{x}=\left\langle 0, \mathrm{r}_{\mathrm{p}}>\right.$ and uniformly distributed over the indicated range.

The average height of the waste column, $\hat{h}$, is:

$$
\hat{\mathrm{h}}=\frac{\pi \mathrm{r} p}{2},
$$

whereas the maximum value of $h$ is $2 r_{p}$. Since the ratio of the maximum value of height to the average value is $4 / \pi$, a slightly conservative assumption would be to assume that the maximum height should be used in calculating the waste volume. But since the values are so close, either choice is reasonable. For a very detailed analysis, in which a great many simulations would be run, the location parameter, $x$, could be treated as a random variable selected from a uniform distribution; however, this appears to be excessive for this analysis. Therefore, the average volume of waste excavated, for each borehole penetrating a horizontally emplaced waste package, is taken to be:

$$
\mathrm{V}_{\mathrm{e}}=\frac{\mathrm{r}_{\mathrm{p}}\left(\pi \mathrm{r}_{\mathrm{d}}\right)^{2}}{2}
$$

\section{H.3.2 Concentration of Waste Released}

The need whether to consider the excavated rack, in addition to the excavated waste itself, depends upon the relative concentrations of radionuclides in the two locations. Now, the concentration of waste in the waste package could be considered to be:

$$
C_{W}=\frac{A_{S} Q_{w}}{N_{T} V_{p}}
$$

where $A_{S}$ is the specific activity of the emplaced waste (curies per MTHM), $\mathrm{Q}_{\mathrm{w}}$ is the total quantity of emplaced waste (MTHM), $\mathrm{N}_{\mathrm{T}}$ is the total number of waste-packages, and $V_{p}$ is the volume of a single waste package.
The concentration of waste in the host rock depends on a number of factors including, the solubility of the waste, the length of time the waste has been dissolving, the speed at which the waste is being dispersed in the groundwater system, the porosity of the rock, and the degree of saturation of the rock. A's an upper limit on the concentration of waste in the rock (closely following the assumptions for waste leaching used in the groundwater release scenario classes), it can be assumed that the water is at the saturation limit for the uranium matrix and that the rock was fully saturated. Then, neglecting sorption on the rock and accounting for waste only dissolved in groundwater, the concentration of waste in the host rock is given by:

$$
\mathrm{C}_{\mathrm{r}}=\mathrm{A}_{\mathrm{S}} \mathrm{C}_{\mathrm{S}} \in \mathrm{F}
$$

where $\mathrm{C}_{\mathrm{r}}$ is the concentration of radionuclides in the host rock $\left(\mathrm{Ci} / \mathrm{m}^{3}\right), \mathrm{A}_{\mathrm{s}}$ is the specific activity of the emplaced waste (Ci/MTHM), $\mathrm{C}_{\mathrm{s}}$ is the solubility limit for the uranium matrix in water $\left(\mathrm{gm} \mathrm{UO}_{2} / \mathrm{gm} \mathrm{H}_{2} \mathrm{O}\right), \epsilon$ is the porosity of the rock, and $\mathrm{F}$ is a conversion factor, where

$$
\begin{aligned}
F= & (1 . \mathrm{E}-06 \mathrm{MT} / \mathrm{gm}) \times\left(1 . \mathrm{E}+06 \mathrm{cc} / \mathrm{m}^{3}\right) \mathrm{x} \\
& \left(1.0 \mathrm{gm} / \mathrm{cc} \text { of } \mathrm{H}_{2} \mathrm{O}\right) .
\end{aligned}
$$

Then, the ratio of concentration in the host rock to concentration in the waste will be:

$$
\mathrm{C}_{\mathrm{r}} / \mathrm{C}_{\mathrm{W}}=\frac{\mathrm{C}_{\mathrm{s}} \epsilon \mathrm{F}}{\left(\mathrm{Q}_{\mathrm{W}} / \mathrm{N}_{\mathrm{T}} \mathrm{V}_{\mathrm{p}}\right)}
$$

For the values assumed in this analysis $(\epsilon=0.36-a$ high representative value, and $\mathrm{C}_{\mathrm{s}}=0.001$ - the upper limit of the range sampled), the ratio indicated in Equation $\mathrm{H} .11$ became $3.6 \mathrm{E}-04: 2.49$. Thus, for equivalent waste volumes, the amount of radioactivity released by excavating host rock will be about 0.01 percent of the amount released by excavating waste directly, given the assumptions which tend to overestimate the amount of contamination in the rock.

However, in addition, the rock could be contaminated in much of the space below the emplacement horizon. Given a single borehole, the length of a cylinder of contaminated rock could be as much as the distance from the emplacement horizon to the water table (assuming that the much larger quantities of water in the saturated zone will substantially reduce the concentration). This is a conservative estimate of the amount of contaminated host rock, since there may not be enough waste emplaced to raise all the vadose water below the repository horizon to the saturation limit. According to the SCP Overview (DOE, 1988), the static water table is 1300 to 2000 feet below the ground surface, and the proposed repository will be about 1000 feet below ground surface. Therefore, the length of a contaminated rock column would be from 300 to 1000 feet (approximately 100 to 330 meters) long. For vertically emplaced wašte packages, the length of the 


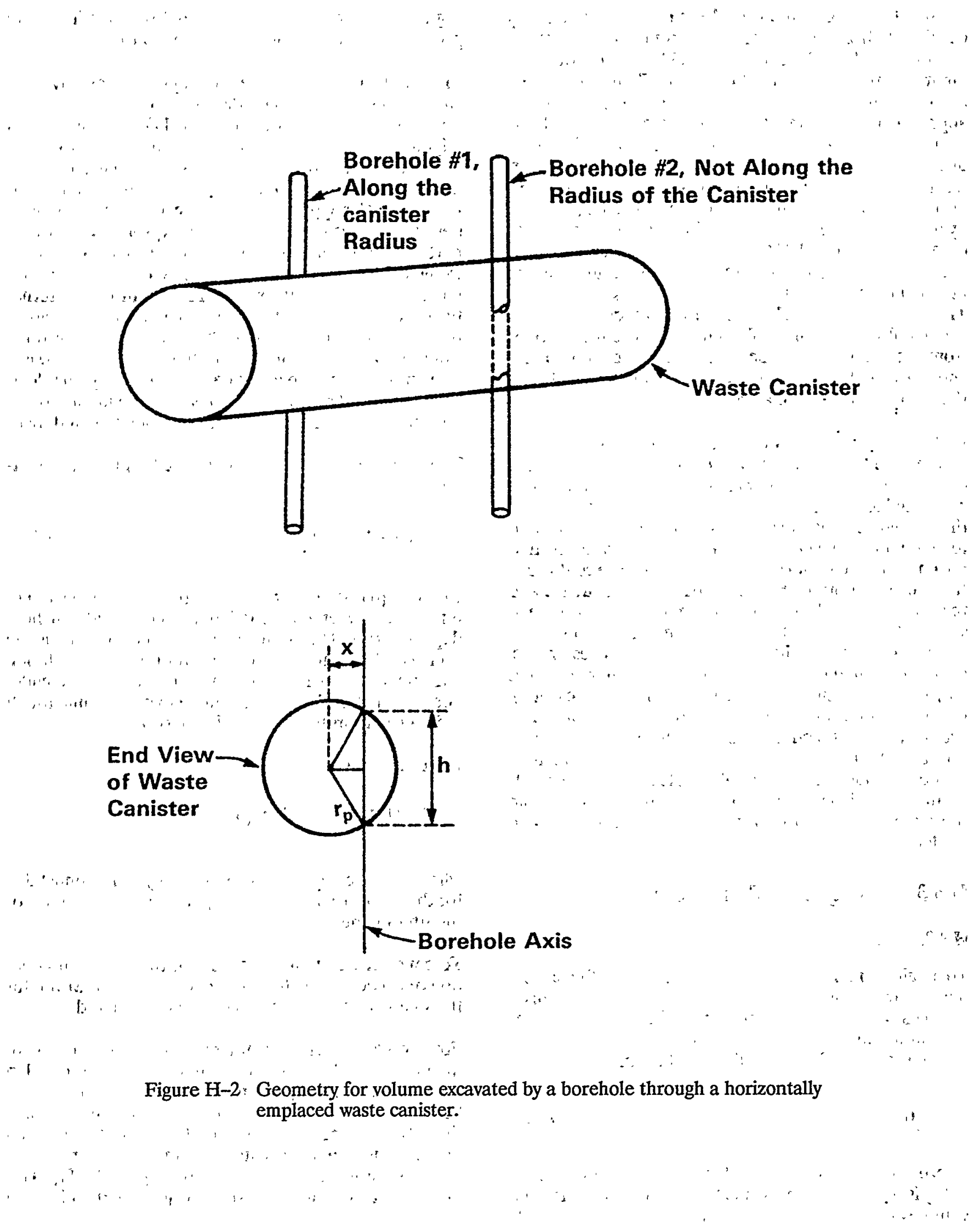


intercepted waste column was $4.3 \mathrm{~m}$ (SCP, p.8.3.5.13-83) (DOE, 1988), and the average intercepted waste column for horizontal emplacement was $0.53 \mathrm{~m}$. Thus, the contaminated rock volume could be from 77 times the intercepted volume of waste, for vertical emplacement, up to approximately 630 times the intercepted volume for horizontal emplacement. Therefore, the ratio of consequences between rock excavation and waste excavation would be approximately 0.011 and 0.091 , for vertical and horizontal emplacement respectively. Since the probability of excavating of waste is only about 0.0015 , for vertical emplacement, and 0.0114, for horizontal emplacement, the excavation of contaminated rock alone could contribute significantly to the consequences of this scenario. That is, the incremental risk (i.e., the consequences of the event multiplied by the probability of the event occurring) from the excavation of rock could be 7.3 to 8.0 (vertical and horizontal emplacement, respectively) times that of the excavation of waste alöne.

If the sorption of radionuclides by the host rock were accounted for, the significance of the excavation of rock could be greater than the previous estimate; however, if radionuclides were sorbed, then their concentration in the groundwater would decrease. For very long times and for radionuclides with long half-lives, it is possible that the entire rock column down to the water table could be at the concentration limit for a particular radionuclide and that the rock, itself, could be contaminated by sorption to several times that concentration limit. Such considerations, which were omitted from the previous estimates, could more than compensate for other assumptions that may have overestimated the consequences of excavating host rock. For example, if a saturation condition of 0.2 , on average, was assumed instead of a value of 1.0 (complete saturation), the previously estimated consequences would be reduced by a factor of 0.2 . Regardless, the result of this evaluation appears to be clear: consequences from the excavation of host rock should be included in the model.

\section{H.3.3 Consequence Estimation}

\section{H.3.3.1 Excavation of waste}

To begin a more precise consideration of the consequences from this scenario class, one considers the consequences of excavating waste first. The consequence of excavating waste by a single borehole at some time, $t$, is just the release of radionuclides at that time:

$$
C_{i}(t)=\frac{V_{e}}{V_{T}} I_{i}(t)
$$

where $C_{i}(t)$ is the incremental release of nuclide $i$ at time $t, V_{e}$ is given by Equations $H .9 a$ and $9 b, V_{T}$ is the total volume of waste emplaced and as used in Equation $\mathrm{H} .10 \mathrm{a}$ is given by the product, $N_{T} V_{p}$, and $I_{i}(t)$ is the inventory present in the repository as a function of time.

The available inventory in the repository at any time changes, because of: (1) radioactive decay and, in some cases, production, and (2) radionuclide dissolution and migration caused by groundwater. Changes due to radioactive décay are treated using conventional equations. Changes due to dissolution and migration are important to treat in this type of analysis because of the coupling between drilling into a repository and groundwater transport. That is" it might be expected that a "tight" repository would be more vulnerable to releases by drilling, because more of the waste would remain in the canisters. Alternatively, a "loose" repository that releases a lot of radioactive material to the geosphere, beginning at an early time, would be less vulnerable to drilling because less waste remains in place. The coupling is not precisely this clear, because, as: discussed previously, substantial consequences could result from excavating contaminated rock.

These two factors could be considered explicitly, by writing:

$$
I_{i}(t)=D_{i}(t) L(t)
$$

where $D_{i}(t)$ is the function of time describing radionuclide decay and production (which is radionuclidedependent), and $L(t)$ is the function of time describing the removal of inventory from the repository by dissolution and migration (this function can be radionuclidedependent also, but it was assumed to be the same for all radionuclides in the Phase 1 demonstration).

$$
\begin{aligned}
& \text { For decay only, } \\
& \qquad \mathrm{D}_{\mathrm{i}}(\mathrm{t})=\mathrm{I}_{\mathrm{i}}(0) \exp \left(-a_{\mathrm{i}} \mathrm{t}\right)
\end{aligned}
$$

where $I_{i}(0)$ is the emplaced inventory of radionuclide $i$ for the entire repository and $a_{\mathrm{i}}$ is the decay constant for the ith radionuclide.

To consider decay and production, the Bateman equations must be used instead of Equation H.14; however, for the Phase 1 analysis, only decay was considered.

For the source term treatment used in the analysis of radionuclide release to the groundwater, as discussed in Section 5 of this report, it was-assumed that releases began from the engineered barrier system (EBS) at some time after closure, $T_{s}$, and that release from the uranium matrix occured at a constant rate, until the entire matrix was gone after passage of the time period, $T_{L}$. This means that the function, $L(t)$, in Equation $H .13$ is given by: 


$$
\begin{aligned}
& 1 \cdots \because t<T_{S} \\
& L(t)=\left\{1-\frac{\left(t-T_{S}\right)}{T_{L}} T_{S} \leq t<\left(T_{S}+T_{L}\right)\right. \text {. } \\
& 0 \quad t \geq\left(T_{S}+T_{L}\right)
\end{aligned}
$$

where $T_{s}$ is the time at which releases from the EBS start, and $T_{L}$ is the time for the waste to move completely from the EBS to the geosphere.

The previous equation assumes, implicitly, that the amount of waste excavated by drilling is small compared to the total amount of waste in the repository, since the inventory is reduced in time only by the amount of radionuclides. removed by groundwater and not by the amount removed by drilling.

It is clear from Equations H.12 through H.15 that the consequences of excavating waste by a single borehole depend significantly on the time at which such excavation occurs. One approach to treating this issue is to simulatea number of realizations in which the number and drilling times of the boreholes are random variables. Another approach would be to divide the time interval of interest into subintervals and to use a representative consequence for each interval. The approach chosen for this Phase 1 analysis was to. calculate the expected value of consequences over the entire interval of interest. Since Equation $\mathrm{H} .12$ represents the consequence (incremental increase in radionuclide $i$ released to the environment) from a single borehole excavated at time, $t$, the consequence of $\mathrm{N}$ boreholes excavated at time, $t$, is just:

$$
\therefore \quad \mathrm{C}_{\mathrm{i}^{\prime}}^{\mathrm{N}}(\mathrm{t})=\mathrm{NC}_{\mathrm{i}}(\mathrm{t})
$$

Taking this value of the consequence of $\mathrm{N}$ boreholes as representative of the consequences that occur over some time increment, $\delta t$ (where $t$ is some time in the interval $\delta t)$, then the expected value of consequences, averaged over all possible values of number of boreholes, is:

$$
\begin{aligned}
\hat{C}_{i}(t) & =\sum_{N=1}^{\infty} P(N) C_{i}^{N}(t) \\
& =\sum_{N=1}^{\infty} P(N) N C_{i}(t)
\end{aligned}
$$

where $\mathrm{P}(\mathrm{N})$ is the probability of $\mathrm{N}$ boreholes over the time interval, $\delta$ t. However, since $P(N)$ is given by Equation H.2, the equation becomes:

$$
\hat{C}_{i}(t)=\sum_{N=1}^{\infty} \frac{(R \delta t)^{N} \exp (-R \delta t)}{N !} N C_{i}(t)
$$

Since $C_{i}(t)$ and $\exp (-R \delta t)$ do not depend on the number of boreholes, $N$, these terms can be taken from under the summation to give:

$$
\hat{C}_{i}(t)=C_{i}(t) \exp (-R \delta t) \sum_{N=1}^{\infty} \frac{(R \delta t)^{N}}{(N-1) !}
$$

or

$$
\hat{C}_{i}(t)=C_{i}(t) \exp (-R \delta t)(R \delta t) \sum_{N=1}^{\infty} \frac{(R \delta t)^{N-1}}{(N-1) !}
$$

or

$$
\hat{C}_{i}(t)=C_{i}(t) \exp (-R \delta t)(R \delta t) \sum_{N=0}^{\infty} \frac{(R \delta t)^{N}}{(N) !}
$$

or

$$
\hat{C}_{i}(t)=C_{i}(t) \exp (-R \delta t)(R \delta t) \exp (+R \delta t)
$$

or

$$
\hat{\mathrm{C}}_{\mathrm{i}}(\mathrm{t})=\mathrm{C}_{\mathrm{i}}(\mathrm{t})(\mathrm{R} \delta \mathrm{t})
$$

By taking the limit of Equation $\mathrm{H} .17$ as $8 \mathrm{t}$ approaches zero, the new equation is:

$$
\mathrm{d} \hat{C}_{\mathrm{i}}(\mathrm{t})=\mathrm{C}_{\mathrm{i}}(\mathrm{t})(\mathrm{Rd} \mathrm{t})
$$

Then, by integrating this result over the time period of interest, one finds:

$$
\hat{C}_{i}(t)=R \int_{T_{d}}^{T_{p}} C_{i}(t) d t
$$

Combining Equations H.12 and H.13 with Equation H.19, one obtains:

$$
\hat{C}_{i}(t)=R \frac{V_{e}}{V_{T}} \int_{T_{d}}^{T_{p}} D_{i}(t) L(t) d t
$$

where $\dot{D}_{i}(t)$ can be obtained from Equation $\mathrm{H}_{1} .14$, and $L(t)$ can be obtained from Equation H.15.

To perform the integration indicated in Equation H.20, it is useful to note the following: (1) if $T_{d} \leq T_{p}$, then the integral in Equation H.20 is zero (no drilling during the time period of interest); and (2) if $T_{d}>T_{S}+T_{L}$, then the integral in Equation H.20 is zero (drilling commences after all the waste has migrated from the EBS). Assuming that $T_{d}>T_{p}$ and that $T_{d}<T_{s}+T_{L}$, then one can write: 


$$
\hat{\mathrm{C}}_{\mathrm{i}}(\mathrm{t})=\mathrm{R} \frac{\mathrm{V}_{\mathrm{e}}}{\mathrm{V}_{\mathrm{T}}}\left(\mathrm{I}_{\alpha}+\mathrm{I}_{\beta}\right)
$$

where,

$$
I_{a}= \begin{cases}0 & \text { if } T_{d}>T_{S} \\ \frac{I_{i}(0)}{a_{i}}\left[\exp \left(-a_{i} T_{d}\right)-\exp \left(-a_{i} T_{S}\right)\right] & \text { if } T_{d}<T_{S}\end{cases}
$$

and

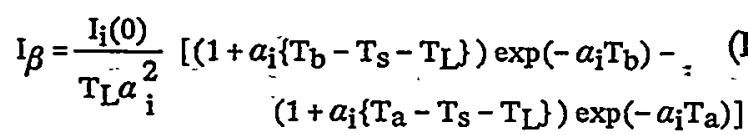

where,

$$
T_{a}= \begin{cases}T_{S} & \text { if } T_{d}<T_{s} \\ T_{d} & \text { if } T_{d}>T_{s_{i}},\end{cases}
$$

and

$$
T_{a}=\left\{\begin{aligned}
T_{S}+T_{L} & \text { if } T_{p}>T_{S}+T_{L} \\
T_{p} & \text { if } T_{p}<T_{S}+T_{L}
\end{aligned}\right.
$$

\section{H.3.3.2 Excavation of contaminated rock}

The formulas in the previous section provided an estimate of the consequences of excavating waste. Since the prior analysis also showed that the excavation of contaminated rock could be significant and that the probability of excavating rock was much higher than excavating waste, the following analysis was developed to estimate the consequences of excavating contaminated rock.

One can proceed in a manner very similar to that used for estimating the consequences of excavating waste. One can rewrite Equation H.12 for the excavation of rock:

$$
C_{i}^{\prime}(t)=\frac{V_{e}^{\prime}}{V_{T}^{\prime}} \cdot I_{i}^{\prime}(t)
$$

where $C_{\dot{i}}^{\prime}(t)$ is the incremental release from excavated rock of nuclide $\mathbf{i}$ at time $t, V_{e}^{\prime}$ is the volume of rock excavated by a single borehole, $V_{T}^{\prime}$ is the total volume of rock that is potentially contaminated by waste from the repository, and $I_{i}^{\prime}(t)$ is the inventory present in the contaminated rock as a function of time.
As an approximation to the total volume of contaminated rock, one can use:

$$
\mathrm{V}_{\mathrm{T}}^{\prime}=\mathrm{A}_{\mathbf{r}} \mathrm{d}_{\mathrm{r}}
$$

where $A_{r}$ has been defined previously as the area of the repository and $d_{r}$ is the depth of rock underlying the repository subject to contamination.

As discussed previously, a reasonable assumption is that the concentration of waste in the rock is reduced substantially below the water table, because more flow is available to dilute and disperse the contamination entering from the unsaturated zone. However, if a borehole is used to:extract water from the saturated zone, radionuclides dispersed in the aquifer could be brought into the accessible environment. For the Yucca Mountain repository, the water table is at different depths below the repository horizon depending on the lateral location in the repository. This variation in depth is shown in Table 9.3.1 of Section 9.3. Based on the information in this table and taking the weighted average of these depths, one obtains an average depth of $249.1 \mathrm{~m}$.

A consistent approximation to the volume of rock excavated is then given by:

$$
V_{\mathrm{e}}^{\prime}=\pi \mathrm{r}_{\mathrm{d}}^{2} \mathrm{~d}_{\mathrm{r}}
$$

Then

$$
\mathrm{V}_{\mathrm{e}}^{\prime} / \mathrm{V}_{\mathrm{T}}^{\prime}=\pi \mathrm{r}_{\mathrm{d}}^{2} / \mathrm{A}_{\mathrm{r}}^{\prime} \quad \ldots
$$

As in the analysis for the excavation of waste, one can express the time dependence of the repository inventory as the product of a term related to radioactive decay, $D^{\prime}(t)$, and a term related to migration of radionuclides from the repository into the geosphere, $L^{\prime}(t)$. In an analogue to Equation H.13, one has:. .

$$
I_{i}^{\prime}(t)=D_{i}^{\prime}(t) L^{\prime}(t)
$$

where $D_{i}^{\prime}(t)$ is the function of time describing radionuclide decay and production (which is radionuclidedependent), and $L^{\prime}(t)$ is the function of time describing movement of inventory from the repository to the host rock by dissolution and migration (this function can be radionuclide-dependent also, but it was assumed to be the same for all radionuclides in the Phase 1 demonstration).

To be, consistent with the analysis for the excavation of waste, one assumes that the decay function for waste in the geosphere is the same as for waste in the repository, and that the removal function for the geosphere, $L^{\prime}(t)$, is the complement of the removal fünction for the repository. That is: 


$$
D_{i}^{\prime}(t)=D_{i}(t)^{\prime}
$$

and

$$
L^{\prime}(t)=1-L(t) .
$$

where $D_{i}(t)$ is given by Equation $H .14$ and $L(t)$ is given by Equation H.15.

These assumptions comprise a compartmental analysis for the waste: (1) whatever waste does not decay must be either in the repository or in the geosphere; and (2) further undecayed waste moving out of the repository must be in the geosphere. This estimate of waste excavated is conservative, because the waste transported by other means, such as groundwater or gas movement to the accessible environment, are not assumed to be removed from the compartments subject to excavation.

By combining Equations $\mathrm{H} .15$ and H.30b, one obtains:

$$
\begin{aligned}
& 0 \quad t<T_{S} \\
& L^{\prime}(t)=\left\{\frac{\left(t-T_{S}\right)}{T_{L}} \quad T_{S}<t<\left(T_{S}+T_{L}\right)\right. \\
& 1 \quad t>\left(T_{S}+T_{L}\right)
\end{aligned}
$$

In a manner similar to the derivation of Equations H.16 through H.20, one obtains the analogous result for excavation of contaminated rock:

$$
\hat{C}_{\mathrm{i}}^{\prime}(t)=R \frac{V_{e}^{\prime}}{V_{T}^{\prime}} \int_{T_{d}}^{T_{p}} D_{i}(t) L^{\prime}(t) d t
$$

As in the previous analysis, to perform the integration indicated in Equation H.32, it is useful to note the following: (1) if $T_{d} \geq T_{p}$, then the integral in Equation $H .20$ is zero (no drilling during the time period of interest); and (2) if $T_{i p}<T_{s}$, then the integral in Equation H.20 is zero (leaching commences after the time period of interest, so all the waste is in the EBS). Assuming that $T_{d}<T_{p}$ and that $T_{p}>T_{s}$, then one may write:

$$
\hat{\mathrm{C}}_{\mathrm{i}}^{\prime}(\mathrm{t})=\mathrm{R} \frac{\mathrm{V}_{\mathrm{e}}^{\prime}}{\mathrm{V}_{\mathrm{T}}^{\prime}}\left(\mathrm{I}_{a}^{\prime}+\mathrm{I}{ }_{\beta}^{\prime}\right)
$$

If $T_{s}+T_{L}>T_{p}$, then $T_{d}<T_{S}+T_{L}$ and:

$$
\mathrm{I}_{\beta}=0
$$

and

$$
\mathrm{I}_{a}=\frac{\mathrm{I}_{\mathrm{i}}(0)}{\left.\mathrm{T}_{\mathrm{L}} \alpha_{\mathrm{i}}^{2}\left(1+a_{\mathrm{i}}\left\{\mathrm{T}_{\mathrm{p}}-\mathrm{T}_{\mathrm{S}}\right\}\right) \exp \left(-a_{\mathrm{i}} \mathrm{T}_{\mathrm{p}}\right)\right]}
$$

where

$$
T_{a}= \begin{cases}T_{s} & \text { if } T_{d}<T_{s} \\ T_{d} & \text { if } T_{d}>T_{s}\end{cases}
$$

If $T_{s}+T_{L}<T_{p}$, then:

$\mathrm{I}_{\beta}=\frac{\mathrm{I}_{\mathrm{i}}(0)}{a_{\mathrm{i}}}\left[\exp \left(-a_{\mathrm{i}} \mathrm{T}_{\mathrm{p}}\right)-\exp \left(-a_{\mathrm{i}} \mathrm{T}_{\mathrm{c}}\right)\right]$

where

$T_{c}=\left\{\begin{array}{cc}T_{s}+T_{L} & \text { if } T_{d}<T_{S}+T_{L} \\ T_{d} & \text { if } T_{d}>T_{S}+T_{L}\end{array}\right.$

and

$$
\begin{aligned}
& \mathrm{I}_{a}= \begin{cases}0 & \text { if } \mathrm{T}_{\mathrm{d}}>\mathrm{T}_{\mathrm{S}}+\mathrm{T}_{\mathrm{L}}\end{cases} \\
& \begin{array}{r}
\frac{\mathrm{I}_{\mathrm{j}}(0)}{\mathrm{T}_{\mathrm{L}} a_{\mathrm{i}}^{2}}\left[\left(1+a_{\mathrm{i}}\left\{\mathrm{T}_{\mathrm{a}}-\mathrm{T}_{\mathrm{S}}\right\}\right) \exp \left(-a_{\mathrm{i}} \mathrm{T}_{\mathrm{a}}\right)-\right. \\
\left.\left(1+a_{\mathrm{i}} \mathrm{T}_{\mathrm{L}}\right) \exp \left(-a_{\mathrm{i}}\left\{\mathrm{T}_{\mathrm{S}}+\mathrm{T}_{\mathrm{L}}\right\}\right)\right]
\end{array} \\
& \text { if } \mathrm{T}_{\mathrm{d}}<\mathrm{T}_{\mathrm{s}}+\mathrm{T}_{\mathrm{L}} \\
& T_{a}=\left\{\begin{array}{ll}
T_{S} & \text { if } T_{d}<T_{s} \\
T_{d} & \text { if } T_{d}>T_{s}
\end{array} .\right.
\end{aligned}
$$

If the events of excavating rock and waste were mutually exclusive, then one could just multiply each consequence by its probability of occurence and sum to find the average consequence. However, every time waste is excavated, there is nothing to prevent the column of host rock from also being excavated (unless it is assumed that drilling would stop if waste were brought to the surface). Therefore, it was assumed for this Phase 1 analysis, that the 
consequences given by Equations $\mathrm{H} .33$ to $\mathrm{H} .35$ occurred with a conditional probability of 1.0 (i.e., if drilling occurred with probability given by Equation H.6). To find the average consequences, the consequences of excavating waste, as given by Equations H.21 to H.24, must be multiplied by the conditional probability of such excavation, $\mathrm{Pe}$, as given by Equation H.7, and summed with the average consequence of excavating host rock. That is,

$$
\bar{C}_{i}(t)=P_{e} \hat{C}_{i}(t)+\hat{C}_{i}^{\prime}(t)
$$

where $\bar{C}_{i}(t)$ is the overall average consequence and the other terms have been defined previously. 


\section{DRILLING SCENARIO}

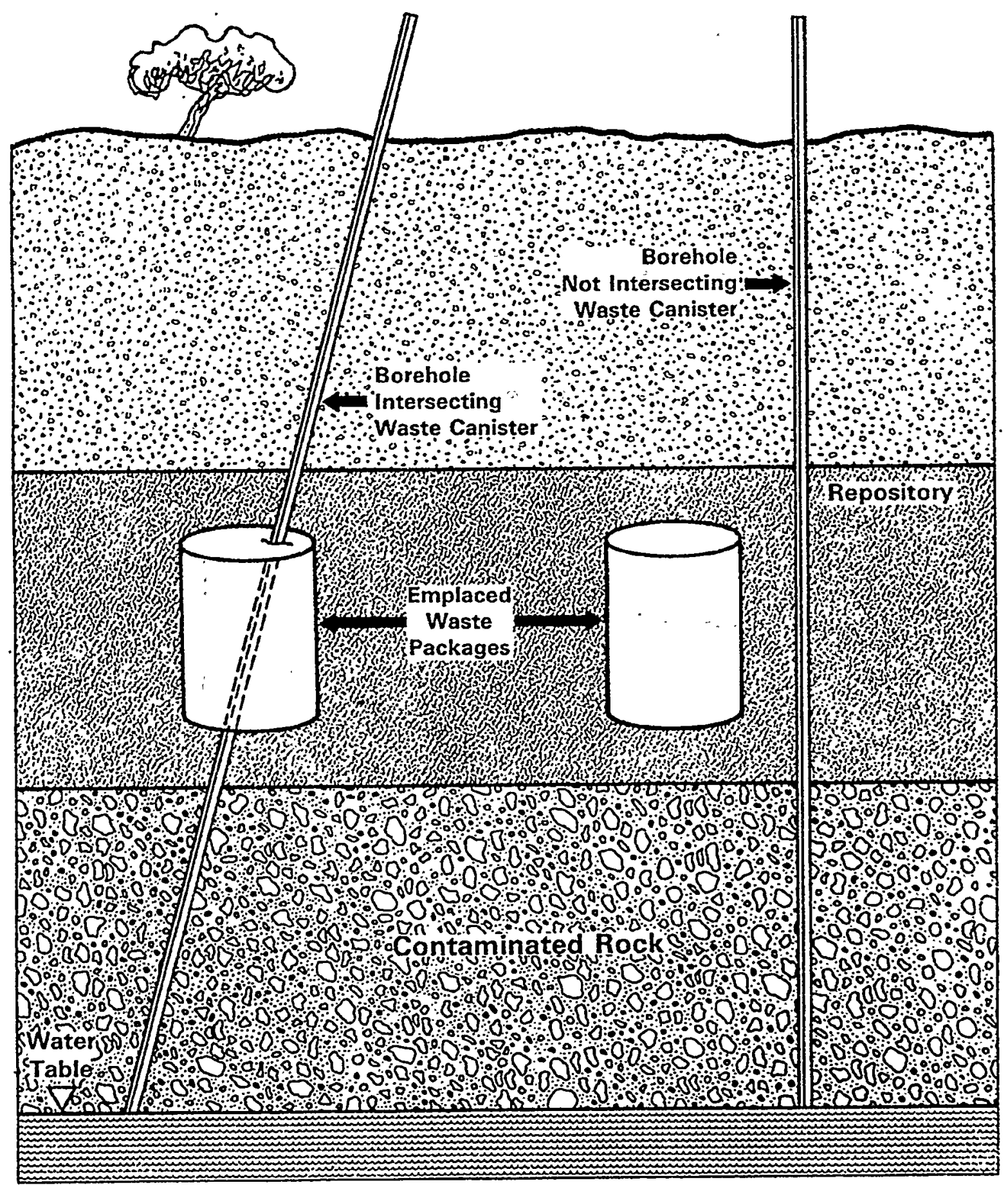

Figure $\mathrm{H}-3$ Conceptual view of drilling through waste canister and contaminated rock below the repository and drilling into contaminated rock. 


\section{TIME CONSIDERATIONS}
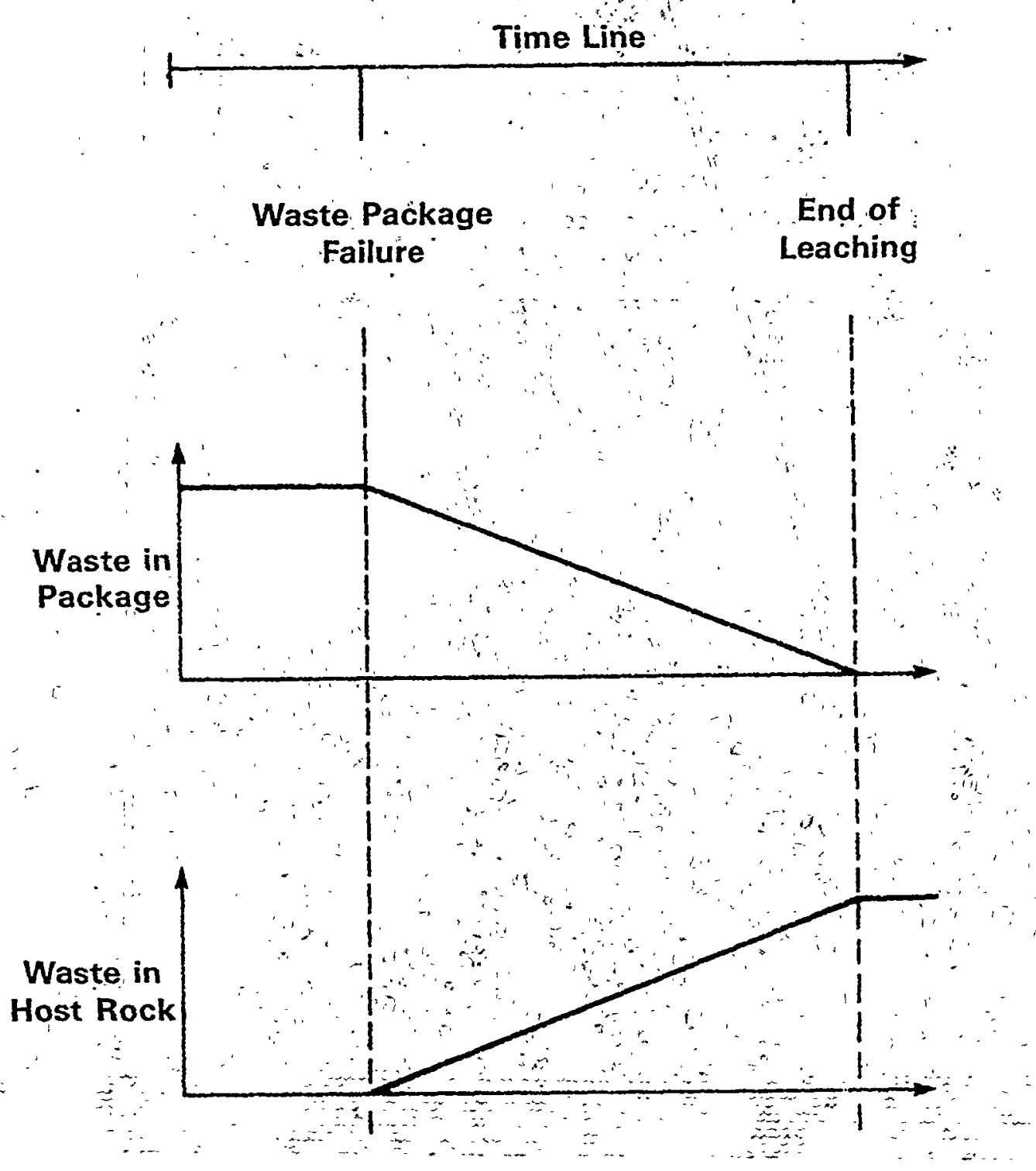

Figure H-4 Depiction of quantity of waste in packages and host rock from the time of waste emplacement until the end of leaching (all waste leached from waste package). 


\section{APPENDIX I-SYSTEM CODE STEPS}

\section{I.1 Discussion}

The following is a more detailed step-by-step outline of the system code operation than that provided in Section 4.4.4.

$$
\text { " i. in..... }
$$

1. Set parameters and determine the dimensions of the neccessary arrays.

2. "Open' input and output files.

A. ËPALMM.DAT: an inputfile of Environmental Protection Agency (EPA) release limits (40 CFR Part 191, Appendix A, Table 1) for 28 selected radionuclides per 10,000 Metric Tons Heavy Metal (MTHM)

B. SYS.INP : a file of analyst-supplied system code input for a particular run, consisting of input/output flags, a flag denoting the manner of execution (i.e., internal ys. external), and information about the specific scenarios to be modeled in this particular run

C. SYS.DAT : a detailed output file, with the type and amount of data placed in this file dependent on the system code input flag values

D. CCDF.DAT : an output file which will contain data needed to graph a complementary cumulative distribution function (CCDF)

3. Read into the program the input/output flags, simulation time, and scenario information from the SYS.INP file.

4. Read in the EPA release limits from EPALIM.DAT and calculate a weighting factor for each radionuclide (based upon an initial repository inventory of 70,000 MTHM) using the formula:

$$
\underset{\text { for }}{\text { weighting factor }} \underset{\text { radionuclide } n}{ }=\frac{1}{7 \times \text { (Release limit for radionuclide } n)}
$$

5. Sequence through the analyst-supplied scenario classes.
A. Select the first scenario from SYS.INP.
B. If the system code is executing internally, run the Latin Hypercube Sampling (LHS) routine to generate consequence module parametric input vectors.

C. Determine (from SYS.INP) whether the groundwater release pathway is accessed for radionuclide release from the repository: :

D. If the groundwater release pathway is accessed,

1a) Run the groundwater flow and transport model (NEFTRAN) (if the run is internal). 1b) Request the name of the ground- ${ }^{*}$ water model output file to access (for external system code runs); the file name is supplied by SYS.INP.

2) Open the groundwater flow and transport model output file.

3) Read in the radionuclides and cumulative releases for each parametric input vector until all the data are input to the program.

4) Call the ORDER subroutine to 's

a. Compare the released radionuclide names against radionuclide names for which EPA limits are given.

b. Calculate the normalized radionuclide releases using the EPA release limit weighting factors (see step 4 above) :

c. Place the normalized releases into a four-dimensional array (CUMREL), according to scenario class, released radionuclide, input vector, and release pathway.

5) Return to the main program from the ORDER subroutine.

E. If the groundwater release pathway is not accessed for radionuclide release, continue with step $F$ below.

F: Repeat steps D and E above for the gaseous release pathway and then for the direct release pathway, if either pathway is accessed for radionuclide release. (This information is in SYS.INP).

G. Return to step A and determine, by checking SYS.INP, whether more scenario classes are to be modeled. If so, continue at step B; otherwise, continue with step 6 below.

\section{Summing Calculations}

6. Sum the normalized radionuclide releases in the CUMREL array over release pathway, into the three-dimensional PEPASUM array. 
7. Sum the normalized releases in the CUMREL array by radionuclide released into the three-dimensional REPASUM array.

8. Sum the REPASUM array over release pathway into the two-dimensional SEPASUM array.

9. Sum the PEPASUM array by radionuclide released into two-dimensional FEPASUM array.

10. Check for any errors by comparing the results in the SEPASUM array against those in the FEPASUM array.

\section{Calculations for CCDF}

11. For each scenario treated, sort the summed normalized releases in SEPASUM in ascending order, from the top of the array to the bottom, using the ASORT subroutine.

12. Place the ordered releases into the EPASUM array by scenario and vector, along with the probability of each consequence, given that each vector in a scenario is equally probable, i.e.,

Probability of a particular release $=\begin{gathered}\text { (number of vectors } \\ \text { in a scenario })^{-1}\end{gathered}$

13. Compress EPASUM by comparing each release with all other releases within the same scenario. If a match is found, the probabilities are combined, and the duplicate release values are deleted.

14. Calculate the total CCDF.

A: Copy the releases and their associated likelihoods by scenario from the EPASUM array into TSDF, a three-dimensional array, multiplying the likelihoods by the probability of the scenario itself, as the transfer occurs.

B. Sort TSDF so that the releases are in ascending order, from the top of the array to the bottom.

C. Compress the TSDF array and recalculate the radionuclide release probabilities, as was done for the EPASUM array in step 13.

D. Create a running cumulative probability, in the third dimension of TSDF, by summinig probabilities from the bottom of the array to the top.

15. Generate the system code output files.

A. Write the date and time of the run to SYS.DAT.

B. Fill the SYS.DAT file according to the output flags set in SYS.INP.

C. Copy the TSDF-array into the CCDF.DAT output file. 


\section{APPENDIX J-DOCUMENTATION OF FILES AND PROGRAMS ON INEL CRAY XMP/24 FOR REPOSITORY PERFORMANCE CALCULATIONS}

\section{J.1 Introduction}

This appendix documents briefly some significant computer programs, data files, and output files used to generate and manipulate the source term and radionuclide transport results presented in this report.

\section{J.2 Fortran Programs}

\section{J.2.1 NEFTRAN6}

This is the modified version of NEFTRAN (Longsine, et al., 1987) used for this demonstration. It was modified from the standard version in the following ways:

i a. All calculations having to do with the determination of the flow through saturated flow tubes using Darcy's law were removed. Flux was an input variable based on infiltration and fracture flow, as determined by saturated hydraulic conductivity.

b. Most input variables needed for the unsaturated flow and transport calculations were contained in subroutine GETRV. This subroutine read the random input vectors on input file TAPE10, as generated by the program LHSVAX, and generated an output vector file of radionuclide releases accumulated over time (either 10,000 or 100,000 years), that was written to an output file, TAPE20.

c. Minor changes were made to the output format of TAPE20 to include the scenario number on each record.

\section{J.2.2 CCDFLIM}

This program was used for the sensitivity and uncertainty analyses described in Section 9.5. The CCDFLIM program took the TAPE20 output files generated by NEFTRAN6 for the four columns and generated a complementary cumulative distribution function (CCDF) for each scenario. It multiplied the output cumulative releases for each radionuclide by their respective Environmental Protection Agency (EPA) release limit factors (from 40 CFR Part 191) to get an EPA ratio for each vector. The vectors were then combined for the four columns, sorted and written to a file for transmission to the U.S. Nuclear Regulatory Commission (NRC). These results were plotted with, the commercial graphics package, GRAPHER, on a personal computer. The CCDFL.IM program also calculated the average contribution to the EPA ratios by radionuclide and sorted them in descending order. In addition, the program could screen output vectors on the basis of limits imposed on the input parameters or combinations of parameters provided to NEFTRAN. This capability was used in the analyses that examined the sensitivity of the radionuclide releases to the NRC subsystem performance criteria (see Section 9.5).

\section{J.2.3 COMBINE}

This program combined the TAPE20 output files from NEFTRAN for the four columns into a single combined TAPE20 output file. The program was developed to avoid: (1) sending four lengthy files from the CRAY system to the National Institutes of Health system via BITNET; and (2) a problem on BITNET, which caused some of the long output lines to be clipped at 79 columns. The revised output file was identical to the old TAPE20 output, except that the long lines were no longer written in a list-directed format, but rather in formatted form with a line length of 68 characters. If the output for a particular radionuclide chain was all zeros, the list-directed output was still used to take advantage of this format's compact structure.

\section{J.2.4 LHSVAX}

This program generated the LHS sample for input to NEFTRAN6. It was modified from the original version in the following way:

a. A random number generator, RAN1, from Numerical Recipes, was added.

b. It read in the names of the input and output files.

\section{J.2.5 STEP}

This program performed the stepwise linear regression and rank regression on the outputs of NEFTRAN6 for each scenario, to determine sensitivities and uncertainties (see Section 9.5 of this report). The main modification to this program was to take the TAPE20 output from the four columns generated by NEFTRAN6 and combine them into EPA ratios for each vector using the EPA release limit factors. The combined EPA ratios are written to a temporary file and read into the STEP program to generate the regressions. 


\section{J.2.6 C14B}

This program calculated the carbon-14 release from the waste packages as a function of time. The program assumed that the canisters failed with a normal probability distribution. Following failure, oxygen attacked the fuel matrix and the C-14 inventory was released according to a rate based on the spallation time, randomly. picked from a uniform probability distribution bounded by two lines that are functions of temperature. To this release rate was added the prompt release of $\mathrm{C}-14$ at the time of canister failure. The auxiliary analysis of the release of gaseous $C-1^{7} 4$ is discussed in Appendix $D$ of this report.

\section{J.3 Batch Script Files}

The following batch file executed programs in the batch mode on the Cray using the batch queue function QSUB:

The STATCON.SUB batch file executed in sequence with the programs LHSVAX and NEFTRAN6, for all four columns, and then with the program CCDFLIM, to generate a CCDF. The main purpose of this script file was to simplify the multistep operation for generating $a_{\text {, }}$ CCDF, particularly for the statistical convergence exer-: cise that demonstrated the sensitivity of the CCDF to the number of Latin Hypercube vectors samples chosen. (either 100 or 500) (see Appendix E for discussion). A new random seed for LHSVAX was chosen for each of the runs with 100 vectors.

\section{J.4 Data Files}

The following is a list of the input data files used:

ympyuc2.dat: This file was used for all scenarios to generate the LHS, -samples., for NEFTRAN6 based on the distribution and ranges specified for 47 variables. When used in the statistical convergence test (Appendix E), a new randominput seed (specifiable in this file) was chosen for each CCDF run.

epalim.dat: Thisfile contains the EPA release limits by radionuclide in terms of permissible releases per 10,000 metric tons heavy. metal, as provided in 40 CFR Part 191, Appendix A, Table 1.

t51n1: This was the-NEFTRAN6 card image input file for the basic parameters in Column $\mathrm{A}$, for the base-case scenario, 10,000 years, 500 vectors. t52n1: $\quad$ This is the same as t51n1 above, but for Column B.

t53n1: - This is the same as t51n1 above, but for Column C.

t54n1: This is the same as t51n1 above, but for Column D.

t51100: This is the same as t51n1 above, but for 100,000 years. Results based on this data was used in the sènsitivity and uncertainty analyses discussed in Section 9.5 of this report.

t52100: This is the same as t52n1 above, but for 100,000 years. Results based on this data was used in the sensitivity and uncertainty analyses discussed in Section 9.5 of this report.

t53100: This is the same as t53n1 above, but for 100,000 years. Results based on this data was used in the sensitivity and uncertainty analyses discussed in Section 9.5 of this report.

t54100: This is the same as t54n1 above, but for 100,000 years. Results based on this data was used in the sensitivity and uncertainty: analyses discussed in Section 9.5 of this report.

TAPE20: . The random vectors produced by LHS,VAX for the input file ympyuc.dat were stored in this file.

\section{J.5 Output Files}

The following is a list of the output data files used:

tape2051.10: These were the TAPE20 output files tape2052.10: - from NEFTRAN6 for the base-case tape2053.10: scenario, 10,000-year cumulative retape2054.10: leases for the four columns referred to in the text as Columns $\mathrm{A}, \mathrm{B}, \mathrm{C}$, and D, respectively.

tape201.500: tape202.500: tape203.500: tape204.500:

These were the TAPE20, output files from NEFTRAN6 for the base-case scenario, 100,000 -year cumulative releases for the four columns referred to in the text as Columns $A, B, C$, and $D$, respectively. These data were used in the sensitivity and uncertainty analyses discussed in Section 9.5 of this report.

tape20cmb.10: This was the combined output for tape2051.10, tape2052.10, tape2053.10, 
and tape2054.10, as produced by program COMBINE.

ccdf10.out: This was the output file used in plotting the 10,000-year base-case scenario CCDFs in Section 9.5. ccdf100.out: This was the output file used in plotting the 100,000-year base-case scenario CCDFs in Section 9.5.

TAPE6: $\quad$ This was the normal printed output file for each NEFTRAN6 run. 


\begin{tabular}{|c|c|}
\hline $\begin{array}{l}\text { NRC FORM } 335 \\
(2-89) \\
\text { NRCM } 1102, \\
3201,3202\end{array}$ & $\begin{array}{l}\text { U.S. NUCLEAR REGULATORY COMMISSION } \\
\text { BIBLIOGRAPHIC DATA SHEET } \\
\text { (See instructions on the reverse) }\end{array}$ \\
\hline
\end{tabular}

2. TITLE AND SUBTITLE

Initial Demonstration of the U.S. NRC's Capability to Conduct a Performance

Assessment for a High-Level Waste Repository.

1. REPORT NUMBER

(Assigned by NRC, Add Vol.,

Supp., Rev., and Addendum 'Num-

bers, 'If any.)

NUREG-1327

3. DATE REPORT PUBLISHED

\begin{tabular}{|l|l}
\hline MONTH & YEAR \\
\hline
\end{tabular}

May 1992

4. FIN OR GRANT NUMBER

5. AUTHOR(S)

6. TYPE OF REPORT

Technical

R. Codell, N. Eisenberg, D. Fehringer, W. Ford,

T. Margulies*, T. McCartin*, J. Park, J. Randall*

7. PERIOD COVERED (Inclusive Dates)

8. PERFORMING ORGANIZATION - NAME AND ADDRESS (If NRC, provide Division, Offlce or Region, U.S. Nuclear Regulatory Commission, and malling address; if contractor, provlde name and malling address.)

Office of Nuclear Material Safety and Safeguards

* Office of Nuclear Regulatory Research

U.S. Nuclear Regulatory Commission

Washington, DC 20555

9. SPONSORING ORGANIZATION - NAME AND ADDRESS (if NRC, type "Same as above"; if contractor, provide NRC Division, Office or Region,

U.S. Nuclear Regulatory Commission, and mailing address.)

Same as above

10. SUPPLEMENTARY NOTES

11. ABSTRACT (200 words or less)

In order to better review licensing submittals for a High-Level Waste Repository, the U.S. Nuclear Regulatory Commission staff has expanded and improved its capability to conduct performance assessments. This report documents an initial demonstration of this capability. The demonstration made use of the limited data from Yucca Mountain, Nevada to investigate a small set of scenario classes. Models of release and transport of radionuclides from a repository via the groundwater and direct release pathways provided preliminary estimates of releases to the accessible environment for a 10,000 year simulation time. Latin hypercube sampling of input parameters was used to express results as distributions and to investigate model sensitivities. This methodology demonstration should not be interpreted as an estimate of performance of the proposed repository at Yucca Mountain, Nevada.

12. KEY WORDS/DESCRIPTORS (List words or phrases that will assist researchers in locating the report.)

13. AVAILABILITY STATEMENT Unlimited

EPA Standard

Geologic repository

High-level waste

Performance assessment

Probabilistic risk assessment

14. SECURITY CLASSIFICATION

(This Page)

Unclassified

(This Report)

Unclassified

15. NUMBER OF PAGES

16. PRICE 